University of Louisville

ThinkIR: The University of Louisville's Institutional Repository

$5-2014$

\title{
A heuristic algorithm for determining the part set in a powder-bed additive manufacturing machine.
}

Sonja Dieder

University of Louisville

Follow this and additional works at: https://ir.library.louisville.edu/etd

Part of the Industrial Engineering Commons

\section{Recommended Citation}

Dieder, Sonja, "A heuristic algorithm for determining the part set in a powder-bed additive manufacturing machine." (2014). Electronic Theses and Dissertations. Paper 345.

https://doi.org/10.18297/etd/345

This Doctoral Dissertation is brought to you for free and open access by ThinkIR: The University of Louisville's Institutional Repository. It has been accepted for inclusion in Electronic Theses and Dissertations by an authorized administrator of ThinkIR: The University of Louisville's Institutional Repository. This title appears here courtesy of the author, who has retained all other copyrights. For more information, please contact thinkir@louisville.edu. 


\title{
A HEURISTIC ALGORITHM FOR DETERMINING THE PART SET IN A POWDER-BED ADDITIVE MANUFACTURING MACHINE
}

\author{
By \\ Sonja Dieder \\ Diplom-Kauffrau, AKAD, College of higher education Pinneberg, 2004 \\ Master of Science, University of Louisville, 2010
}

\author{
A Dissertation \\ Submitted to the Faculty of the \\ J. B. School of Engineering of the University of Louisville \\ in Partial Fulfillment of the Requirements \\ for the Degree of \\ Doctor of Philosophy \\ Department of Industrial Engineering \\ University of Louisville \\ Louisville, Kentucky, USA
}

May 2014 
(C) Copyright 2014 by Sonja Dieder

All rights Reserved 



\title{
A HEURISTIC ALGORITHM FOR DETERMINING THE PART SET IN A POWDER-BED ADDITIVE MANUFACTURING MACHINE
}

\author{
By \\ Sonja Dieder \\ Diplom-Kauffrau, AKAD, College of higher education Pinneberg, 2004 \\ Master of Science, University of Louisville, 2010 \\ A Dissertation Approved on
}

February, 202014

by the following Dissertation Committee

Dr. William E. Biles, Dissertation Director

Dr. Brent Stucker

Dr. Gerald W. Evans

Prof. James A. Leach 


\title{
DEDICATION
}

This dissertation is dedicated to the loving memory of my father

\author{
Wilhelm Dieder
}

And to my mother

\section{Maria Dieder}

My deepest gratitude goes to my father. He tried to teach me in Math when I was a young girl with endless patience and without despairing $(;$ 


\section{ACKNOWLEDGEMENTS}

I would like to express my deepest respect and gratitude to my dissertation director Dr. William Biles for developing and providing outstanding and constant support from the original idea to the innovation. This dissertation study would not have been possible without his patient guidance and enthusiastic encouragement of this research work and during all these years in the program.

I would also like to thank Dr. Brent Stucker for his valuable support and advice in the area of Additive Manufacturing. Special thanks to Dr. Gerald Evans for contributing his extensive knowledge in Simulation and Decision Making. Great appreciation is also offered to Professor James Leach for his excellent support during this dissertation work and all the graduate school years. He taught accurately and repeatedly to build up a solid foundation of Graphical Visualization for being in a position for this research work.

I would also like to thank Joseph Vicars for his assistance with a SolidWorks model.

My grateful thanks are also extended to Mr. Timothy Gornet who assisted with his excellent skills and advices of the build setup and the background knowledge of the SLS machine. I would also like to thank Mr. Randall Storey and Dr. Nathan Johnson for their technical support with infrastructure and software issues. 
Particular thanks to Dr. Gail DePuy, Director of IE Graduate Programs, for contributing her excellent knowledge in Foundations of Optimization and Experimental Design in Engineering. She offered a great support during the program.

Special acknowledgement also goes to Peggy Sue Prater for her assistance with regulations, as well as organizational, operational and personal matters over all the years of that program.

I feel special gratitude for my beloved one around me for supporting me with strong encouragement, motivation and patience in my ongoing process of profound change. Also special thanks to my fellow student, Peter Brem for his friendship and for sharing the general ups and downs that come along with this challenge.

In addition I would like to express my gratitude to Siemens AG and Nokia Siemens Networks GmbH \& Co. for the encouragement to pursue the Ph.D. Also my special thanks to Hartmut Müller-Leitloff, Martin Lüst and Stephan Kalb for promoting and motivating me and for providing advice and actions over a long time. 


\section{ABSTRACT \\ A HEURISTIC ALGORITHM FOR DETERMING THE PART SET IN A POWDER-BED ADDITIVE MANUFACTURING MACHINE}

\section{Sonja Dieder}

\section{February 20, 2014}

The goal of this research is to develop a procedure for the placement of a priority part into a planned build in a powder-bed additive manufacturing machine. Toward that goal, a heuristic procedure was developed that seeks to maximize the revenue in a scheduled build, subject to due-date constraints; i.e., all parts with the closest due date will not only be included in the build, but will be placed near the bottom of the build.

Likewise, any part in the scheduled build that does not have an immediate due date is a candidate for removal in order to accommodate a higher priority part, the order for which arrives after the build is underway. The build volume for this experiment with the SLS2500+ machine is 13 -inch x 15-inch x 18-inch rectilinear container.

To achieve this optimization of the build, the experiment for this research involved a penalty which is based on failure to meet the due date constraint.

The $m$ parts in the build are placed such that are placed the highest priority parts, including those with immediate due date constraints, are positioned near the bottom of the build volume. 
The focus of this study is to determine which "unbuilt" parts $x(i)$ will be removed to make room for higher priority parts. Toward that end, each part is assigned a priority $p(i), i=1, \ldots, m$ until the build is full. If an order for a part having a higher priority $p(i)$ than any of the parts in the build, the procedure developed here seeks to replace at least one of the parts in the scheduled build.

Hence, the dimensions of the lower priority parts are key, since the part that is removed must provide sufficient space for the new part. Importantly, the enactment of the procedure developed here takes place in real time, with little or no interruption of the progress of the build.

The resulting Excel file will be sorted as to place the immediate items at the bottom on the build. The solution is valid for a single and also for a multiple build.

Simulations of this heuristic procedure were shown to substantially increase the revenue desired from the planned build by adding higher priority parts. 


\section{TABLE OF CONTENTS}

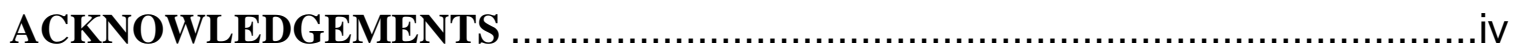

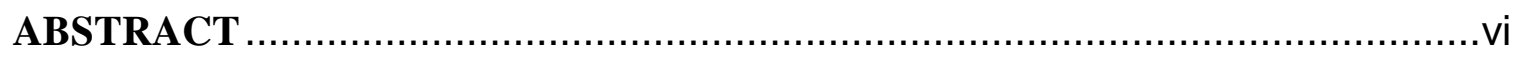

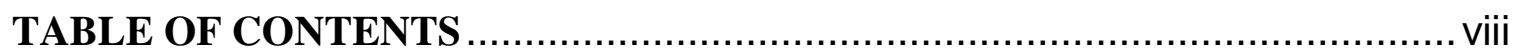

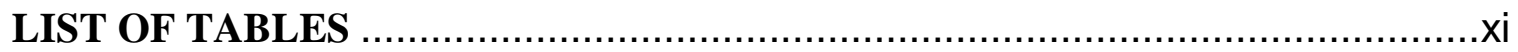

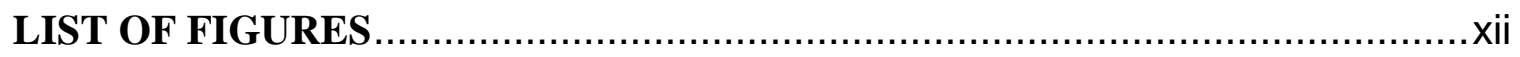

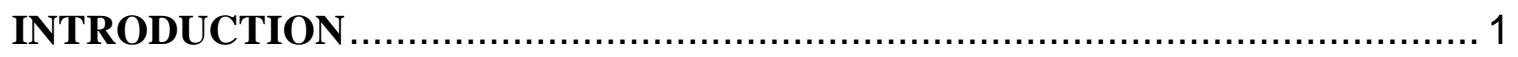

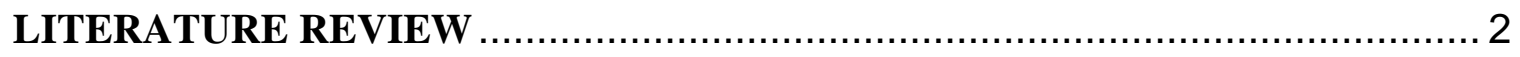

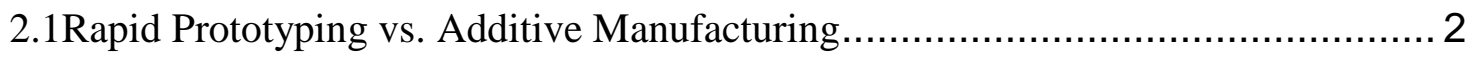

2.1.1Fused Deposition Modeling (FDM) ......................................... 4

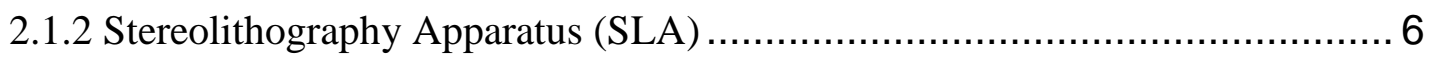

2.1.3D Printing (3DP) $\ldots \ldots \ldots \ldots \ldots \ldots \ldots \ldots \ldots \ldots \ldots \ldots \ldots \ldots \ldots \ldots \ldots \ldots \ldots \ldots \ldots \ldots \ldots \ldots . . \ldots$

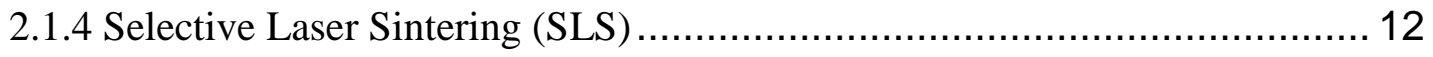

2.1.4.1.Indirect Metal Selective Laser Sintering (IMSLS) ....................... 15

2.1.4.2.Selective Laser Melting (SLM) ......................................... 15

2.1.5.Direct Metal Laser Sintering (DMLS) ...................................... 23

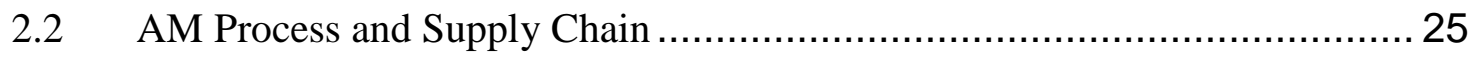




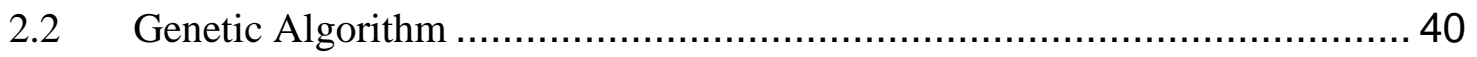

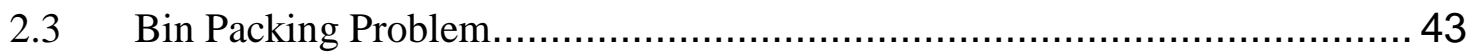

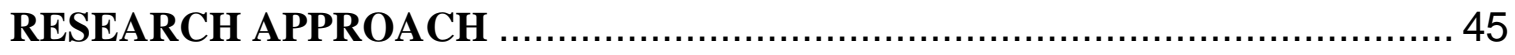

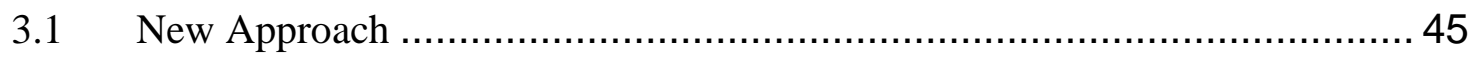

3.2 Additional Literature Review ...................................................... 46

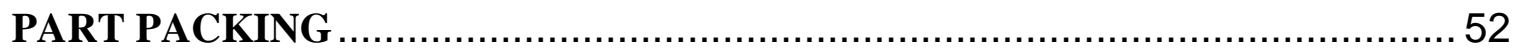

4.1 The Selective Laser Sintering Machine SLS 2500+.................................. 52

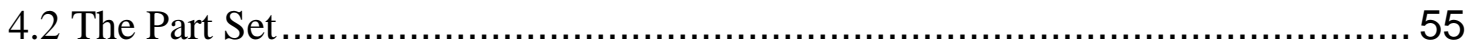

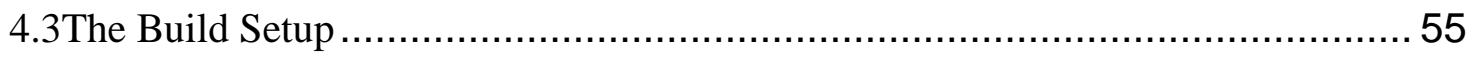

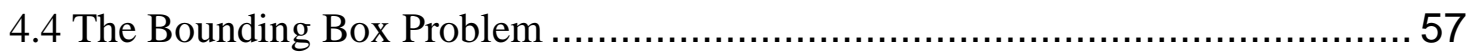

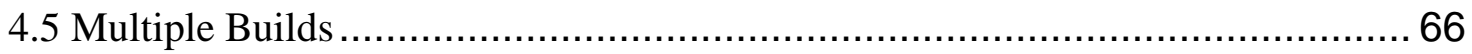

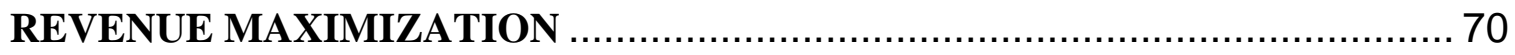

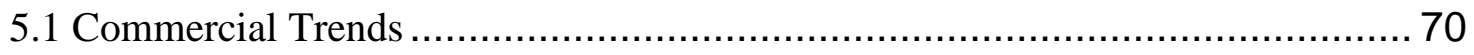

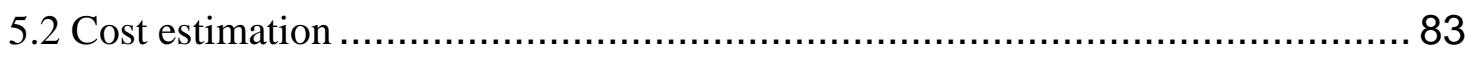

5.3Development of the Mathematical Model ................................................... 88

OPTIMIZATION APPROACHES AND EXPERIMENTAL RESULTS ..............93

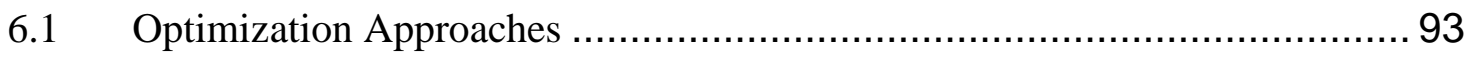

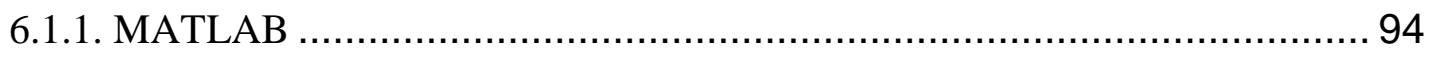

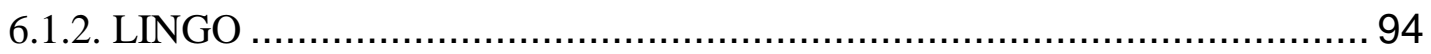

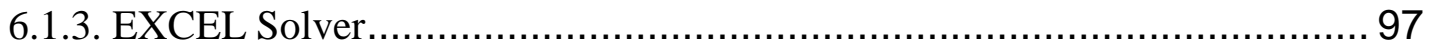

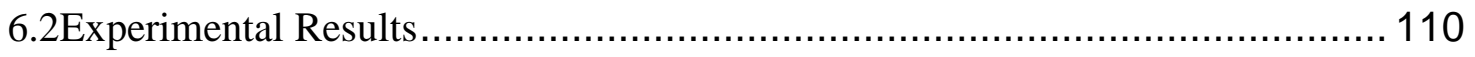




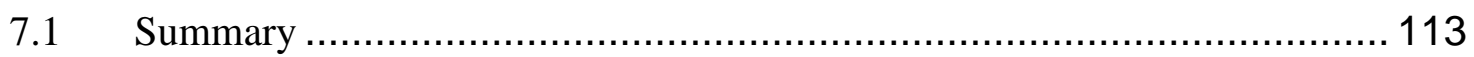

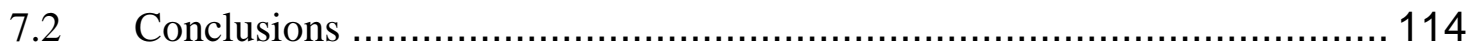

7.3 Recommendations for Future Work ……....................................... 114

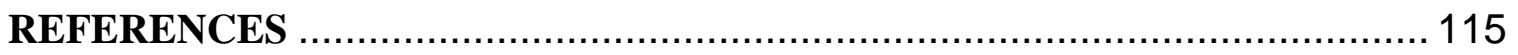

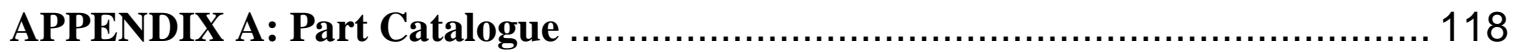

APPENDIX B: MATLAB GA for Bin Packing .......................................... 153

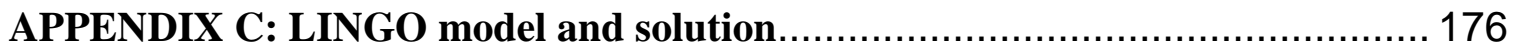

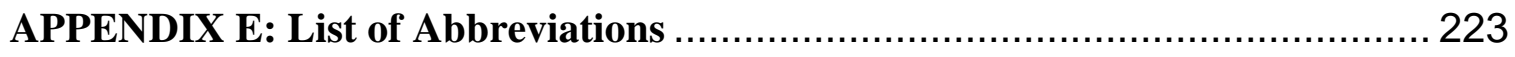

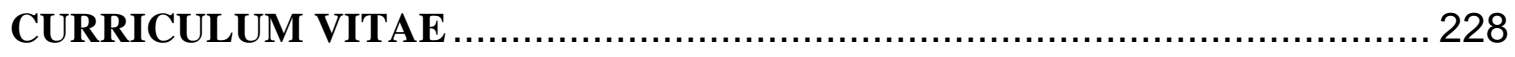




\section{LIST OF TABLES}

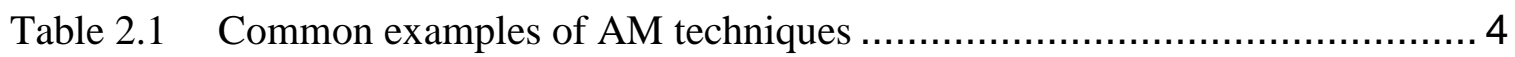

Table 2.2 Summary Extrusion methods (Gebhardt, 2004) ............................ 5

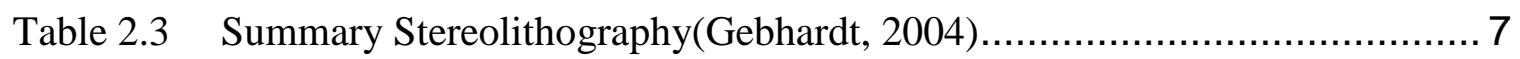

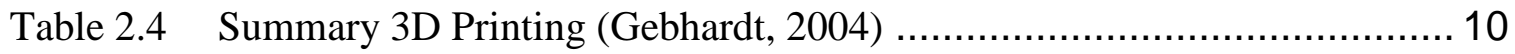

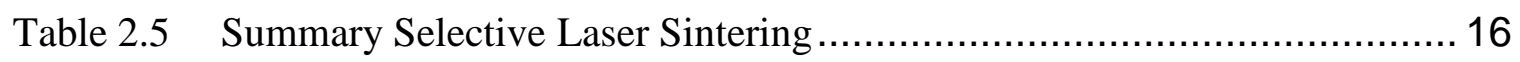

Table 2.6 Checklist for additional purchase of components(Zäh, 2006) ................. 17

Table 2.7 Checklist for procurement of a system(Zäh, 2006) ........................... 20

Table 2.8 Lean and agile supply chain operators (Mason-Jones et al. 2000) ............ 30

Table 2.9 Strategic reasons for using RM for individual cases ...................... 31

Table 5.1 Excel overview of all parts, dimensions and Bounding Volume.............. 98

Table 5.2 Excel Columns for the Solver solution................................. 101 


\section{LIST OF FIGURES}

Figure $2.1 \quad$ Fused Deposition Modeling(Gebhardt, 2004) ............................ 5

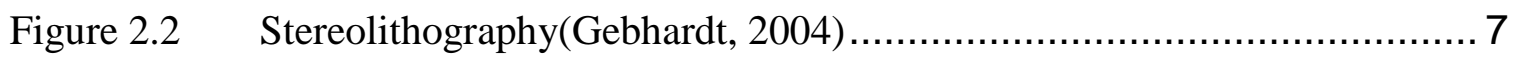

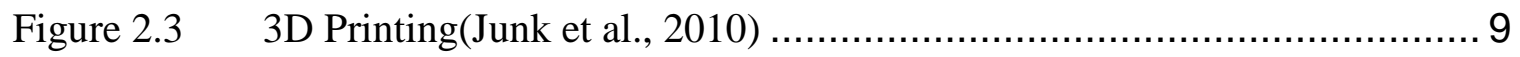

Figure 2.5 Laser Sintering(Boillat et al., 2004) ....................................... 14

Figure 2.6 Product supply chain matrix (Fisher 1997) .............................. 29

Figure 2.7 Modified production and supply chain matrix (Fisher 1997) .............. 30

Figure $3.1 \quad$ Inputs, outputs and processes incl. in a product's life cycle ................ 48

Figure 3.2 Inputs, outputs and the other side of economics: SALES ................ 51

Figure 4.1 Major components of the SLS System .................................. 53

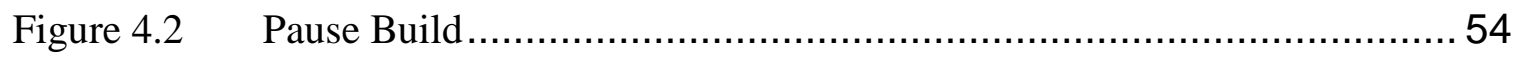

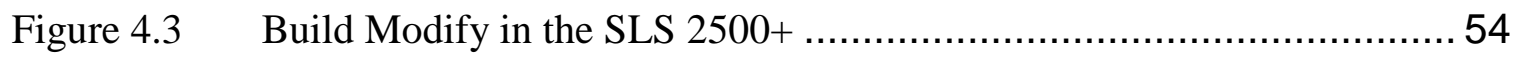

Figure $4.4 \quad$ Mouth tray as SolidWorks model ....................................... 56

Figure $4.5 \quad$ Build Setup from the Part Set ......................................... 56

Figure 4.6 Build Setup from the Part Set with the main information...................57

Figure 4.7 Procedure of finding out the minimum BB of a model .................... 62

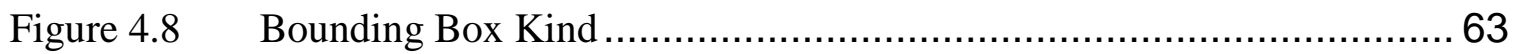

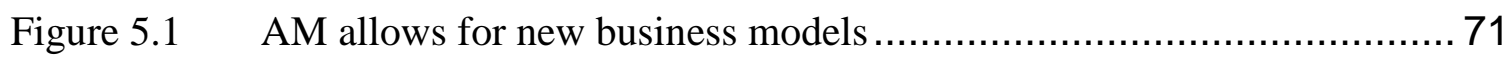

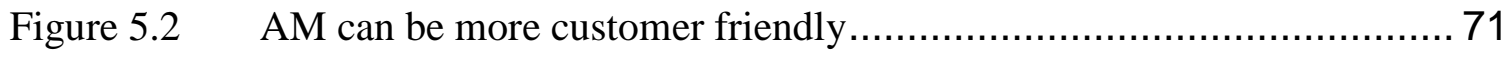

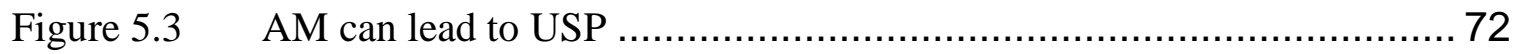




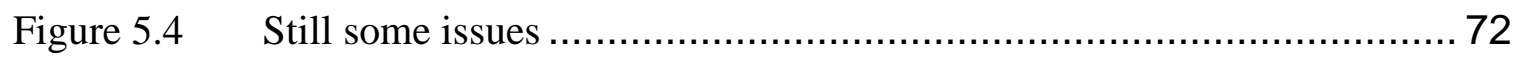

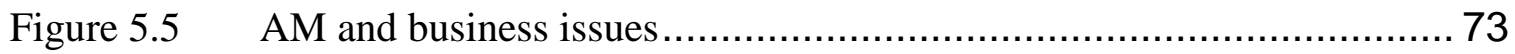

Figure 5.6 Individual products from Shapeways marketplace ............................ 74

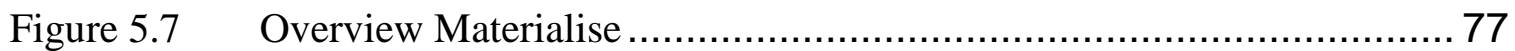

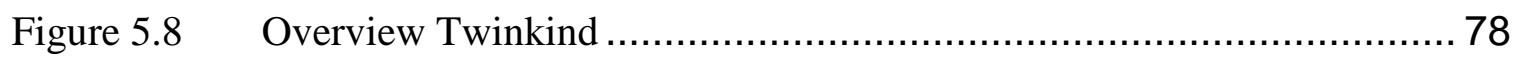

Figure 5.9 RM supply chain instead of RP supply chain ................................ 79

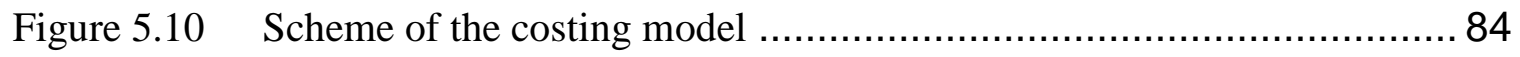

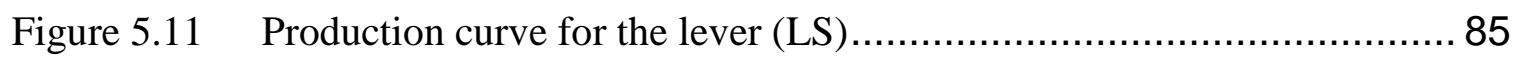

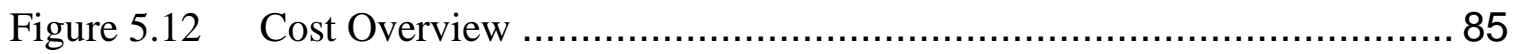

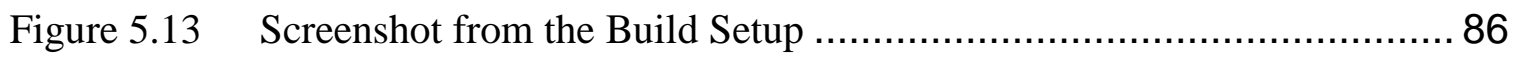

Figure 5.14 Screenshot from the Build Setup - Part Info ….............................. 87

Figure 5.15 Screenshot from the Build Setup - Time Estimate............................ 87

Figure 5.16 Screenshot Solver Parameter.................................................. 102

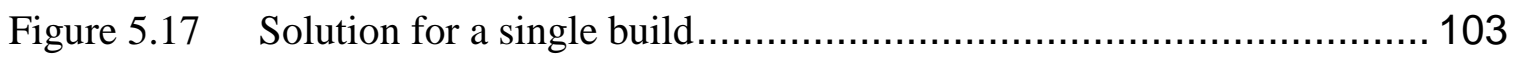

Figure 5.18 Visual verification for the single machine solution ......................... 104

Figure 5.19 Visual verification for the single machine solution - information....... 104

Figure 5.20 Solution for multiple machines - first part................................... 105

Figure 5.21 Solution for multiple machines - second part................................ 106

Figure 5.22 Solution replacement of the parts............................................. 107

Figure 5.23 Visual verificationfor replacement of the parts .............................. 108

Figure 5.24 Visual verificatiofor replacement of the parts - information ............... 108 


\section{CHAPTER 1}

\section{INTRODUCTION}

Rapid Prototyping is the general heading about different procedures for the quick production of pattern components constructed from digital data. In 2009 the F42 Committee on Additive Manufacturing Technologies (ASTM International) adopted the term Additive Manufacturing (AM) for these procedures. The Technical Committee 261 standardized AM for ISO (International Organization for Standardization). Improvements in the quality of the output from these machines have led to a higher quality, more precise part - often equal to that needed for final products. Parts are now fabricated directly by layer-by-layer deposition of material using three-dimensional Computer Aided Design (CAD) data. In the powder-bed additive manufacturing process, a rastering infra-red laser beam heats the surface of a powder bed to fuse the powder in a cross-section that matches that of a prototype being replicated.

The bin packing problem can be described as follows: given a set of boxes of different sizes, how should one pack them into containers of a given size, in order to use a few containers as possible.

The objective of this research is to design $m$ parts to a "build" with the possibility that part way through the build one or more higher priority parts arrive. Which "unbuilt" parts can be removed from the build to make room for the higher priority parts? 


\section{CHAPTER 2}

\section{LITERATURE REVIEW}

This chapter gives an overview about Rapid Prototyping vs. Additive Manufacturing and it's technologies as well as Genetic Algorithms, Cutting and Packing Optimization and a summary of research in that area so far.

\subsection{Rapid Prototyping vs. Additive Manufacturing}

Rapid Prototyping (RP) can be defined as a process for rapidly creating a system or part representation as a prototype or base model from which further models and eventually the final product will be derived. The term Rapid Prototyping describe a process of developing business and software solutions in a piecewise fashion that allows clients to test ideas and provide feedback during the development process. In a context of product development, the term RP was used widely to describe technologies which created physical prototypes directly from digital data. However, the term RP overlooks the basic principle of these technologies in that they can often fabricate final parts using an additive approach.(Gibson et al., 2010) and now Additive Manufacturing is the worldwide standard name for these processes in the technical community (http://www.astm.org/COMMITTEE/F42.htm, http://www.iso.org/iso/standards_development/technical_committees/other_bodies/iso_te chnical_committee.htm?commid=629086) 
ASTM defined a Standard Terminology for Additive Manufacturing Technologies. The recent version F2792-12a includes terms, definitions of terms, descriptions of terms, nomenclature, and acronyms associated with AM technologies in an effort to standardize terminology used by AM users, producers, researchers, educators, press/media and others.

The major terms in this dissertation will also complement with the official definition of the Standard Terminology.

\section{$\underline{\text { Standard Terminology: }}$}

“Additive Manufacturing (AM), - a process of joining materials to make objects from 3D model data, usually layer upon layer, a opposed to subtractive manufacturing methodologies."

"Rapid Prototyping (RP), - additive manufacturing of a design, often iterative, for form, fit, or functional testing, or combination thereof'.(ASTM International, 2012)

Additive Manufacturing first emerged in 1987, with Stereolithography (SL) from 3D Systems, a process that solidifies thin layers of ultraviolet (UV) light-sensitive liquid polymer using a laser. The SLA-1 was the first commercially available AM system in the world (Wohlers and Gornet, 2011).

In Rapid Prototyping, shapes are constructed not by ablation through turning or milling, but rather the part arises through joining volume elements layer by layer. Based on that explanation, Rapid Prototyping methods are also called "generative production methods". 
Common examples of AM techniques are shown in Table 2.1 (Padhye and Deb, 2011)

Table 2.1 Common examples of AM techniques

\begin{tabular}{|l|l|}
\hline Technique & short cut \\
\hline Fused Deposition Modeling & FDM \\
\hline Stereolithography & SLA \\
\hline 3D printing & 3DP \\
\hline Selective Laser Sintering & \\
\hline Direct Metal Deposition & SLS \\
\hline
\end{tabular}

\subsubsection{Fused Deposition Modeling (FDM)}

Standard Terminology: "a material extrusion process used to make thermoplastic parts through heated extrusion and deposition of materials layer by layer; term denotes machines built by Stratasys, Inc"..(ASTM International, 2012)

Fused Deposition Modeling (FDM) was developed in the 1980s by S. Scott Crump. The FDM process consists of having a heated, melted thread of plastic pass onto a "build-platform" in a layer-by-layer fashion via an extrusion nozzle. The nozzle is controlled by a mechanical "print head" and computer aided manufacturing software that contains the final image of the product. Upon hitting the build platform, the liquid solidifies and the platform lowers where the next layer of hot material is laid upon it. The process continues until the product is complete(http://www.prototypepros.com/rapid- 
prototyping/fused-deposition-modeling.fdm/). Table 2.2 gives a short summary describing the FDM method.

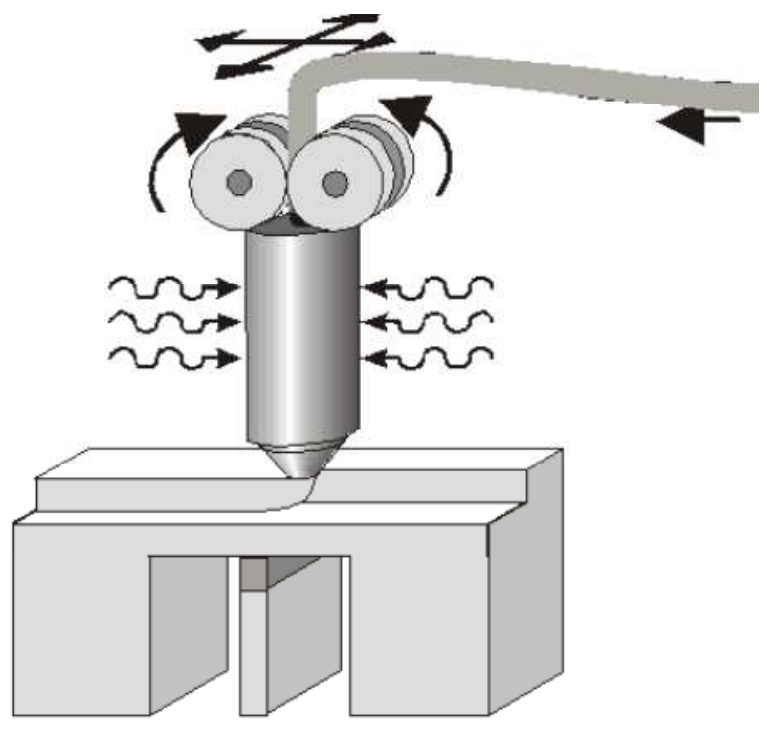

Figure 2.1 Fused Deposition Modeling(Gebhardt, 2004)

Table 2.2 Summary Extrusion methods (Gebhardt, 2004)

\begin{tabular}{|l|l|}
\hline \multicolumn{2}{|c|}{ Extrusion methods } \\
\hline Method & $\begin{array}{l}\text { Fusion of solid plastics (wire or block) in a heated nozzle. Layered } \\
\text { construct through extrusion. Solidification through cooling. Pillars } \\
\text { needed. }\end{array}$ \\
\hline Materials & Different kinds of plastic, partially nominally series identical (ABS \\
& Acrylonitrile butadiene styrene, PPSF Polyphenylsulfone) \\
\hline Advantages & Higher mechanical and thermal loading capacity then \\
&
\end{tabular}




\begin{tabular}{|l|l|}
\hline & Stereolithography. \\
\hline Disadvantages & Rougher surfaces, lower level of detail then Stereolithography \\
\hline
\end{tabular}

\subsubsection{Stereolithography Apparatus (SLA)}

$\underline{\text { Standard Terminology: }}$

"Stereolithography (SL), - a vat photopolymerization process used to produce parts from photopolymer materials in a liquid state using one or more lasers to selectively cure to a predetermined thickness and harden the material into shape layer upon layer."

"Stereolithography Apparatus (SLA), - denotes the SL machines from 3D Systems Corporation" (ASTM International, 2012).

Stereolithography was invented and patented in 1986 by Charles Hull of 3D Systems Inc. (http://www.wikipedia.org). It is a method and apparatus for making solid objects by successively printing thin layers of the ultraviolet curable material one on top of the other.(http://www.3dsystems.com/news/25th-anniversary/) The material used is liquid photo-curable resin, acrylate. Under the initiation of photons, small molecules (monomers) are polymerized into large molecules. Based on this principle, the part is built in a vat of liquid resin.(Yan and Gu, 1996). Table 2.3 gives a short summary of the Stereolithography process. 


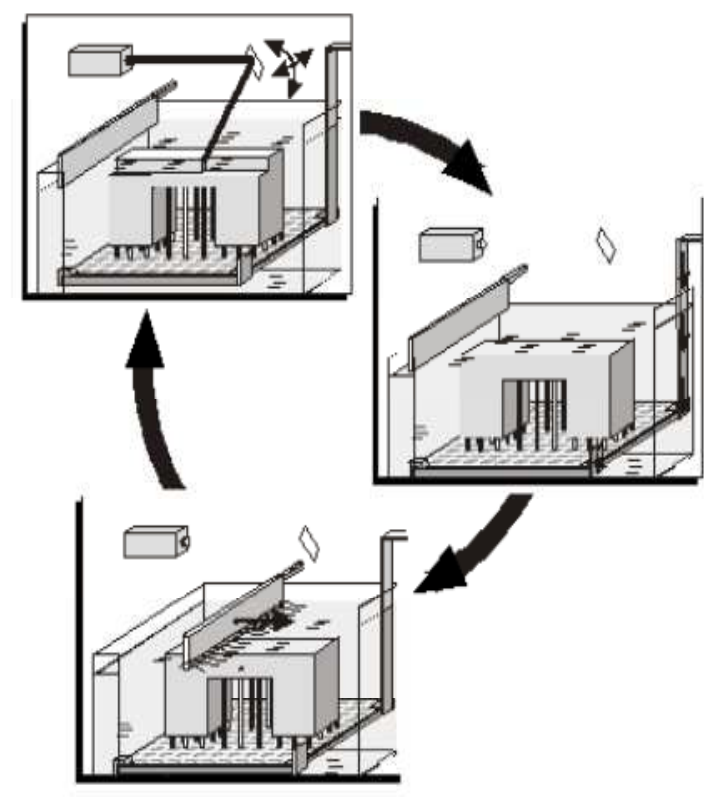

Figure 2.2 Stereolithography(Gebhardt, 2004)

Table 2.3 Summary Stereolithography(Gebhardt, 2004)

\begin{tabular}{|l|l|}
\hline \multicolumn{2}{|c|}{ Stereolithography } \\
\hline Method & $\begin{array}{l}\text { Local hardening of liquid monomer through UV radiation (laser, } \\
\text { lamp), pillar or support material is needed }\end{array}$ \\
\hline Materials & Epoxy resins, acrylates \\
\hline Advantages & High level of detail, very good surfaces \\
\hline Disadvantages & $\begin{array}{l}\text { Lower mechanical and thermal loading capacity then Laser Sintering } \\
\text { and Extrusion techniques. Specialty resins for higher temperatures } \\
\text { available }\end{array}$ \\
\hline
\end{tabular}




\subsubsection{Printing (3DP)}

Standard Terminology: "the fabrication of objects through the deposition of a material using a print head, nozzle, or another printer technology".(ASTM International, 2012)

3D printing was invented by Prof. Emmanuel Sachs from Massachusetts Institute of Technology (MIT). This technology uses ink-jet printing nozzles to jet binder droplets onto solid powder surface. After one layer is formed, the next layer of powder is spread on the former layer. By providing a linear nozzle array, the forming velocity can be accelerated. 3D printing was commercialized by Soligen Corporation in the US in the name of DSPC (Direct Shell Production Casting) used for manufacturing of ceramic shells and cores for casting. Other similar machines are 3DP (Extruhone, US), and 3DP (Z-Corp, US). 


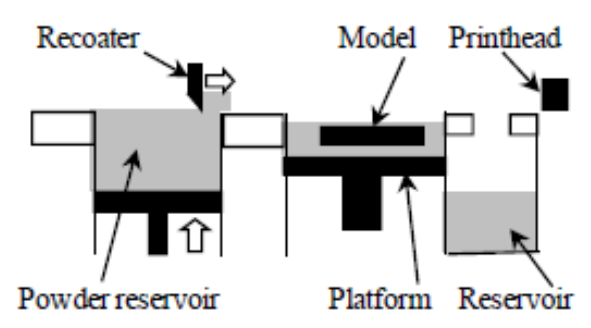

a. Supplying powders
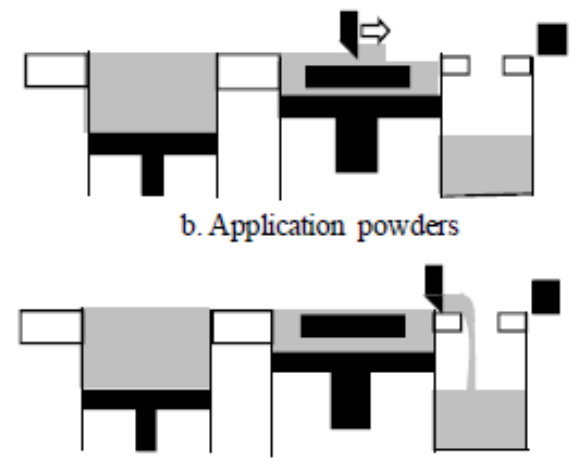

c. Strip residual powders off

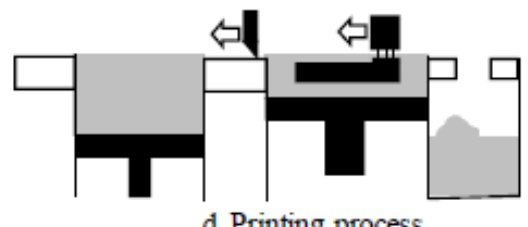

d. Printing process

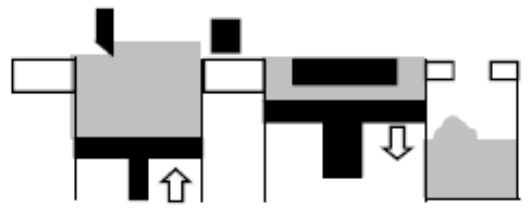

e. Lowering the platform

Figure 2.3 3D Printing(Junk et al., 2010)

3D printing needs no additional support, and can form an extensive range of materials that can be bonded by available binders such as ceramics with binder, metals with binder and polymers with binder. (Yan et al., 2009). Table 2.5 gives a summary of 3D printing technology. 
Table 2.4 Summary 3D Printing (Gebhardt, 2004)

\begin{tabular}{|l|l|}
\hline \multicolumn{2}{|l|}{ 3D Printing } \\
\hline Method & $\begin{array}{l}\text { Injection of binder fluids in a powder bed. Mechanical load through } \\
\text { infiltrate. No pillars needed. }\end{array}$ \\
\hline Materials & Starch/Water, plaster-ceramic/water, metal \\
\hline Advantages & Rapid and cost-effective, cold process, color models possible \\
\hline Disadvantages & $\begin{array}{l}\text { Minimal level of detail, rough surfaces. } \\
\text { Starch and plaster + infiltration: low loading capacity, undefined } \\
\text { mechanical properties }\end{array}$ \\
\hline
\end{tabular}

Actually iMaterialise offers a wide variety of 17 different materials and 70 possible color and finish combinations for 3D printing. 
i.materialige

Materials Discover a widevarlety of high cualty SD priming materala Wake your ldeas reai in 17 oifferent materlas acd 70 posalde coigrand firish cambinations
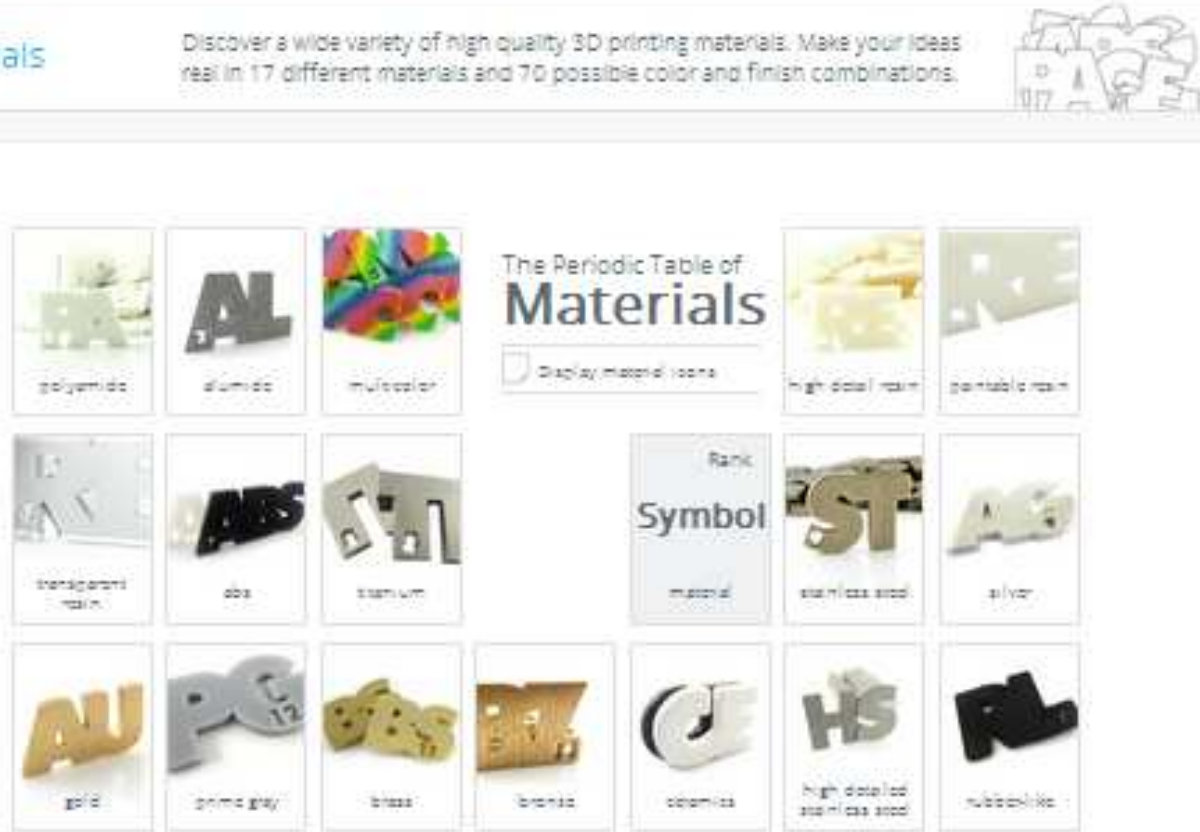

Figure 2.4 Materials for 3D printing (http://i.materialise.com/materials)

1. Polyamide

2. Alumide

3. Multicolor

4. High detail resin

5. Paintable resin

6. Transparent resin

7. ABS

8. Titanium

9. Stainless Steel 
10. Silver

11. Gold

12. Prime gray

13. Brass

14. Bronze

15. Ceramics

16. High detailed stainless steel

17. Rubber-like

\subsubsection{Selective Laser Sintering (SLS)}

$\underline{\text { Standard Terminology: }}$

Laser Sintering (LS), - "a powder bed fusion process used to produce objects from powdered materials using one or more lasers to selectively fuse or melt the particles at the surface, layer by layer, in an enclosed chamber".

Selective Laser Sintering (SLS), - "denotes the LS process and machines from 3D Systems Corporation”. (ASTM International, 2012)

In 1992, Selective Laser Sintering from DTM (now a part of 3D Systems) and the Soliform Stereolithography system from Teijin Seiki became available. Using heat from a laser, SLS fuses powder materials. The Soliform technology was originally developed by DuPont under the Somos name and was subsequently licensed to Teijin Seiki for 
exclusive distribution rights in parts of East Asia. Also in 1992, Allied Signal introduced vinylether Exactomer resin products for SL. (Wohlers and Gornet, 2011)

The generative technology, Sintering, was invented at the beginning of the $90 \mathrm{~s}$. At that time it was named as Laser Sintering, because all systems worked with a laser. For differentiation to industrial Sinter methods and due to solidification only in selected sections, the term Selective Laser Sintering (SLS) was more appropriate. In 2001 the ARCAM machine was introduced which works with an electron beam instead a laser. In 2005 the Speed Part AB machine was introduced which works with an infrared emitter. Based on those new technologies the generic name "Selective Sintering" or "Sintering" is generally used. (Gebhardt, 2007)

In the SLS process, a rastering infrared laser beam heats the surface of a powder bed to fuse the powder in a cross-section that matches that of a prototype being replicated. The surface is then covered with another layer of powder and the cycle is repeated. The current fused layer is bonded to that beneath to build up the $3 \mathrm{D}$ shape of a part. (Berzins et al., 1996)

The obtained part has a rigid but porous structure. The loose powder can be removed and recycled. Small powder particles tend to melt earlier and more completely than big ones under the laser radiation. The surface tension of the droplets leads to the accumulation of liquid phase at the contact points of the large, solid grains.

This process is called "the necking phenomenon" because the bonding between the particles usually look like necks. (Boillat et al., 2004) 


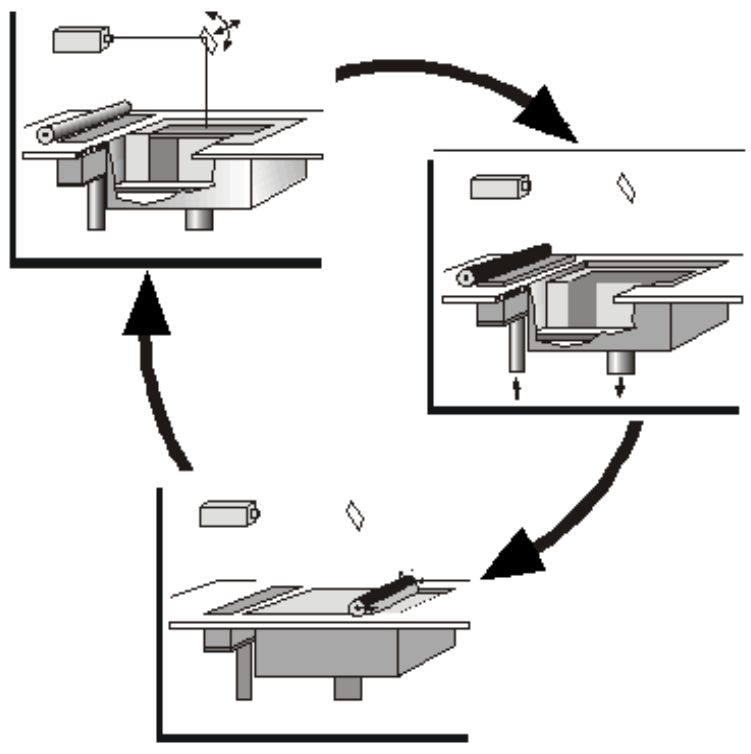

Figure 2.5 Laser Sintering(Boillat et al., 2004)

The EOS $\mathrm{GmbH}$ is manufacturer of layer manufacturing techniques (LMT). These techniques, also sometimes referred to as solid freeform manufacturing (SFM) and other names, enable physical parts to be manufactured directly from computer-aided design (CAD) data, quickly and automatically. They stated that their machine EOSINT (SLS) builds with a similar procedure to STEREOS (SLA), in that the part is built up layer by layer on a platform by scanning a laser beam over the material surface. The fundamental differences are that the material is in powder form and the solidifying process is a thermally induced phase change rather than a chemical reaction. In principle almost any fusible material can be used, but it has to be available with suitable surface properties for recoating and optical and thermal properties matched to the laser radiation. Suitable materials include thermoplastics and low-to-medium melting point metals. This can be extended to other materials such as ceramics or high melting point metals. (Behrendt and Shellabear, 1995)

The following process variants became known in Selective Laser Sintering: 
- Indirect Metal Selective Laser Sintering (IMSLS)

- $\quad$ Selective Laser Melting (SLM)

\subsubsection{Indirect Metal Selective Laser Sintering (IMSLS)}

Indirect Metal Selective Laser Sintering (IMSLS) allows steel/bronze composite parts to be made through a combination of selective laser sintering of a polymer coated steel powder to create a "green" part, followed by furnace infiltration of the green part with bronze. The resulting parts are fully dense functional components which can be exploited for demanding engineering applications, such as injection moulding tooling.(Zakaria and Dalgarno, 2010)

\subsubsection{Selective Laser Melting (SLM)}

Selective Laser Melting (SLM) has been developed driven by the need to produce near full dense objects with mechanical properties comparable to those of bulk materials and the desire to avoid lengthy post processing cycles. Polymers as well as metals can be completely molten by a laser beam. The appellation Selective Laser Melting is reserved for metallic materials.

In the ease of processing (e.g. laser absorption, surface tension and viscosity of the liquid metal, etc.), all metals may be thought of as candidate materials; however, large differences exist. For each new material, a process-window needs to be determined experimentally in order to ovoid scan track instabilities (sphereodisation of the liquid melt pool, also known as "balling") and part porosity.

In recent years, the idea of full melting metal powders was explored, supported by the continuously improving process parameters (smaller layer thickness, smaller spot 
size, etc.), resulting in mechanical properties being much better than those of early time selective laser sintered parts and comparable with bulk metal properties.(Kruth et al., 2005a)

Table 2.5 gives a summary of SLS technologies.

Table 2.5 Summary Selective Laser Sintering

\begin{tabular}{|l|l|}
\hline \multicolumn{2}{|c|}{ Selective Laser Sintering } \\
\hline Method & $\begin{array}{l}\text { Local fusing of powdered thermoplastic material, layer formation after } \\
\text { solidification. No pillars needed. }\end{array}$ \\
\hline Materials & Plastics (polyamide, polystyrene), metals, sands, ceramics \\
\hline Advantages & Plastics: high mechanical and thermal load then Stereolithography \\
\hline Disadvantages & Rougher surface, lower level of detail then Stereolithography \\
&
\end{tabular}

Sintering and melting can be used with all materials which behave like thermoplastics. Therefore, Sintering provides a significantly wider variety of materials then Stereolithography. The resultant components are mechanically and thermally loadable. According to the material and application they can be used as a functional model and often as the end product. Based on that fact, Sintering is the key to Direct Tooling, (the direct manufacturing of tools and tool inserts) and also for Direct Manufacturing, the generative production of end products. 
Powder that has not been melted can be partially recovered and can be put back in the process, mostly by mixing with unused powder. The recycling rate depends on the degree of damage and lies in case of polyamide powders between 50 and $30 \%$ used powder in the new construction process.(Gebhardt, 2007)

To help in the decision process for choosing the best application and the most economical generative production process, there are two checklists available, one checklist for additional purchase of components and the second checklist for procurement of a system. Table 2.6 gives a checklist for selecting an SLS system.

Table 2.6 Checklist for additional purchase of components(Zäh, 2006)

\begin{tabular}{|l|l|}
\hline \multicolumn{2}{|l|}{ Preconditions } \\
\hline 1. & Are STL, IGES, VDA data to manufacturers ready to submit? \\
\hline 2. & Are 3D-constructions ready for transmitting? \\
\hline 4. & Are all requirements of the components defined? \\
\hline 4.1 & Roughness Level \\
\hline 4.2 & Loading capacity \\
\hline 4.3 & Heat resistance/acid resistance \\
\hline 4.4 & Surface (coated, structured, etc.) \\
\hline
\end{tabular}




\begin{tabular}{|l|l|}
\hline 4.7 & Additional requirements \\
\hline 5. & Is the budget defined? \\
\hline 6. & Is the technology predetermined? \\
\hline 7. & Is the system operator detected? \\
\hline
\end{tabular}

\begin{tabular}{|l|l|}
\hline \multicolumn{2}{|l|}{ Questions for determination of the right Rapid-Technology } \\
\hline 1. & Material properties required \\
\hline 2. & Roughness Level required \\
\hline 3. & Complexity of the parts \\
\hline 4. & Size of the parts \\
\hline 5. & Numbers of the parts \\
\hline
\end{tabular}

\begin{tabular}{|l|l|}
\hline \multicolumn{2}{|l|}{ Definitions with the system operator } \\
\hline 1. & Shipping costs \\
\hline 2. & Technology to apply \\
\hline 3. & Component costs \\
\hline 4. & Delivery deadline \\
\hline
\end{tabular}




\begin{tabular}{|l|l|}
\hline 5. & Consequences for the delay of the delivery date \\
\hline 6. & Dispatch type \\
\hline 7. & Deadline for changes of the geometry \\
\hline 8. & Costs of data preparation \\
\hline
\end{tabular}

\begin{tabular}{|l|l|}
\hline \multicolumn{2}{|l|}{ Characteristics of the right manufacturer } \\
\hline 1. & Experiences with complying Rapid Technologies? \\
\hline 2. & Customer references? \\
\hline 3. & Component costs in the range of market level? \\
\hline 4. & Established company inside Rapid area? \\
\hline 5. & Advisory Service for possibilities and restrictions of appropriate \\
proceedings? \\
\hline 6. & Manufacturer has appropriate resources (systems, employees) \\
\hline 7. & Proximity of the manufacturer \\
\hline 8. & New or regular supplier? \\
\hline
\end{tabular}

Table 2.7 gives a checklist to guide the procurement of an SLS system. 
Table 2.7 Checklist for procurement of a system(Zäh, 2006)

\begin{tabular}{|l|l|}
\hline \multicolumn{2}{|l|}{ Data Conditions } \\
\hline 1. & $\begin{array}{l}\text { Is there an assessment realized by using STL data (mistake corrections, } \\
\text { supporting constructions, and slice-data-creation) technically usable in the } \\
\text { current software programs of the company? }\end{array}$ \\
\hline 2. & Are there existing connections for data transfer in both directions from/to \\
the customer realized (internet connection, direct interconnections) $?$
\end{tabular}

\begin{tabular}{|l|l|}
\hline \multicolumn{2}{|l|}{ Workshop Conditions } \\
\hline 1. & Are media connections (power supply, cooling units, compressed air, or \\
& protective gas) present? \\
\hline 2. & Existing network connection (Ethernet)? \\
\hline
\end{tabular}




\begin{tabular}{|l|l|}
\hline 3. & System requirements for temperatures/moisture/air purity can be fulfilled? \\
\hline 4. & $\begin{array}{l}\text { Are there special conditions for the facility environment (load capacity of } \\
\text { the ground, extraction units, vibration through other production plants) } ?\end{array}$ \\
\hline 5. & Existing space sufficient?(plant with periphery) \\
\hline 6. & Existent storage room for building material sufficient? \\
\hline 7. & Logistics assured? (transportation of components) \\
\hline 8. & $\begin{array}{l}\text { After treatment of components ensured? } \\
\text { preparation/material recycling is necessary? }\end{array}$ \\
\hline 9. & \begin{tabular}{l} 
Which periphery equipment for after treatment of components/material \\
\hline
\end{tabular}
\end{tabular}

\begin{tabular}{|l|l|}
\hline \multicolumn{2}{|l|}{ Procurement of a system } \\
\hline 1. & Life cycle of plant components? \\
\hline 2. & How many different materials can be used? \\
& Are there different suppliers for the material $?$ \\
\hline 3. & What is the cost of building materials? \\
\hline 4. & Are required quality of the component reproducible abided? \\
& \begin{tabular}{l} 
(surface, strength, dimensional accuracy, life cycle) \\
\hline
\end{tabular}
\end{tabular}




\begin{tabular}{|c|c|}
\hline 5. & Are regulations or laws on hazardous material to apply? \\
\hline 6. & Is the supply of spare parts ensured, also for the future? \\
\hline 7. & Availability of service technicians? \\
\hline 8. & Setup times (material handling, establishment of build jobs)? \\
\hline 9. & Are the employees able to make maintenance by themselves? \\
\hline 10. & Are maintenance contracts necessary? \\
\hline 11. & Estimation of costs for service and maintenance? \\
\hline 12. & Cycles and scope for needed Software/Hardware-Updates? \\
\hline 13. & Stage of development for new materials? \\
\hline 14. & $\begin{array}{l}\text { Are safety data sheets for materials and for operation of the system } \\
\text { available? }\end{array}$ \\
\hline
\end{tabular}

\begin{tabular}{|l|l|}
\hline \multicolumn{2}{|l|}{ Employees } \\
\hline 1. & Is operating staff available? \\
\hline 2. & Is the training strategy scheduled? \\
\hline 3. & $\begin{array}{l}\text { Is there operating staff for possible after treatment for components } \\
\text { available? }\end{array}$ \\
\hline 4. & Flexibility of the employees in case of working time? \\
\hline
\end{tabular}




\subsubsection{Direct Metal Laser Sintering (DMLS)}

Standard Terminology: "a powder bed fusion process used to make metal parts directly from metal powders without intermediate "green" or "brown" parts; term denotes metal-based laser sintering systems from EOS GmbH - Electro Optical Systems".(ASTM International, 2012)

The One-Stage SLS Process, also known under its commercial name Direct Metal Laser Sintering (DMLS), is practiced with different materials. One of the main issues is porosity. The One-Stage Liquid sintering is a portion of the practiced thermal sintering with left over porosity. The material composition, the grain size and post treatment with shot penning have helped to some extent to reduce this problem. The recently introduced $20^{\mu m}$ metal powders bring a significant improvement in mechanical properties surface quality and porosity of the productivity decreases strongly. (Levy et al., 2003)

The development with respect to functional, customized products will be influenced in the future by achievable progress of the generative methods. New technologies for layer manufacturing on plastic and metal basis, named Selective Laser Sintering (SLS) and Selective Laser Melting (SLM), already known today economically for Rapid Prototyping and Rapid Manufacturing, which are major contributions for the flexibility of production technology. Through these methods it is possible to implement complex functional components from several different plastics (polyamide, glass fiberreinforced plastics) and metal alloys (aluminum, titanium, steel alloy) in a short time without complex CAD-CAM-interfaces. Typical examples for application are biocompatible implants for the medical technology, mold inserts with internal cooling channels for tool and mold construction as well as components for the aerospace industry. 
The generation of control data for the tool-free manufacturing is based directly on the 3D-CAD-datas. It is not surprising, because these advantages instead of the traditional cutting manufacturing, that the manufacturer of these machines have had a high market growth in recent years. But there are also disadvantages. There is a lack of process knowledge for a continuous first-time-right production of components without rejects. There is also a lack of additional experimental research.

For producing parts in large series, there are some changes needed in case of build-up rate of the material and the quality of the produced parts. A higher consciousness of the constructors and user is needed for continuous using of the methods in the industrial area.

To ensure additional market growth of the generative production methods, numerous tasks in the area of research must be solved in close cooperation with the industry:

- Component design

- Process modeling (FEM)

- Process development and security

- Material development

- Quality assurance

- Energy and resource efficiency(Abele and Reinhart, 2011)

$\underline{\text { Standard Terminology: }}$

CAD, -“Computer-Aided Design.The use of computers for the design of real or virtual objects." 
STL,-“in additive manufacturing, file format for 3D model data used by machines to build physical parts; STL is the de facto standard interface for additive manufacturing systems. The STL format originated from the term Stereolithography." (ASTM International, 2012)

\subsection{AM Process and Supply Chain}

The Standard Terminology for Additive Manufacturing Technologies provides also a structure for grouping current and future AM machine technologies. These terms are useful for educational and standards-development purposes and are intended to clarify which machine types share processing similarities.

These seven process categories are defined:

- "binder jetting, $n$ - an additive manufacturing process in which a liquid bonding agent is selectively deposited to join powder materials.

- directed energy deposition, $n$ - an additive manufacturing process in which focused thermal energy is used to fuse materials by melting as they are being deposited.

- material extrusion, $n$ - an additive manufacturing process in which material is selectively dispensed through a nozzle or orifice.

- material jetting, $n$ - an additive manufacturing process in which droplets of build material are selectively deposited.

- powder bed fusion, $n$ - an additive manufacturing process in which thermal energy selectively fuses regions of a powder bed. 
- sheet lamination, $n$ - an additive manufacturing process in which sheets of material are bonded to form an object.

- vat photopolymerization, $n$ - an additive manufacturing process in which liquid photopolymer in a vat is selectively cured by light-activated polymerization."

(ASTM International, 2012)

In the literature eight key steps of the AM process were defined:

\section{Step 1: Conceptualization and CAD}

The generic AM process starts with 3D CAD information. Most 3D CAD systems are solid modeling systems with some surface modeling components.

\section{Step2: Conversion to STL}

The CAD model has to be converted into the STL format for building using AM technology. It works by removing any construction data, modeling history, etc., and approximating the surfaces of the model with a series of triangular facets.

\section{Step 3: Transfer and manipulation of STL file on AM machine}

The created STL files can be sent directly to the target AM machine. The first task would be to verify that the part is correct. The AM system software normally has a visualization tool that allows the user to view and manipulate the part. The user can make a reposition of the part or even change the orientation to allow it to be built at a specific location within the machine. It is quite common to build more than one part in an AM machine at a time. 


\section{Step 4: Machine setup}

Some machines are designed to run with a variety of materials and may also have some parameters that require optimization to suit the type of part that is to be built, or permit parts to be built quicker but with poorer layer resolution, for example. Such machines can have numerous setup options available.

\section{Step 5: Build}

Beginning from this step, the process switches to the computer-controlled building phase. All AM machines will have a similar sequence of layer control, using a height adjustable platform, material deposition and layer formation simultaneously while others will separate them. All machines will repeat the process until either the build is complete or there is no source material remaining.

\section{Step 6: Part removal and cleanup}

The part must be either separated from a build platform on which the part was produced or removed from excess build material surrounding the part. Some parts are ready to use and some parts need a manual finishing.

\section{Step 7: Post-processing of part}

Post-processing refers to the (usually manual) stages of finishing the parts for application purposes. This may involve abrasive finishing, like polishing and sandpapering, or application of coatings. 


\section{Step 8: Application}

Some AM processing inherently create parts with small voids or bubbles trapped inside them, which could be the source for part failure under mechanical stress. In addition, some processes may cause the material to degrade during build or for materials not to bond, link, or crystallize in an optimum way. However, AM materials and processes are improving all the time, and many applications do not require high performance from many of their components. The number of applications for the output from AM processes is therefore constantly increasing.(Gibson et al., 2010)

Advantages of additive manufacture lie in the ability to produce highly complex parts that require no tooling and thus reduce the costs of manufacture, especially for low volumes (Hopkinson and Dickens 2001, Griffiths 2002). As high volumes do not need to be manufactured to offset the cost of tooling then the possibilities for affordable, highly complex custom parts becomes apparent. In theory, each part that is produced could be a custom part.

It must be stated that current RM (Rapid Manufacturing) is being done on RP (Rapid Prototyping) systems such as laser sintering (LS) or stereolithography (SL). However, though the machines have improved considerably over the past ten years, these systems require further development for full scale manufacturing, such as:

1. The machines have been designed for prototyping and are therefore relatively slow, inaccurate and give poor surface finish.

2. The cost of materials and machines is prohibitive.

3. Materials selection is limited to a few polymeric, metallic and ceramic materials. 
4. The materials available have little information available with regard to their true engineering characteristics.

In the development of suitable supply chain practices for the appropriation of value, a number of supply chain concepts have been developed. These include:

- Lean

- Agile

- Leagility and Postponement

- Mass Customization

- Demand chain

These concepts have been used as a basis for arguments that will become applicable on the successful realization of RM and are discussed in more detail below.

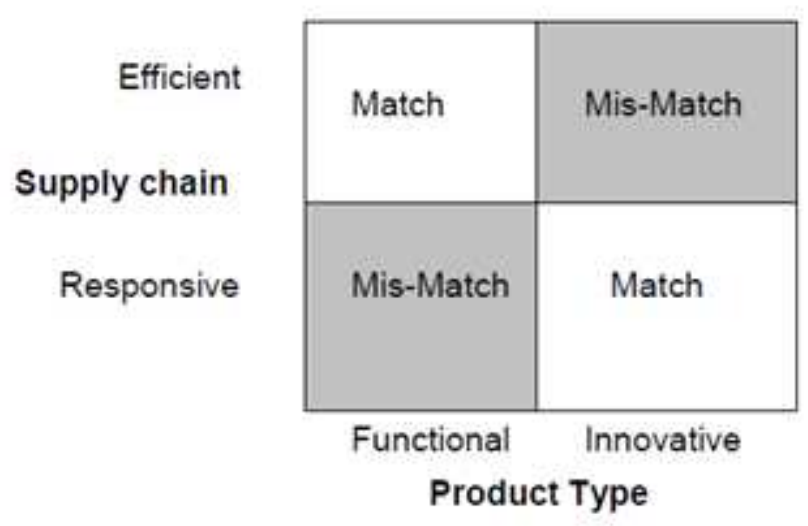

Figure 2.6 Product supply chain matrix (Fisher 1997) 
Table 2.8 Lean and agile supply chain operators (Mason-Jones et al. 2000)

\begin{tabular}{|l|c|c|}
\hline \multicolumn{1}{|c|}{ Distinguishing Attributes } & Lean Supply & Agile Supply \\
\hline Typical products & Commodities & Innovative \\
\hline Market place demand & Predictable & Volatile \\
\hline Product variety & Low & High \\
\hline Product lifecycle & Long & Short \\
\hline Customer drivers & Cost & Availability \\
\hline Profit margin & Low & High \\
\hline Dominant costs & Physical costs & Marketability costs \\
\hline Stock out penalties & Long term contractual & Immediate and volatile \\
\hline Purchasing policy & Buy goods & Assign capacity \\
\hline Information enrichment & Highly desirable & Obligatory \\
\hline Forecasting mechanism & Algorithmic & Consultative \\
\hline
\end{tabular}

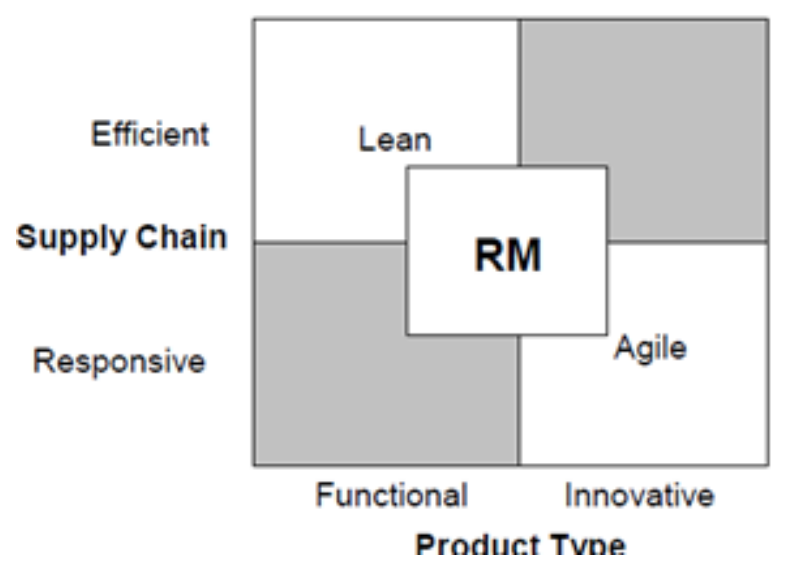

Figure 2.7 Modified production and supply chain matrix (Fisher 1997)

Each case operates in a very different market. Case 1 produces automotive vehicles at medium to high volumes for sale to the consumer. Case 2 operates in the Formula 1 arena and as such a highly competitive sector where development of the race car is of paramount importance, i.e. improved performance on the track equals increased revenue. Case 3 produces hearing devices for the consumer; comfort and quality are key market levers. A summary of the strategic reasons for using RM are shown in the Table 2.9 . 
Table 2.9 Strategic reasons for using RM for individual cases

\begin{tabular}{|c|c|c|}
\hline Case 1 & Case 2 & Case 3 \\
\hline $\begin{array}{l}\text { Use of RM to provide interim } \\
\text { production solution and } \\
\text { reduce costs of a vehicle }\end{array}$ & $\begin{array}{l}\text { RM used to provide } \\
\text { increased capacity of } \\
\text { individual products for wind } \\
\text { tunnel testing }\end{array}$ & $\begin{array}{l}\text { Coupled with 3D scanning } \\
\text { methods, mass } \\
\text { customisation of ITE devices } \\
\text { for individual customers }\end{array}$ \\
\hline
\end{tabular}

Lean

The application of RM for the fulfilment of lean principles in an organization has been demonstrated by the three cases presented. Taking each of the factors discussed with illustration from the cases it is possible to see the possible impact that RM can have on this SCM paradigm. The eight characteristics discussed by Cox $1999 \mathrm{~b}$ have been affected by the introduction of RM in these organizations. Case 1 in particular highlights the ability of RM to impact the lean SCM paradigm. Through the use of RM, the time pressures due to an engineering issue were solved. This consequently highlighted the ability of RM as a production method to influence the four criteria seen above. A summary of the effect of RM on lean criteria for case 1 now follows:

\section{Produce only when necessary through JIT}

The component was produced as to requirements of the production schedule. The 1800 components built were produced in 6 batches of 300 at a production time of 8 hours per batch.

\section{Dematerialised supply chain}

An intrinsic quality of the RM production system is the necessity of digital data and raw materials for production. The use of digital data means that the systems are ideal for developing a dematerialised supply chain, where components are produced with little 
to no work in progress. In this specific case the data produced by the designer was sent directly to the RM machine operators and then placed upon the bed for manufacture.

\section{Reduced set up, changeover time and number of assemblies}

Again an intrinsic quality of RM, case 1, as mentioned previously, used an existing prototyping facility within the organization to produce the parts in question. In order to begin production the only set up that was required was to fill the LS machine with raw material and place the digital data on the "virtual" bed of the machine. Therefore changeover time was minimal. In addition, after the first batch had been set up, subsequent batches require less time to set as the "build" file can be saved along with the 3D CAD data for use in the future. This case has not shown the reduction of the number of assemblies with the use of RM; however, examples of this exist in other industries. Wohlers, 2005, has presented how RM can be used to rationalize the number of assemblies in a product, specifically, the development of a single part by On-DemandManufacture (ODM) for Boeing. The use of RM and innovative design reduced an air ducting component from an assembly of 10 components to a single piece that could be produced using LS.

\section{Elimination of waste}

The waste eliminated in Case 1 revolved around the reduction in time for the component to be delivered to the manufacturing organization. The use of RM for the component reduced the waiting time of the initial batch of components from 6 weeks to 8 hours. The total production of RM components during this 6 week period resulted in a total of 1800 components. The use of RM saved each of these vehicles (900 in total) $£ 40$ due to the delays for traditional manufacturing resulting in a company saving of $£ 36,000$. 
In addition to this cost saving, distribution costs were minimized as the components were produced on site.

\section{Agile}

The impact of RM for an agile supply chain has been demonstrated by case 2 . Kochan, 2003 shows how RP (though arguably it is RM) has been exploited at Renault F1 as a flexible manufacturing system. The business model for Renault F1 is very different to that shown in case 1 , as their prime focus is on speed of vehicle development to gain fractions of a second on the racetrack. The wind tunnel facility that the RM systems support tests 30-40 new aerodynamic designs per day on 50\% scale models. Traditionally the components would have been produced by model makers from carbon fiber.

The reasons for utilizing RM in case 2 are two-fold: Firstly, each component required by the wind tunnel is unique, i.e. the components are incrementally different. The fact that each component is different means that traditional manufacturing methods such as injection molding would be unsuitable as the cost of tooling would be prohibitive. The second reason for utilizing $\mathrm{RM}$ is that traditionally wind tunnel parts were manufactured by laminating a machined mold with carbon fiber. This consumed both labor and capacity on existing machining facilities which reduced the time available for race car production. Renault F1 is able to offer a service to their designers and wind tunnel facility that ensures time is not taken from essential race car manufacturing equipment. Indeed a $24 \mathrm{hr}$ turnaround time from receipt of CAD data at the facility to having the part ready for testing has been quoted. In addition to this it is also possible to have another 30 different variations of the component being built at the same time. The 
use of RM has meant that Renault F1 has increased the number of designs made and tested by a factor of 10 .

The products produced by RM at Renault F1 show the key characteristics of the agile products as described by Mason-Jones et al. 2000 (Table A comparison of lean and agile supply chain operators). The components have high variety, are innovative and have a short product lifecycle. The availability of these components at the correct time is key to the future of the business.

In addition to the production of test components, RM is also now being used for the production of race car components. The parts in question are lightly stressed components such as complex air ducting components and parts for the electrical system (Goode, 2003). Additionally, the demands of each race circuit are quite different; as such the RM components are able to be optimized for each race without expensive tooling changes. The move to RM has also had implications on operations at Renault. Due to the low labor content of RM production the machines are able to run $24 \mathrm{hrs}$ a day 7 days a week. However, the facility operates over a normal working week (8:30 am - 6:30 pm, Monday through Friday) with systems in place to inform operatives in the event of a breakdown or build completion. Using the criteria for agile manufacturing set out in section 4.2 the impact of RM on the agile paradigm outlining the attribute shown by case 2 in comparison to traditional manufacturing methods can be summarized.

\section{Low cost products with fast re-configurability and fast response}

As with case 1 the RM system is able to be reconfigured for each different build through the addition or subtraction of components to the "virtual" build area. The response of this set up and re-configurability is limited only to the speed of the operator 
and software at placing the components. Traditionally these components would have required newly machined mold patterns (taking up time from race car component production) and subsequent mold production and lamination.

\section{Reduced stock levels}

The stock levels of components have not changed as the components are individual and only used for testing their lifetime is very short. However, if a component requires reproduction it is only necessary to find the requisite $3 \mathrm{D}$ CAD data for production. In comparison to traditional methods the storage of the original molding would be required and thus in effect the use of RM has reduced the stock levels of physical components at the factory.

\section{Reduced waste}

Waste has been reduced in various forms when compared to the original manufacturing operation. Firstly the removal of molds has been possible; in addition the removal of labor for carbon fiber lamination has meant that this skilled labor can be moved to the race car. Time that was previously required for the machining of patterns on race car production equipment has been removed releasing capacity for manufacture of chassis components.

\section{Increased value}

Labor has been able to be moved from the production of test components to the value adding activities of race car production and component design. 


\section{Reduced logistics cost}

The use of RM in case 2 has resulted in the reduction of mold tools in the production of components for the test facility. Therefore storage of these mold tools is no longer required and existing designs are now stored virtually (as the 3D CAD file).

\section{Reduced part count}

Part count reduction has also been possible in specific instances, for example radiator test components have been consolidated from an assembly of 5 items to a single part.

\section{Increased flexibility}

The use of RM in case 2 has resulted in an increase in the number of components tested by the wind tunnel (x10) and in addition production of a greater number of variants (50-100 variants of every component tested in the wind tunnel). Additionally race car components have been able to be produced where the mechanical demands have been met by the RM process. This is truly agile manufacturing as the RM systems produce individual parts not only from build to build but also in the same batch of components.

\section{Mass Customization}

Case 3 has been identified as a suitable demonstration of how RM can be utilized for the production of mass customized components. In many ways the case echoes case 2 . The production of customized hearing aids requires the same agility and flexibility within the business as that shown by case 2 . In fact for the demonstration of an agile paradigm the two are interchangeable. However, where case 3 differs is in the production of body 
fitting customized components. Case 3 has exploited recent advances in 3D scanning techniques and RM and developed these into a new business concept.

Using 3D scan data taken from the molded impression the detail of the human ear canal can be exported to suitable software, manipulated and a final CAD model produced for manufacturing. In addition to getting the form of the shell correct for a good fit, articles such as ventilation holes and receiver holes are added during the CAD phase. RM techniques are then used to build the individual ITE devices from biocompatible materials; usually stereolithography resins (Hopkinson et al. 2005). Previously, this was done by taking a deep impression of the ear and then molding a hollow shell from the impression. However, problems exist with this method. For example manual finishing of the product can result in a badly fitting device or the impression of the ear may not provide all necessary information. The production of these devices was dependent on the skill of operatives, both in taking a suitable impression and finishing the final shell. In terms of the company's operations the move to RM has significant benefits:

\section{Tooling has been eliminated}

2. Labor has been reduced in manufacture and finishing

3. Weekend or overnight production possible without increased labor

4. Lower cost product with increased quality

These benefits all stem from the ability to take 3D CAD data and reproduce this directly in an RM machine. Wohlers (2005) has reported on the hearing aid industry being a great proponent of RM and quotes that Siemens Hearing Solutions had sold more than 150,000 units to mid -year 2003 at a rate of 2000 products per week. This surely demonstrates that 
$\mathrm{RM}$ (even with RP equipment) is a viable manufacturing technique and offers Companies savings in terms of waste reduction. In addition, the application of RM in this area proves the effective use of RM as a tool for customization and mass customized products, offering both advantages for the manufacturer and the user of the component. Referring to Alford et al. (2000), though the product is not based in the automotive sector; it does demonstrate the use of RM for core customization, i.e. intrinsically linked to the customer's wants and needs. The development of RM as a flexible manufacturing has direct influence on the agile and lean paradigms discussed. With particular reference to Anderson and Pine (1997) agile manufacturing capability is one of the key process infrastructures that is needed for mass customization.

It is clear that RM has the potential to change or modify these paradigms greatly. The opportunities available for reduction in costs of production through the natural rationalization of logistics, labor, stock holding and the ability to deal with unstable demand patterns are all apparent. The ability to remove these costs could also affect the manufacturing environment on a global scale, by returning manufacturing to the country of origin, as labor costs are no longer a burden. Rapid Manufacturing could also realize the first truly flexible and JIT supply chain paradigm, that can respond to customer demand and changes in taste and design with ease.

Additionally, the introduction of Rapid Manufacturing could lead to increased value in products through the realization of truly customized production. The ability to produce innovative customized products through an efficient and responsive supply chain could mean both increases in overall market share for organizations and increased satisfaction for the consumer. 
The impact on manufacturing will be the most profound. Rapid Manufacturing will change design leading to a reduction in both the number of components necessary for assemblies and a reduction in waste, whether this be time or cost.

The ability to produce part and products locally will have profound effects on the lead times and costs of these parts, brought about partly through the removal of inventory costs and a reduced cost of distribution. Indeed, no longer will it be necessary to produce parts cheaply thousands of miles away; for low volume and custom products, they could be produced for less, in a more convenient location.

Multiple RM machinery can currently be operated by a single operator, thus reducing the demands placed on the labor force and, consequently, bringing manufacturing back from low wage economies. Thus the economies of the global work place could be replaced by the economies of technology.

The RM cases discussed highlight many of the advantages that are hoped will become mainstream as RM evolves. The automotive case outlines the advantages of RM in terms of speed to market (reduced by one month compared to traditional production) and the subsequent improvement in stock levels (i.e. products can be sold earlier). Again the leagility of the process is born out as no changes in skills or tooling are necessary to build different parts and changeover times are eliminated.

Renault F1 are currently using RP as a manufacturing method which allows them to produce low volume (custom) components efficiently (24/7) with a low labor requirement. RM offers the flexibility of producing thousands of individual components from a 3D CAD data source for wind tunnel testing, and the production of highly complex structures for race cars. 
The case of the hearing aid industry serves to show the reduction in manufacturing operations for a complex customized component that benefits, in terms operations management, from reduced labor, reduced waste (finishing) and greater flexibility of production (i.e. a greater number of production hours per week) are possible.

Though many questions remain to be answered on how the development of RM and full customization can be implemented, the impact of this technology on the manufacturing and consumer environment will be immense (Tuck et al., 2007).

\subsection{Genetic Algorithm}

Genetic Algorithms represent an attempt, using natural processes for imitation of the evolution implement in computational algorithms, to find the optimal solution for a problem.

Foundations of GA were laid in the 1960s in the USA from John Holland in his 1975 published monograph. Only 10 years later the heuristic methods for optimization were developed and with David E. Goldberg's book "Genetic Algorithms in Search, Optimization, and Machine Learning" this topic was available to a broader audience.

Heuristic methods have been used effectively in many applications for many years and they have a great potential in the area of optimization of fault-tolerant systems. In this case, GA helps because of the steered chance iteratively search to find better solutions until the optimum case is determined. To resolve such topics GAs imitate natural processes. The transfer performance for technical tasks is not simply to define the target of the specific task, but to choose the appropriate representation (genetic coding). 
The description of the objective function (fitness) in mathematical form is of significant importance for using a GA.

The procedure of a Genetic Algorithm works as follows. The structure at the start is the transformation of a chromosome, whereby an individual is defined as a binary code. In the cell, chromosomes are carriers of genetic information, on which the genes are linearly arranged. There will be an initial population with $\mathrm{n}$ chromosomes with random inserted zeros and ones.

These chromosomes are in conformity with $\mathrm{n}$ solutions, e.g. $\mathrm{n}$ systems with typically very low chances of success to survive and produce offspring. The chances of survival will be defined by Darwin's fitness. The numerical value fitness will be determined through simulation and is the basis for the next step, the selection.

The selection of parents for the successor generation is determined randomly with probability of reproduction or frequency of reproduction. In other words, in each case there are two (or more) chromosomes chosen based on these principles and they are crossed (crossover operation) at one (or more) random places.

With the new individuals (descendent), the population will be replaced in whole or in part and this will be defined as the new starting population. As long as the goal of the optimization for the GA is not matched, the procedure of evolutionary cycle will be repeated.

With the progress of the GA, the idea is to eliminate the worst individuals (solutions) and to constantly improve the offspring solutions. (Eusgeld, 2009) 
Genetic Algorithms were often used for the bin packing problem in "transportation terms: given a set of boxes of different sizes, how should one pack them all into containers of a given size, in order to use a few containers as possible?

\section{Advantages:}

The programming of a genetic algorithm can be very simple because the basic scheme is always the same. Only the presentation of the solution as gene, combination, mutation and fitness must be programmed.

\section{Disadvantages:}

Based on the essence of the evolution, the results are very good. In the string mathematical sense, there is no expectation for the "optimal" solution. Based on that idea, genetic algorithms are used when a correct solution is either unknown or when it's not possible to calculate in an acceptable length of time.

Through the influence of randomness it can be assumed that a good solution will be lost over time. The best solution so far has to be memorized.

Ideally the genetic algorithm runs endlessly as in nature. However, based on an appropriate criterion there will be a termination - often without knowledge of the difference between a "good" solution and the "optimal" solution. (von Rimscha, 2008)

GA's were developed e.g. for transportation problems, knapsack problem, traveling salesman problem and by researching for 1D, 2D and 3D Bin Packing problems. To find efficient Genetic algorithms researchers worked with e.g. global optimization, simulated annealing, ant colony and local search. A comprehensive 
literature review for GA as a basement for that research was made. (Dieder and Biles, 2014a)

\subsection{Bin Packing Problem}

A Bin Packing Problem is similar to the knapsack problem. In the knapsack problem the task is to fill the knapsack with different sized objects so that the content knapsack is optimally filled. Starting with the empty knapsack, the task is to fill objects in sequence while offering the best relation of size and value.

Problem: Given $k$ objects with the volume of each $v_{k}$ and the value of $w_{k}$ and the knapsack with the volume $V$.

Searched: $\quad$ A combination of $n$ objects which would fit and shall have a high priority.

This kind of problem occurs in the logistics area (truck loading) as well as also often in the field of cutting optimization (e.g. cutting of clothing or stamping of shapes from a metal plate). (Gerdes et al., 2004)

In the literature, there are different mathematical models and computational solutions solving Bin Packing Problems for e.g. warehouse problems, truck loading by application of e.g. Genetic Algorithms, heuristics or arc flow formulation. By searching for a solution to place the parts into the bin, researchers found ways e.g. to improve the computational time, to rotate the parts for making the space in the bin more efficient and it was important to find solutions by don't loosing good solutions. A comprehensive 
literature review for Bin Packing as a basement for that research was made. (Dieder and Biles, 2014b) 


\section{CHAPTER 3}

\section{RESEARCH APPROACH}

The goal of this experiment was researching the packing of the build volume by maximizing the revenue and meeting at the same time the due date constraint.. There will be m parts to a "build" with the possibility that orders for one or more higher priority parts arrive part-way through the build. The focus of this study is which "unbuilt" parts can be removed from the build to make room for the higher priority parts.

The SLS Sinterstation 2500+ has a cubical build volume with the dimensions $13 " x 15 " x 18 "$.

\subsection{New Approach}

The main advantage of the SLS $2500+$ is that the build can be changed while the job is running! That was the feature that provided the inspiration for that dissertation.

The logical forward-thinking approach is to not seek an optimally packed "bin", but optimize with the objective of maximizing revenue for the completed bin while satisfying due-date constraints on any parts. So it occurs that the first parts built will be those that satisfy an immediate due-date constraint, and then the parts that provide the

greatest revenue last. 
To achieve the maximization of the revenue by meeting at the same time the due date constraint is realized by placing the parts with the closest due date at the bottom of the build and put on that the parts with the highest priority.

Former research in that area so far optimized the build by seeking to find the optimal bin packing solution. Because of the limitation of current optimization tools a solution was found by implementing a penalty be based on failure to meet the due date constraint with Excel Solver. The resulting Excel file will be sorted as to place the immediate items at the bottom of the build. That gives the opportunity to replace the parts on the top (with the longest due date) for movement.

\subsection{Additional Literature Review}

To ensure the new approach with the economical view, this chapter will present a summary of an additional literature review.

\section{5, Benchmarking of different SLS/SLM Processes as Rapid Manufacturing Techniques}

J.-P. Kruth, B. Vandenbroucke, J. Van Vaerenbergh and P. Mercells summarized the shift of Rapid Prototyping to Rapid Manufacturing because of technical improvements of Layer Manufacturing processes. They examined different SLS/SLM processes with regard to conditions that become very important for manufacturing, such as accuracy, material, mechanical properties, speed and reliability.

They described, that the competitive advantages of SLS/SLM are geometrical freedom, mass customization and material flexibility and worked out that the most important challenge was to reach high process accuracy for any geometrical shape - also 
economic aspects like production time (production time consists of powder depositioning time, scanning time and file loading time) and costs (as no manpower is required during the process, production costs are mainly determined by machine hours) were discussed. (Kruth et al., 2005b)

2010, Experimental analysis of selective laser sintering of polyamide powders: an energy perspective

Alessandro Franco, Michele Lanzetta and Luca Romoli saw that SLS has a potential as an environmental benign alternative to traditional processes but only few authors deal with the process optimization including energy aspects. They paid attention to the correlation between the technological results and the energy input in the process characterized by the Energy Density parameter.

With the view of reducing energy consumption they worked out that most of the energy $(35 \%)$ was consumed by the chamber heaters, followed by the stepper motors for the piston control (25\%), the laser (20\%) and the roller drives (20\%). (Franco et al., 2010)

2011, A Comparative Evaluation of Energy Consumption of Selective Laser Sintering and Injection Molding of Nylon Parts

The research of Cassandra Telenko and Carolyn Conner Seepersad focused on estimating and comparing the energy consumption required for different production volumes of nylon parts using either Selective Laser Sintering (SLS) or Injection Molding (IM). 
They described that SLS and competing AM technologies are generally assumed to be more environmentally sustainable than conventional manufacturing methods because the additive process minimizes tooling, material waste, and chemical fluids. They showed the following inputs, outputs and processes included in a product's life cycle.

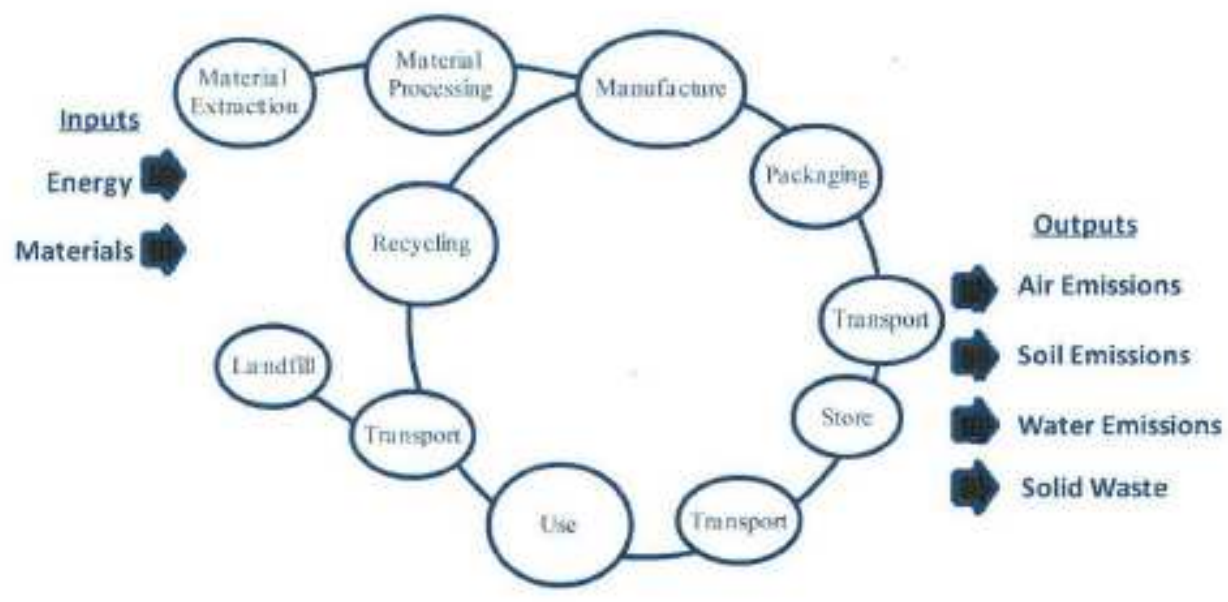

Figure 3.1 Inputs, outputs and processes incl. in a product's life cycle

The results and analysis support three major recommendations for reducing the energy consumption of SLS:

- build volumes should be packed as densely as possible to maximize the part output per build height because SLS energy consumption is dependent upon the height of the build and the corresponding number of SLS layers.

- material-related energy consumption could be improved by engineering infinitely recyclable powder and reducing powder loss during handling. 
- reducing the time required to scan and prepare each layer would significantly lower the energy consumption of SLS. (Telenko and Conner Seepersad, 2011)

\section{2, Combined Build-Time, Energy Consumption and Cost Estimation for Direct Metal Laser Sintering}

M. Baumers, C. Tuck, R. Wildmann, I. Ashcroft, E. Rosamond and R. Hague demonstrated in their research the construction of a combined estimator of build-time, energy consumption and cost for parallel additive techniques such as DMSL which reflects technically efficient machine operation. The application of this methodology shows that the cost and energy consumption of the DMLS process are determined by the user's ability to fill the available build space.

They summarized, that the proposed method can be used to estimate the production of own designs in build volumes that are populated (where necessary) with parts drawn from a representative basket. (Baumers et al., 2011)

\section{2, Towards energy and resource efficient manufacturing: A process and systems} approach

Joost R. Duflou, John W. Sutherland, David Dornfeld, Christoph Herrmann, Jack Jeswiet, Sami Kara, Michael Hauschild and KarelKellens discussed and identified methods and techniques for analysis and system optimization with relation to environmental impact reducing measures in general, energy and resource efficiency in specific. 
The work was related to different levels:

- unit process level

- multi-machine systems

- multi-facility level

- $\quad$ supply-chain level

The outcome was that the different opportunities for efficiency improvement were identified at the respective distinguished levels can be combined in an integrated effort for impact reduction and economy improvement. The possible measures were not mutually independent: energy or material resource saving measures at unit process level will, for example typically result in a decrease in possible energy reuse at multi-machine level. An overall reduction in electrical energy consumption will reduce the impact of choice of location for a production facility in absolute terms. (Duflou et al., 2012)

Also Ruffoet. al and Son published articles for cost estimation in the International Journal Research and Taylor presented a workshop with scenarios and strategies for energy technology perspectives.

At the end there were a lot of research work in the area Inputs regarding Energy and Materials mainly with the view of costs and time. This research looks on the other side from the economical point of view - to the Sales Part (Ruffo et al., 2006) 


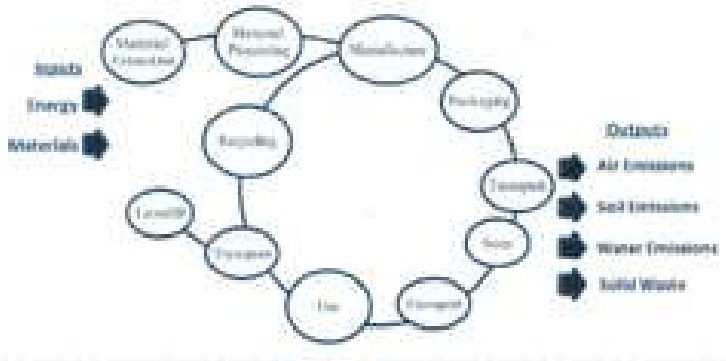

SALES

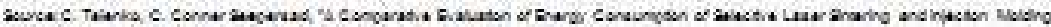

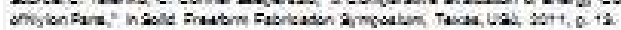

Figure 3.2 Inputs, outputs and the other side of economics: SALES 


\section{CHAPTER 4}

\section{PART PACKING}

The part will be packed in the Build Setup of the Selective Laser Sintering Machine SLS 2500+.

4.1 The Selective Laser Sintering Machine SLS 2500+

This research was done with the Selective Laser Sintering machine from DTM, SLS 2500+. With this model it is possible to produce components made of plastics and metallic material. The machine is inserted in the area of

- Concept- and geometry models from model material

- Functional samples from polyamides or metal

- Technical Prototypes

Major components of the SLS Systems are: 


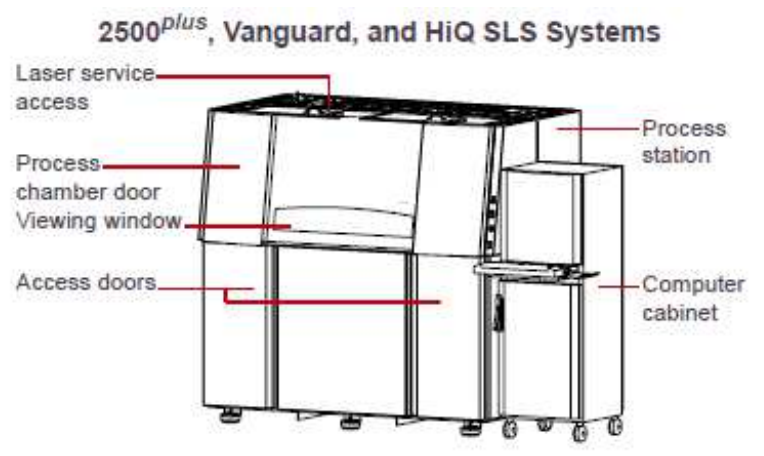

Figure 4.1 Major components of the SLS System

The SLS2500+ is known for those process behaviors:

- Simple workability

- Low processing temperature (short heating and cooling times)

- No restrictions of design space

- No supporting geometries needed

- Simple unpacking

- Good productivity

- Recycling of material

- complete recyclability (Glanemann)

With the SLS 2500+ it is possible to make changes during a build with the Build Modify dialog box.

\section{$\underline{\text { Pausing a Build }}$}

It is possible to stop the build and display options when the Pause Build is active: 
Figure 4.2 Pause Build

The subsection contains three topics:

- Modifying Part and Build Profiles

- Adding and Deleting Parts and Other Changes

- Running a Prime Cycle

\section{Build Modify}

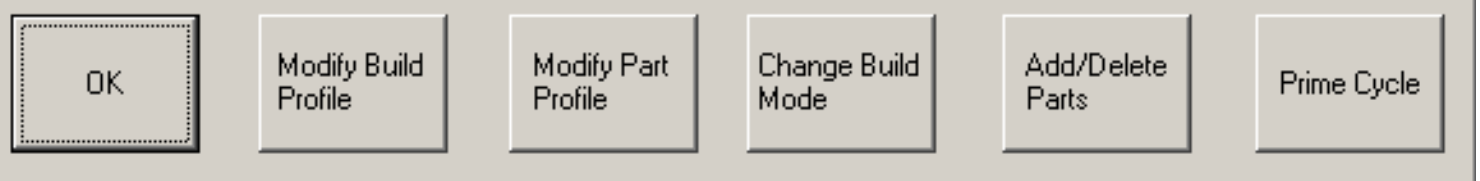

Figure 4.3 Build Modify in the SLS 2500+

\section{$\underline{\text { Modifying Part and Build Profiles }}$}

It is possible to change parameters (e.g. temperature) in the Change Build Mode dialog box.

\section{Adding and Deleting Parts and Other Changes}

In the Build Setup application can be use to modify most aspects of the build packet during the build. Changes are made below the plane, such as adding or moving parts, will not affect the current build, although they will be saved and will affect future runs of this build packet. Parts are initially displayed in Box view. 


\section{Running a Prime Cycle}

The Prime Cycle button enables the potential to spread powder across the part bed without moving the part piston, which can compensate for a short feed.

It is possible when a build is terminated before completion to restart it. This depends on the material in use and the temperature at which the build was running.

When a build is complete, there is a need to remove the sintered parts from the process chamber and clean. The parts and the surrounding powder are called a part cake. Removing parts from the part cake is called breakout.(3D Systems, 2004)

The SLS Sinterstation 2500+ has a cubical build volume with the dimensions $13 " x 15 " x 18 "$.

\subsection{The Part Set}

The Part Set contains 125 parts with different sizes and different geometries and is introduced in Appendix A.

\subsection{The Build Setup}

From each part a stl file has to be created. In this research SolidWorks was used for creating the technical engineering drawing and reformatting it to a STL file. 


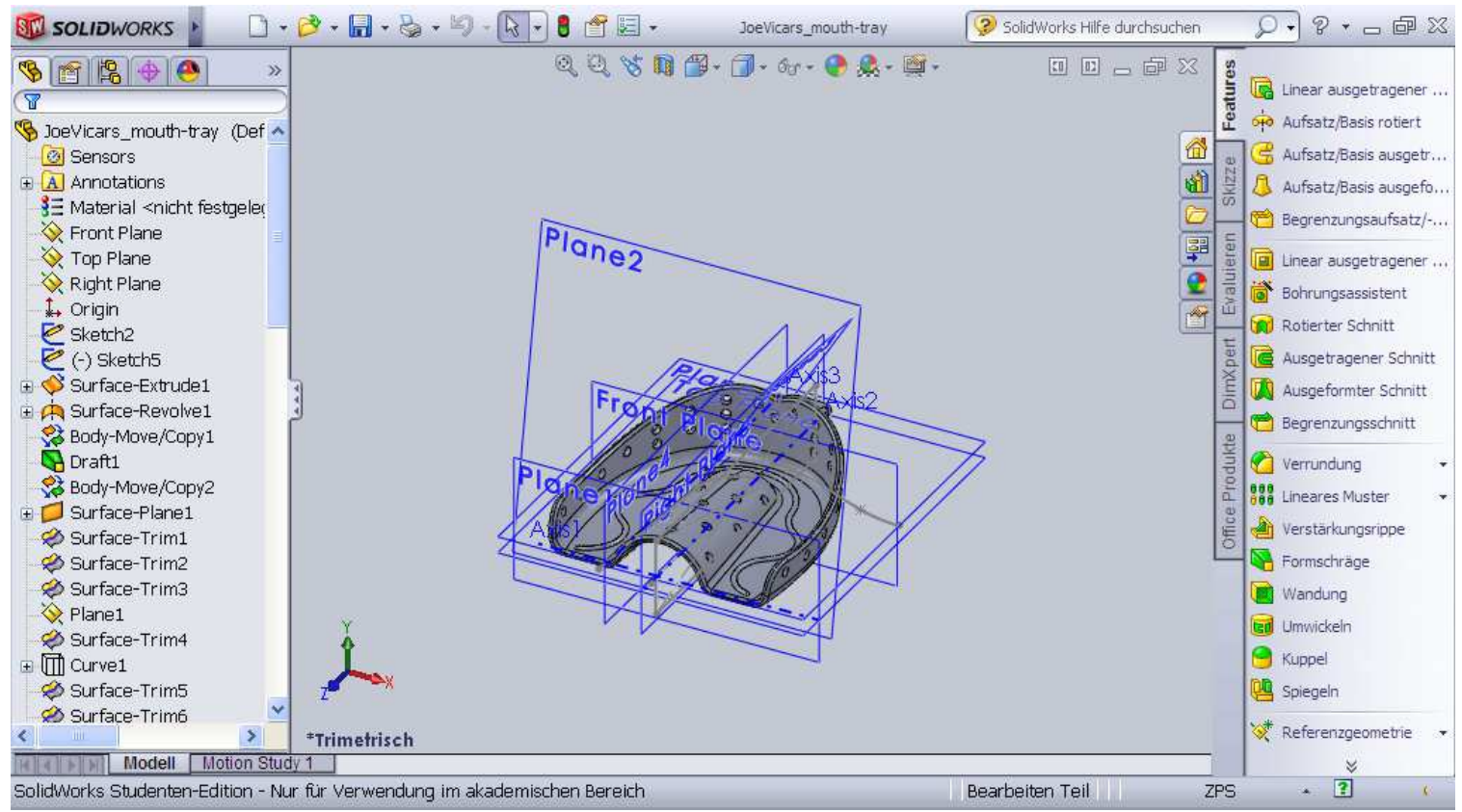

Figure 4.4 Mouth tray as SolidWorks model

In the Build Setup each part is added by the STL file.

Lit Build Setup 3.4 - Platform: SLS 2500 Plus - Material: DuraForm Polyamide Powder V3.4 - File: G:IPr... - $[$ ] $\mathrm{X}$ Eile Edit Select view Show Color Parameter Iools Left Panel Window Help

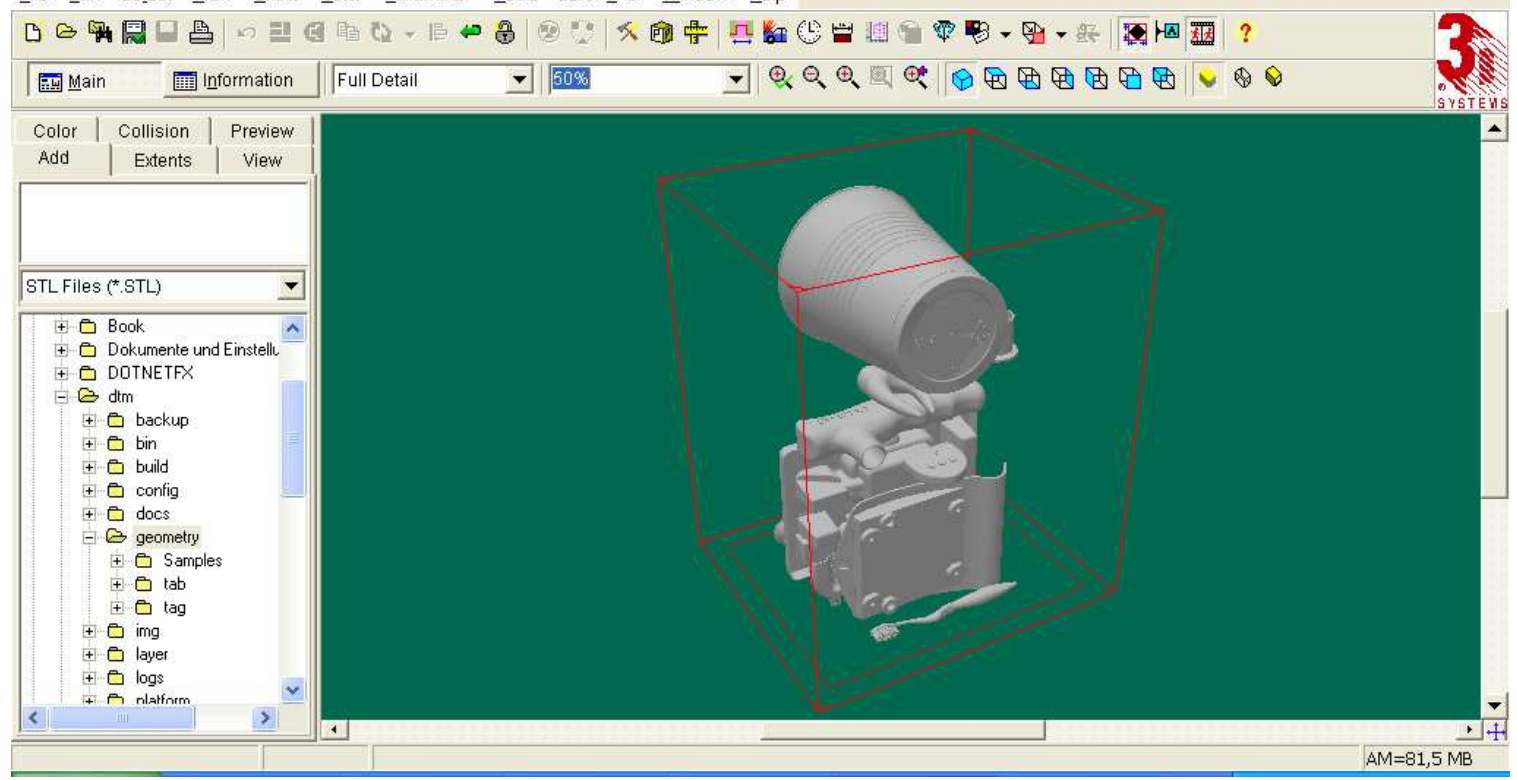

Figure 4.5 Build Setup from the Part Set 
The Information page in the Build Setup shows the details about material and all the parts which are placed in that build:

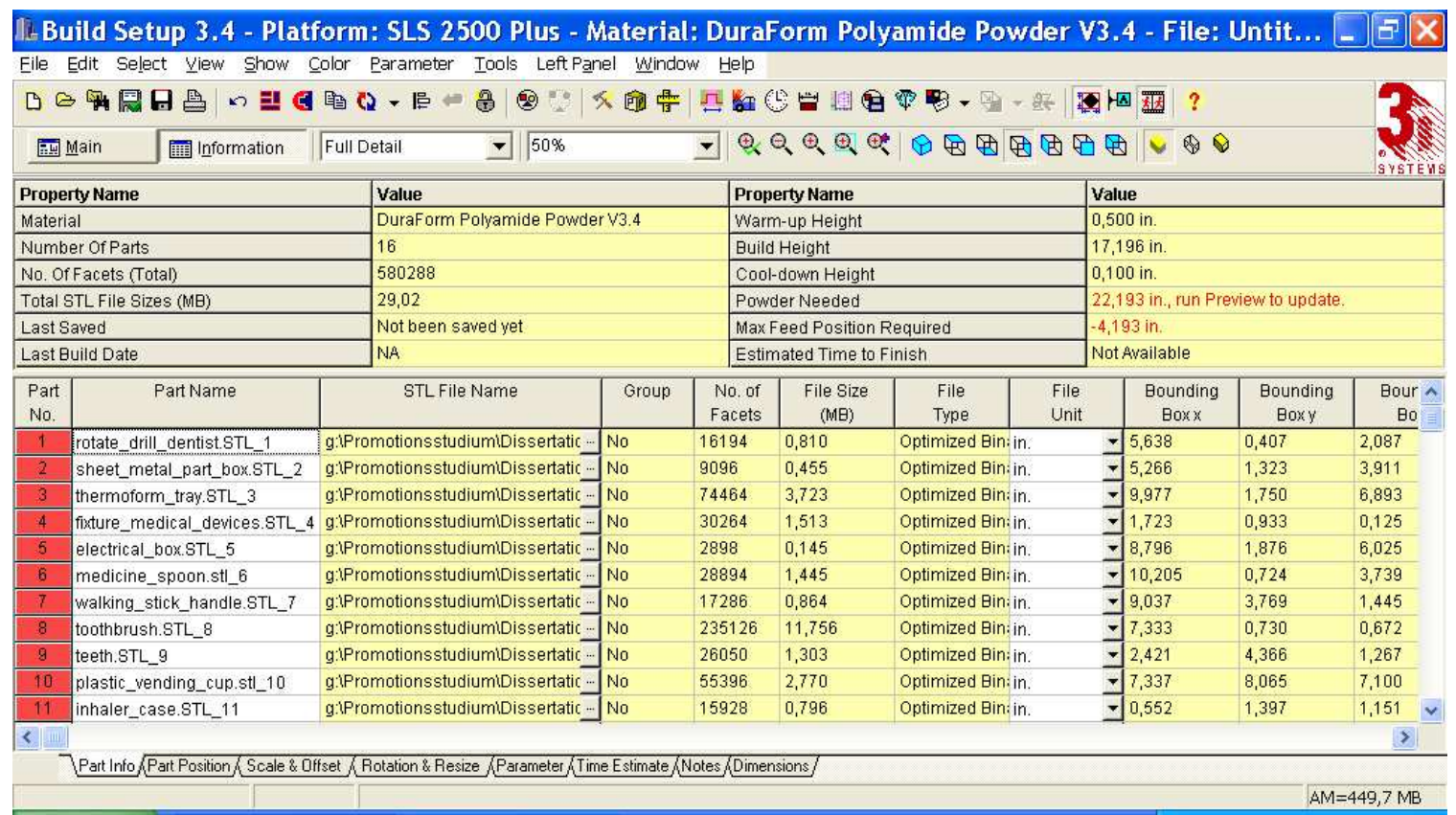

Figure 4.6 Build Setup from the Part Set with the main information

\subsection{The Bounding Box Problem}

In computer graphics and computational geometry, a bounding volume for a set of objects is a closed volume that completely contains the union of the objects in the set. Bounding volumes are used to improve the efficiency of geometrical operations by using simple volumes to contain more complex objects. Normally, simpler volumes have simpler ways to test for overlap.

A bounding volume for a set of objects is also a bounding volume for the single object consisting of their union, and the other way around. Therefore it is possible to confine the description to the case of a single object, which is assumed to be non-empty and bounded (finite). 
A bounding box is a cuboid, or in 2-D a rectangle, containing the object. In dynamical simulation, bounding boxes are preferred to other shapes of bounding volume such as bounding spheres or cylinders for objects that are roughly cuboid in shape when the intersection test needs to be fairly accurate. The benefit is obvious, for example, for objects that rest upon other, such as a car resting on the ground: a bounding sphere would show the car as possibly intersecting with the ground, which then would need to be rejected by a more expensive test of the actual model of the car; a bounding box immediately shows the car as not intersecting with the ground, saving the more expensive test.

In many applications the bounding box is aligned with the axes of the co-ordinate system, and it is then known as an axis-aligned bounding box (AABB). To distinguish the general case from an $\mathrm{AABB}$, an arbitrary bounding box is sometimes called an oriented bounding box (OBB). AABBs are much simpler to test for intersection than OBBs, but have the disadvantage that when the model is rotated they cannot be simply rotated with it, but need to be recomputed (http://en.wikipedia.org/wiki/Bounding_volume).

Following research is very interesting in that area:

2010, Efficient collision detection using a dual OBB-sphere bounding volume hierarchy

Jung-Woo Changa, Wenping Wangb and Myung-Soo Kima presented an efficient algorithm for collision detection between static rigid objects using a dual bounding volume hierarchy which consists of an oriented bounding box (OBB) tree enhanced with bounding spheres. This approach combines the compactness of OBBs and the simplicity of spheres. The majority of distant objects are separated using the simpler sphere tests. 
The remaining objects are in close proximity, where some separation axes are significantly more effective than others.

This formula clearly shows that the performance mainly depends on two factors: the tightness of the bounding volumes and the simplicity of the overlap test for a pair of bounding volumes.

The main contribution of this work can be summarized as follows:

- A dual OBB-sphere tree was proposed, where each OBB node is enhanced with a bounding sphere. The more efficient sphere test is applied first to eliminate distant objects.

- A selection of five separation axes that are effective in separating objects which are very close but not overlapping were proposed. For a wide range of experiments, the performance improvement has been observed over conventional OBB algorithms.

A fast OBB-based collision detection algorithm that uses both OBBs and spherical bounding volumes was presented. They have shown how to combine the compactness of OBBs and the efficient overlap test for spheres. Out of the 15 possible separation axes for two OBBs, a selection of 5 axes which detect separation most effectively was done. Experimental results show that this scheme makes favorable speed up with respect to existing algorithms based on OBBs (Changa et al., 2010).

2004, Oriented bounding box and octree based global interference detection in 5axis machining of free-form surfaces

Global interference detection is a critical problem in 5-axis NC machining of freeform surfaces. Based on the hierarchical oriented bounding box (OBB) which is used in 
virtual reality to detect spatial collisions between 3D objects, a new global interference detection method is developed in this paper from S. Ding, M. A Mannan and A. N. Poo. In this method, in order to simplify the computation process of updating tool positions and orientations in 5-axis machining, the cutter and cutter holder are modeled by a hierarchical OBB structure, whereas the workpiece surfaces are approximated by an octree.

The bounding volumes used are usually simple geometrical shapes such as spheres, ellipses and cubes. These simple geometric components are used to enclose the objects of interest. Collision detection is checked by first checking overlaps between these simple bounding geometric volumes. If there is no collision between these bounding volumes, there would be no collision between the objects they contained. However, if collisions do occur between these bounding volumes, there is still no certainty that collisions would occur between theobjects they enclose.

The idea behind bounding volume is to approximate 3D objects with simple geometric shapes so as to reduce the number of pairs that are needed to be checked for collisions.

In this method, in order to reduce the computation burden of updating the moving and rotating tool during the machining process, hierarchical OBBs are applied to model the cutter and the cutter holder. Further, in order to apply the separating axis theory, which is effective in solving 3D object collision problems in computer graphics, an octree is used to approximate the freeform surfaces. With this strategy, interference detection is conducted between the octants of the octree and the OBBs using the separating axis theorem. When interference is detected between the bounding volumes, the discretized 
surface points stored in the leaf octants of the surface octree are further checked with vector calculation to determine whether these points really collide with the tool (Ding et al., 2004).

\section{1, Determination of the minimum bounding box of an arbitrary solid: an iterative approach}

C. K. Chan and S. T. Tan worked out that if an arbitrary model is reoriented in such a way that the bounding box of its projected areas to the three principal planes are minimum, the volume of the bounding box of the reoriented model so derived is also a

minimum. This is because the three mutually perpendicular faces of the bounding box $\left(B_{x y}, B_{y z}, B_{z x}\right)$ of the model are also the two-dimensional bounding boxes of the projected areas of the model. The following procedure is adopted. A simple example is used to illustrate the main idea of the algorithm. A model is shown in Figure 4.7. The steps involved are:

1. Find the bounding box of the model as shown in Figure 4.7

2. In stage 1 , construct an axis $R_{z}$ (it could be $R_{x}, R_{y}$ or $R_{z}$ ) normal to the $X Y$ plane and passing through the box center (see Figure 4.7).

3. The model iteratively rotated about $R_{z}$ until its projected bounding box area on $X Y$ plane achieves a minimum. The resultant model is shown in Figure b. The so-called $X Y$-bounding box whose $y$ edge length is shorter than the $x$ edge length was the result.

4. In stage 2 , the model is rotated about $R_{y}$ until its projected bounding box are on $Z X$ plane is a minimum Axis $R_{y}$ is selected because the $y$ edge length remains unchanged 
during the rotations. The $Z X$-bounding box whose $z$ edge length is shorter than the $x$ edge length as shown in Figure 4.7 was the result.

5. In stage 3, axis $R_{z}$, which is normal to the $y$ edge length and $z$ edge length, is selected. The model is rotated about $R_{z}$ until its projected bounding box area on $Z Y$ plane achieves a minimum (see Figure 4.7).

6. The model is now oriented at a position which gives an approximate minimum bounding box volume. The rotation sequence thus followed is $R_{z} \rightarrow R_{y} \rightarrow R_{x}$ which is recorded for further analysis.

(a)

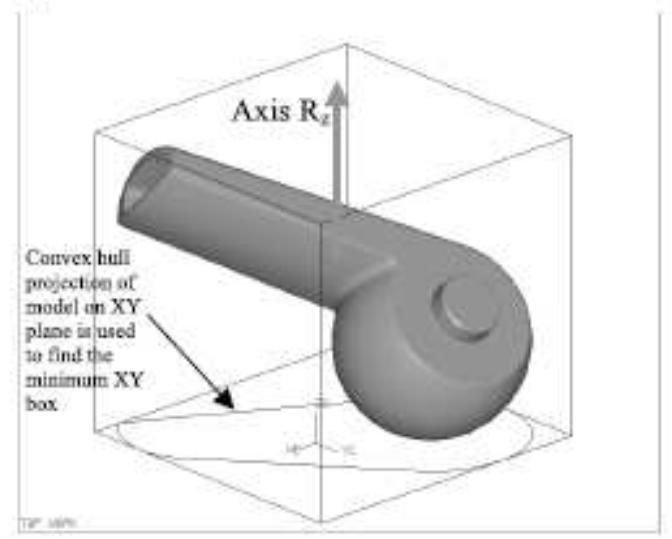

(c)

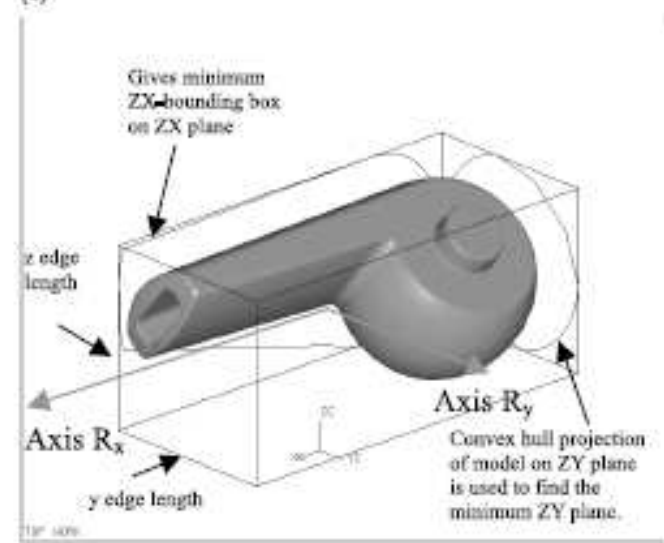

(b)

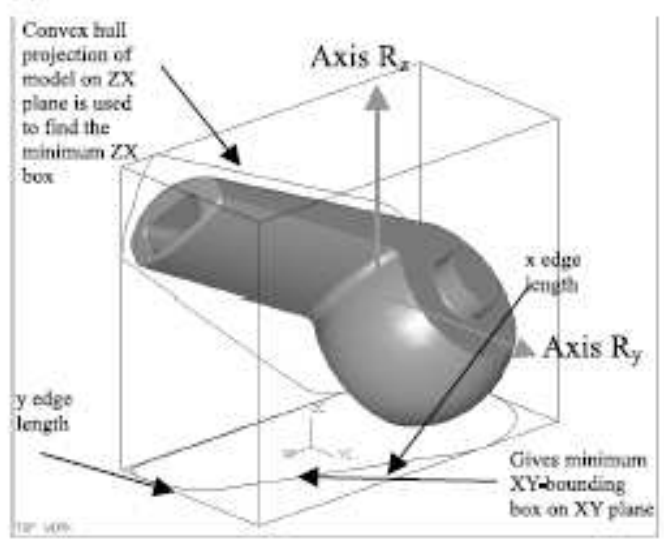

(d)

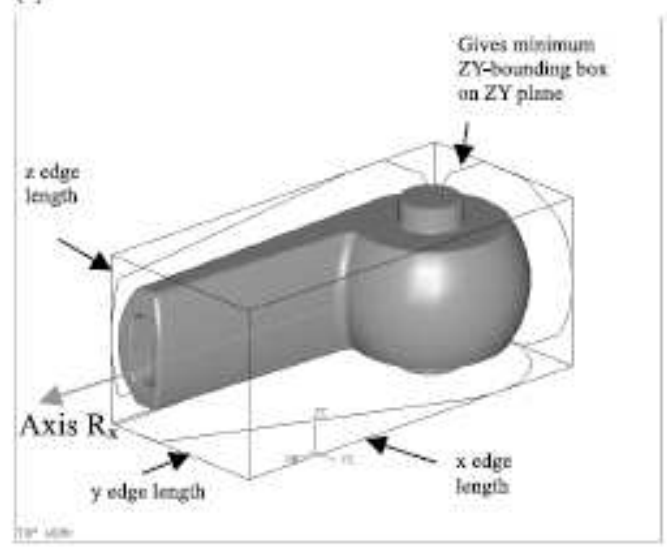

Figure 4.7 Procedure of finding out the minimum BB of a model

(Chan and Tan, 2001) 


\section{2, Collision Detection Based on Bounding Box for NC Machining Simulation}

The Bounding box algorithm from Yao Wang, Yan-juan Hu, Jiu-chen Fan, Yufeng Zhang and Qi-jiu Zhang included: Axis-Aligned Bounding Boxes (AABB), Oriented Bounding Box (OBB), Sphere, Fixed Directions Hulls (FDH), etc., as shown in Figure4.8:

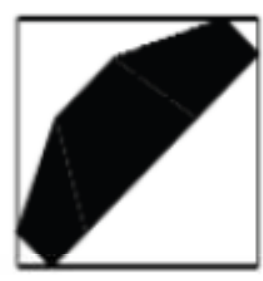

(a) $\mathrm{AABB}$

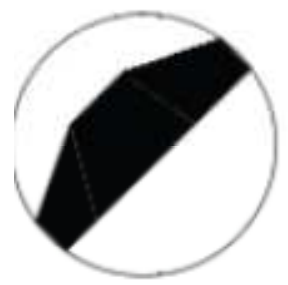

(c) Sphere

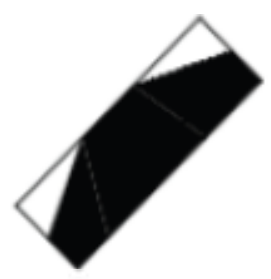

(b) $\mathrm{OBB}$

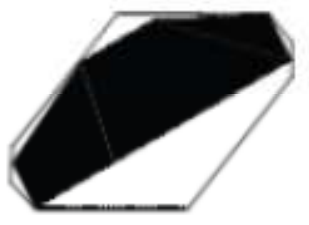

(d) $\mathrm{FDH}$

Figure 4.8 Bounding Box Kind

Simplicity and tightness of bounding box directly affect the efficiency of collision detection. Simplicity is that the bounding box should be simple geometrical body, at least simpler than the object enveloped by bounding box, and can realize the calculation of intersecting detection rapidly.

Tightness is that bounding box closes to the object which is enveloped as much as possible. Inbounding box algorithms, the simplicity of AABB is good, but its tightness is poor, after the object rotating, $\mathrm{AABB}$ should be do the same rotation and update. Either geometrical body or intersecting detection of Sphere is very simple, but its tightness is 
very poor. The tightness of $\mathrm{OBB}$ is best, and it can multiply shorten the number of bounding boxes involved in intersecting detection and basic geometrical elements, after geometrical object rotating, it only need to do the same rotation for the substrate of OBB. The total performance of $\mathrm{OBB}$ is better than $\mathrm{AABB}$ and Sphere. For the collision detection of rigid bodies, OBB is the better choice, but, after the rigid body deforming, the update of OBB tree is a difficult problem which is not solved so far. Both simplicity and tightness of FDH are very good, because the normal vectors of all surfaces of bounding box come from the fixed direction vector set. After object rotating, calculation of FDH is not complex, and also, after object deforming, it can regenerate bounding boxes for the deformed object rapidly.

This paper introduces condition and kind of collision generating, and also analyzed detection algorithms, in which FDH algorithm is studied mainly. Detection includes three steps: crudity detection, further detection and subtlety detection. In crudity detection stage, AABB algorithm and two-dimensional projection are adopted to find latent crossed object pair, which improves detection efficiency. In further detection stage, FDH algorithm is used to judge if collision happens by assuring and traversing hierarchical tree of bounding box, doing intersection detection of bounding box. In subtlety detection stage, the intersection detection of basic volumes is implemented, after space volumes are judged, the volumes are projected on two-dimensional plane to be detected, which can simplify computation and improve detection efficiency. The application examples proved that the presented algorithm is effective and efficiency (Wang et al., 2012). 


\section{3, Precise convex hull computation for freeform models using a hierarchical Gauss map and a Coons bounding volume hierarchy}

Yong-Joon Kim, Myung-Soo Kim and Gershon Elber presented an interactivespeed algorithm for computing the precise convex hull of freeform geometric models. The algorithm was based on two pre-built data structures: (i) a Gauss map organized in a hierarchy of normal pyramids and (ii) a Coons bounding volume hierarchy $(\mathrm{CBVH})$ which effectively approximates freeform surfaces with a hierarchy of bilinear surfaces. For the axis direction of each normal pyramid, a point on the convex hull boundary using the CBVH was presented. The sampled points together with the hierarchy of normal pyramids served as a hierarchical approximation of the convex hull, with which the majority of redundant surface patches was eliminated. The precise trimmed surface patches was computed on the convex hull boundary using a numerical tracing technique and then stitch them together in a correct topology while filling the gaps with tritangent planes and bitangent developable scrolls.

Algorithms for convex objects are usually more efficient than for non-convex

ones. The convex hull computation as a simple problem of constructing the upper envelope of support distance functions defined by the given surfaces was reformulated. Using a $\mathrm{CBVH}$ for freeform surfaces and their normal cones and a hierarchical tessellation of the Gaussian sphere, an efficient convex hull algorithm can be developed while greatly improving both the efficiency and robustness of the previous algorithm was shown(Kim et al., 2013) 


\subsection{Multiple Builds}

Companies, like Shapeways (world's largest 3D printer marketplace) and Materialise (with the biggest machine fleet in Europe) have created services where consumers can customize objects using simplified web based customization software, and order the resulting items as $3 \mathrm{D}$ printed unique objects. This allows consumers to create custom cases for their mobile phones. Nokia has released the $3 \mathrm{D}$ designs for its case so that owners can customize their own case and have it 3D printed.

The current slow print speed of 3D printers limits their use for mass production. To reduce this overhead, several fused filament machines now offer multiple extruder heads. These can be used to print in multiple colors, with different polymers, or to make multiple prints simultaneously. This increases their overall print speed during multiple instance production, while requiring less capital cost than duplicate machines since they can share a single controller.

Distinct from the use of multiple machines, multi-material machines are restricted to making identical copies of the same part, but can offer multi-color and multi-material features when needed. The print speed increases proportionately to the number of heads. Furthermore, the energy cost is reduced due to the fact that they share the same heated print volume. Together, these two features reduce overhead costs (http://en.wikipedia.org/wiki/3D_printing).

Another article in that field is very interesting: 


\section{1, Energy Inputs to Additive Manufacturing does capacity utilization matter?}

The available additive manufacturing (AM) platforms differ in terms of their operating principle, but also with respect to energy input usage. This study from $\mathrm{M}$. Baumers, C. Tuck, R. Wildman, I. Ashcroft and R. Hague presented an overview of electricity consumption across several major AM technology variants, reporting specific energy consumption during the production of dedicated test parts (ranging from 61 to 4849 MJ per kg deposited). Applying a consistent methodology, energy consumption during single part builds is compared to the energy requirements of full build experiments with multiple parts (up to 240 units). It is shown empirically that the effect of capacity utilization on energy efficiency varies strongly across different platforms.

The term - additive manufacturing- describes the use of a collection of technologies capable of joining materials to manufacture complex products in a single process step. Moreover, the technique allows the production of multiple components in a parallel manner (Ruffo et al., 2006) entirely without the need for tooling (Hague et al., 2004). The single-step nature of the additive processes affords an unprecedented level of transparency with respect to the energy inputs employed in the manufacture of complex end-use components. This advantage has received little attention in the literature and motivates the current paper. Due to the parallel characteristics of additive processes, allowing the contemporaneous production of multiple parts in a build, it must be expected that the degree of capacity utilization during additive production impacts the total energy

inputs. Hence, any corresponding summary metrics of energy consumption, such as the specific energy consumption per kg of material deposited, are also likely to be affected. 
Regarding the work based on experimental results, it also reports whether the data were obtained from build configurations holding only a single test part or from builds with multiple parts.

In contrast to the simplicity of the power monitoring setup, the creation of a standardized level of full build capacity utilization across different additive platforms proved non-trivial. The idea pursued in this research was to apply a custom-developed build volume packing algorithm, producing densely packed, albeit sub-optimal, build configurations for use in the full build experiments. The resulting implementation is capable of generating build configurations both in full 3D mode as well as in a 2D mode constrained to the substrate area. A simple algorithm is used to insert and translate voxel representations of the test part in the build volumes in order to produce a densely packed configuration. In the full 3D packing mode, used only for the full build on EOSINT P 390, the algorithm was also allowed to flip test parts upside-down.

The current research has conclusively demonstrated that the realized degree of capacity utilization has an impact on process energy efficiency. In the performed experiments, this impact on energy savings in terms of specific energy consumption per $\mathrm{kg}$ of material deposited ranged from small $(-3.17 \%$ for FDM) to extreme $(-97.79 \%$ for LS). Considering the LS and EBM processes, which include extensive energy expenditure for atmosphere generation, warm-up and cool-down, full capacity utilization will result in far greater energy efficiency compared to a single part mode of production. This may pose problems in the estimation of process energy consumption for additively produced parts if the composition of the production build is unknown. Contrasting this, the results indicate that the FDM process (where system warm-up and cool-down do not enter the energy consumption metric at all) does not benefit significantly from full 
capacity utilization. It appears that FDM can be applied in a serial fashion generating output part-by-part without incurring a significant energy efficiency loss. Operating LS or EBM equipment in this way would result in a severe penalty to the environmental performance of the process. 


\section{CHAPTER 5}

\section{REVENUE MAXIMIZATION}

This chapter is divided in five subchapters. The first subchapter implies some commercial trends. The second subchapter describes the cost estimation. The third subchapter gives some basics of Operations Research and the development of a Mathematical Model. The fourth subchapter shows the optimization of the mathematical

model by analyzing and solving with optimization tools. The last chapter contains a summary.

\subsection{Commercial Trends}

The Company Berenschot summarized the business opportunities, issues and the vision for the future for $\mathrm{AM}$ as follows: 


\section{AM allows for new business models}

\section{Traditional automobile spare part supply chain}

Design Transport
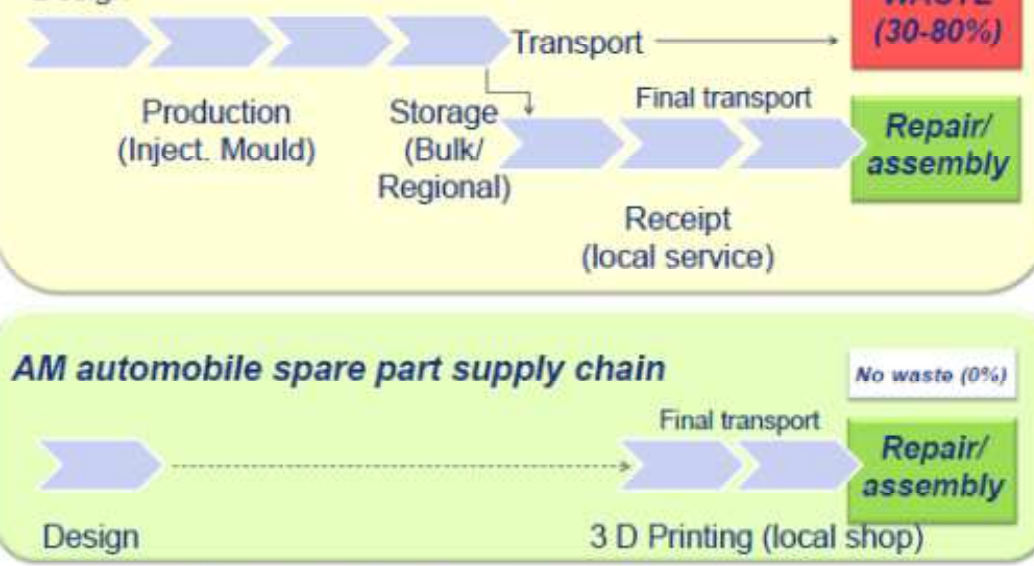

Shorter value chain, supreme lead times, lower costs

Berenschot

Figure 5.1 AM allows for new business models

\section{AM can be more customer friendly}
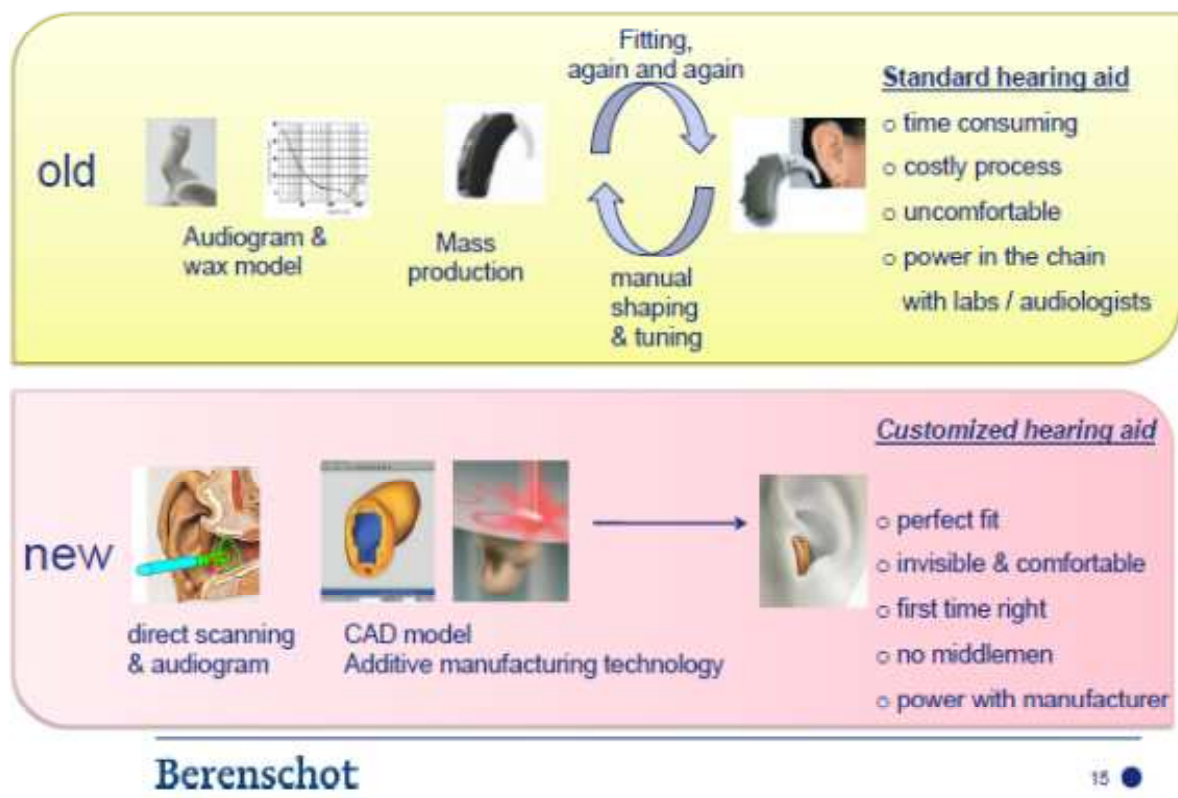

Figure 5.2 AM can be more customer friendly 


\section{AM can lead to USP}

- "Adding a personal touch" to existing products (customized add-ons)

- Driven by consumer demand

- "Engineering the impossible" (new functionalities)

- Driven by technology / engineering

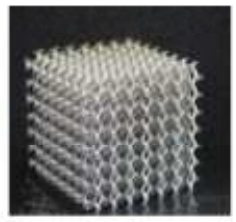

- The affordable alternative enabling very small batch sizes

- Driven by process economics

- Full customization, driven by consumer demand

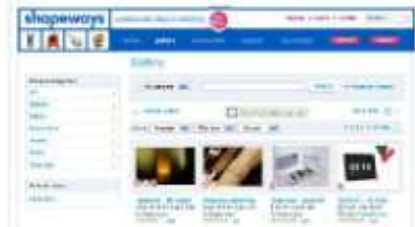

\section{Berenschot}

Figure 5.3 AM can lead to USP

$$
\begin{aligned}
& \text { 3. Still some issues } \\
& \pm \text { A limited number of commercially available materials, } \\
& \text { mostly polymers : limited specifications \& functionality } \\
& \pm \text { Few machines for processing metals or non-polymers } \\
& \pm \text { Machines able to handle few materials or colours } \\
& \pm \text { Machine size limits product sizes (avg. } 40^{\star} 40^{\star} 40 \mathrm{~cm} \text { ) } \\
& \pm \text { Machine speed is limited } \\
& \pm \text { Costs are coming down rapidly. In the near future } \\
& \text { 'production machines' available from } \$ 5.000 \text { up ? } \\
& \text { 'desk top machines' available from } \$ 1.500 \text { up? } \\
& \text { but most materials are still expensive }
\end{aligned}
$$

\section{Berenschot}

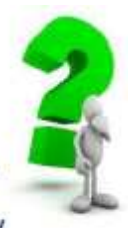

Figure 5.4 Still some issues 


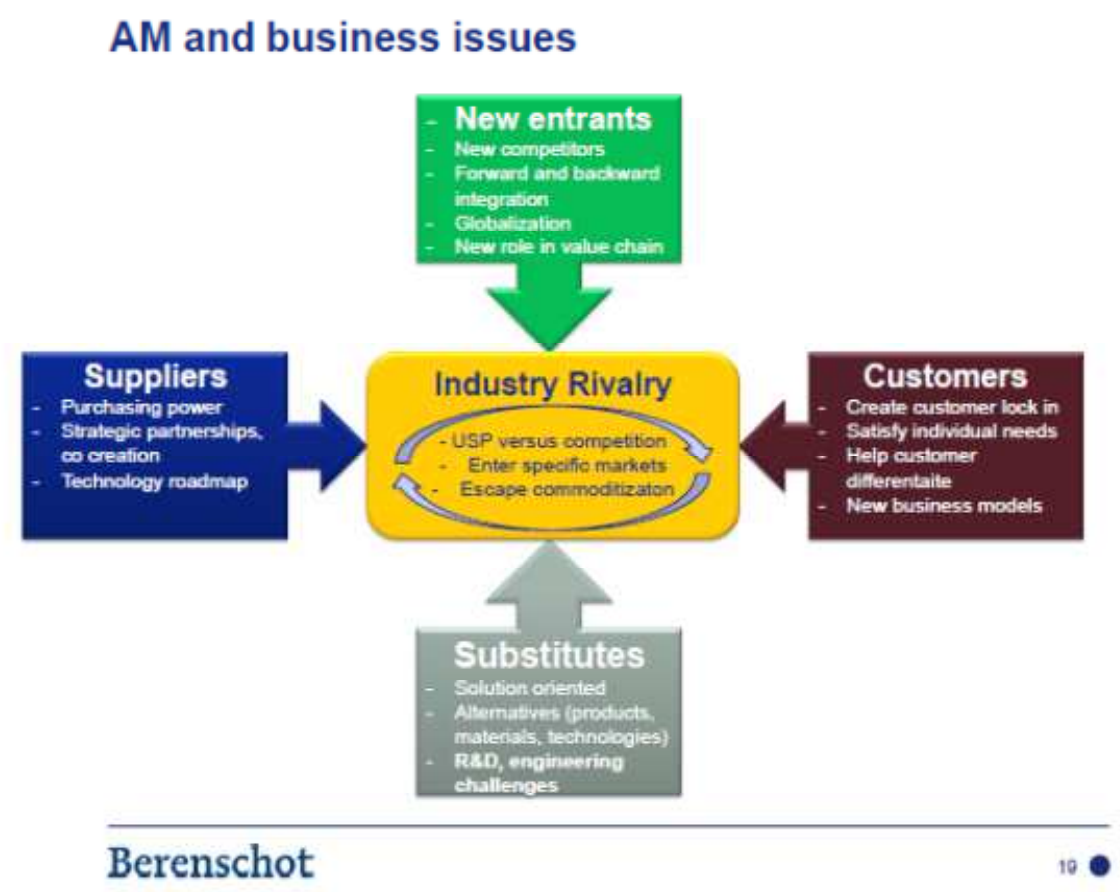

Figure 5.5 AM and business issues

The Company Econolyst, focused on Integrating AM into mainstream production:

Why is econolyst interested in the service side of RM

- Manufacturing activity in the West is progressively being focused on value added 'service' activities coupled with technology

- There is a lot of work going on (and investment) in RM processes and materials

- However, little is being done on the management and implementation of the technology into business

- The flexibility of the technology makes the implementation possibilities very broad.

- There is significant opportunity to develop 'service based products' within the emerging RM supply chain 
(http://www.rm-

platform.com/index2.php?option=com_docman\&task=doc_view\&gid=121\&Itemid=5)

Examples for such companies, focused on service based products are e.g. Shapeways, Materialise, Twinkind, which are introduced in the next section. Also possible problems are explained.

Shapeways was founded in 2008. The company works similar to a marketplace. Individuals can make, buy and sell their own products at the homepage from Shapeways:
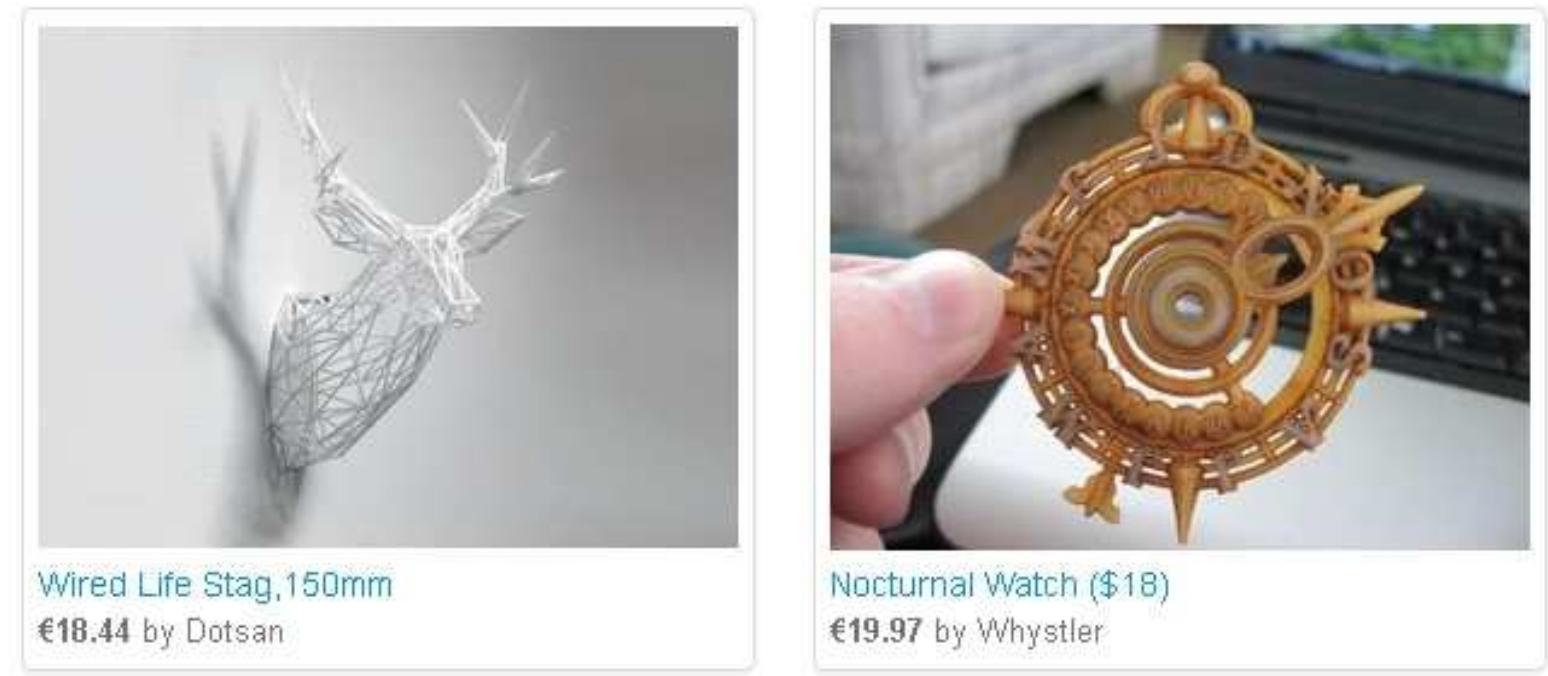

Figure 5.6 Individual products from Shapeways marketplace

Recently Shapeways community member Dotsan designed an amazing Stag Wire $570 \mathrm{~mm}$ that used the full size of the largest Nylon (WSF) 3D printer. Shapeways did manage to print two of these for Dotsan, but the model was so fine, with $1 \mathrm{~mm}$ wires for such a large object it failed during printing and broke during post processing, so it took Shapeways multiple prints to get it to survive. Shapeways packed it very, very carefully and shipped it to Dotsan with the fingers crossed, hoping that it was not damaged in transport. 
Fortunately, the 3D prints were delivered to Dotsan intact. Unfortunately, the risks involved in printing, post processing, packaging, and shipping the item are too great and Shapeways have asked Dotsan to take the design down from sale on Shapeways to ensure his customers don't have a negative experience. This is not something Shapeways wanted to do, they struggled and debated internally about the ramifications of this, but in the end they were forced to take this action for a number of reasons, the two main issues were:

- The cost of such a large, wiry model with very little mass does not match the actual cost of 3D printing, especially as the model is prone to failure at any point along the supply chain so they would have to reprint multiple times.

- When a model of this size fails and they need to reprint, it will consume capacity and delay all other models in the queue, especially large ones.

Shapeways needs to look at how they address the pricing structure to account for large wiry models such as this in the future. They could look at them on a case by case basis, which could slow down the production of large models, lead to rejections after acceptance if they are too fragile and add a degree of unpredictability. Or they could address the pricing structure at Shapeways to better reflect the actual cost of 3D printing.

At the moment, they only charge for the amount of material used and not the overall size (bounding box) of an object that we 3D print. The size of an object DOES influence the actual cost of printing. If Shapeways were to bring the bounding box into the pricing equation, it would make some thin, wiry 3D prints more expensive, but it would reduce the cost of many 3D prints that are thicker, with greater density. Thin wiry 
models are more prone to print failure, damage during cleaning, post processing and shipping so there is additional cost (and delays) when they need to reprint a model.

Shapeways already offers a volume and density discount on Nylon (strong \&flexible) materials. For models that have greater than $10 \%$ density (material volume divided by bounding box volume), after the first $20 \mathrm{~cm}^{3}$, the remaining volume is calculated with a $50 \%$ discount.

Unfortunately Shapeways will not print this Wired Life Stag due to their pricing structure. They created an alternative $580 \mathrm{~mm}$ high flat version and a $75 \mathrm{~mm}, 150 \mathrm{~mm}$ and a 300mm version. This is a truly inspiring piece, designed to use the minimum material and the largest print size while keeping the cost low. This is huge at 570mm high it's a show stopper and a head turner. Shapeways have been pushed to their limits to produce and ship this. It is fragile and care must be taken but once it is hanging from a wall with a small pin or nail. The fine $1 \mathrm{~mm}$ wire structure comes together to create a wonderful huge majestic stag head and a wonderful balance of weight in the form while almost being invisible.(http://www.shapeways.com/about).

Materialise was founded in 1990. The Online 3D printing service provides services for creating, sharing and selling designs. 


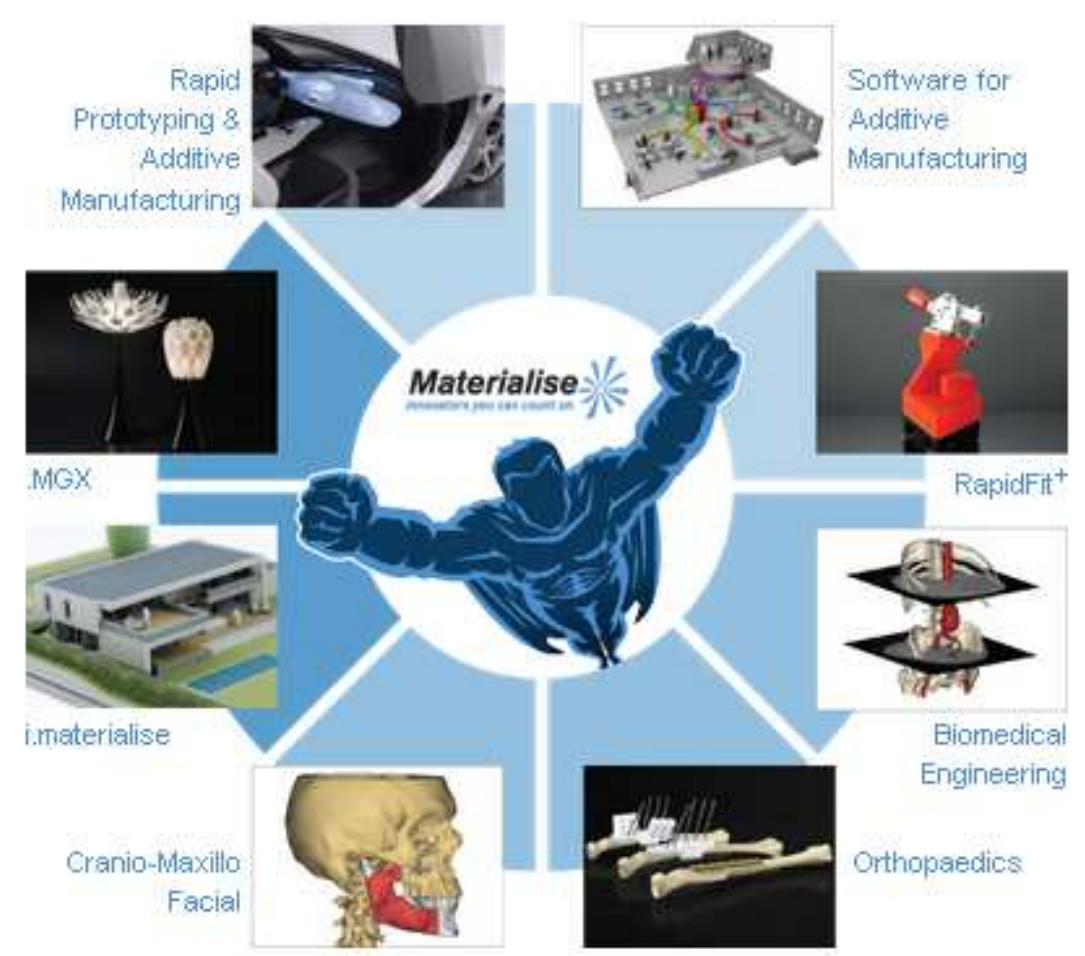

Figure 5.7 Overview Materialise

Through their work with Additive Manufacturing (AM), also known in the popular media as 3D printing, Materialise is helping bring great ideas to life. They work with others to put great products aimed at niche markets directly into the marketplace as well as helping make the prototypes of products later manufactured by the millions. What's more, through our software, they enable others to do the same with their own AM equipment and services.

The software is also powering new innovations in biomedical research, helping others make discoveries that save lives. Furthermore, they are taking patient-specific healthcare to new heights by working closely with surgeons for the planning and execution of complicated surgical procedures. Their work with surgeons and the 
improved medical solutions being created with their software are getting people back on their feet, and putting smiles back on patient's faces.

Materialise is also putting the power of Additive Manufacturing into the hands of everyday people. With an easy-to-use online service, now anyone can create a truly customized object, whether they are experts at computer modeling or beginners who are discovering 3D printing for the first time. They have also challenged some of the world's top designers to use this technology in the creation of an award winning line of 3D printed objects available for sale worldwide or from their own store in Brussels, the world's first store dedicated to 3D printed design.(http://www.materialise.com/aboutmaterialise).

Twinkind was founded in June 2012. They offers custom made live like 3D mini twins.

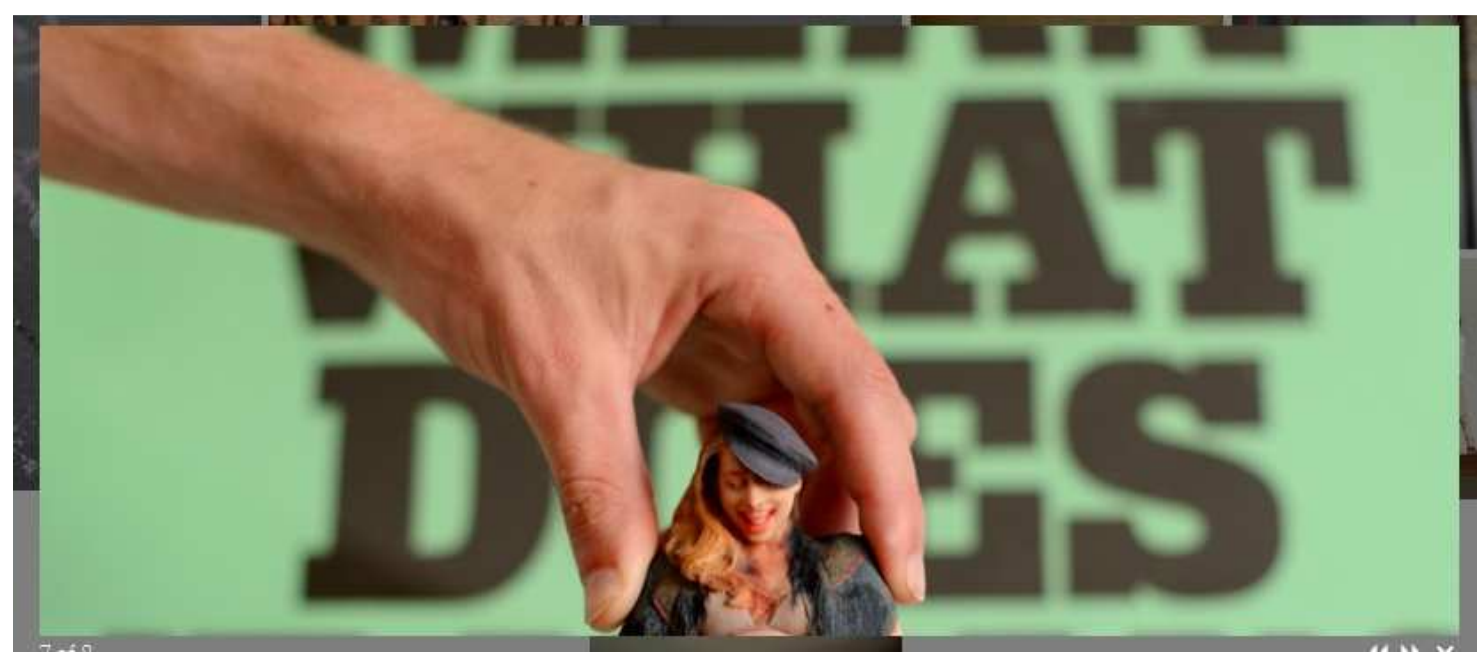

Figure 5.8 Overview Twinkind

Twinkind is a new service that creates custom 3D printed photorealistic figurines. The company's studio in Hamburg, Germany is equipped with a multi-camera 3D 
scanner that instantaneously captures a 3D scan of the subject. The digital likeness is then 3D printed in full color. The figurines can be printed in a range of sizes from 6 inches to 13 inches (http://www.twinkind.com/de/product).

Econolyst summarized the differences of the Rapid Prototyping supply chain instead the Rapid Manufacturing supply chain (see Figure 5.9).

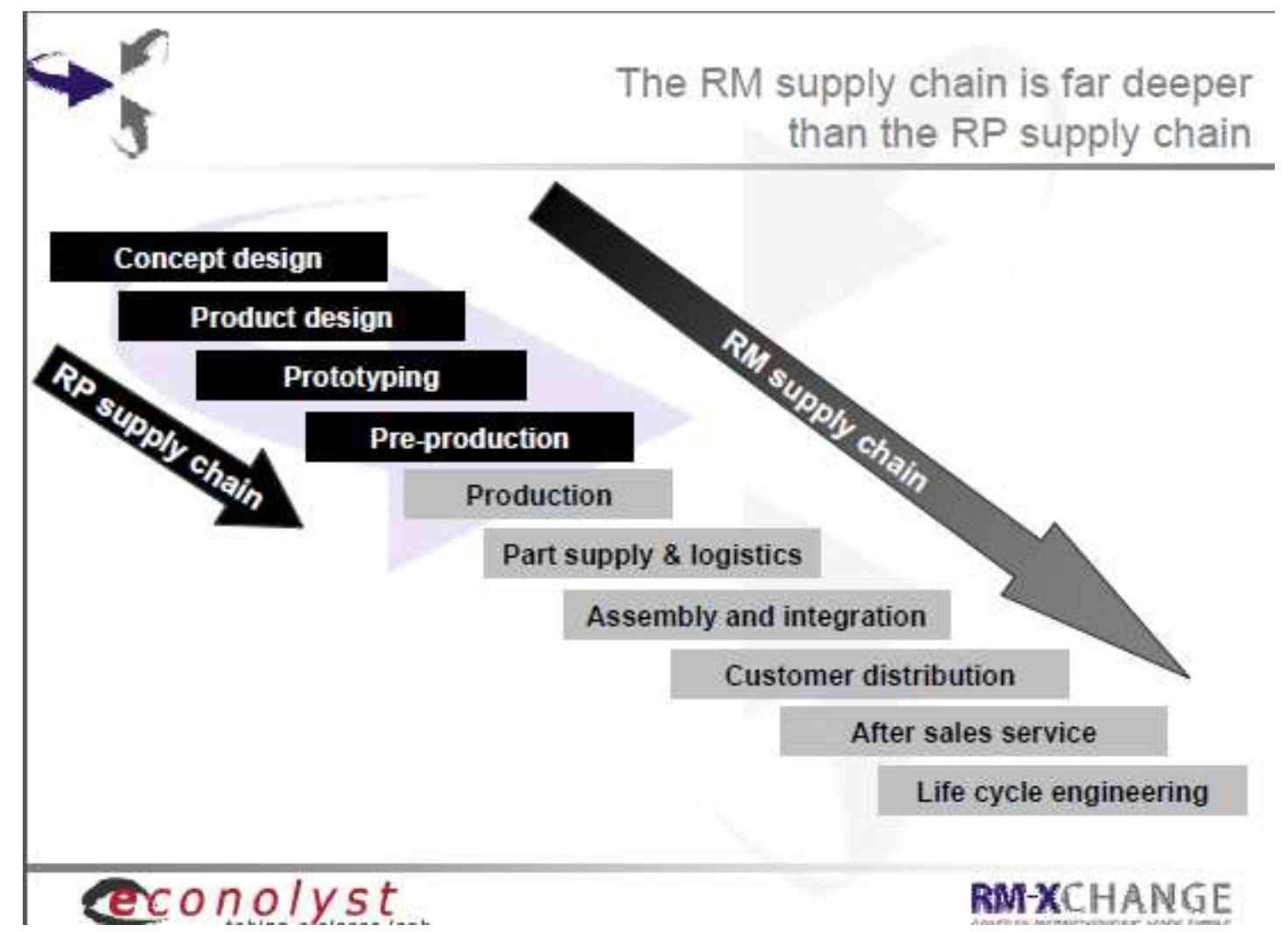

Figure 5.9 RM supply chain instead of RP supply chain

Econolyst showed their view about what tools will companies need to manage an RM customization supply chain:

- Companies will need tools to integrate the customer into the supply chain (possible intermediaries at first, such as orthodontist, doctor, and optician) but ultimately the consumer 
- Companies will need the tools to control design intent, IP issues, quality, after sales issues, part failure, liability and warranty

- Companies will need the tools to undertake make or buy analysis and to develop cost effective RM part supply methodologies

- If companies decide to buy RM parts from third parties they will need to specify issues such as quality, material and process conformance and data control within the supply chain

- This area of RM could stimulate a whole new raft of unique businesses that are consumer -trend orientated. (95\% business and marketing and 5\% engineering). Tools need to be simple and accessible.

They showed also what tools will companies need to manage an "RM high value supply chain":

- RM part users will need to become 'intelligent customers' capable of managing the RM procurement process

- They will need tools to make fundamental engineering decisions on RM material properties (mechanical, thermal, electrical, magnetic, aesthetic, toxicity)

- They will need access to process information (build envelope, accuracy, repeatability, bed variance, speed)

- They will need tools to provide rapid cost comparisons between RM and traditional technologies

- They will need tools to assess 'business confidence' in potential suppliers 
- They will need tools to identify or mark unique RM parts and link parts with associated documentation

- They will need tools to conduct e-auctions and access underutilized capacity on disparate build platforms (GRID-RM)

- Companies that use RM for high value low volume applications will need tools to rapidly deploy digital data and part specifications

- After part generation RM users will need tools to associate and archive digital data such as build log files, SPC data, material conformance and machine calibration certificates

Econolyst also described what tools will companies need to manage a 'design optimized RM supply chain’:

- Companies that design RM optimized products will need new CAD systems and design tools that integrate geometric and parametric design with FEA and CFD.

- Such tools will require an extended set of material properties data such as mechanical properties, density and surface finish that are all specific to RM processes

- Companies may need new post manufacture testing procedures and processes such as new forms of NDT or new processes for fluid and gas flow analysis

They provide tools for these following groups:

- Product designers and engineers need information at their 'finger tips' about RM materials and process capabilities

- Manufacturing engineers need to understand the process capabilities and constraints of RM technologies in order to integrate them into the supply chain 
- Purchasing and procurement engineers need confidence in the capability of their supply chain

- Quality engineers need to ensure part traceability and conformance

The following questions can help companies to make a real build of the actual status of knowledge and skills:

- Do they know how to control their machines (and post processes) to provide repeatability of supply?

- Can they demonstrate material traceability and control?

- Can they demonstrate procedures for part traceability and control?

- Can they demonstrate procedures for digital data control?

- Do they understand Total Quality Management and business excellence (ISO9000:2000 $\mathrm{BEM})$ ?

- Do they provide inspection and quality assurance (SPC, Batch sampling)?

- Do they have in-house access to calibrated metrology equipment and the skills to use it?

- Do they have experience of integrating part delivery into a manufacturing (JIT) supply chain (not just an RP supply chain)?

- Are they financial stable and capable of entering into a supplier agreement?

- Do they have a cost-down (Lean RM) strategy?

- Can they provide maintenance and calibration certification for all their machines and metrology? 
- Do they have well trained and capable staff?

(http://www.econolyst.co.uk/resources/documents/files/Report\%20-

\%20March\%202008\%20-\%20East\%20Midlamnds\%20Development\%20Agency\%20-

\%20East\%20Midlands\%20RM\%20Strategy.pdf).

\subsection{Cost estimation}

For identifying realistic cost estimation some interesting aspects from former research take place:

\section{6, Cost estimation for rapid manufacturing - laser sintering production for low to medium volumes}

M. Ruffo, C. Tuck and R. Hague researched in the area of cost estimation for rapid manufacturing. The flexibility of additive techniques allows the production of more than one part at a time. In addition, the parts in production can be different from one another. For this reason it is possible to define RM as a parallel process, where different parts can be built contemporaneously. Also, if the production regards only copies of the same part, the graph of Figure 5.10 is incorrect for lower production volumes. In fact, just as the IM (injection molding) process has to amortize the initial cost of the tool, the RM process needs to amortize the investment of buying the machine. Therefore, the RM

production curve must have a deflection for low-volume production, taking into consideration the fixed time and cost described above. 


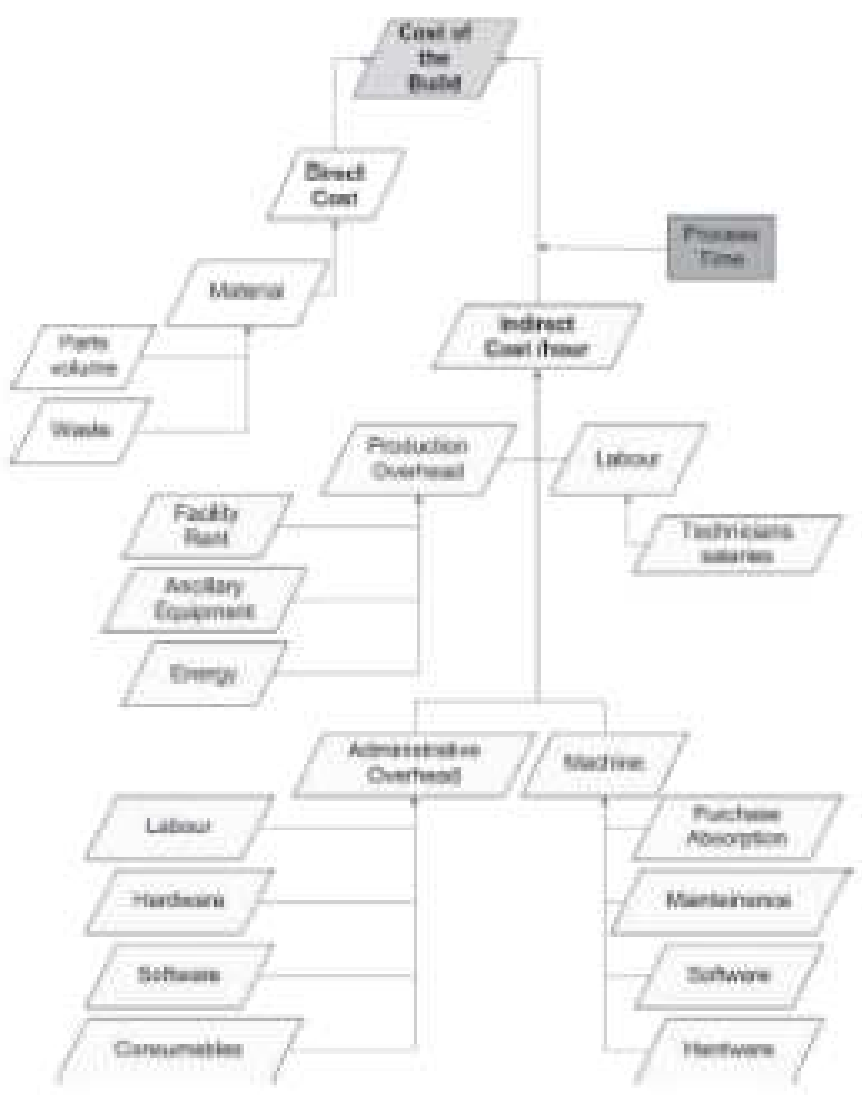

Figure 5.10 Scheme of the costing model

The value of PR (Packing Ratio) can vary: between zero, in the case of an empty bed (no production), and one, if the volume of the components equalizes the volume of the beds. The higher the packing ratio, the lower the waste in material and the production time per component, with a consequent cost saving.

The resulting curve relating the cost/part with the production volume is shown in Figure 5.11. A full machine bed envelope comprised 896 components, with each lever having a volume of $7106 \mathrm{~mm} 3$. The packing ratio intuitively varies with the number of components 'nested' in the build envelope, so each increment on the $\mathrm{x}$ axis corresponds to a different packing ratio. The optimum packing ratio was 0.12 for any full bed (896 components and multiples thereof). 


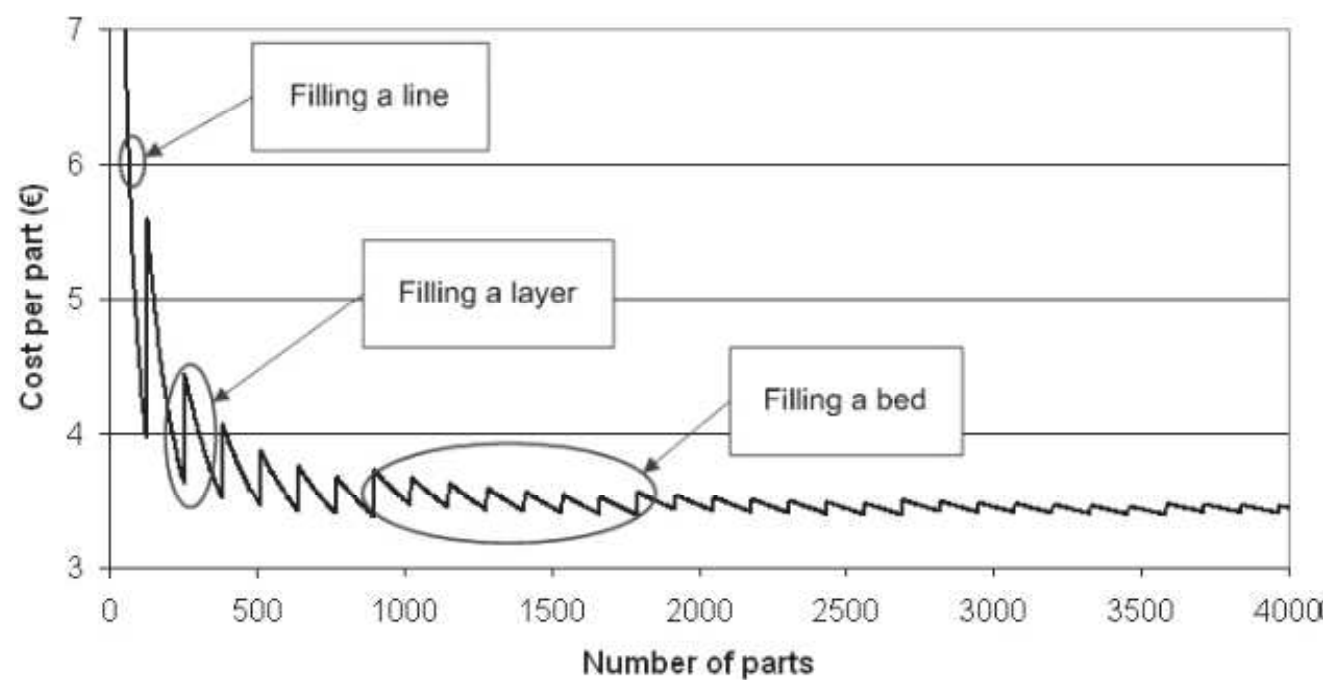

Figure 5.11 Production curve for the lever (LS)

Both the initial transition and the final stabilized value of the curve depend upon:

(a) the part size - big parts quickly fill layers and machine beds, splitting the additional cost between fewer parts; small parts allow a more fractionated assignment of indirect costs;

(b) the packing ratio - it influences both build time and material waste, being a fundamental parameter for cost estimations.

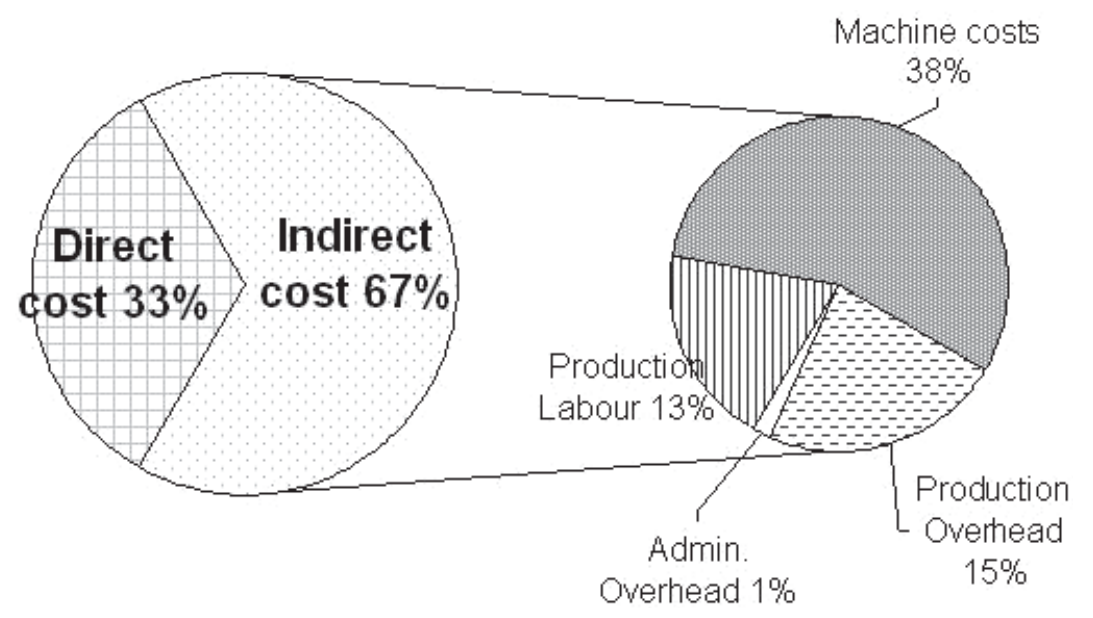

Figure 5.12 Cost Overview 
The main outcome achieved shows a curve relating the cost per part to the production volume. The curve has a saw tooth shape, owing to the filling of the machine bed-space. Specifically, if adding parts to a production set-up does not increase the number of layers (i.e. parts are added next to each other in the horizontal directions), the time and cost of the build is efficient. In contrast, when a new part needs to be placed on a new layer, both time and cost for the build increase dramatically, owing to the enlarged build-height (which means additional layers for recoating). The same effect is present when the additional part causes the set-up of a new machine-bed.

Costs are visible by using the information's which are retrievable from the Build Setup Software. For that example of build with parts

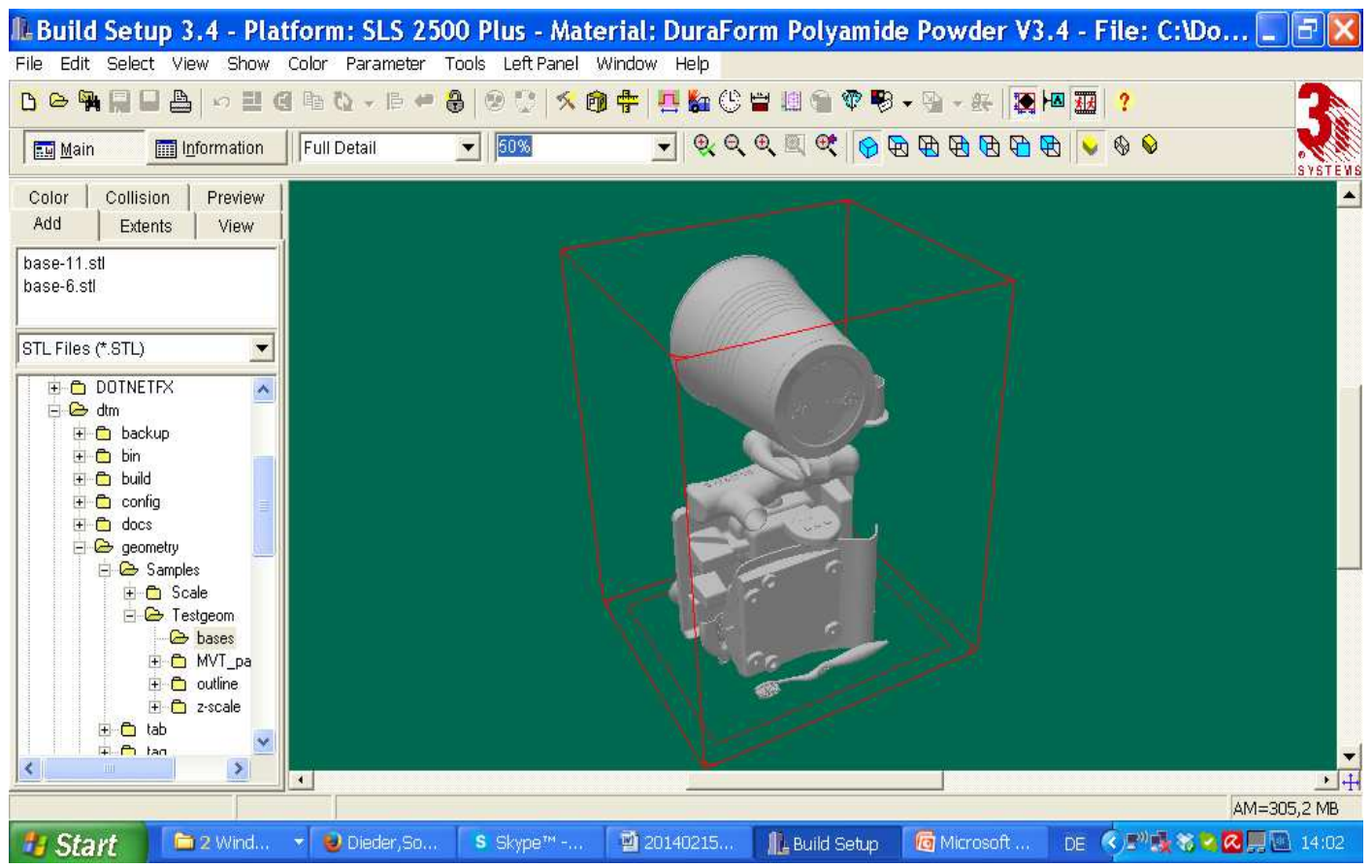

Figure 5.13 Screenshot from the Build Setup

the information button gives a lot of information like how much powder is needed or the estimated time to finish. 


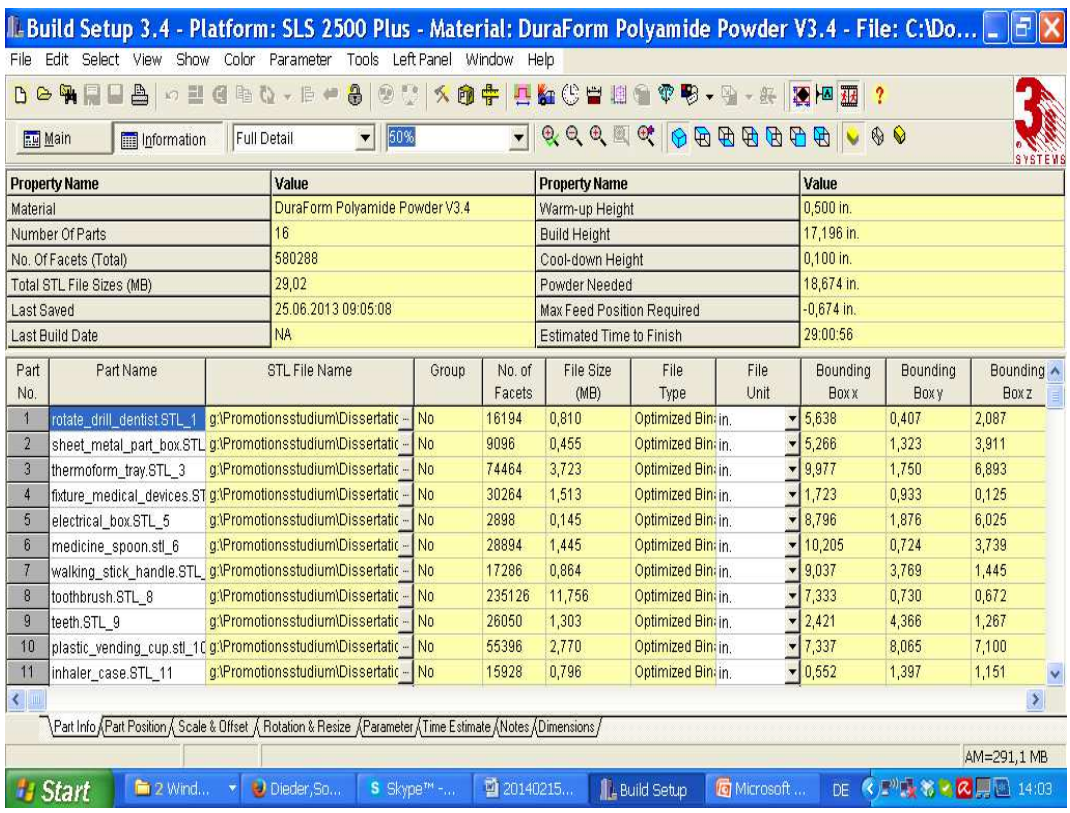

Figure 5.14 Screenshot from the Build Setup - Part Info

Another important point for calculating costs is the Total Scan Time and the percentage of the Build Volume - that means what proportion of the total build is occupied by the particular part.

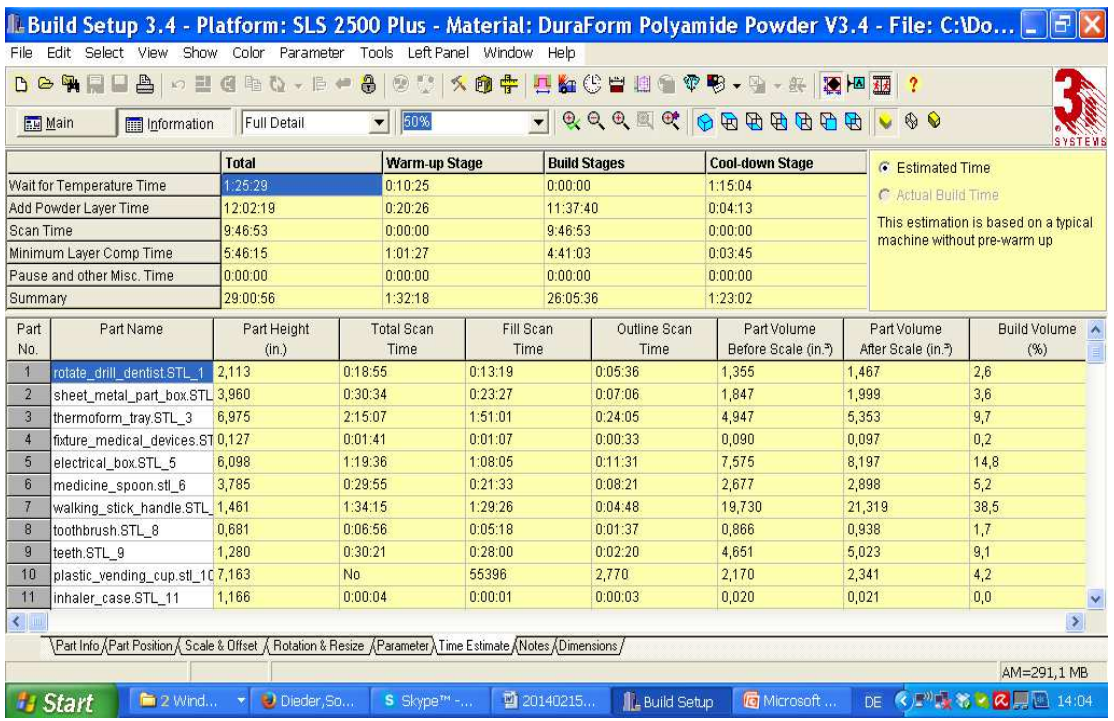

Figure 5.15 Screenshot from the Build Setup - Time Estimate 
Per conversation with Mr. Timothy Gornet he approximated the cost of the build with $\$ 6,000$ (height of $15 "$ and about $\$ 400 /$ in). Therefore a revenue value of $\$ 10,000$ is generated; if the parts are packed so that they occupy a total of $3400 \mathrm{~m}^{3}$ inches (that meet $97 \%$ of the total build volume, because there must be some space between parts).

\subsection{Development of the Mathematical Model}

A related problem is that as the complexity and the specialization in an organization increase, it becomes more and more difficult to allocate the available resources to the various activities in a way that is most effective for the organization as a whole. These kinds of problems and the need to find a better way to solve them provided the environment for the emergence of Operations Research (OR).

As its name implies, operations research involves "research on operations". Thus, operations research is applied to problems that concern how to conduct and coordinate the operations (i.e. the activities) within an organization. The nature of organization is essentially immaterial, and, in fact, OR has been applied extensively in such diverse areas as manufacturing, transportation, construction, telecommunications, financial planning, health care, the military, and public services, to name just a few. Therefore, the breadth of application is unusually wide.

The - "research" part of the name means that operations research uses an approach that resemble the way research is conducted in established scientific fields. To a considerable extent, the scientific method is used to investigate the problem of concern. (In fact, the term "management science" sometimes is used as a synonym for operations research). 
One way of summarizing the usual (overlapping) phases of an OR study is the following:

1. Define the problem of interest and gather relevant data.

2. Formulate a mathematical model to represent the problem.

3. Develop a computer-based procedure for deriving solutions to the problem from the model.

4. Test the model and refine it as needed.

5. Prepare for the ongoing application of the model as prescribed by management.

\section{Implement.}

The first order of business is to study the relevant system and develop a welldefined statement of the problem to be considered. This includes, determining such things as the appropriate objectives, constraints on what can be done, interrelationships between the area to be studied and other areas, of organization, possible alternative courses of action, and time limits for making a decision, and so on.

The purpose of this research is to maximize the revenue for all parts from the part catalogue.

The constraints for that problem are the fixed size of the build volume with 13 "x15"x18" and the due date constraints, because the contractual agreed delivery time shall not be exceeded.

After the decision maker's problem is defined, the next phase is to reformulate this problem in a form that is convenient for analysis. The conventional OR approach for 
doing this is to construct a mathematical model that represents the essence of the problem.

If there are $n$ related quantifiable decisions to be made, they are represented as decision variables $\left(s a y, x_{1}, x_{2}, \ldots, x_{n}\right)$ whose respective values are to be determined. The appropriate measure of performance (e.g. profit) is then expressed as a mathematical function of these decision variables (for example, $P=3 x_{1}+2 x_{2}+\ldots+5 x_{n}$ ). This function is called the objective function. Any restrictions on the values that can be assigned to these decision variables are also expressed mathematically, typically by means of inequalities or equations (for example, $x 1+3 x_{1} x_{2}+2 x_{2} \leq 10$ ). Such mathematical expression, for the restrictions are often called constraints. The constraints (namely, the coefficient and righthand sides) in the constraints and the objective function are called the parameters of the model.

The mathematical model might then say that the problem is to choose the values of the decision variables so as to maximize the objective function, subject to the specified constraints.

$$
\begin{gathered}
\text { Maximize } Z=f\left(\mathrm{x}_{1}, \ldots, \mathrm{x}_{125}\right) \\
=\sum_{i=1}^{N} \mathrm{~S}_{i} \mathrm{x}_{i}
\end{gathered}
$$

With constraints:

$$
\begin{aligned}
& \sum_{i=1}^{N} \mathrm{v}_{i} \mathrm{x}_{i} \leq \mathrm{L} \\
& \mathrm{x}_{i} \leq \mathrm{n}_{i} \text { for } \mathrm{i}=1, \ldots, \mathrm{N} \\
& \mathrm{x}_{i} \geq 0 \text { and integer for } \mathrm{i}=1, \ldots, \mathrm{N}
\end{aligned}
$$




$$
\begin{aligned}
& \mathrm{N} \equiv \text { number of different types of parts } \mathrm{i} \\
& \mathrm{x}_{i} \equiv \text { number of parts of type } \mathrm{i} \text { built, } \quad \mathrm{i}=1, \ldots, \mathrm{N} \\
& \mathrm{S}_{i} \equiv \text { selling price per unit of part of type } \mathrm{i} \\
& \mathrm{v}_{i} \equiv \text { volume of bounding box for part of type } \mathrm{i} \\
& \mathrm{L} \equiv \text { total volume available } \\
& \mathrm{n}_{i} \equiv \text { number of parts of type } \mathrm{i} \text { needed in the current build }
\end{aligned}
$$

In addition to the limitation problem there is also to implement the due date constraint. This will be realized by a penalty function.

$$
\mathrm{p}_{i} \equiv \text { penalty cost per part for type } \mathrm{i} \text { for not meeting its due-date, } \mathrm{n}_{i}-\mathrm{x}_{i}
$$

The multiple-objective optimization problem is

Maximize $Z=\sum_{i=1}^{N} \mathrm{~S}_{i} \mathrm{x}_{i}-\sum_{i=1}^{N}\left(\mathrm{p}_{i}\right) *\left(\mathrm{n}_{i}-\mathrm{x}_{i}\right)$

With constraints

$$
\begin{aligned}
& \sum_{i=1}^{N} \mathrm{v}_{i} \mathrm{x}_{i} \leq \mathrm{L} \\
& \mathrm{x}_{i} \leq \mathrm{n}_{i} \text { for } \mathrm{i}=1, \ldots, \mathrm{N} \\
& \mathrm{x}_{i} \geq 0 \text { and integer for } \mathrm{i}=1, \ldots, \mathrm{N}
\end{aligned}
$$

$$
\begin{aligned}
& \mathrm{N} \equiv \text { number of different types of parts } \mathrm{i} \\
& \mathrm{x}_{i} \equiv \text { number of parts of type i built, } \mathrm{i}=1, \ldots, \mathrm{N} \\
& \mathrm{S}_{i} \equiv \text { selling price per unit of part of type } \mathrm{i}
\end{aligned}
$$


$\mathrm{v}_{i} \equiv$ volume of bounding box for part of type $\mathrm{i}$

$\mathrm{L} \equiv$ total volume available

$\mathrm{n}_{i} \equiv$ number of parts of type in the current build

After a mathematical model is formulated for the problem under consideration, the next phase in an OR study is to develop a procedure (usually a computer-based procedure) for deriving solutions to the problem from this model (Hillier and Lieberman, 2010). 


\section{CHAPTER 6}

\section{OPTIMIZATION APPROACHES AND EXPERIMENTAL RESULTS}

\subsection{Optimization Approaches}

The process of optimizing systematically and simultaneously a collection of objective functions is called multi-objective optimization (MOO) or vector optimization. In this research a multi-objective optimization is using because of the goal to maximize the revenue by meeting at the same time the due date constraint.

Because genetic algorithms do not require gradient information, they can be effective regardless of the nature of the objective functions and constraints. They combine the use of random numbers and information from previous iterations to evaluate and improve a population of points (a group of potential solutions) rather than a single point at a time.

Genetic algorithms are global optimization techniques, which mean they converge to the global solution rather than to a local solution. However, this distinction becomes unclear when working with multi-objective optimization, which usually entails a set of solution points. (Marler and Arora, 2004) 


\subsubsection{MATLAB}

MATLAB ${ }^{\circledR}$ is a high-level language and interactive environment for numerical computation, visualization, and programming.

(http://www.mathworks.com/products/matlab/).

A $2 \mathrm{D}$ box packing algorithm with MATLAB will be provided in the Appendix B. Mathworks suggests also using a GA for multi-objective optimization.

\subsubsection{LINGO}

LINGO is a comprehensive tool designed to make building and solving mathematical optimization models easier and more efficient. LINGO provides a completely integrated package that includes a powerful language for expressing optimization models, a full-featured environment for building and editing problems, and a set of fast built-in solvers capable of efficiently solving most classes of optimization models (LINGO 11 User's Manual).

The entire models in detail are implemented in the Appendix B. The first LINGO model solved only the limitation constraint. The total Build Volume of 3510 inches (13"x15"x18") will be filled with the following parts: 1297122 of $\mathrm{x}_{13}, 1$ of $\mathrm{x}_{16}, 2$ of $\mathrm{x}_{19}$ and 14 of $\mathrm{x}_{100}$ after executing of 11 iterations.

By implementing the penalty for not meeting the number required today into the second LINGO model the result showed to fill these parts in the build:

$$
\begin{aligned}
& X(1) \quad 1.000000 \\
& X(3) \quad 2.000000
\end{aligned}
$$




\begin{tabular}{|c|c|}
\hline$X(5)$ & 1.000000 \\
\hline$X(7)$ & 1.000000 \\
\hline$X(12)$ & 3.000000 \\
\hline$X(13)$ & 1.000000 \\
\hline$X(14)$ & 1.000000 \\
\hline$X(16)$ & 3.000000 \\
\hline$X(23)$ & 2.000000 \\
\hline$X(26)$ & 1.000000 \\
\hline$X(29)$ & 1.000000 \\
\hline$X(37)$ & 1.000000 \\
\hline$X(42)$ & 1.000000 \\
\hline$X(48)$ & 2.000000 \\
\hline$X(49)$ & 2.000000 \\
\hline$X(50)$ & 3.000000 \\
\hline$X(52)$ & 1.000000 \\
\hline$X(53)$ & 1.000000 \\
\hline$X(54)$ & 4.000000 \\
\hline$X(57)$ & 2.000000 \\
\hline
\end{tabular}




$$
\begin{aligned}
& \mathrm{X}(67) \quad 2.000000 \\
& \mathrm{X}(69) \quad 4.000000 \\
& X(72) \quad 4.000000 \\
& \mathrm{X}(78) \quad 4.000000 \\
& \mathrm{X}(79) \quad 4.000000 \\
& X(84) \quad 2.000000 \\
& X(86) \quad 4.000000 \\
& \mathrm{X}(87) \quad 3.000000 \\
& X(88) \quad 2.000000 \\
& \mathrm{X}(91) \quad 1.000000 \\
& \mathrm{X}(93) \quad 1.000000 \\
& \mathrm{X}(95) \quad 2.000000 \\
& \mathrm{X}(96) \quad 4.000000 \\
& \mathrm{X}(99) \quad 3.000000 \\
& \mathrm{X}(105) \quad 1.000000 \\
& X(106) \quad 3.000000 \\
& \text { X( 107) } \quad 1.000000 \\
& \mathrm{X}(108) \quad 2.000000
\end{aligned}
$$




$\begin{array}{ll}X(114) & 4.000000 \\ X(115) & 1.000000 \\ X(117) & 3.000000 \\ X(119) & 2.000000 \\ X(120) & 3.000000 \\ X(121) & 3.000000 \\ X(122) & 1.000000 \\ X(123) & 3.000000\end{array}$

with an objective value of $\$-82999.85$. There is negative revenue by producing that build - that means it is not possible to build each of the parts needed with one build. Regarding the high demand with the short due date the next step is to check how many machines are needed.

\subsubsection{EXCEL Solver}

Spreadsheet software, such as Excel, is a popular tool for analyzing and solving small linear programming problems. The main features of a linear programming model, including all its parameters, can be easily entered onto a spreadsheet. However, spreadsheet software can do much more than just display data. With including some additional information, the spreadsheet can be used to quickly analyze potential solutions. For example, a potential solution can be checked to see if it is feasible and what $\mathrm{Z}$ value (profit or cost) it achieves. Much of the power of the spreadsheet lies in its ability to 
immediately reveal the results of any changes, made in the solution (Hillier and Lieberman, 2010).

The Excel Software is universally available and easy to apply to multi-objective optimization.

The first Excel spreadsheet shows the overview of all parts with all dimensions and the Bounding Volume of each part. The Build Volume of the SLS 2500+ is given by the dimensions 13 "x15"x18".

Table 5.1 Excel overview of all parts, dimensions and Bounding Volume

Part

Nozzle

Shell bottle

Hooke's joint Collar

Hooke's joint Pin

Hooke's joint Locking Pin

Hooke's joint Fork

Hooke's joint Center Piece

Clerget 9B 130 Cylinder

Clutch Plate

Wallpaper

P-51 Throttle Quadrant Cover

P-51 Landing Gear Retract Hook

Gear Wheel Module

Engine 4 Cyl Tube 5

Engine 4 Cyl Hood

Engine 4 Cyl Flywheel

Engine 4 Cyl Tube 2

Engine 4 CylT Connection

Engine $4 \mathrm{Cyl}$ Inverter

Engine 4 Cyl Chassis Quadruple

Engine 4 Cyl Ring

Engine $4 \mathrm{Cyl}$ Axis 34mm

Engine 4 Cyl Flywheel 2

Engine 4 Cyl Tube 4

\section{BBX}

0,685

0,392

0,170

0,170

0,017

0,299

0,326

0,540

1,553

1,041

0,820

0,280

0,068

0,019

0,061

0,095

0,044

0,044

0,068

0,217

0,044

0,017

0,326

1,333
BBY

0,704

0,841

0,041

0,651

0,017

0,556

0,366

0,923

0,906

1,034

0,240

0,411

0,202

0,119

0,041

0,058

0,078

0,020

0,037

0,081

0,027

0,115

1,140

1,713
BBZ

0,233

0,141

0,164

0,164

0,164

0,561

0,354

0,536

2,217

1,007

0,207

0,130

0,197

0,018

0,005

0,092

0,013

0,016

0,066

0,184

0,043

0,016

1,102

0,717
Bounding

Volume

0,112362

0,046484

0,001143

0,018150

0,000047

0,093263

0,042238

0,267153

3,119359

1,083929

0,040738

0,014960

0,002706

0,000041

0,000013

0,000507

0,000045

0,000014

0,000166

0,003234

0,000051

0,000031

0,409547

1,637219 


\begin{tabular}{|c|c|c|c|c|}
\hline Engine 4 Cyl Tube 3 & 0,860 & 0,232 & 0,157 & 0,031325 \\
\hline Engine 4 Cyl Piston & 0,407 & 0,407 & 1,969 & 0,326163 \\
\hline Engine 4 Cyl Dowel & 0,163 & 0,489 & 0,157 & 0,012514 \\
\hline Engine 4 Cyl Panel & 2,198 & 1,466 & 0,079 & 0,254559 \\
\hline Engine 4 Cyl Spacer & 1,832 & 0,814 & 0,236 & 0,351935 \\
\hline Engine 4 Cyl Cylinder & 0,733 & 1,588 & 0,654 & 0,761259 \\
\hline Engine 4 Cyl Valve Cover & 0,651 & 0,163 & 0,630 & 0,066851 \\
\hline Engine 4 Cyl Arm & 0,204 & 1,221 & 0,079 & 0,019678 \\
\hline Engine $4 \mathrm{Cyl}$ Axis $28 \mathrm{~mm}$ & 0,204 & 1,140 & 0,197 & 0,045814 \\
\hline Engine 4 Cyl Assbly Inv & & & & \\
\hline ArmTube 1 & 0,224 & 1,425 & 0,216 & 0,068947 \\
\hline $\begin{array}{l}\text { Engine } 4 \text { Cyl Assbly Inv Arm } \\
\text { Tube } 2 \\
\text { Engine } 4 \text { Cyl Assbly Cyl Piston }\end{array}$ & 0,223 & 1,425 & 0,216 & 0,068639 \\
\hline Hood & 0,407 & 0,407 & 1,969 & 0,326163 \\
\hline Camera Holder & 6,920 & 0,733 & 8,465 & 42,937527 \\
\hline Wine Bottle Klein & 13,900 & 9,047 & 6,050 & 760,807465 \\
\hline Brake & 12,213 & 12,213 & 2,362 & 352,309706 \\
\hline Grabcad Trophy & 7,161 & 14,004 & 6,923 & 694,256744 \\
\hline Klein Stein & 3,460 & 6,513 & 5,059 & 114,004464 \\
\hline Charger Hat iPhone & 1,520 & 1,284 & 1,571 & 3,066089 \\
\hline Apple iPod Shuffle & 1,288 & 1,204 & 0,344 & 0,533459 \\
\hline Clip & 2,304 & 0,917 & 0,591 & 1,248646 \\
\hline EOS UK Plug Fixer & 1,580 & 0,946 & 1,512 & 2,259956 \\
\hline JBL Speaker & 2,854 & 2,253 & 2,750 & 17,682671 \\
\hline Inline Acustic Box & 11,304 & 16,501 & 10,589 & 1975,137622 \\
\hline Piston Sample & 1,625 & 2,443 & 1,575 & 6,252553 \\
\hline Cat Pumpkin & 11,828 & 11,311 & 11,423 & 1528,243281 \\
\hline Logo Vietnam Electricity & 8,549 & 1,547 & 8,268 & 109,346805 \\
\hline 2 Euro & 1,018 & 1,018 & 0,095 & 0,098451 \\
\hline Chocolate Riddle & 2,280 & 0,305 & 5,197 & 3,613994 \\
\hline Battery Bracket & 2,524 & 0,407 & 0,850 & 0,873178 \\
\hline Laptop Paper Holder & 4,071 & 2,023 & 0,606 & 4,990794 \\
\hline 3M Stethoscope & 11,322 & 0,979 & 6,558 & 72,690433 \\
\hline Traffic Light & 2,496 & 6,106 & 2,361 & 35,983000 \\
\hline iPhone 5C & 2,430 & 5,089 & 0,353 & 4,365293 \\
\hline iPhone 4S Irig Case & 3,816 & 4,858 & 1,133 & 21,003699 \\
\hline Apple Lightning Pin Adapter & 1,068 & 1,080 & 0,222 & 0,256064 \\
\hline Ribbon Stand & 4,249 & 2,267 & 2,867 & 27,616329 \\
\hline iShare & 4,168 & 1,018 & 0,551 & 2,337906 \\
\hline iPhone 5 Cover & 2,791 & 5,122 & 0,866 & 12,379905 \\
\hline iPod & 2,516 & 4,229 & 0,551 & 5,862730 \\
\hline Apple of Eden Lamp & 6,716 & 6,681 & 6,495 & 291,428026 \\
\hline Apple WiFi Router & 14,248 & 5,498 & 6,339 & 496,568760 \\
\hline iPad Model & 1,832 & 0,130 & 2,196 & 0,522999 \\
\hline
\end{tabular}




\begin{tabular}{|c|c|c|c|c|}
\hline Speaker & 4,485 & 8,386 & 4,500 & 169,250445 \\
\hline Playing Card & 2,585 & 3,619 & 0,030 & 0,280653 \\
\hline Shaft Lubricator & 6,651 & 4,966 & 6,929 & 228,857013 \\
\hline Coupling Flange & 1,221 & 13,637 & 13,189 & 219,607098 \\
\hline Clock & 6,106 & 9,917 & 2,626 & 159,012708 \\
\hline Edge Protector & 1,622 & 1,637 & 1,575 & 4,181962 \\
\hline Soft Jaws - Full Wrap & 12,211 & 1,710 & 11,811 & 246,623247 \\
\hline Rubber Stamp & 4,067 & 6,214 & 3,937 & 99,497195 \\
\hline USB Keychain Holder & 0,691 & 0,329 & 0,938 & 0,213244 \\
\hline Junction Box & 3,420 & 2,353 & 5,039 & 40,550143 \\
\hline Engine Crankcase Cover & 2,972 & 15,669 & 7,126 & 331,845478 \\
\hline Shaft and Guide Support & 4,437 & 5,618 & 2,008 & 50,053549 \\
\hline Mount for Maxon Gearmotor & 1,506 & 1,370 & 1,102 & 2,273668 \\
\hline Face Mill & 8,544 & 8,537 & 2,223 & 162,145905 \\
\hline EMI Filter & 2,378 & 2,497 & 1,900 & 11,281945 \\
\hline Sony PCM D50 & 3,318 & 6,277 & 1,343 & 27,970776 \\
\hline \multicolumn{5}{|l|}{ FPV Camera Turnigy 600 TVL } \\
\hline PAL & 1,301 & 1,233 & 1,159 & 1,859190 \\
\hline Grill for Stove & 16,283 & 8,142 & 0,472 & 62,575960 \\
\hline Engine Spoket & 3,852 & 3,834 & 0,394 & 5,818816 \\
\hline Sheet Metal Pipe & 3,053 & 3,053 & 11,811 & 110,088075 \\
\hline Electric Eel Eurosocket & 12,886 & 1,851 & 1,459 & 34,800048 \\
\hline Ship's Propeller & 9,189 & 2,768 & 8,887 & 226,042196 \\
\hline Impeller & 5,317 & 1,669 & 5,143 & 45,639357 \\
\hline Can Cover & 2,401 & 0,326 & 2,322 & 1,817490 \\
\hline Mount for IG & 1,750 & 2,361 & 3,094 & 12,783635 \\
\hline Record Player Clip & 0,749 & 1,070 & 1,892 & 1,516306 \\
\hline Engine Mount & 6,885 & 2,544 & 4,075 & 71,375418 \\
\hline Jet Engine Bracket & 7,505 & 2,646 & 3,963 & 78,698165 \\
\hline Battery Cover & 2,227 & 0,183 & 1,177 & 0,479676 \\
\hline Roller Handle and Knob & 5,745 & 1,990 & 1,535 & 17,548964 \\
\hline Pasta Spoon & 2,897 & 2,269 & 11,071 & 72,772927 \\
\hline Pivot Guide & 7,309 & 4,375 & 3,543 & 113,294068 \\
\hline Mouth Tray & 2,384 & 0,766 & 2,886 & 5,270252 \\
\hline Carotid Bifurcation & 0,002 & 0,001 & 0,006 & 0,000000 \\
\hline Inhaler Case & 0,552 & 1,397 & 1,151 & 0,887587 \\
\hline Pill Box & 3,541 & 0,979 & 3,425 & 11,873239 \\
\hline Fixture Medical Cevices & 1,723 & 0,933 & 0,125 & 0,200945 \\
\hline Walking Stick Handle & 9,037 & 3,769 & 1,445 & 49,217355 \\
\hline Digital Timer & 2,456 & 2,428 & 0,563 & 3,357264 \\
\hline Thermoform Tray & 9,977 & 1,750 & 6,893 & 120,350057 \\
\hline Rotate Drill Dentist (Drillholder) & 5,638 & 0,407 & 2,087 & 4,788968 \\
\hline Toothbrush & 7,333 & 0,730 & 0,672 & 3,597276 \\
\hline Ferrule Clamp Tool & 2,051 & 2,051 & 1,750 & 7,361552 \\
\hline
\end{tabular}




$\begin{array}{lrrrr}\text { Sheet Metal Part Box } & 5,266 & 1,323 & 3,911 & 27,247616 \\ \text { Teeth } & 2,421 & 4,366 & 1,267 & 13,392299 \\ \text { Electrical Box } & 8,796 & 1,876 & 6,025 & 99,420308 \\ \text { Plastic Vending Cup } & 7,337 & 8,065 & 7,100 & 420,127626 \\ \text { Medicine Spoon } & 10,205 & 0,724 & 3,739 & 27,625302 \\ \text { Zigbee } & 0,992 & 0,289 & 1,098 & 0,314783 \\ \text { LCD TV } & 4,798 & 3,949 & 1,153 & 21,846239 \\ \text { CD Writer Case } & 5,943 & 1,774 & 5,900 & 62,203004 \\ \text { Roof Hook } & 3,827 & 5,659 & 5,669 & 122,773493 \\ \text { Portable Stove } & 8,541 & 1,692 & 7,625 & 110,191712 \\ \text { DVD Burner } & 6,961 & 1,677 & 5,756 & 67,193224 \\ \text { Plate } & 6,690 & 0,770 & 6,470 & 33,328911 \\ \text { Motherboard Adapter Plate } & 7,735 & 0,129 & 7,150 & 7,134377 \\ \text { Bottom Plate } & 3,989 & 1,710 & 2,913 & 19,870126 \\ \text { Faceplate Spider } & 8,937 & 5,377 & 0,032 & 1,537736 \\ \text { Carbon Fiber Dash } & 15,155 & 5,625 & 2,250 & 191,805469\end{array}$

Table 5.2 Excel Columns for the Solver solution

\section{Excel Columns}

\section{A Part Description (text)}

B $\quad \mathrm{BBX}$, in $\quad \mathrm{x}$ dimension of part

C BBY, in $\quad \mathrm{y}$ dimension of part

D BBZ, in $\quad \mathrm{z}$ dimension of part

E $\quad \mathrm{V}(\mathrm{i}), \mathrm{in}^{3}=\mathrm{B} 2 * \mathrm{C} 2 * \mathrm{D} 2 \quad$ bounding volume for part $\mathrm{i}$

$\mathrm{F} \quad \mathrm{S}(\mathrm{i}) \quad=10000 * \mathrm{E} 2 / 3400 \quad$ price changed for part I (per part)

$\mathrm{G} \quad \mathrm{n}(\mathrm{i}) \quad=\mathrm{INT}(10 * \mathrm{RAND}())$ order size for part $\mathrm{i}$

$\mathrm{H} \quad \mathrm{d}(\mathrm{i}) \quad=\mathrm{INT}(3+30 * \mathrm{RAND}()) \quad$ build has to be ready at day 3

I $\quad \mathrm{x}(\mathrm{i}) \quad=$ no. part $\mathrm{i}$ built obtained by Excel Solver application 
J $\quad \mathrm{x}(\mathrm{i}) ” \quad$ = satisfying due-date constraint $\mathrm{IF}(\mathrm{H} 2<6, \mathrm{G} 2, \mathrm{I} 2)$

$\mathrm{K} \quad$ Revenue $(\mathrm{i}) \quad=$ total revenue $\mathrm{J} 2 * \mathrm{~F} 2$

L Penalty Cost (i) = penalty charge for failing to satisfy the due-date for part $\mathrm{i}$

$$
\operatorname{IF}(\mathrm{H} 2<6,0, \mathrm{~J} 2 * .5 * \mathrm{E} 2)
$$

M Volume (i) = total volume for $\mathrm{x}(\mathrm{i})$ "'units of part i $\mathrm{J} 2 * \mathrm{E} 2$

With the Excel Solver an optimization in the Excel spreadsheet is an effective approach.

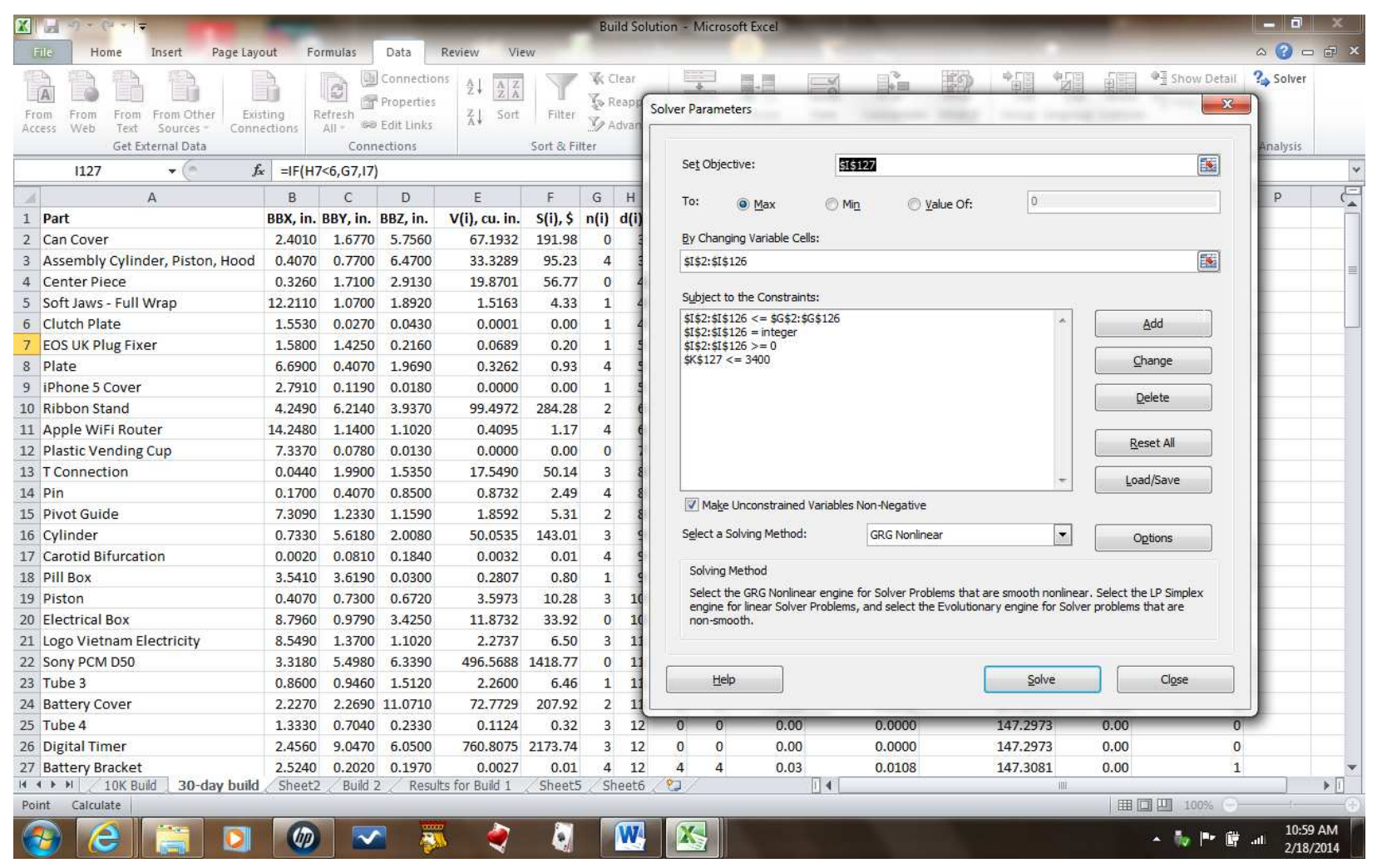

Figure 5.16 Screenshot Solver Parameter 


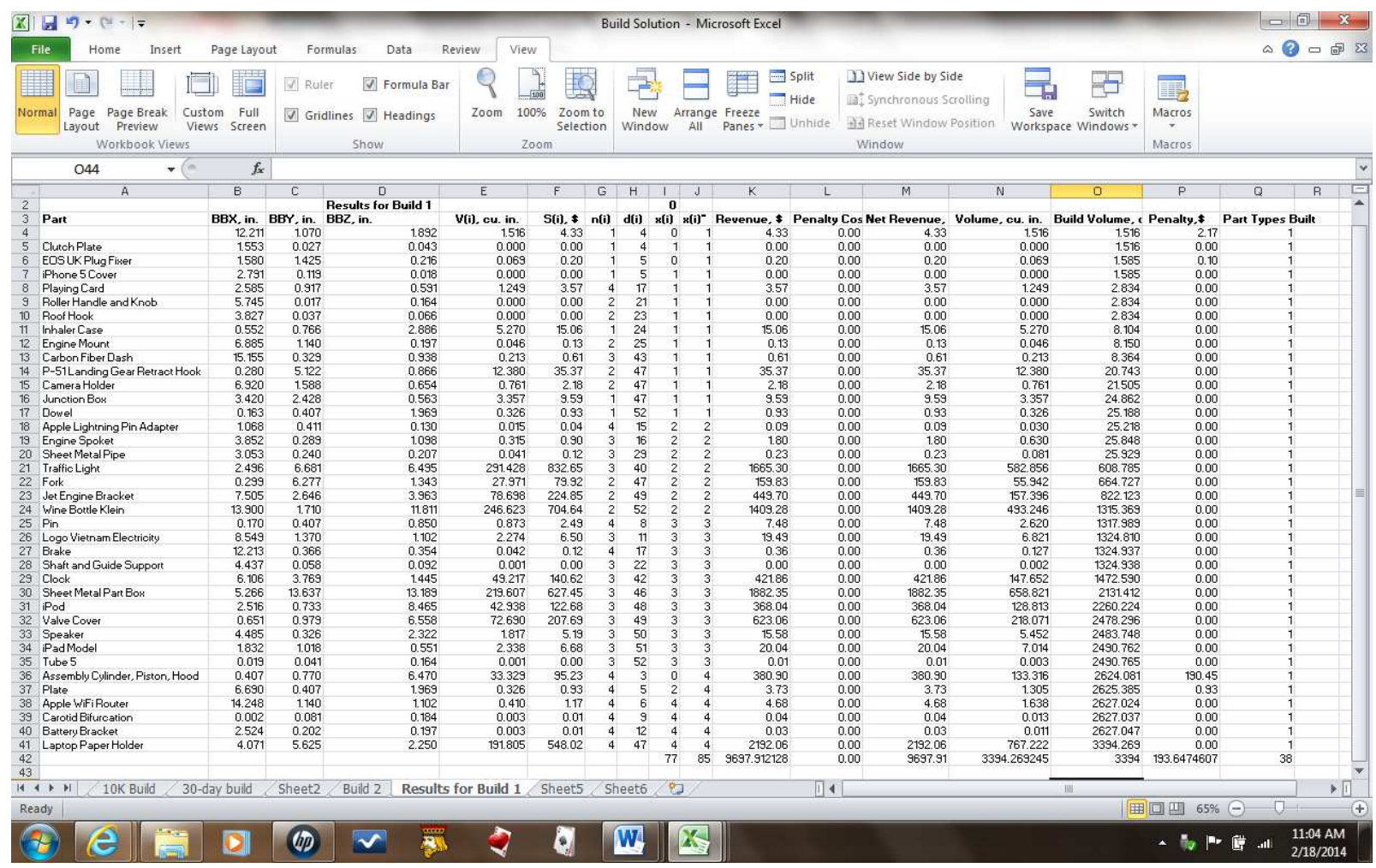

Figure 5.17 Solution for a single build

$\underline{\text { Result }}$

Parts85

Revenue \$9697.91

Build Volume in cu. in. 3394

Penalty cost $\$ 193.64$

The visual verification with the Build Setup Software show that all parts are matching in the Build Volume of the SLS 2500+. 


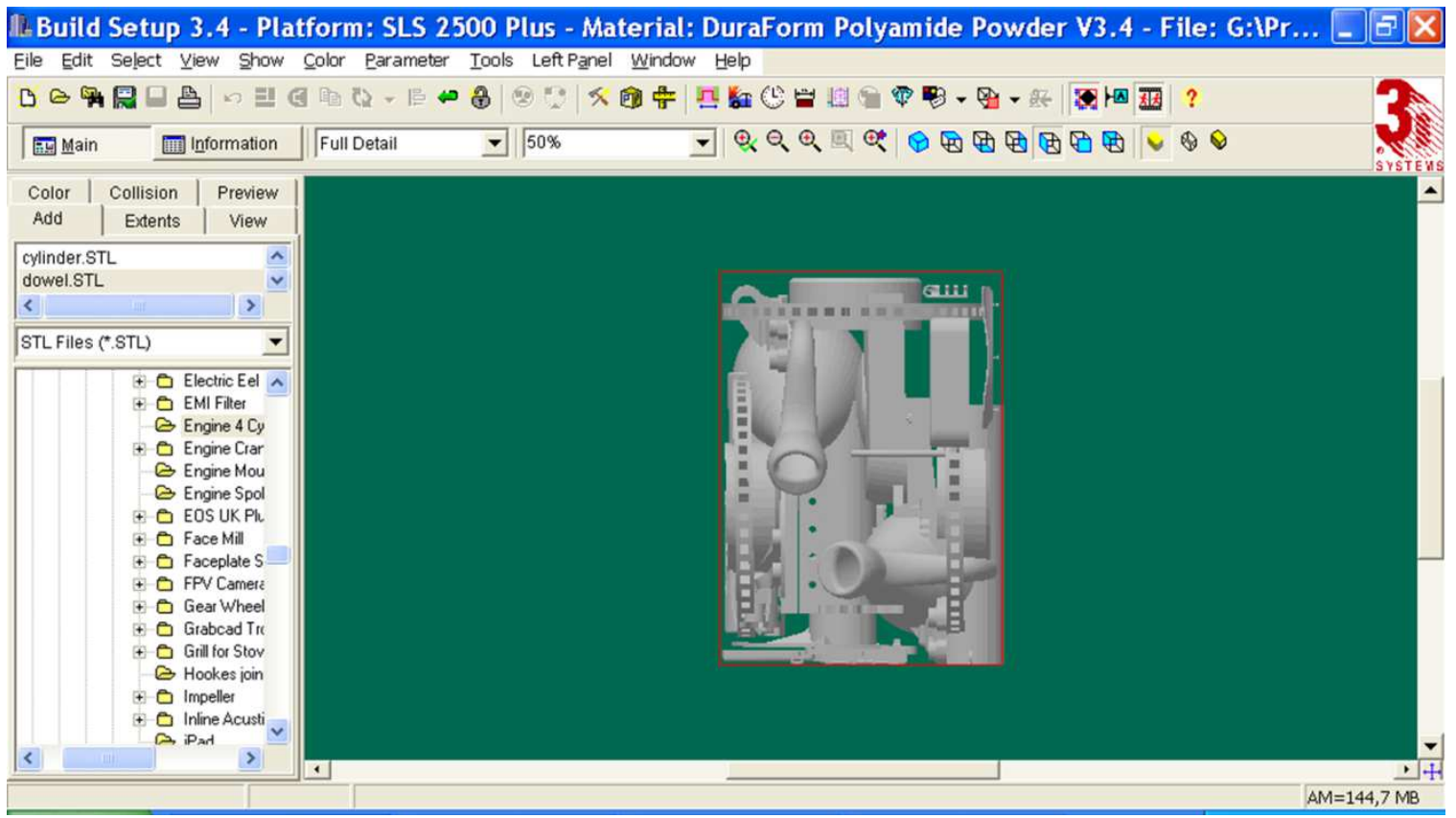

Figure 5.18 Visual verification for the single machine solution

lik Build Setup 3.4 - Platform: SLS 2500 Plus - Material: DuraForm Polyamide Powder V3.4 - File: G:IPr... 0 ]

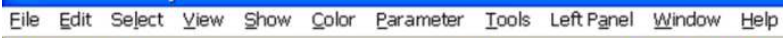

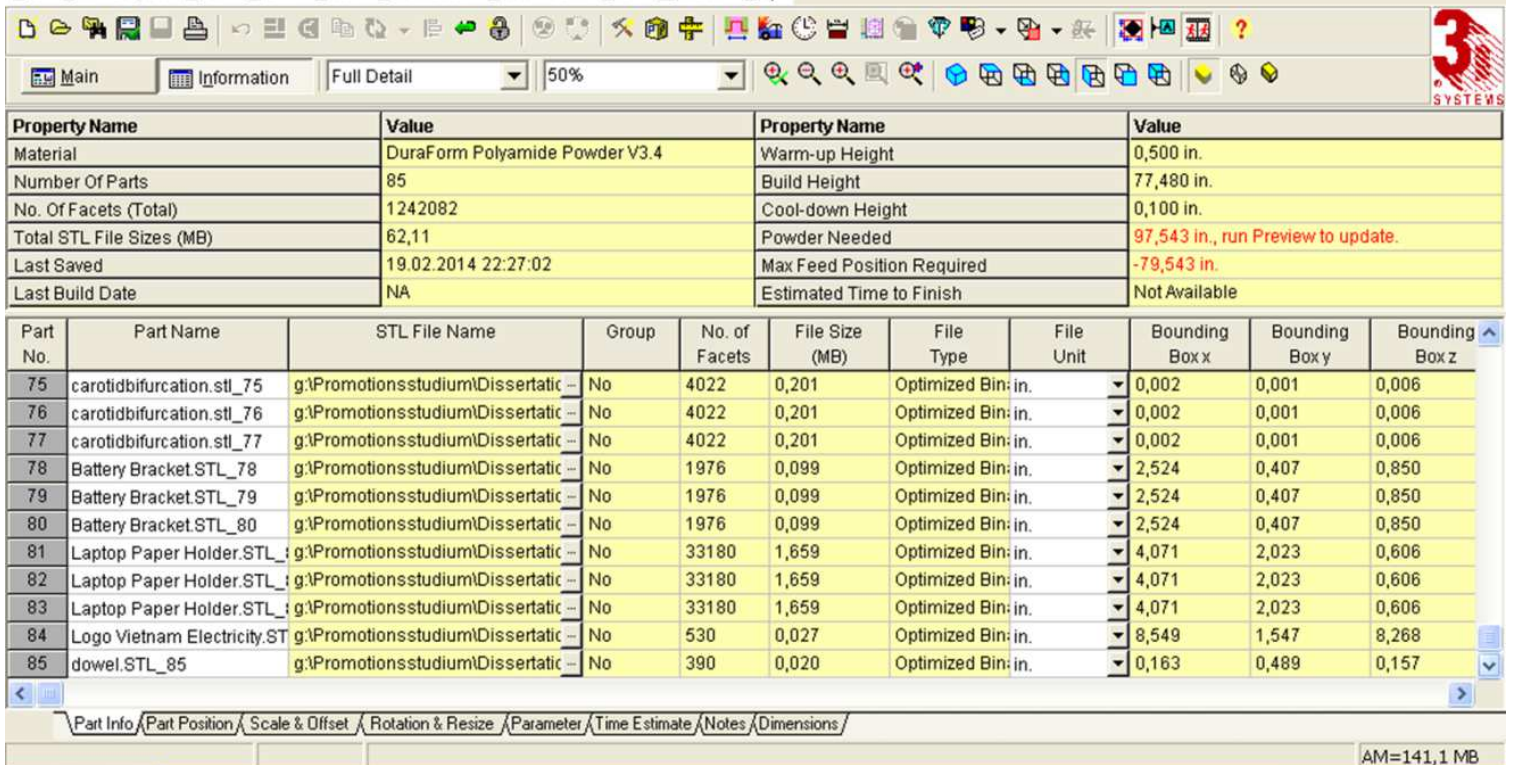

Figure 5.19 Visual verification for the single machine solution - information 


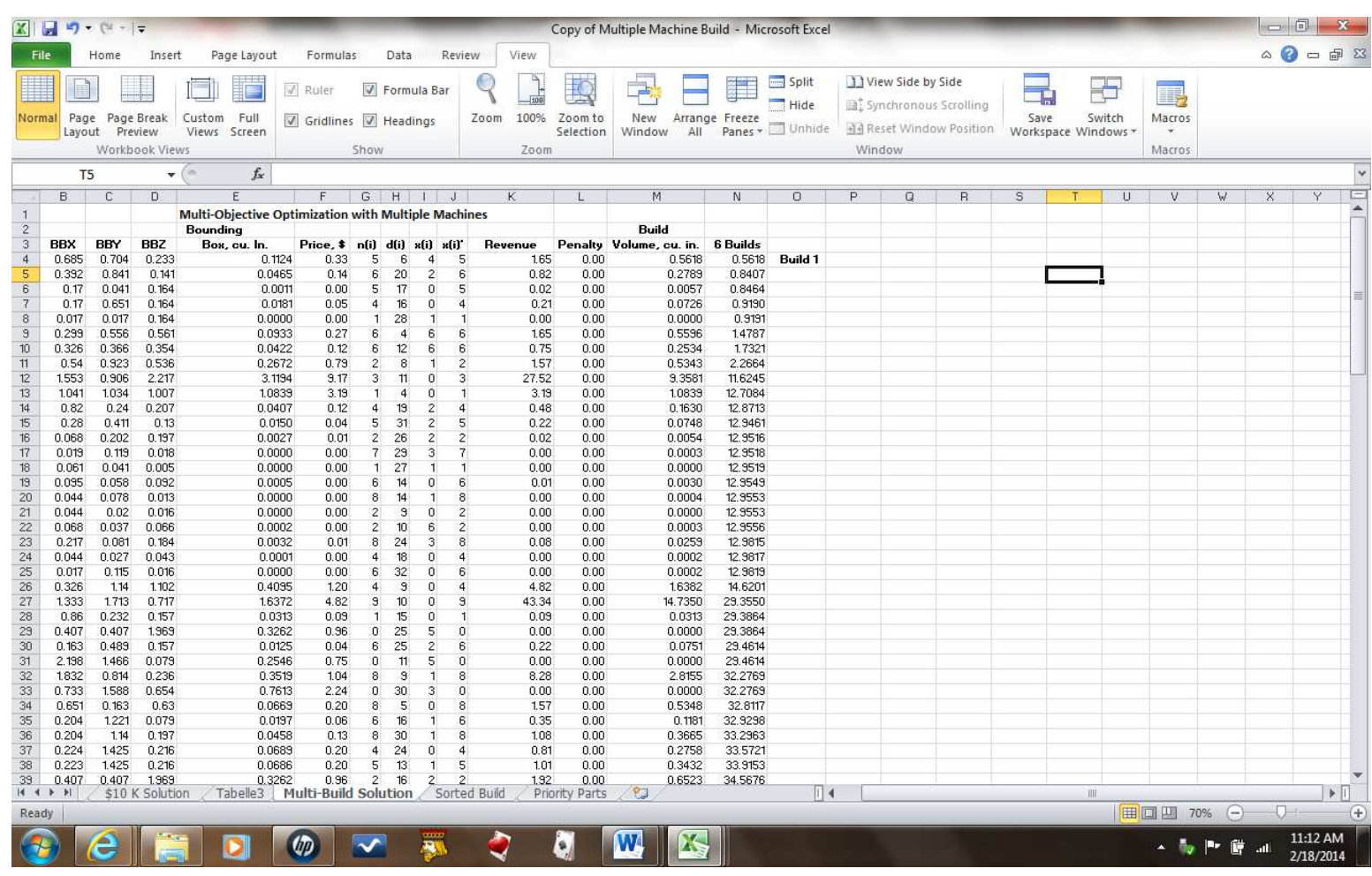

Figure 5.20 Solution for multiple machines - first part

After a single machine build was covered the next was to apply this solution to a multiple machine. 


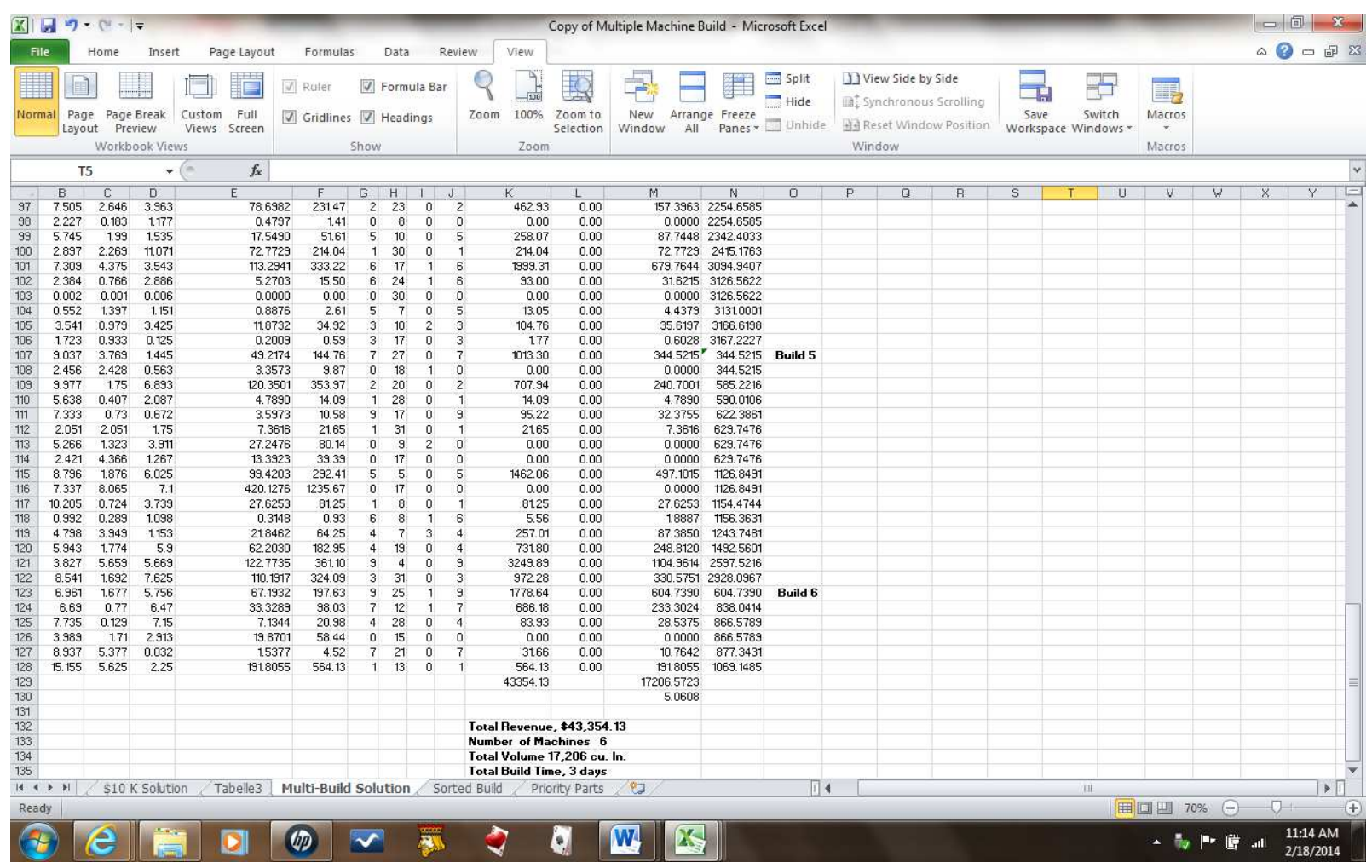

Figure 5.21 Solution for multiple machines - second part

Total Revenue, $\$ 43,354.13$

Number of Machines 6

Total Volume 17,206 cu. In.

Total Build Time, 3 days

Figure 5.22 shows the replacement of parts when a high priority part will come in. 


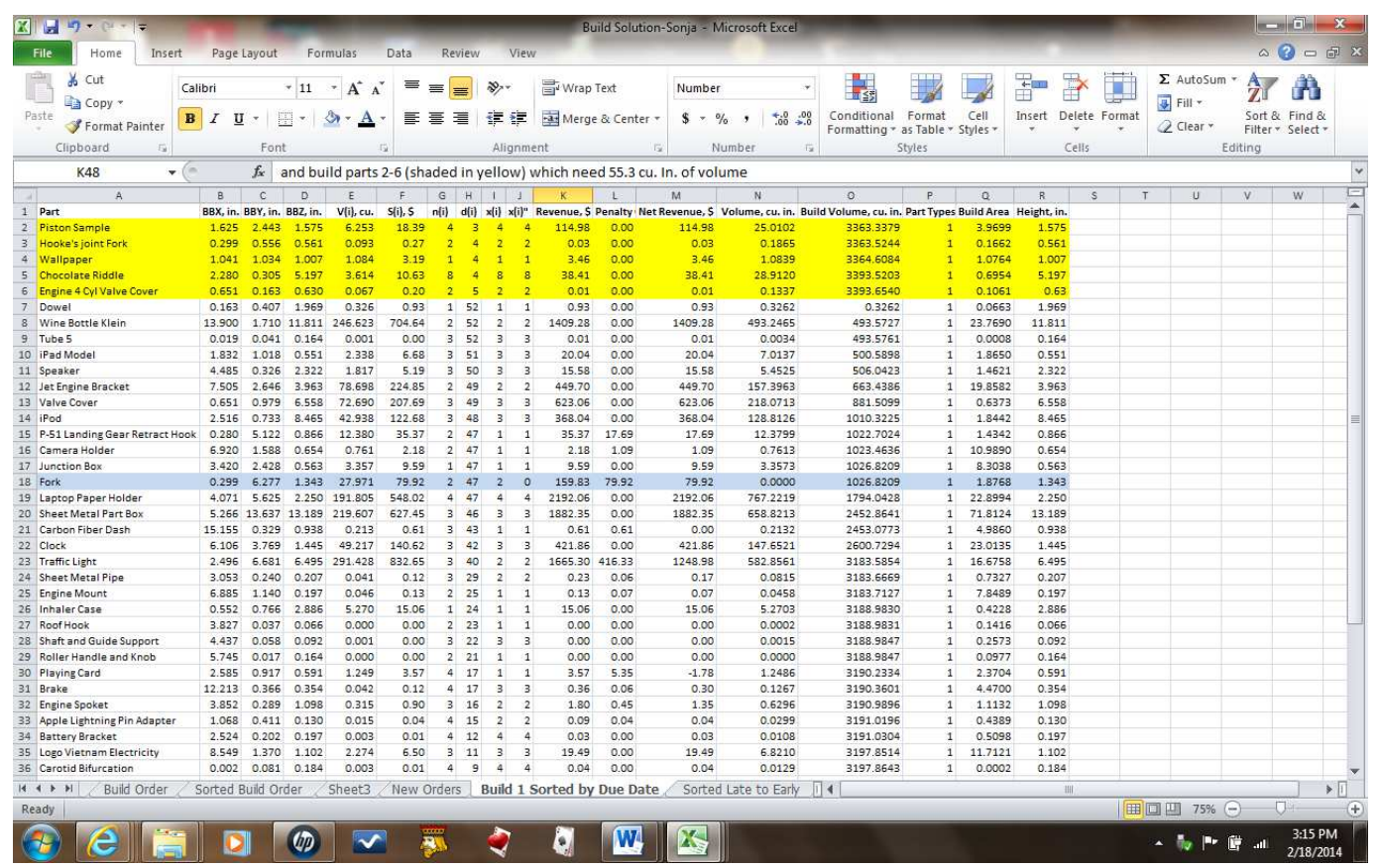

Figure 5.22 Solution replacement of the parts

Build can be easily changed when a high priority part comes in. Both units of part 13 (fork), shaded blue which provides $55.94 \mathrm{cu}$. in.of the volume were replaced with the parts which are shaded yellow.

Also this build was visually verified with the Build Setup Software of the SLS2500+ machine. 


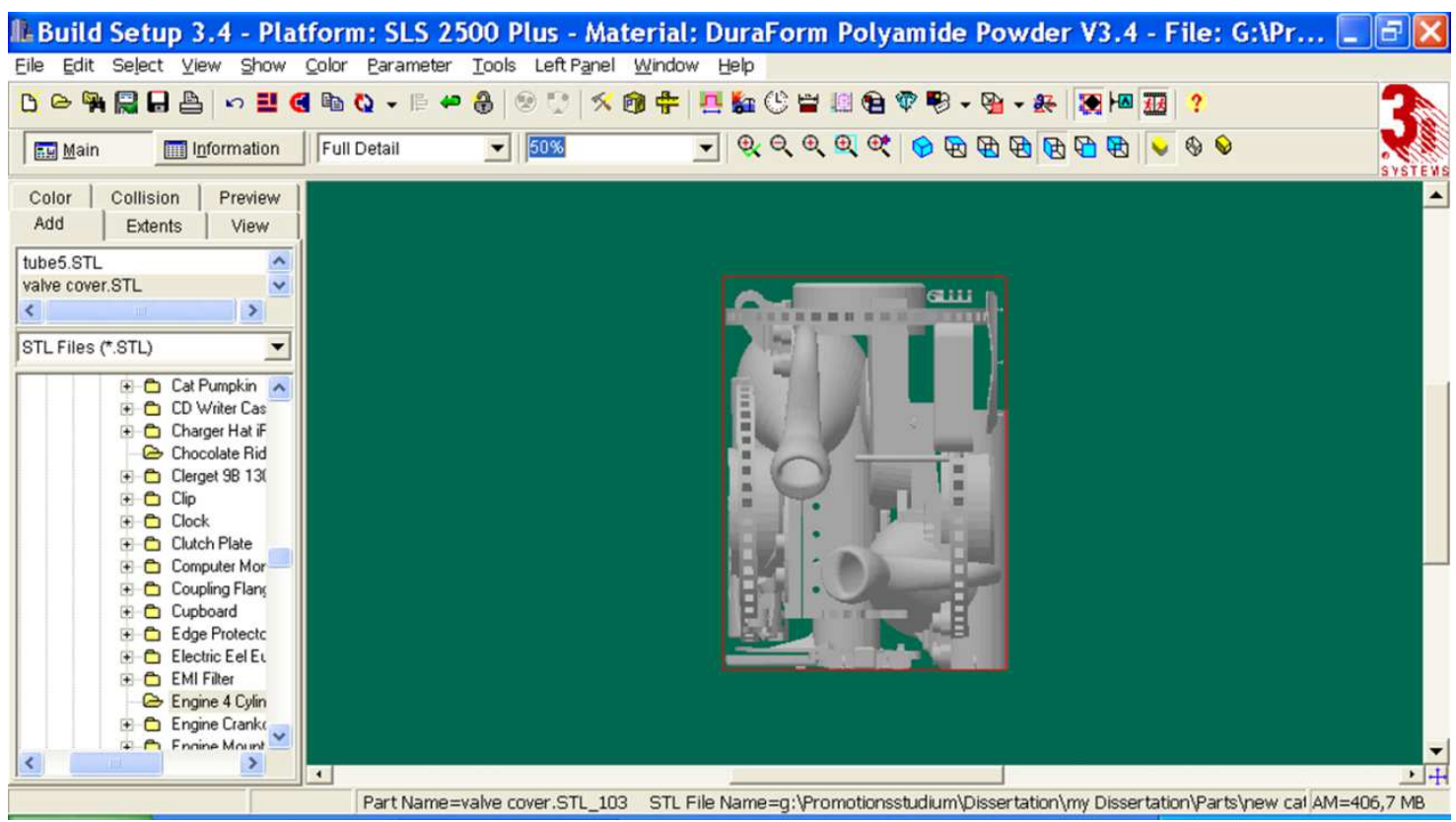

Figure 5.23 Visual verification for replacement of the parts

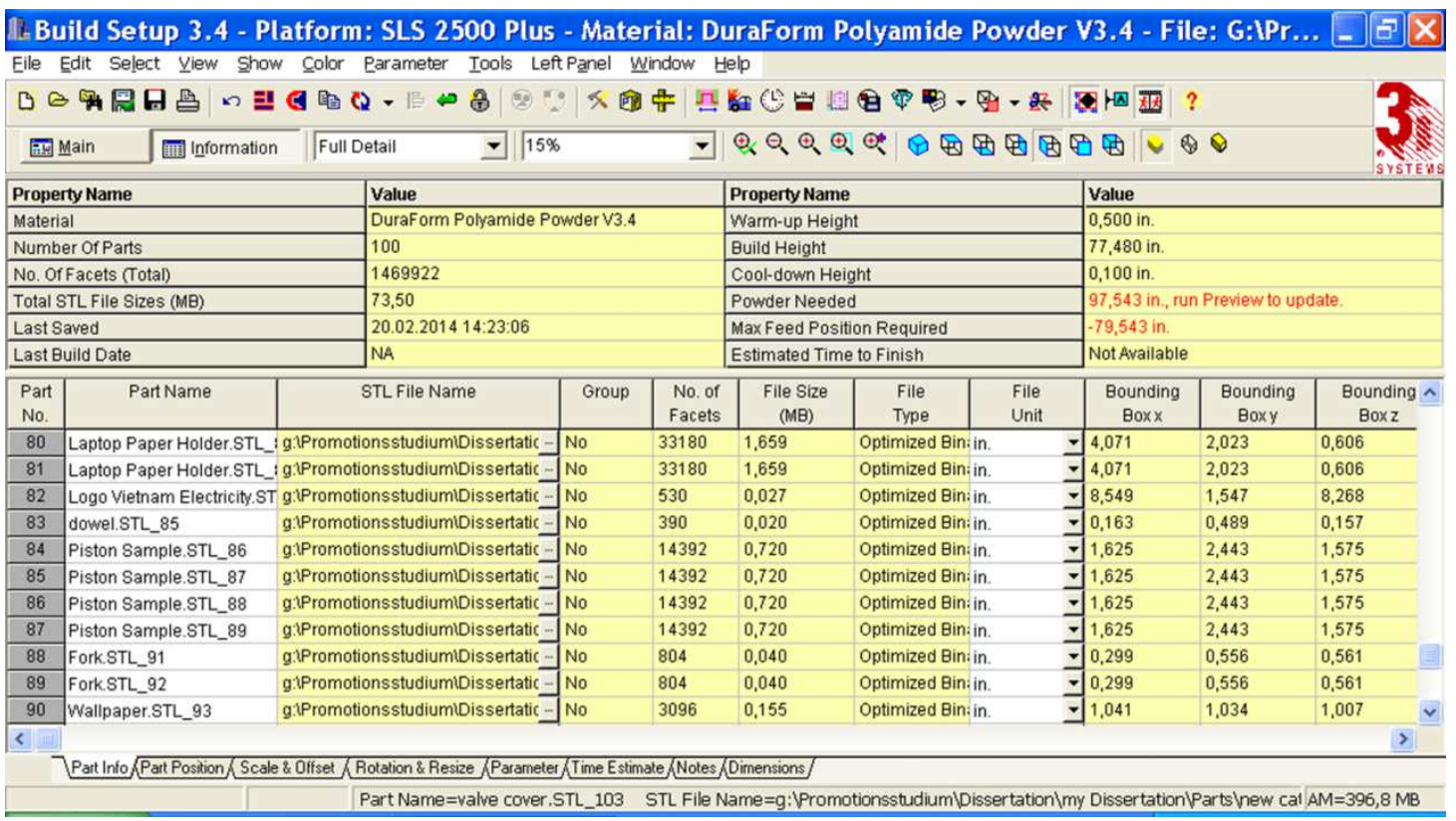

Figure 5.24 Visual verification for replacement of the parts - information 
Through the replacement with this build 100 parts are covering the whole build volume. The assumption of a build volume of $3400 \mathrm{cu}$. in. was supported.

The first version of a large mathematical model inevitably contains many flaws. Some relevant factors or interrelationships undoubtedly y have not been incorporated into the model, and some parameters undoubtedly have not been estimated correctly. This inevitable is given the difficulty of communicating and understanding all the aspects and subtleties of a complex operational problem as well as the difficulty of collecting reliable data.

This process of testing and improving a model to increase its validity is commonly referred to as model validation.

If the model is to be used repeatedly, the next step is to install a well-documented system for applying the model as prescribed by management. This system will include the model, solution procedure (including post optimality analysis), and operating procedures for implementation. Then, even as personnel changes, the system can be called on at regular intervals to provide a specific numerical solution.

After a system is developed for applying the model, the last phase of an OR study is to implement this system as prescribed by management. This phase is a critical one because it is here, and only here, that the benefits of the study are reaped. Therefore, it is important for the OR team to participate in launching this phase, both to make sure that model solutions, are accurately translated to an operating procedure and to rectify any flaws in the solutions that are then uncovered. 
Upon culmination of a study, it is appropriate for the OR team to document its methodology clearly and accurately enough so that the work is reproducible. Replicability should be part of the professional ethical code of the operations researcher. This condition is especially crucial when controversial public policy issues are being studied(Hillier and Lieberman, 2010).

\subsection{Experimental Results}

A mathematical model for that research was formulated by using penalty costs for not meeting the due date. The LINGO optimization tool found a solution but delivered the result that not all of the parts which are ordered can be produced with one build. To find a solution for multiple machines the change to Excel Solver was needed.

By using Excel Solver a single and a multiple machines build were developed for 3 days build. Additionally a solution was found to place the parts with the immediate due-dates at the bottom of the build to replace the parts on top when a high priority part will come in. That is the solution to maximize the revenue with each build.

Basically for an entrepreneur the production of parts with an Additive Manufacturing Machine it is not only a Part Packing Problem. It's rather a question of leading a successful business. The business has to be competitive and in line with market conditions.

These five steps are changing the Part Packing Problem to a secured economical business solution.

Five Steps from a Part Packing to a secured economical business solution

1. Define all foundations which are clear bounded by contracts with existing customers 
It is significant to have the overview of all contractual conditions. This can be binding delivery dates as also surface quality etc. It is a current practice to conclude contractual clauses with often contractual penalties by non-compliance.

2. Identify the market demand

It is also essential to analyze the market demand and it is also necessary to make a Forecast planning with existing customers. Additionally it is important to identify the competitors, their market positions and their actions.

3. Production planning with/without stock

If the market demand is analyzed the next step is to check if the targets are achievable by the normal daily production planning or do there is a need for more machines a stock. There has to be a further analysis for the costs of the stock.

4. Analysis of the economic efficiency

For optimizing the business results there is an absolute must to identify all economic numbers. That is on the one hand the market prices and on the other hands all the costs (labor, machine, material, location etc.).

\section{Maximize Revenue}

Identify opportunities to maximize the revenue. This research for example changed the merely Part Packing to an Optimization problem by maximizing the revenue.

There are a lot of further possibilities to optimize

To be successful in the market in this area it is not only a question to pack the parts in the given dimensions of the Build Volume. 
It's rather a question from considering the constraints, but also to take the opportunity for identifying the optimization potential. In this example the optimization potential is identified by maximizing the revenue. 


\section{CHAPTER 7}

\section{SUMMARY, CONCLUSIONS AND RECOMMENDATIONS}

\subsection{Summary}

The additive manufacturing technology changed a lot for the manufacturer and implies in general a big volume for new commercial trends. For example, the concept of the companies Shapeways and materialize is, offering a marketplace where people can design their own products and they will produce that. Also in the near future it will give a lot of local shops which provide that service. For example if there is a need for an adjusting knob for a washing machine, an agent from this service shop can download the stl file from the internet for that part and produce it shortly.

The next step on this technology trend is then not only the question how to fill the build volume of the machine but have at the same time a look of the costs and the profit. For this research a comprehensive literature research focused on the Bin Packing Problem which was mainly done by using a Genetic Algorithm in the past, the Bounding Box problem, cost analysis and optimization tools.

By using a multi-objective function to maximize the revenue and meeting at the same time the due date constraint the actual available optimization tools are only partially applicable. Therefore LINGO and Excel Solver were evaluated for this purpose. 


\subsection{Conclusions}

This research has demonstrated that the Excel Solver application can be very useful and effective in optimizing Additive Manufacturing builds. This is especially true given the multiple-optimization framework for the problem of maximizing revenue while satisfying due-date constraints, owing to the ease with which the "IF then Else" logic can be implemented. This feature was indispensable in the current work, and gave Excel Solver a significant advantage over the other applications evaluated. The arrival of Priority parts was handled with ease, though somewhat mechanistically; that is, the Solver solution had to be visually searched for the parts to be removed.

\subsection{Recommendations for Future Work}

The research described in this dissertation represents only a beginning of the development of multi-objective optimization tools for application in Additive Manufacturing. This approach can be extended to 3D printing or to any other AM technologies with little difficulty. The greatest challenge is to develop a real-time coupling of the optimization application with the bin-packing visualization software.

Also for future work it would prove beneficial to make research for calculating the build height and a build time estimator. 


\section{REFERENCES}

3D SYSTEMS, I. 2004. SLS Systems User's Guide.

ABELE, E. \& REINHART, G. 2011. Zukunft der Produktion, Herausforderungen, Forschungsfelder, Chancen, München, Carl Hanser Verlag.

ASTM INTERNATIONAL 2012. Standard Teminology for Additive Manufacturing Technologies.

BAUMERS, M., TUCK, C., WILDMAN, R., ASHCROFT, I., ROSAMOND, E. \& HAGUE, R. Combined Build-Time, Energy Consumption and Cost Estimation for Direct Metal Laser Sintering. Institution of Mechanical Engineering, 2011. Journal of Engineering Manufacture, 13.

BEHRENDT, U. \& SHELLABEAR, M. 1995. The EOS rapid prototyping concept. Computers in Industry, 28, 5.

BERZINS, M., CHILDS, T. H. C. \& RYDER, G. R. 1996. The Selective Laser Sintering of Polycarbonate. CIRP Annals, 45, 4.

BOILLAT, E., KOLOSOV, S., GLARDON, R., LOHER, M. \& SALADIN, D. Finite Element And Neural Network Models For Process Optimisation in Selective Laser Sintering. Proceedings of the Institution of Mechanical Engineers, 2004. Journal of Engineering Manufacture, 8.

CHAN, C. K. \& TAN, S. T. 2001. Determination of the minimum bounding box of an arbitrary solid: an iterative approach. Computers and Structures, 79, 16.

CHANGA, J.-W., WANGB, W. \& KIMA, M.-S. 2010. Efficient collision detection using a dual OBB-sphere bounding volume hierarchy. Computer Aided Design, 42, 7.

DIEDER, S. \& BILES, W. E. 2014a. Application of Genetic Algorithm Approaches to Optimizing the Arrangement of Parts in a Rapid Prototyping Build.

DIEDER, S. \& BILES, W. E. 2014b. Applications of the Bin Packing Algorithm to Rapid Prototyping of Manufactured Parts.

DING, S., MANNAN, M. A. \& POO, A. N. 2004. Oriented bounding box and octree based global interference detection in 5-axis machining of free-form surfaces. Computer Aided Design, 36, 13.

DUFLOU, J. R., SUTHERLAND, J. W., DORNFELD, D., HERRMANN, C., JESWIET, J., KARI, S., HAUSCHILD, M. \& KELLENS, K. 2012. Towards energy and resource efficient manufacturing: A processes and systems approach. CIRP Annals - Manufacturing Technology, 61, 33.

EUSGELD, I. 2009. Design von Fehlertoleranten Systemen durch Genetische Algorithmen, Hagen, LiLoLe-Verlag $\mathrm{GmbH}$ (serving life-long learning).

FRANCO, A., LANZETTA, M. \& ROMOLI, L. 2010. Experimental analysis of selective laser sintering of polyamide powders: an ernergy perspective Journal of Cleaner Production, 18, 9.

GEBHARDT, A. 2004. Grundlagen des Rapid Prototyping. RTejournal, 1. 
GEBHARDT, A. 2007. Generative Fertigungsverfahren, München, Carl Hanser Verlag.GERDES, I., KLAWONN, F. \& KRUSE, R. 2004. Evolutionäre Algorithmen, Wiesbaden, Friedr. Vieweg + Sohn Verlage.

GIBSON, I., ROSEN, D. W. \& STUCKER, B. 2010. Additive Manufacturing Technologies, New York, Springer Science + Business.

GLANEMANN, U. DTM SLS Selektives Laser Sintern - Anwendungen, Entwicklungen und Trends [Online]. http://www.hsowl.de/fb7/uploads/media/1_SLS_Anwendungen_Entwicklungen_Glanemann.pdf.

HILLIER, F. S. \& LIEBERMAN, G. J. 2010. Introduction to Operations Research, New York, McGraw-Hill Companies, Inc.

HTTP://EN.WIKIPEDIA.ORG/WIKI/3D_PRINTING.

HTTP://EN.WIKIPEDIA.ORG/WIKI/BOUNDING_VOLUME.

HTTP://I.MATERIALISE.COM/MATERIALS.

HTTP://WWW.3DSYSTEMS.COM/NEWS/25TH-ANNIVERSARY/. Stereolithography [Online]. http://www.3dsystems.com/news/25th-anniversary/.

HTTP://WWW.ASTM.ORG/COMMITTEE/F42.HTM.

HTTP://WWW.ECONOLYST.CO.UK/RESOURCES/DOCUMENTS/FILES/REPORT $\% 20-\% 20 \mathrm{MARCH} \% 202008 \% 20$ -

\%20EAST\%20MIDLAMNDS\%20DEVELOPMENT\%20AGENCY\%20-

$\%$ 20EAST\%20MIDLANDS\%20RM\%20STRATEGY.PDF.

HTTP://WWW.GCEUROPE.COM/PRODUCTS/OP_IMPRESSION_TAKING.PHP. HTTP://WWW.ISO.ORG/ISO/STANDARDS_DEVELOPMENT/TECHNICAL_COM MITTEES/OTHER_BODIES/ISO_TECHNICAL_COMMITTEE.HTM?COMMI $\mathrm{D}=629086$.

HTTP://WWW.MATERIALISE.COM/ABOUT-MATERIALISE.

HTTP://WWW.MATHWORKS.COM/PRODUCTS/MATLAB/.

HTTP://WWW.PROTOTYPEPROS.COM/RAPID-PROTOTYPING/FUSEDDEPOSITION-MODELING.FDM/. Fused Deposition Modeling [Online]. http://www.prototypepros.com/rapid-prototyping/fused-depositionmodeling.fdm/.

HTTP://WWW.RM-

PLATFORM.COM/INDEX2.PHP?OPTION=COM_DOCMAN\&TASK=DOC VIEW\&GID=121\&ITEMID $=5$.

HTTP://WWW.SHAPEWAYS.COM/ABOUT.

HTTP://WWW.TWINKIND.COM/DE/PRODUCT.

HTTP://WWW.WIKIPEDIA.ORG. Stereolithography [Online]. http://WwW.wikipedia.org.

JUNK, S., SÄMANN-SUN, M. \& NIEDERHOFER. Application of 3D Printing for the Rapid Tooling of Thermoforming Moulds. Proceedings of the 36th International MATADOR Conference, 2010 London. Springer.

KIM, Y.-J., KIM, M.-S. \& ELBER, G. 2013. Precise convex hull computation for freeform models using a hierarchical Gauss map and a Coons bounding volume hierarchy. Computer Aided Design.

KRUTH, J. P., MERCELIS, P., FROYEN, L. \& ROMBOUTS, M. 2005a. Binding Mechanisms in Selective Laser Sintering and Selective Laser Melting. Rapid Prototyping Journal, 11, 11. 
KRUTH, J. P., VANDENBROUCKE, J., VAN VAERENBERGH, P. \& MERCELIS, P. Benchmarking Of Different SLS/SLM Processes As Rapid Manufacturing Techniques. Int. Conf. Polymers \& Moulds Innovations (PMI), April 20-23 2005b Gent, Belgium. 7.

LEVY, G. N., SCHINDEL, R. \& KRUTH, J. P. 2003. Rapid Manufacturing and Rapid Tooling with Layer Manufacturing (LM) Technologies, State of the Art and Future Perspectives. CIRP Annals - Manufacturing Technology, 52, 21.

MARLER, R. T. \& ARORA, J. S. 2004. Survey of milti-objective optimization methods for engineering. Struct Multidisc Optim, 26, 26.

PADHYE, N. \& DEB, K. 2011. Multi-objective optimization and multi-criteria decision making in SLS using evolutionary approaches. Rapid Prototyping Journal, 17, 20.

RUFFO, M., TUCK, C. \& HAGUE, R. 2006. Cost estimation for rapid manufacturing laser sintering production for low to medium volumes. IMechE, 230, 10.

TELENKO, C. \& CONNER SEEPERSAD, C. A Comparative Evaluation of Energy Consumption of Selective Laser Sintering and Injection Molding of Nylon Parts. Solid Freeform Fabrication Symposium, August 8-10 2011 Texas, USA. 13.

TUCK, C., HAGUE, R. \& BURNS, N. 2007. Rapid Manufacturing - Impact on Supply Chain Methodologies and Practice. International Journal of Services and Operations Management, 3, 22.

VON RIMSCHA, M. 2008. Algorithmen kompakt und verständlich, Wiesbaden, Vieweg + Teubner Verlag.

WANG, Y., HU, Y.-J., FAN, J.-C., ZHANG, Y.-F. \& ZHANG, Q.-J. 2012. Collision Detection Based on Bounding Box for NC Machining Simulation. Physics Procedia, 24, 5.

WOHLERS, T. \& GORNET, T. 2011. History of additive manufacturing. Wohlers Report 2011, 24.

YAN, X. \& GU, P. 1996. A review of rapid prototyping technologies and systems. Elsevier Computer Aided Design, 28, 9.

YAN, Y., LI, S., ZHANG, R., LIN, F., WU, R., LU, Q., XIONG, Z. \& WANG, X. 2009. Rapid Prototyping and Manufacturing Technology: Principle, Reprensentative Technics, Applications, and Development Trends. Tsinghua Science and Technology, 14, 12.

ZÄH, M. F. 2006. Wirtschaftliche Fertigung mit Rapid-Technologien, München, Wien, Carl Hanser Verlag.

ZAKARIA, K. \& DALGARNO, K. W. Influence of distortion on part accuracy of Indirect Metal Selective Laser Sintering. Proceedings of the 36th International MATADOR Conference, 2010 London. Springer. 


\section{APPENDIX A: Part Catalogue}

Nozzle

BBX 0,685”

BBY 0,704”

BBZ 0,233”

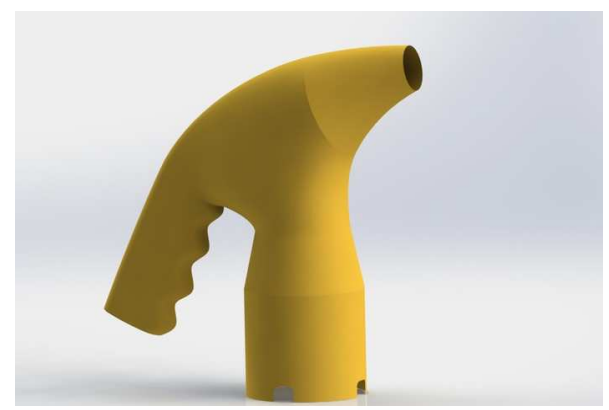

Shell Bottle

BBX 0,392”

BBY 0,841”

BBZ 0,141

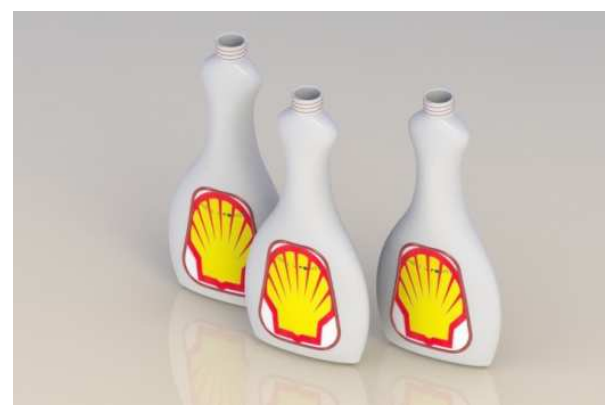

Hooke's Joint Assembly

Collar

Pin
BBX 0,170"

BBX 0,170”

BBY 0,041"

BBY 0,651"
BBZ 0,164”

BBZ 0,164” 
Locking Pin

Fork

Center Piece

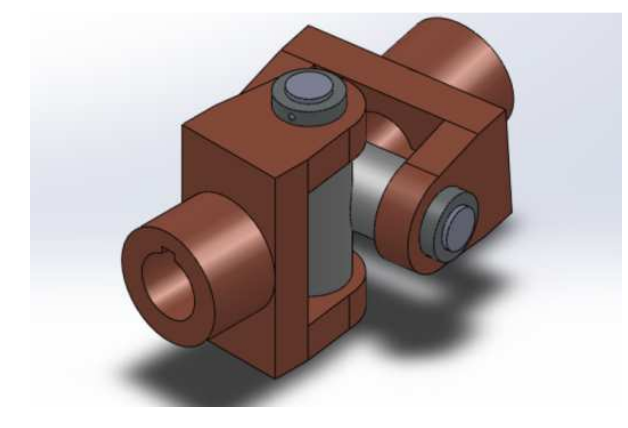

Clerget 9B 130 Cylinder

BBX 0,540”

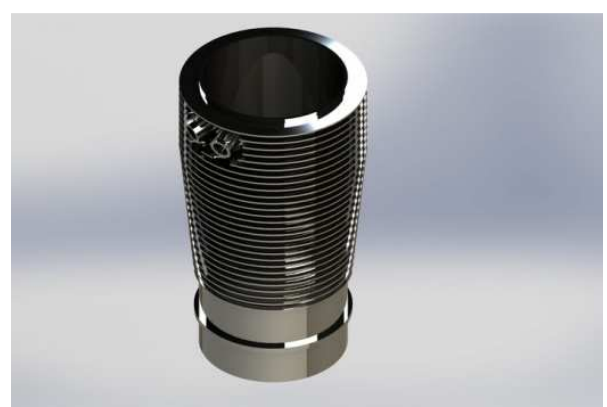

Clutch Plate

BBX 1,553"
BBY 0,017”

BBZ 0,164”

BBX 0,299”

BBX 0,326"

BBY 0,366"

BBZ 0,354"

\section{BBZ 0,536"}

\section{Clutch Plate}

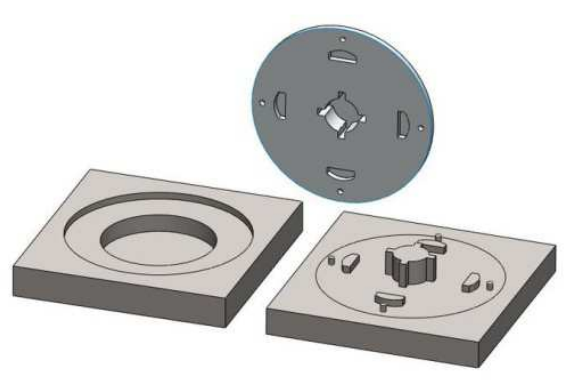

BBY 0,906”

BBZ 2,217” 


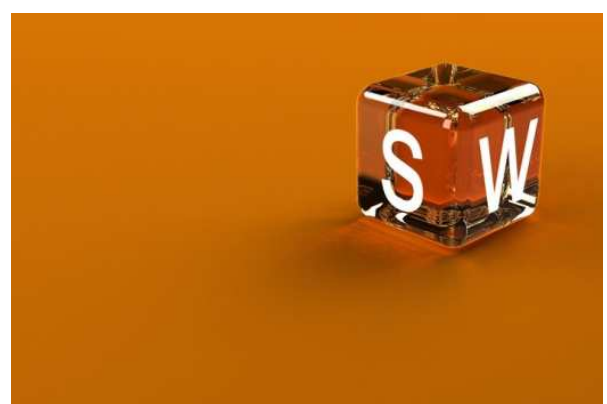

P-51 Throttle Quadrant

Cover

BBX 0,820"

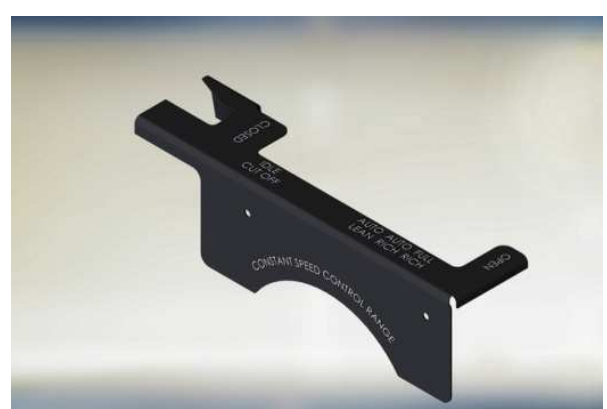

P-51 Landing Gear

Retract Hook

BBX 0,280”
BBY 0,240"

BBZ 0,207” 


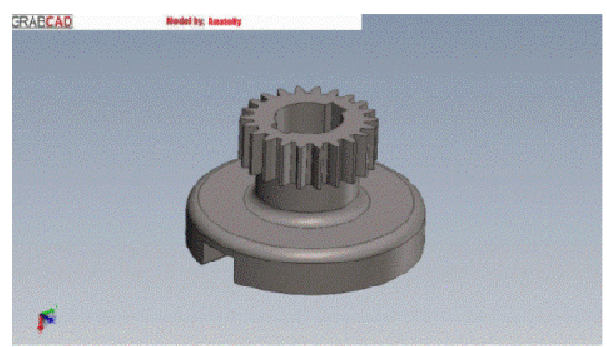

Engine 4 Cylinder

Tube 5

Hood

Flywheel

Tube 2

T Connection

Inverter

Chassis Quadruple

Ring

Axis

Flywheel 2

Tube 4
BBX 0,019”'

BBX 0,061"

BBX 0,095"

BBX 0,044"

BBX 0,044”

BBX 0,068”

BBX 0,217"

BBX 0,044"

BBX 0,017"

BBX 0,326"

BBX 1,333"
BBY 0,119”

BBZ 0,018”

BBY 0,041"

BBZ 0,005

BBY 0,058

BBZ 0,092"

BBY 0,078

BBZ 0,013”

BBY 0,020"

BBZ 0,016"

BBY 0,037”

BBZ 0,066"

BBY 0,081"

BBZ 0,184"

BBY 0,027"

BBZ 0,043"

BBY 0,115"

BBZ 0,016"

BBY 1,140"

BBZ 1,102”

BBY 1,713"
BBZ 0,717” 
Tube 3

Piston

Dowel

Panel

Spacer

Cylinder

Valve Cover

Arm

Axis $28 \mathrm{~mm}$

Assembly Inverter,

Arm Tube 1

Assembly Inverter

Arm Tube 2
Assembly Cylinder

Piston, Hood
BBX 0,860”

BBX 0,407”

BBX 0,163” ^

BBX 2,198"

BBX 1,832”

BBX 0,733”

BBX 0,651"

BBX 0,204"

BBX 0,204"

BBY 1,140"

BBY 0,232”

BBY 0,407"

BBY 0,489”

BBY 1,466"

BBZ 0,079"

BBY 0,814"

BBZ 0,236"

BBY 1,588”

BBZ 0,654”

BBY 0,163”

BBZ 0,630”

BBY 1,221"

BBZ 0,079”
BBZ 0,197”

BBY 1,425"

BBZ 0,216"

BBX 0,223”

BBY 1,425"

BBZ 0,216"

BBX 0,407”
BBY 0,407”

BBZ 1,969" 


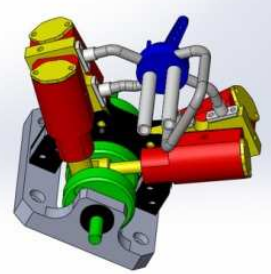

BBZ 8,465"

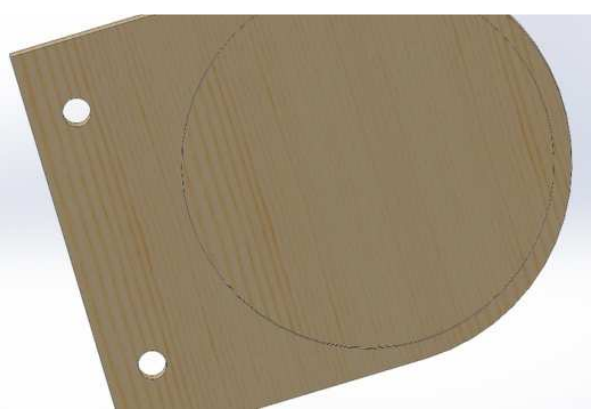

Wine Bottle Klein

BBX 13,900"

BBY 9,047"

BBZ 6,050”

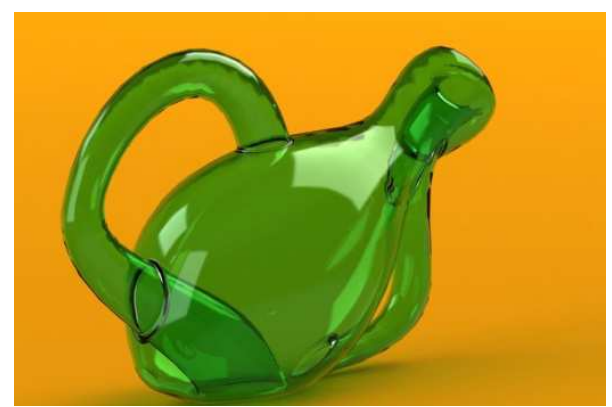


Braket

BBX 12,213"

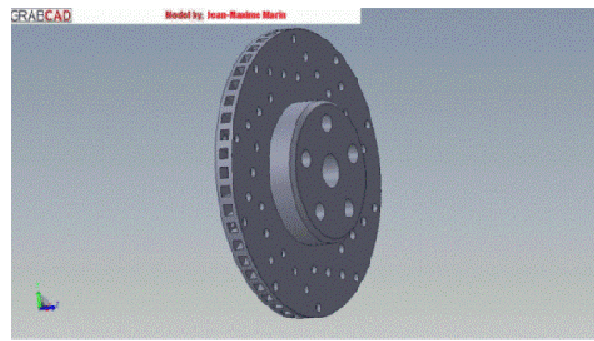

Grabcad Trophy

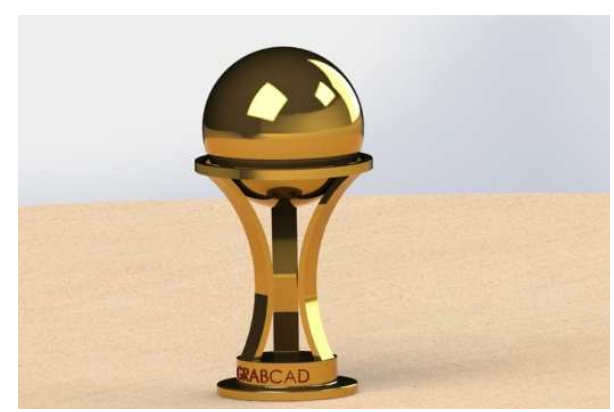

Klein Stein

BBX 3,460"

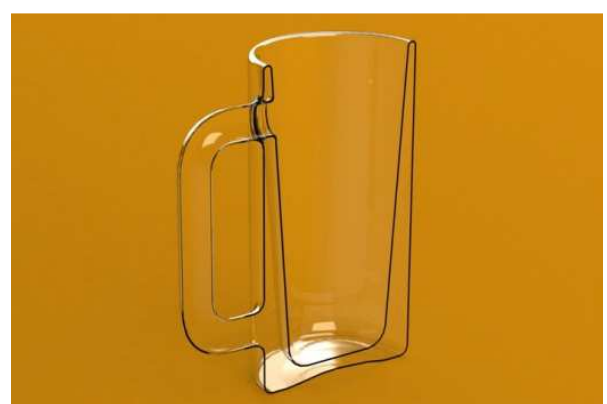

BBX 7,161"
BBY 12,213”

BBZ 2,362”

BBY 14,004"

BBZ 6,923”

BBY 6,513”

BBZ 5,059” 
Charger Hat iPhone

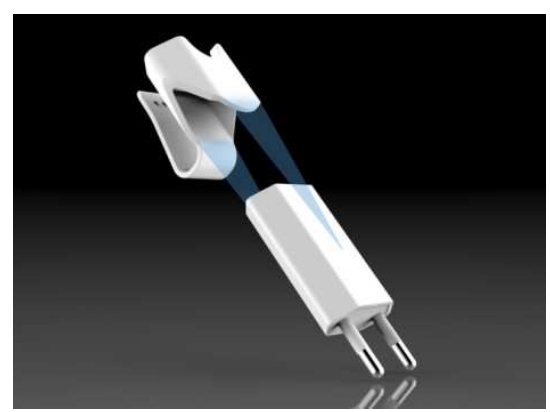

Apple iPod Shuffle

BBX 1,288”

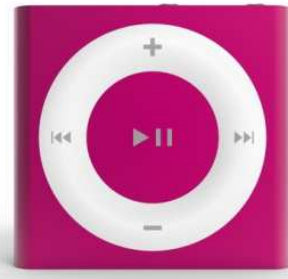

Clip

BBX 2,304”

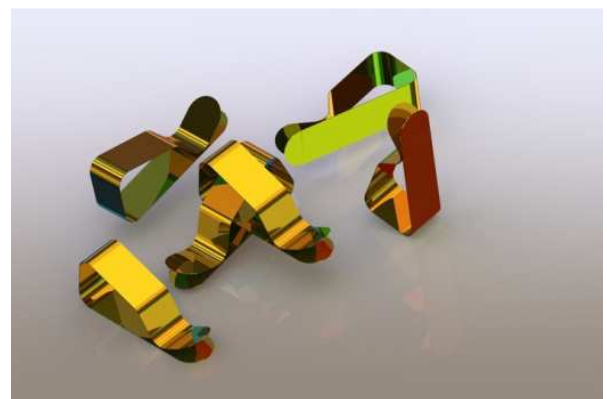

BBY 1,284”

BBZ 1,571”

BBY 1,204”

BBZ 0,344”

BBY 0,917”

BBZ 0,591" 
EOS UK Plug Fixer

BBX 1,580"

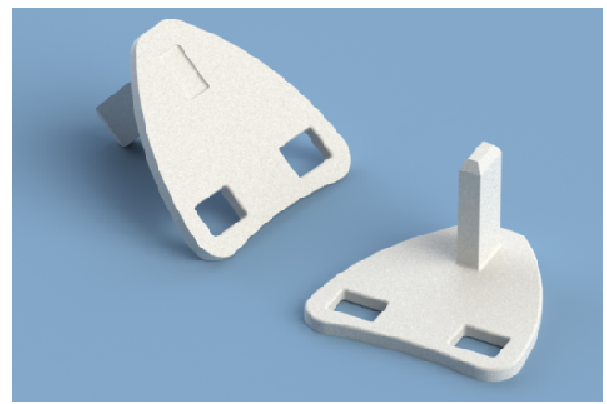

JBL Speaker

BBX 2,854“

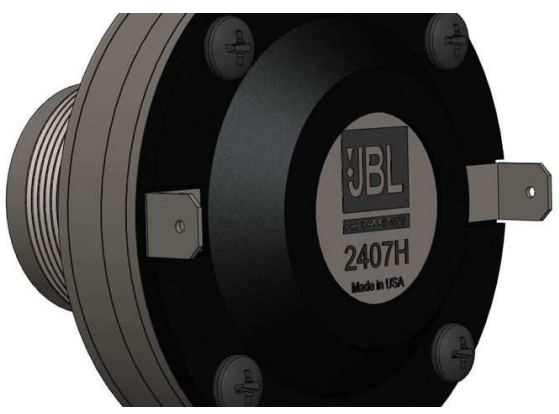

Inline Acustic Box

BBX 11,304““
BBY 0,946”

BBZ 1,512”

BBY 2,253“

BBZ 2,750““

BBY 16,501“

BBZ 10,589““

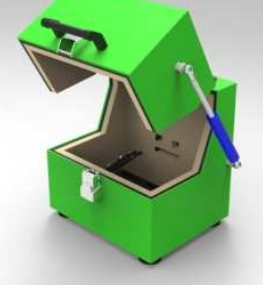


Piston Sample

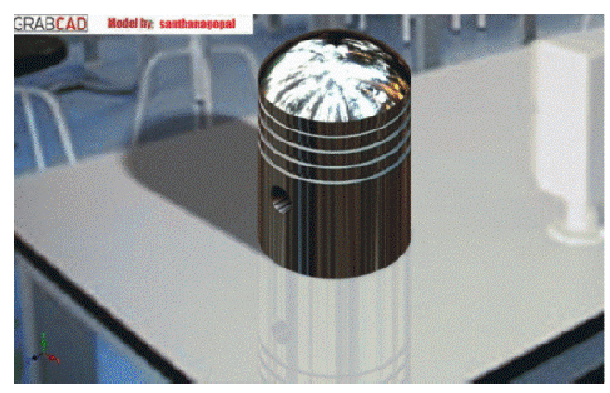

Cat Pumpkin

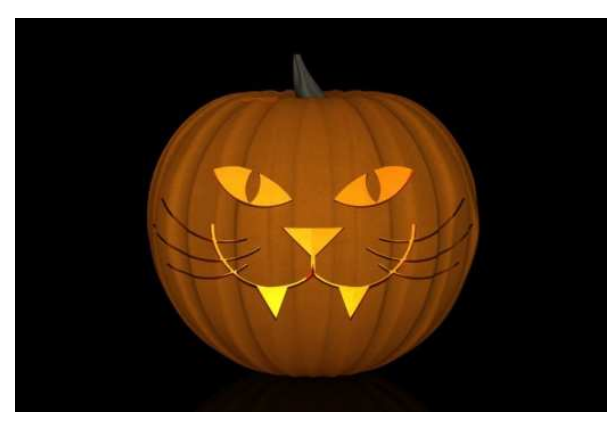

Logo Vietnam Electricity $\quad$ BBX 8,549“

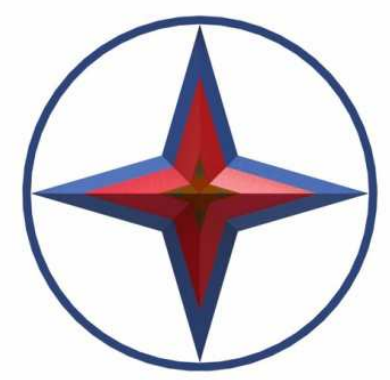

BBZ 1,575“
BBY 2,443““

BBX 11,828“

BBY 11,311“

BBZ 11,423““

BBY 1,547“

BBZ 8,268“ 
2 Euro

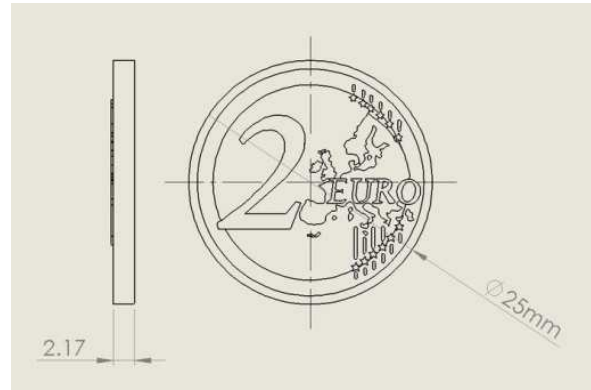

Chocolate Riddle

BBX 2,280“
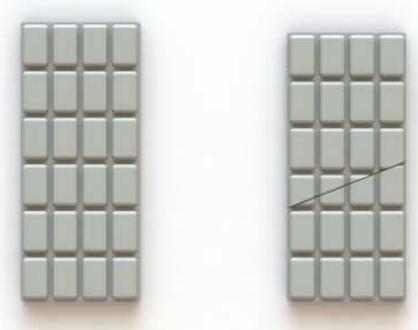

Battery Bracket

BBX 2,524“

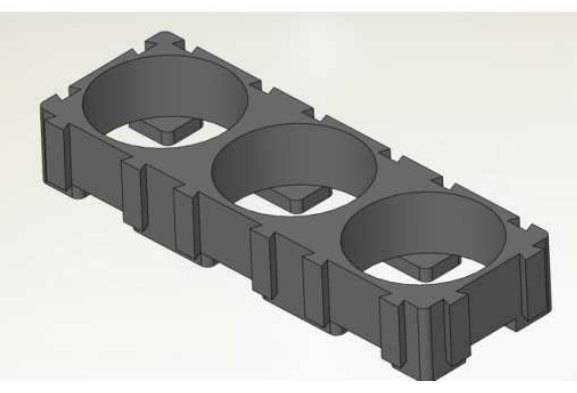

BBY 1,018““

BBZ 0,095“

BBY 0,305“

BBZ 5,197“

BBY 0,407“،

BBZ 0,850““ 


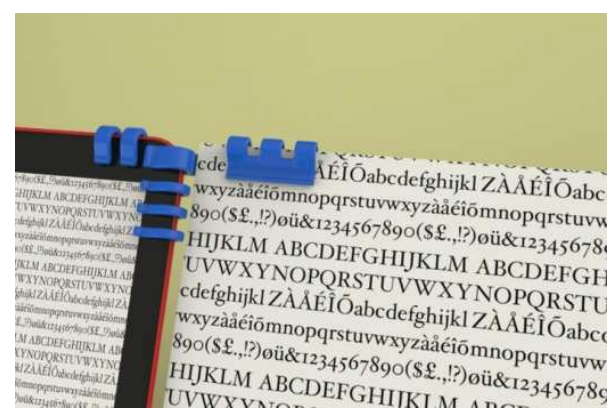

3M Stethoscope

BBX 11,322““

BBY 0,979““

BBZ 6,558“،

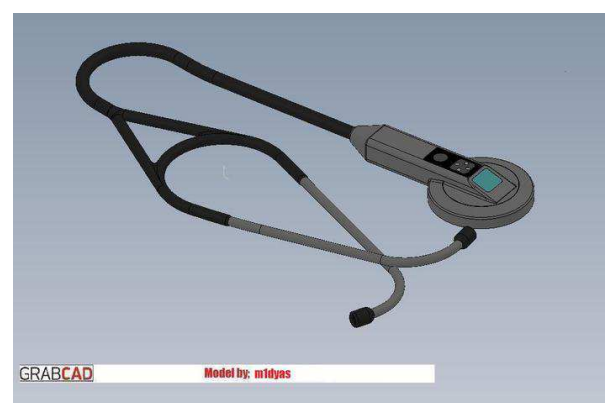

Traffic Light

BBX 2,496“

BBY 6,106““

BBZ 2,361“

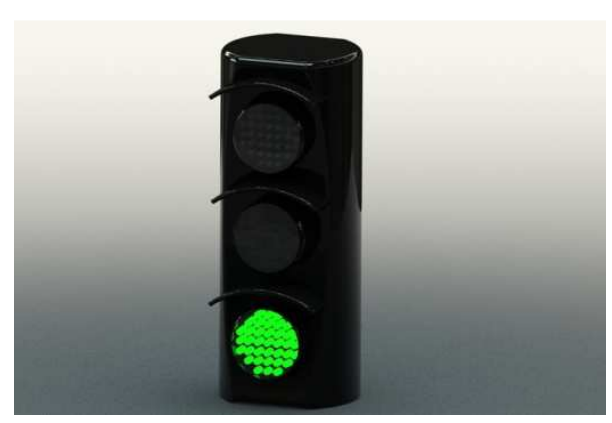


iPhone 5C

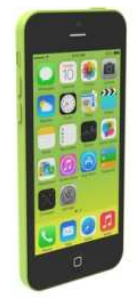

BBX 2,430“

BBY 5.089““

BBZ 0,353“،

BBZ 1,133“،

iPhone 4S Irig Case

BBX 3,816“"

BBY $4,858^{\prime “}$

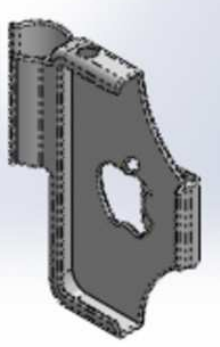

Apple Lightning Pin

Adapters

BBX 1,068“

BBY 1,080““

BBZ 0,222““

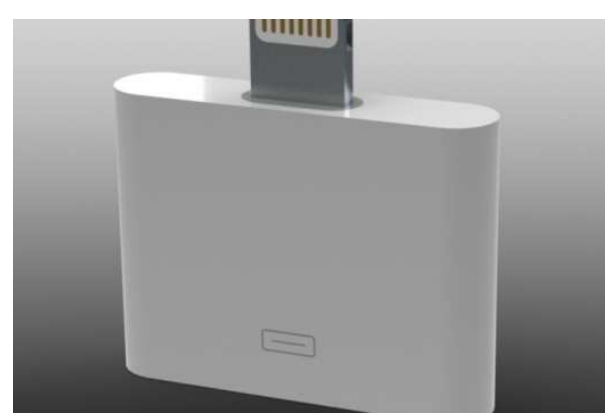




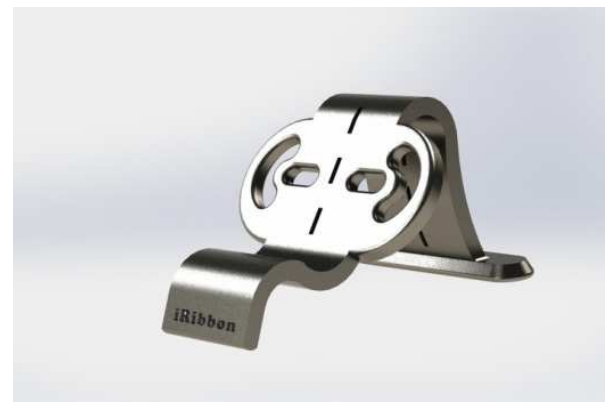

iShare

BBX 4,168“

BBY 1,018“

BBZ 0,551“

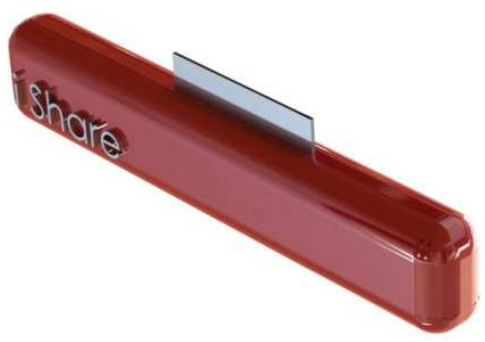

iPhone 5 Cover

BBX 2,791“

BBY 5,122“

BBZ 0,866“

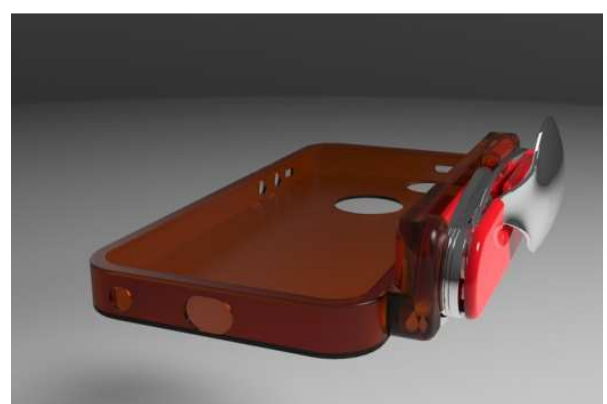



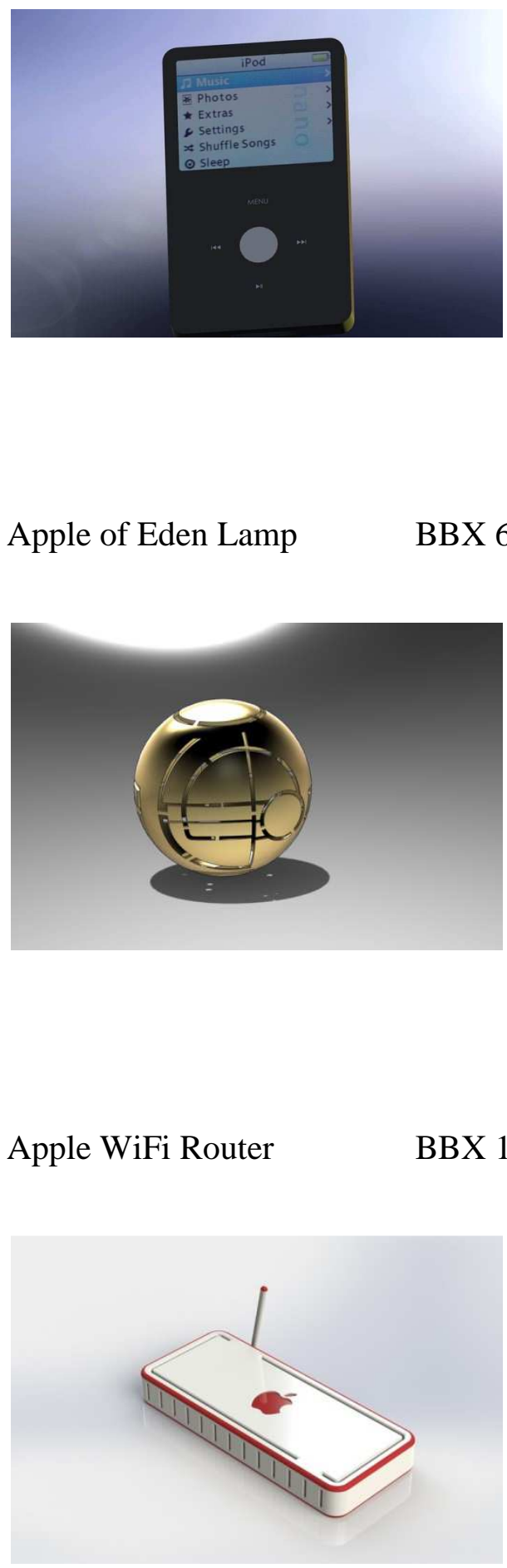
iPad Model

BBX 1,832““

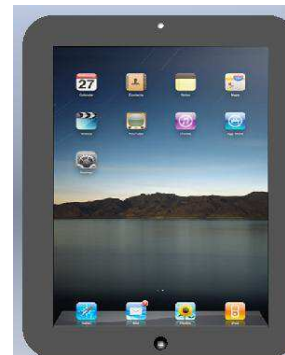

Speaker

BBX 4,485“

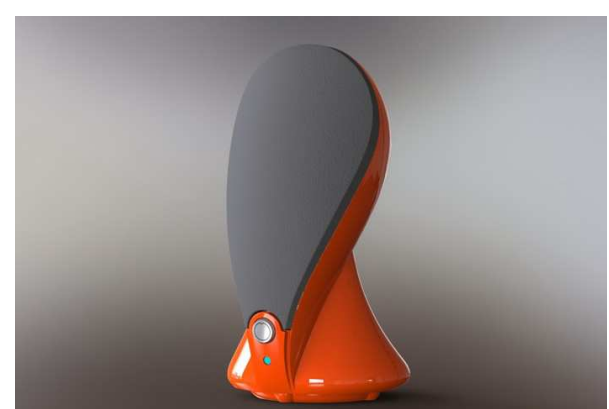

Playing Card

BBX 2,585“

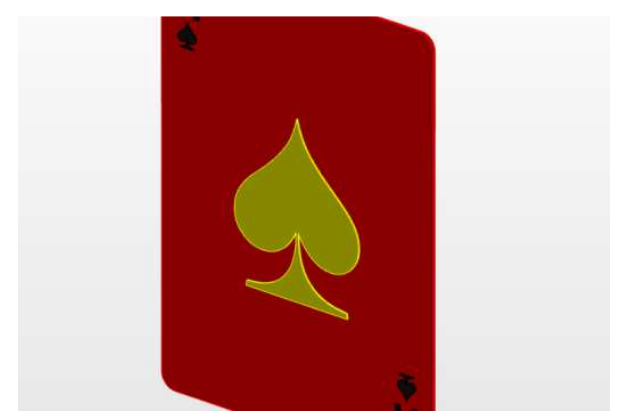

BBY 0,130““

BBZ 2,196“

BBZ 4,500“

BBY 8,386“

BBY 3,619“

BBZ 0,030““ 


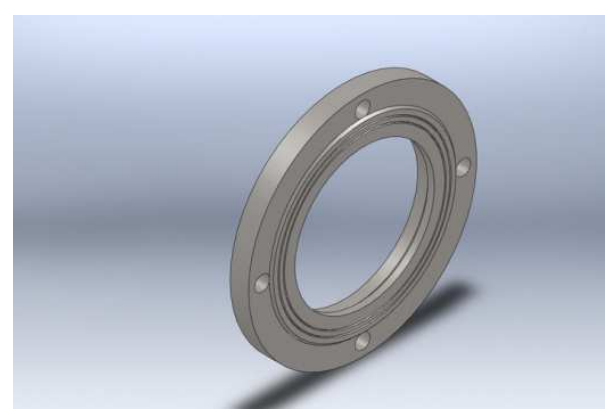

Clock

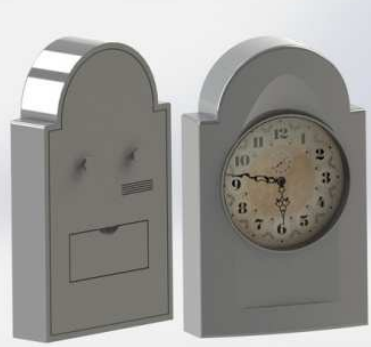


Edge Protector

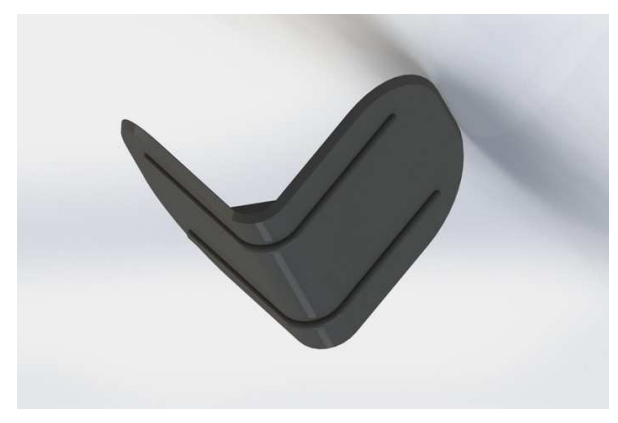

Soft Jaws - Full Wrap

BBX 12,211““

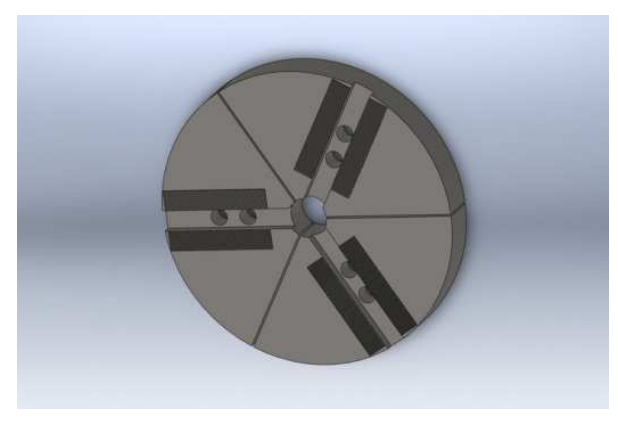

Rubber Stamp

BBX 4,067،

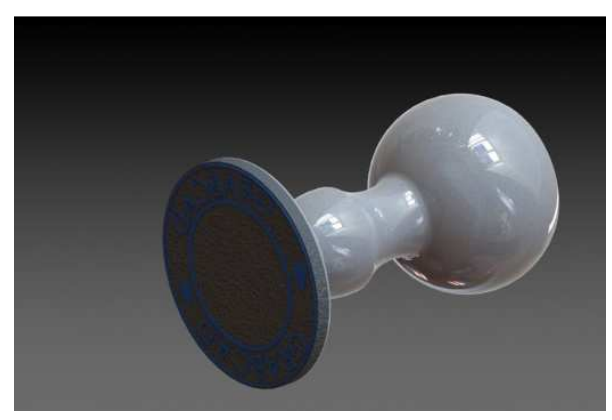

BBY 1,637““

BBZ 1,575“

BBY 1,710“

BBZ 11,811“

BBY 6,214““

BBZ 3,937“ 
USB Keychain Holder

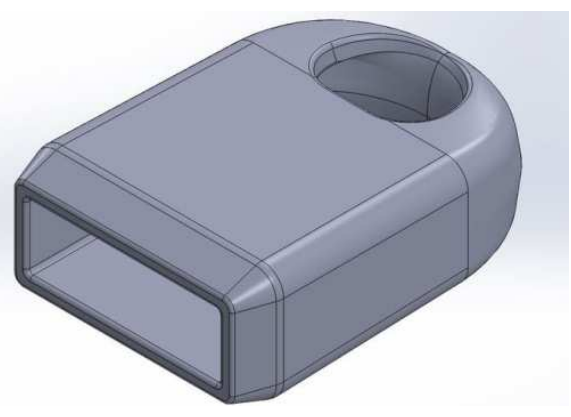

Junction Box

BBX 3,420“

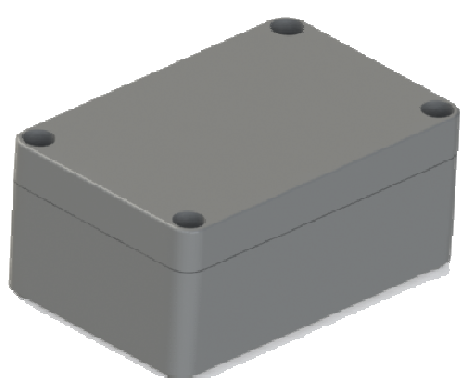

Engine Crankcase Covers $\quad$ BBX 2,972“

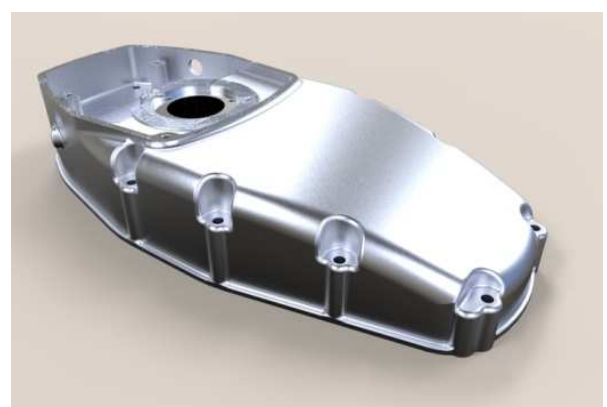

BBY 0,329““

BBZ 0,938“

BBY 2,353““

BBZ 5,039““

BBY 15,669““

BBZ 7,126“ 
Shaft and Guide Support

BBX 4,437““

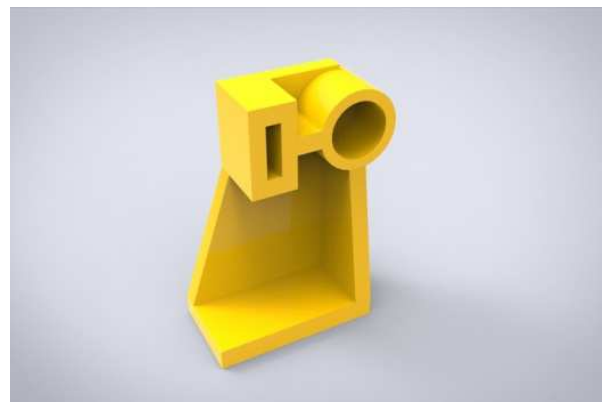

Mount for Maxon

Gearmotor

BBX 1,506“

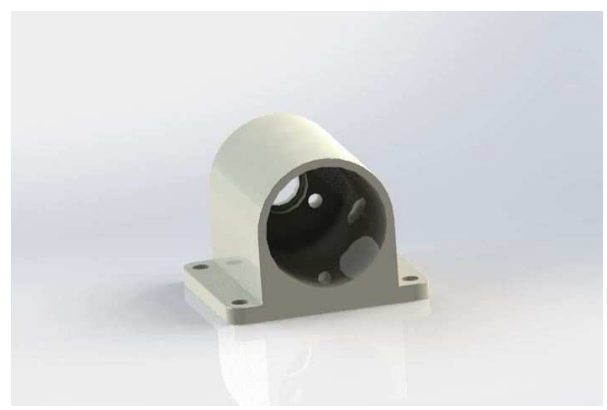

Face Mill

BBX 8,544“
BBY 5,618“

BBZ 2,008“

BBY 1,370“

BBZ 1,102“

BBY 8,537“

BBZ 2,223““

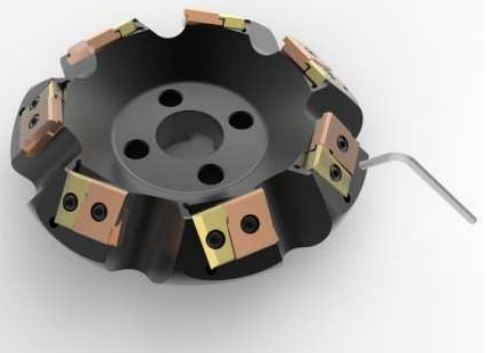


EMI Filter

BBX 2,378“

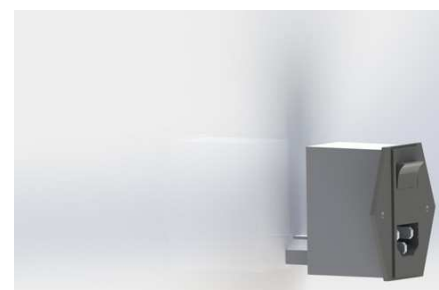

Sony PCM D50

BBX 3,318“،

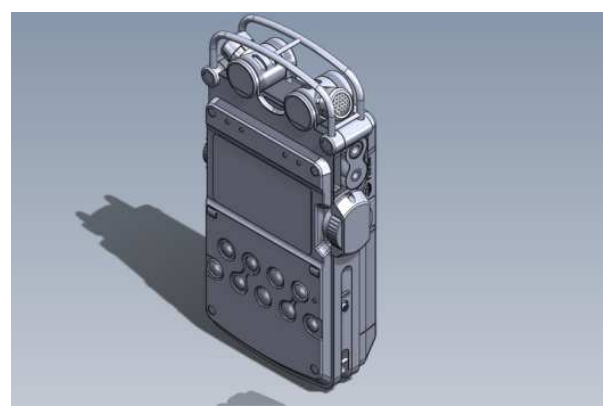

FPV Camera Turnigy 600 BBX 1,301“
BBY 2,497““

BBZ 1,900“
BBY 6,277““

BBZ 1,343“

BBY 1,233“

BBZ 1,159““

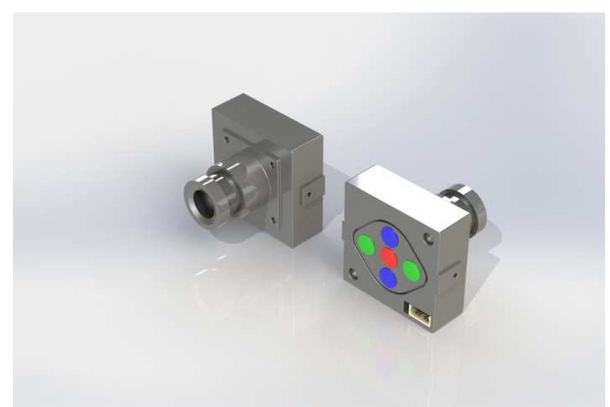


Grill for Stove

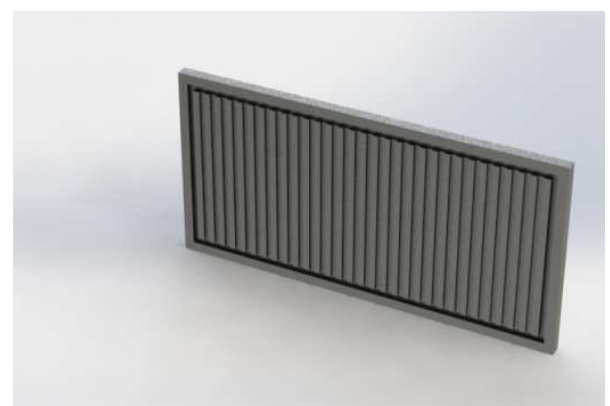

Engine Spoket

BBX 3,852““

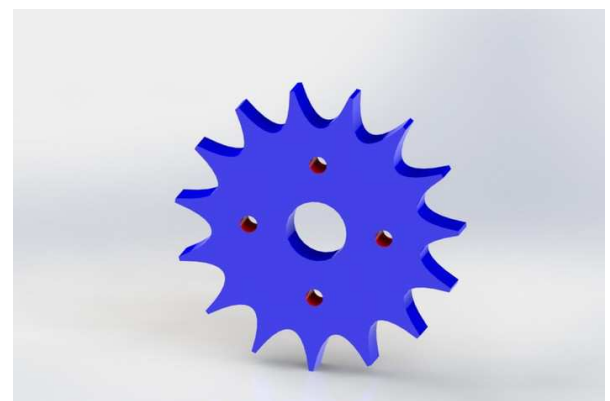

Sheet Metal Pipe

BBX 3,053“
BBY 8,142“

BBZ 0,472“

BBY 3,834“

BBZ 0,394““

BBY 3.053“

BBZ 11,811“

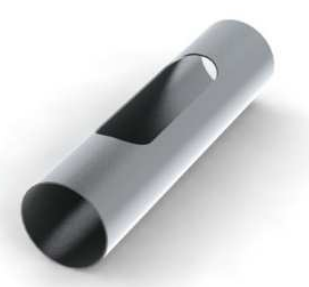


Electric Eel Eurosocket

BBX 12,886“

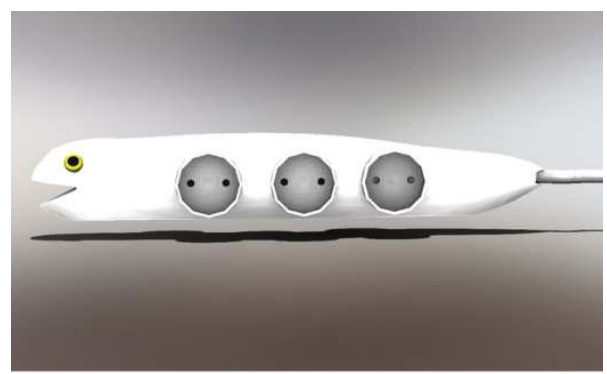

Ship's Propeller

BBX 9,189“

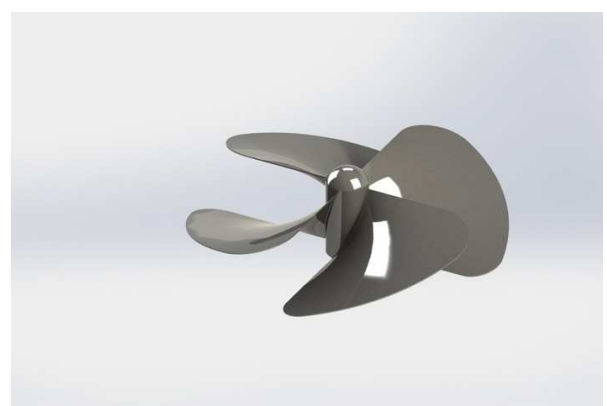

Can Cover

BBX 2,401“
BBY 1,851““

BBZ 1,459““

BBY 2,768“

BBZ 8,887“

BBY 0,326“

BBZ 2,322“

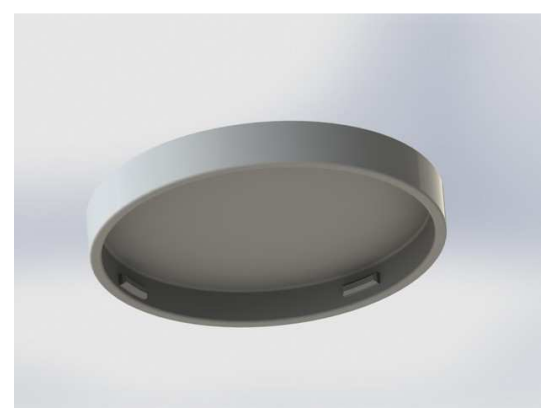



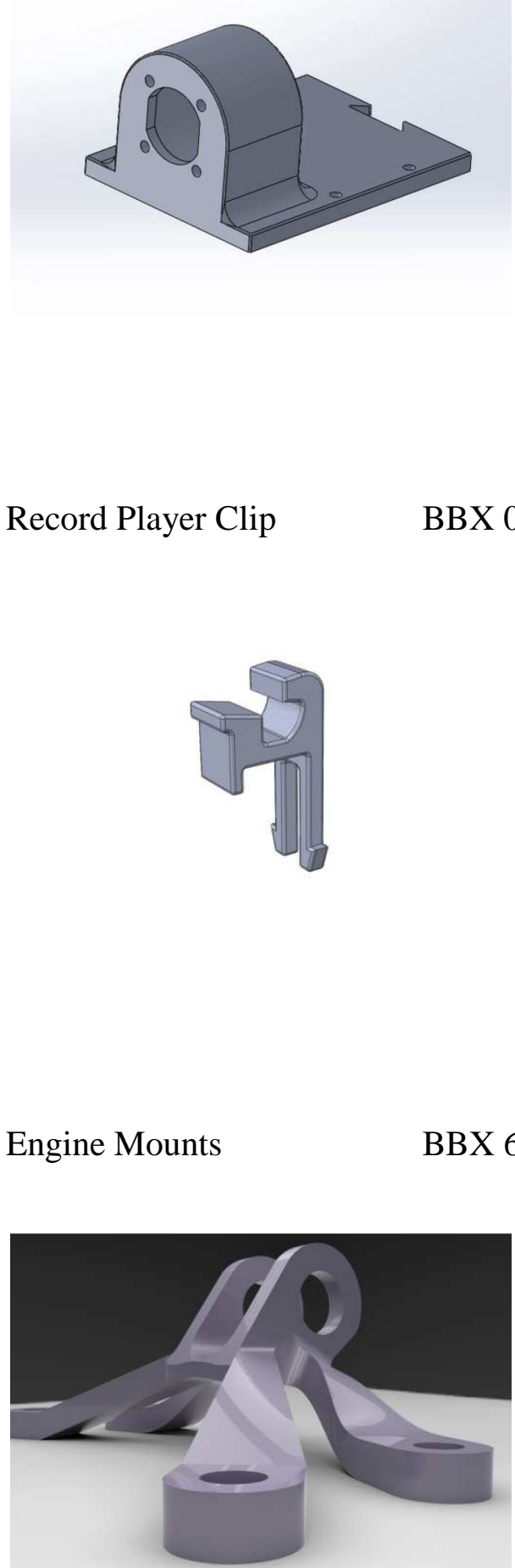

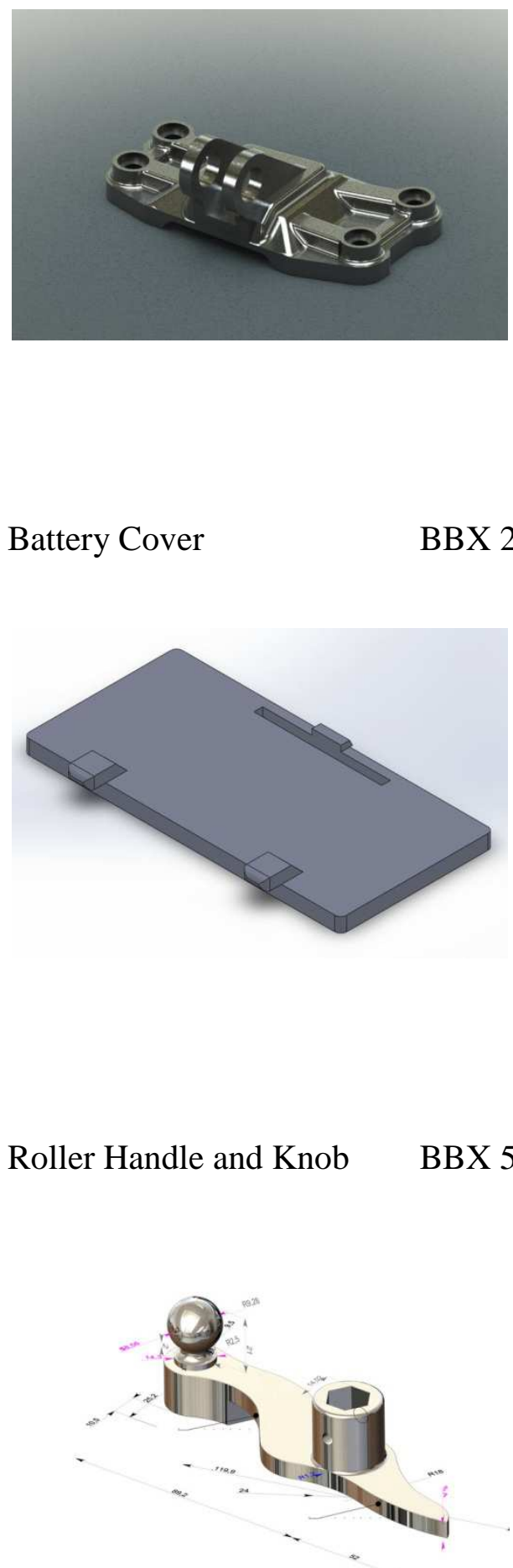


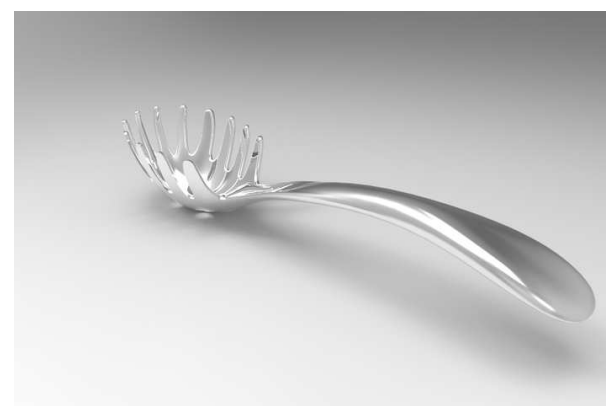

Pivot Guide

BBX 7,309“

BBY 4,375“

BBZ 3,543“

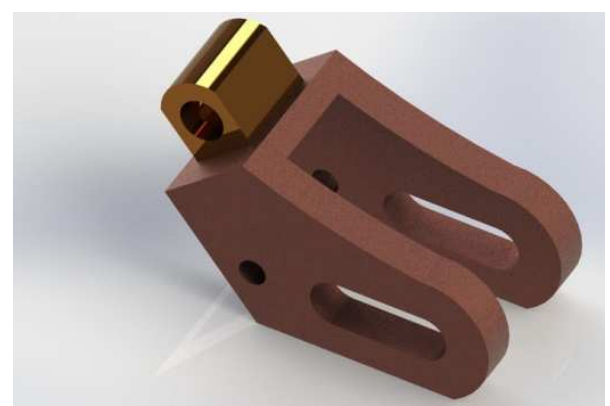

Rotate Drill for the Dentist BBX 5,638"

BBY 0,407”

BBZ 2,087”

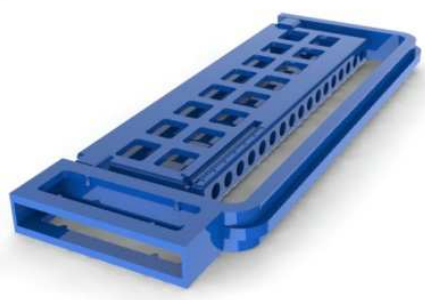



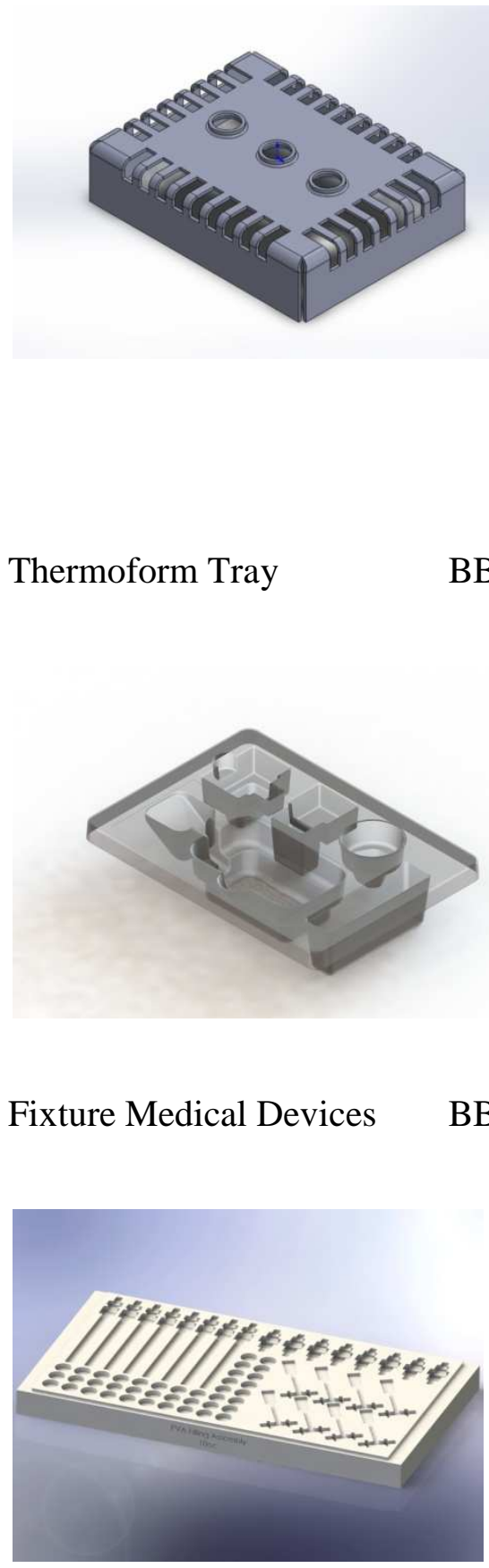
Electrical Box

BBX 8,796"

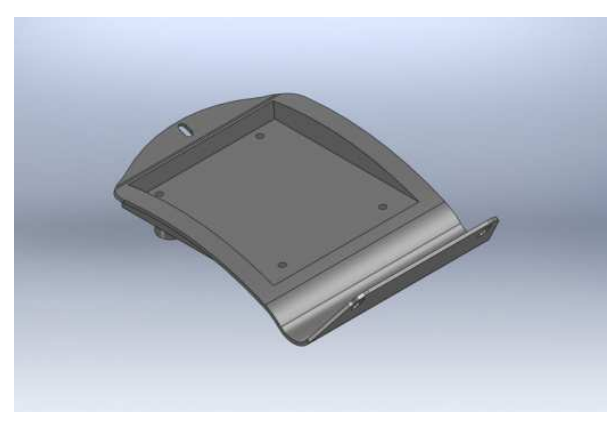

Medicine Spoon

BBX 10,205"

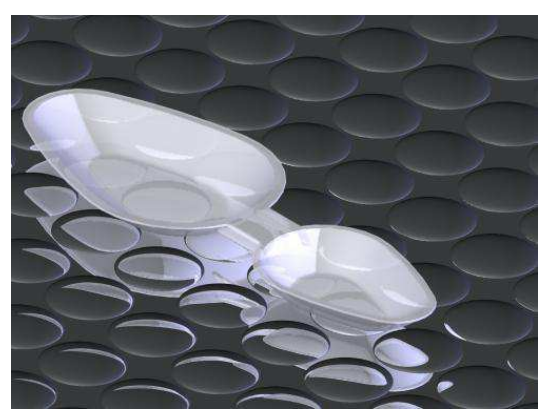

Walking Stick Handle

BBX 9,037"

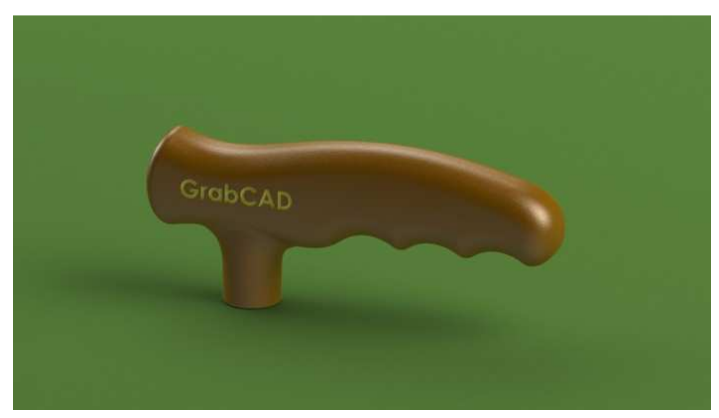

BBY 1,876"

BBZ 6,025"

BBY 0,724"

BBZ 3,739”

BBY 3,769”'

BBZ 1,445" 

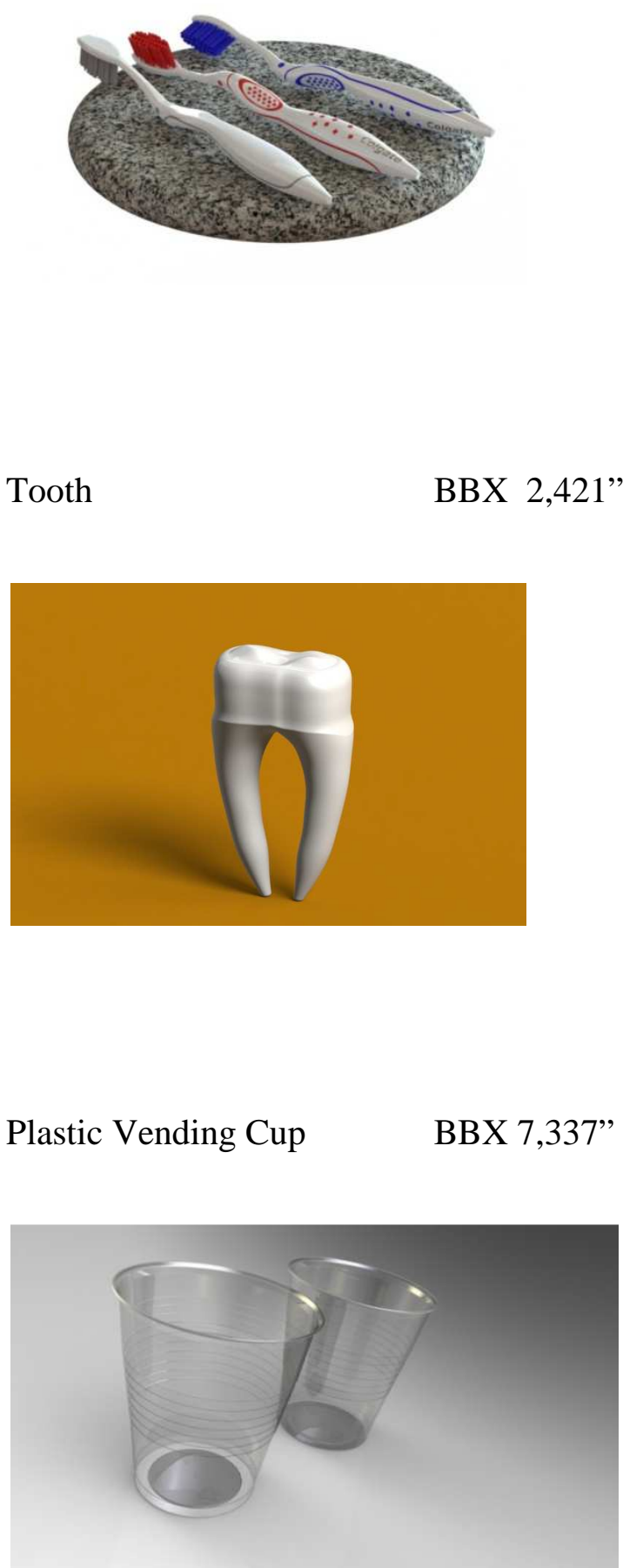


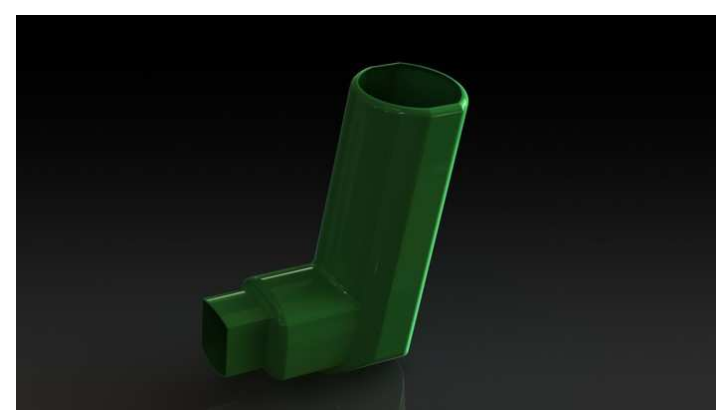

Impression Tray

BBX 2,384”

BBY 0,766”

BBZ 2,886"

(http://www.gceurope.com/products/op_impression_taking.php)

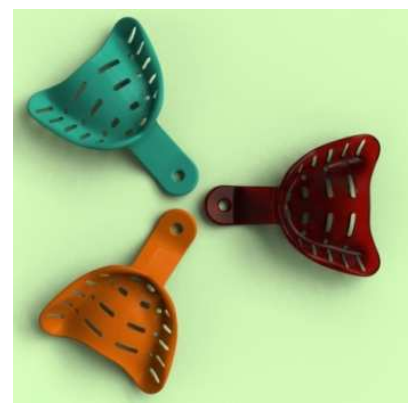

The Solid Works Model for the Impression Tray was done by Joe Vicar, Laser Development Engineer from the University of Louisville.

Carotid Bifurcation

BBX 0,002”

BBY 0,001"

BBZ 0,006” 

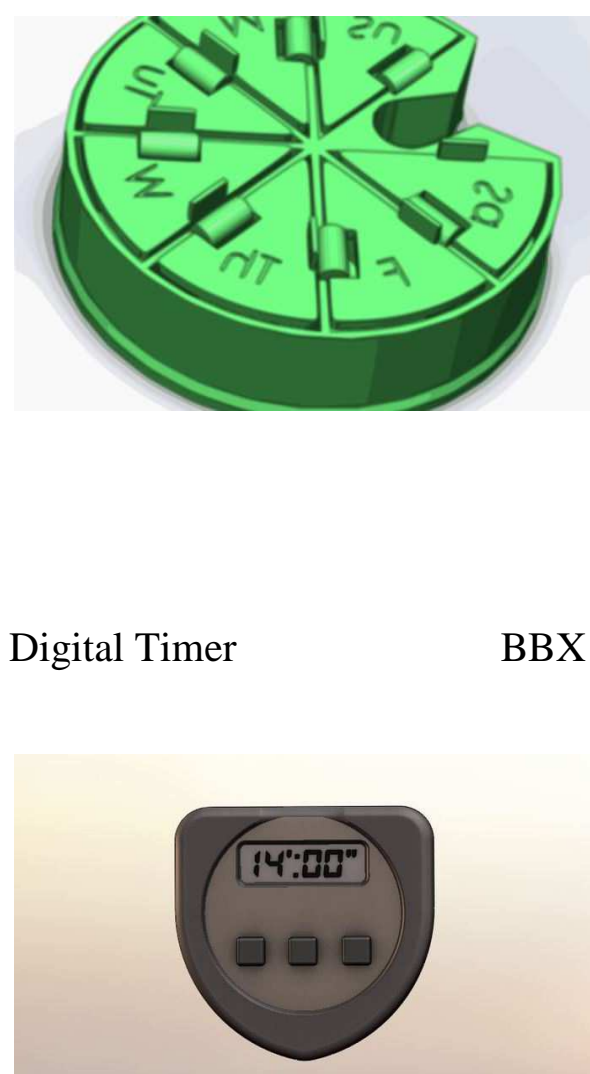

Ferrule, Clamp Tool

BBX 2,051"

BBY 2,051”

BBZ 1,750”

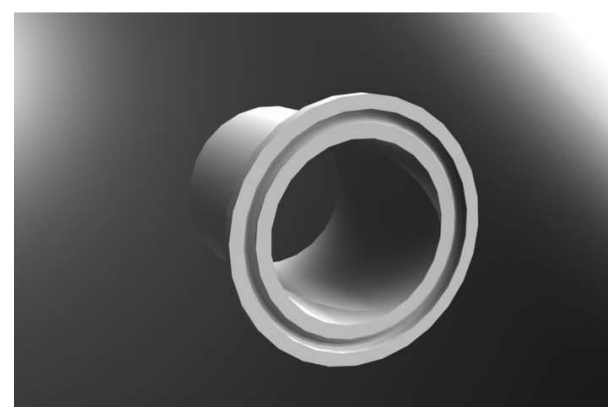


Zigbee

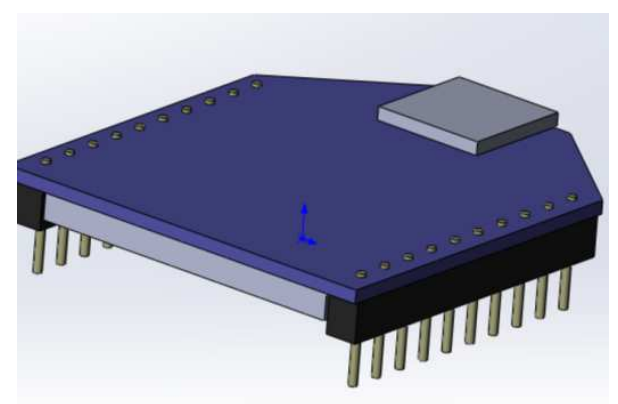

LCD TV

BBX 4,798”

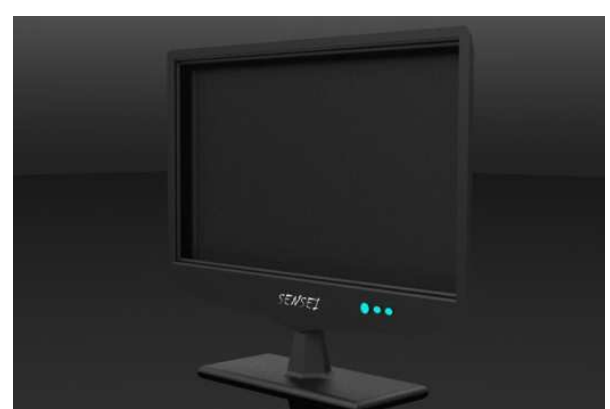

CD Writer Case

BBX 5,943”
BBY 0,289”

BBZ 1.098"
BBY 3,949”

BBZ 1,153

BBY 1,774”

BBZ 5,900”

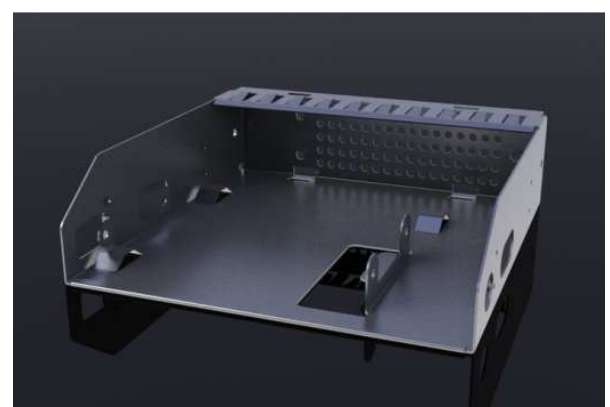


Roof Hook

BBX 3,827"

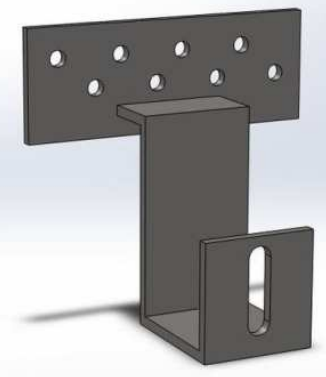

BBY 5,659”

BBZ 5,669”'

BBY 1,692"

BBZ 7,625"

Portable Stove

BBX 8,541"

BBZ 7,625"

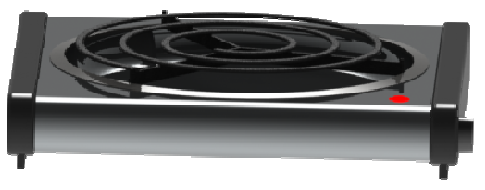

DVD Burner

BBX 6,961"

BBY 1,677”

BBZ 5,756"

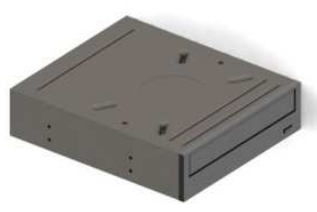


Plate

BBX 6,690"

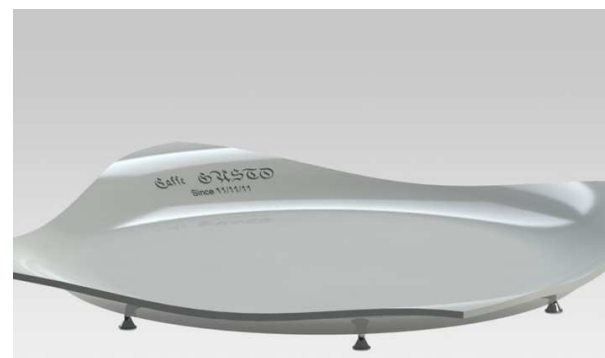

Motherboard Adapter Plate BBX 7,735“

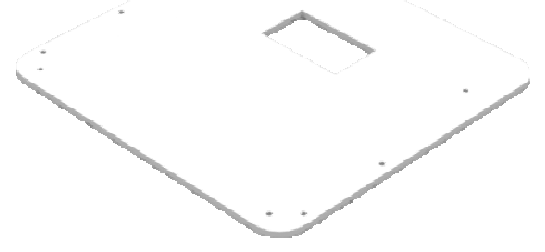

Bottom Plate

BBX 3,989“

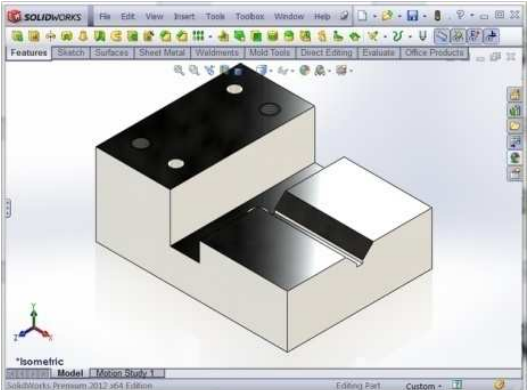

BBY 0,770”

BBZ 6,470”

BBY 0,129““

BBZ 7,150“

BBY 1,710“

BBZ 2,913““ 

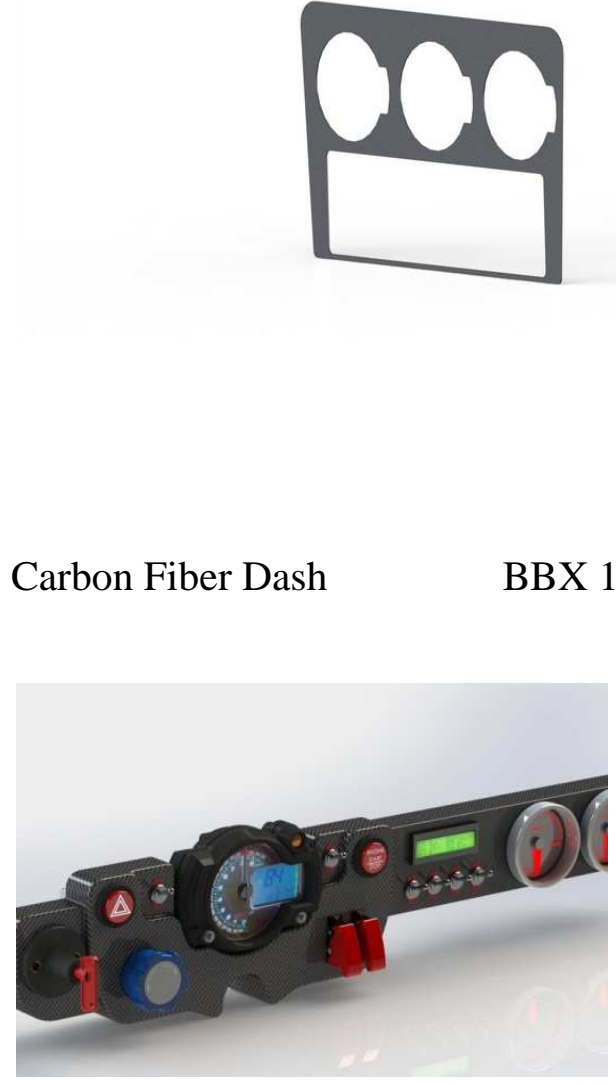

Excluded the mouth tray all photos and models were adapted from grabcad.com. 


\section{APPENDIX B: MATLAB GA for Bin Packing}

\section{ga_2d_box_packing.m}

$\%$ main box sizes:

$\mathrm{a}=2$;

$\mathrm{b}=1$;

$\mathrm{Nb}=30 ; \%$ number of boxes

$\%$ random boxes sizes:

$\operatorname{mab}=\operatorname{mean}([\mathrm{a} b]) ;$

$\mathrm{aa}=0.05 * \mathrm{mab}+0.3 * \mathrm{mab} * \operatorname{rand}(1, \mathrm{Nb})$;

$\mathrm{bb}=0.05 * \mathrm{mab}+0.3 * \mathrm{mab} * \operatorname{rand}(1, \mathrm{Nb})$;

$\mathrm{m} 2=\min ([\mathrm{aa} b \mathrm{~b}] / 2) ; \%$ smallest half-size

$\mathrm{AA}=\mathrm{aa} . * \mathrm{bb} ; \%$ boxes areas 
penalty $=0.2 * a * b$;

nac $=0.8 ; \%$ negative area coefficient

$\mathrm{N}=500 ; \%$ population size

ng $=5000 ; \%$ number of generations

pmpe $=0.05 ; \%$ places exchange mutation probability

$\mathrm{pmbj}=0.01 ; \%$ big gauss jump

pmsj $=0.02 ; \%$ small gauss jump

pmrr $=0.05 ; \%$ random rotation

pmvi $=0.05 ; \%$ random visible/invisible

pmne $=0.1 ; \%$ move to nearest adge

figure;

$\%$ ha1=axes;

ha1=subplot $(2,1,1)$;

$\operatorname{plot}\left(\left[\begin{array}{llll}0 & \text { a a } & 0 & 0\end{array}\right],\left[\begin{array}{lllll}0 & 0 & \text { b b } & 0\end{array}\right],{ }^{\prime}\right.$-');

$\operatorname{xlim}([-0.1 * \mathrm{a} 1.1 * \mathrm{a}])$

$\operatorname{ylim}([-0.1 * \mathrm{~b} 1.1 * \mathrm{~b}])$; 
set(ha1,'NextPlot','add');

ht=title(ha1,'start');

ha2=subplot $(2,1,2)$;

drawnow;

set_cl; \% set color table cl to plot boxes with different colors

$\%$ random initial population:

$\mathrm{G}=\mathrm{zeros}\left(\mathrm{N}, 4^{*} \mathrm{Nb}\right)$;

$\mathrm{Gch}=\mathrm{zeros}(\mathrm{N}, 4 * \mathrm{Nb}) ; \%$ children

for $\mathrm{Nc}=1: \mathrm{N} \%$ for each individual

$\mathrm{G} 1=\mathrm{zeros}(4, \mathrm{Nb}) ; \%$ one individual

$\% \mathrm{G} 1(1, \mathrm{i})=1$ if $\mathrm{i}-\mathrm{box}$ is visible

$\% \mathrm{G} 1(2, \mathrm{i})=1$ if $\mathrm{i}$-box is rotated at 90 degrees

$\% \mathrm{G1}(3, \mathrm{i})$ - x-coordinate of i-box center

$\% \mathrm{G} 1(4, \mathrm{i})$ - y-coordinate of i-box center

$\mathrm{G} 1(1,:)=\operatorname{double}(\operatorname{rand}(1, \mathrm{Nb})<0.2)$; 
$\mathrm{G} 1(2,:)=\operatorname{double}(\operatorname{rand}(1, \mathrm{Nb})<0.5)$;

$\mathrm{G} 1(3,:)=\mathrm{m} 2+(\mathrm{a}-\mathrm{m} 2) * \operatorname{rand}(1, \mathrm{Nb})$;

$\mathrm{G} 1(4,:)=\mathrm{m} 2+(\mathrm{b}-\mathrm{m} 2) * \operatorname{rand}(1, \mathrm{Nb})$;

$\left.\mathrm{G}(\mathrm{Nc},:)=(\mathrm{G} 1(:))^{\prime} ; \%(\mathrm{G} 1(:))\right)^{\prime}$ converts matrix to row-vector

end

hi=imagesc(G,'parent',ha2);

drawnow;

Gpr1=zeros $(4, \mathrm{Nb})$;

Gpr2=zeros $(4, \mathrm{Nb}) ; \%$ two parents

$\operatorname{Gch} 1=\operatorname{zeros}(4, \mathrm{Nb})$;

Gch2=zeros $(4, \mathrm{Nb}) ; \%$ two children

for $n g c=1:$ ng $\%$ generations counting

$\%$ find fitnesses:

fitnesses=zeros $(\mathrm{N}, 1)$; 
for $\mathrm{Nc}=1: \mathrm{N} \%$ for each individual

$$
\mathrm{G} 1(:)=(\mathrm{G}(\mathrm{Nc},:)))^{\prime}
$$

$$
\begin{aligned}
& \text { vis }=\mathrm{G} 1(1,:) ; \\
& \text { ind=find( } \text { vis); } \\
& \mathrm{L}=\text { length(ind); } \\
& \text { if } \mathrm{L}>0 \\
& \% \\
& \text { rot }=\mathrm{G} 1(2, \mathrm{ind}) ; \\
& \mathrm{x}=\mathrm{G} 1(3, \text { ind }) ; \\
& \mathrm{y}=\mathrm{G} 1(4, \mathrm{ind}) ; \\
& \text { if } \mathrm{L}==1
\end{aligned}
$$

aaa=aa(ind);

$\mathrm{bbb}=\mathrm{bb}($ ind $)$;

$$
\text { if rot }
$$

tmp=aaa;

aaa=bbb;

$\mathrm{bbb}=\mathrm{tmp}$;

$$
\text { end }
$$


$\mathrm{A} 0=\mathrm{AA}(\mathrm{ind}) ; \%$ box area

$\mathrm{x} 1=\max ([\mathrm{x}-\mathrm{aaa} / 20])$;

$\mathrm{y} 1=\max ([\mathrm{y}-\mathrm{bbb} / 20]) ;$

$\mathrm{x} 2=\min ([\mathrm{x}+\mathrm{aaa} / 2 \mathrm{a}]) ;$

$\mathrm{y} 2=\min ([y+b b b / 2 b])$

$\% \mathrm{x} 1-\mathrm{x} 2, \mathrm{y} 1-\mathrm{y} 2$ is box (part of current box) that inside main box

if $(\mathrm{x} 1>=\mathrm{x} 2) \|(\mathrm{y} 1>=\mathrm{y} 2)$

$\mathrm{A}=0 ; \%$ box that inside main box area

else

$\mathrm{A}=(\mathrm{x} 2-\mathrm{x} 1)^{*}(\mathrm{y} 2-\mathrm{y} 1) ; \%$ box that inside main box area

end

$\%$ if $\mathrm{A}<\mathrm{A} 0 \%$ if not fully inside main box

if $(\mathrm{aaa} / 2<=\mathrm{x}) \& \&(\mathrm{x}<=\mathrm{a}-\mathrm{aaa} / 2) \& \&(\mathrm{bbb} / 2<=\mathrm{y}) \& \&(\mathrm{y}<=\mathrm{b}-\mathrm{bbb} / 2) \%$ if filly inside

fitness $=\mathrm{A}$;

else

fitness=A-nac*(A0-A)-penalty;

end

else 


\section{fitness $=0$;}

ispen=false; $\%$ true if penality

$\%$ check cross with main box:

$\%$ add boxes arreas and strong subtract out areas:

for $n=1: L \%$ for each box

$$
\text { ind } 1=\operatorname{ind}(n) \text {; }
$$

aaa=aa(ind1);

$\mathrm{bbb}=\mathrm{bb}($ ind 1$)$;

$$
\text { if } \operatorname{rot}(n)
$$

tmp=aaa;

$\mathrm{aaa}=\mathrm{bbb}$

$\mathrm{bbb}=\mathrm{tmp}$

end

$\mathrm{A} 0=\mathrm{AA}($ ind 1$) ; \%$ box area

$\mathrm{x} 1=\max ([\mathrm{x}(\mathrm{n})-\mathrm{aaa} / 20])$;

$\mathrm{y} 1=\max ([\mathrm{y}(\mathrm{n})-\mathrm{bbb} / 20])$;

$x 2=\min ([x(n)+a a a / 2 a]) ;$ 


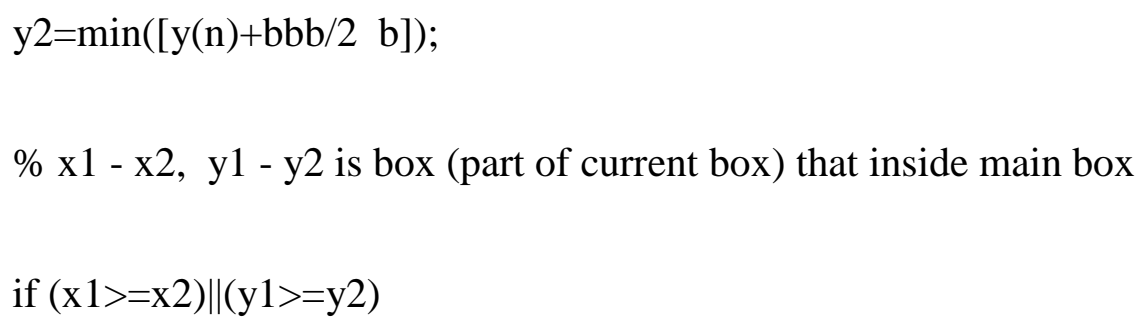




\section{fitness=fitness + A-nac*(A0-A);}

ispen=true; $\%$ penality

end

end

$\%$ for each pair of boxes:

for $\mathrm{n} 1=1: \mathrm{L}-1$

ind $1=\operatorname{ind}(\mathrm{n} 1)$;

aaa1=aa(ind1);

bbb1=bb(ind 1$)$;

if $\operatorname{rot}(\mathrm{n} 1)$

tmp=aaa1;

$$
\begin{aligned}
& \text { aaa1=bbb1; } \\
& \text { bbb1=tmp; }
\end{aligned}
$$

end

$\mathrm{A} 1=\mathrm{AA}($ ind 1$)$;

$\mathrm{x} 1=\mathrm{x}(\mathrm{n} 1)$ 


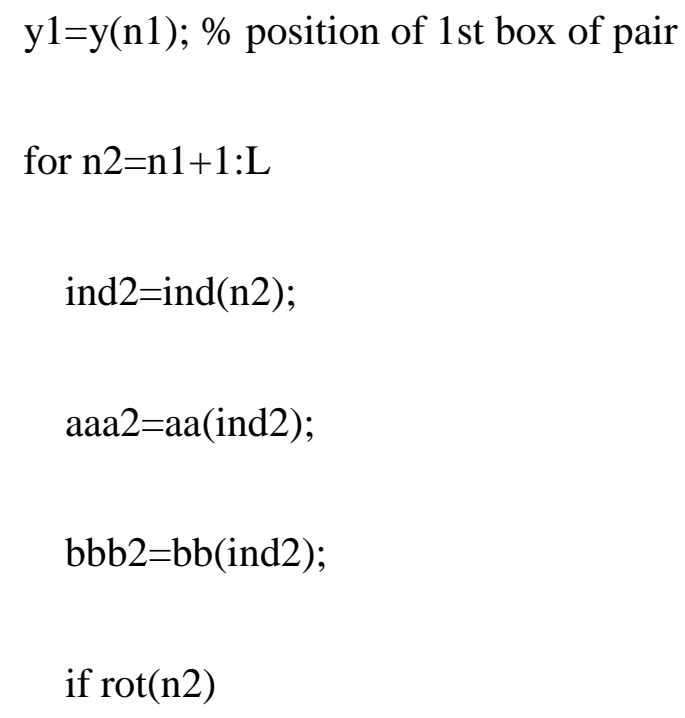


ispen=true;

$A c=(a 12-d x) *(b 12-d y) ; \%$ area of cross

fitness $=$ fitness-Ac-Ac; $\%$ becuse area of $n 1$ and $n 2$ was added fully

fitness $=$ fitness $-2 *$ nac $*$ Ac;

end

end

end

if ispen

fitness=fitness-penalty;

end

end

else

fitness $=0$;

end

fitnesses $(\mathrm{Nc})=$ fitness; 
end

$[\mathrm{fb}$ bi $]=\max ($ fitnesses $) ; \%$ best

$\%$ plot best:

$\mathrm{G} 1(:)=(\mathrm{G}(\mathrm{bi},:)))^{\prime}$;

$\mathrm{Gb}=\mathrm{G}(\mathrm{bi}, \mathrm{:}) ; \%$ best

if $\bmod (n g c, 10)==0$

cla(ha1);

Atmp=0;

for $\mathrm{Nbc}=1: \mathrm{Nb}$

vis1 $=\mathrm{G} 1(1, \mathrm{Nbc})$;

if vis1

$\operatorname{rot} 1=\mathrm{G} 1(2, \mathrm{Nbc})$;

$\mathrm{aaa}=\mathrm{aa}(\mathrm{Nbc})$;

$\mathrm{bbb}=\mathrm{bb}(\mathrm{Nbc})$;

if rot1

tmp=aaa; 


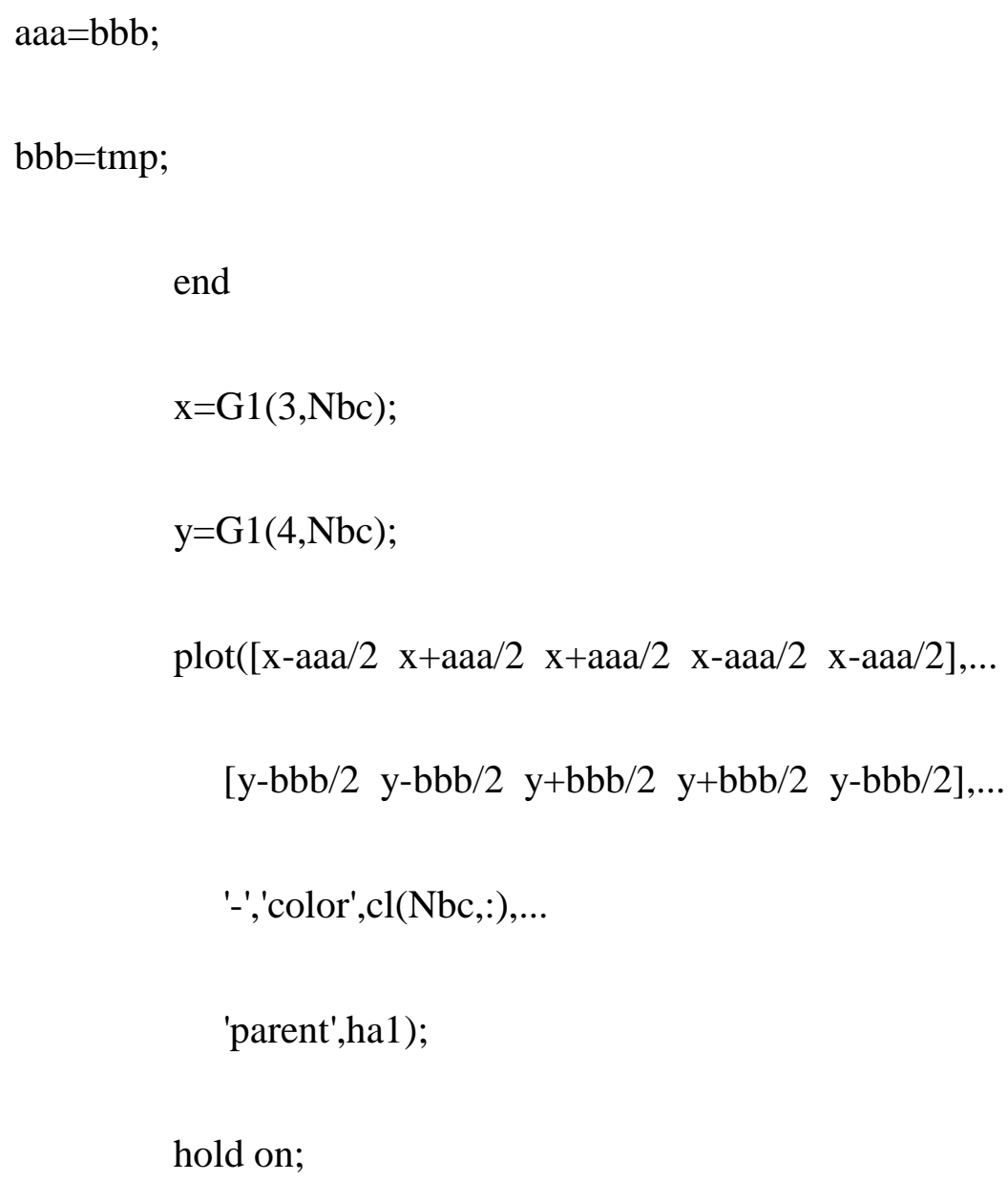


$n v b=$ length(find $(\mathrm{G} 1(1,:)))$; \% number of visible boxes

set(ht,'string',[' generation: ' num2str(ngc) ', boxes: ' num2str(nvb) ', area: ' num2str(fb)]);

drawnow;

end

$\%$ prepare for crossover, selection:

fmn=min(fitnesses);

fst=std(fitnesses);

if fst $<1 \mathrm{e}-7$

fst $=1 \mathrm{e}-7$;

end

$\mathrm{fmn} 1=\mathrm{fmn}-0.01 * \mathrm{fst} ; \%$ little low then minimum

$\mathrm{P}=\mathrm{fitnesses}-\mathrm{fmn} 1 ; \%$ positive values

$\mathrm{p}=\mathrm{P} / \mathrm{sum}(\mathrm{P}) ; \%$ probabilities 
ii=roulette_wheel_indexes(N,p);

$\mathrm{Gp}=\mathrm{G}(\mathrm{ii},:) ; \%$ parents

$\%$ crossover:

for $n=1: 2: \mathrm{N}$

$\operatorname{pr} 1=\mathrm{Gp}(\mathrm{n},:) ;$

pr2=Gp(n+1,:); \% two parents

$\%$ in matrix form:

$\operatorname{Gpr1}(:)=\operatorname{pr} 1 ' ;$

Gpr2(:)=pr2';

for $\mathrm{Nbc}=1: \mathrm{Nb}$

$\%$ visibility:

if rand $<0.5$

$\operatorname{Gch} 1(1, N b c)=\operatorname{Gpr} 1(1, \mathrm{Nbc})$;

else

$\operatorname{Gch} 1(1, N b c)=\operatorname{Gpr} 2(1, \mathrm{Nbc})$; 


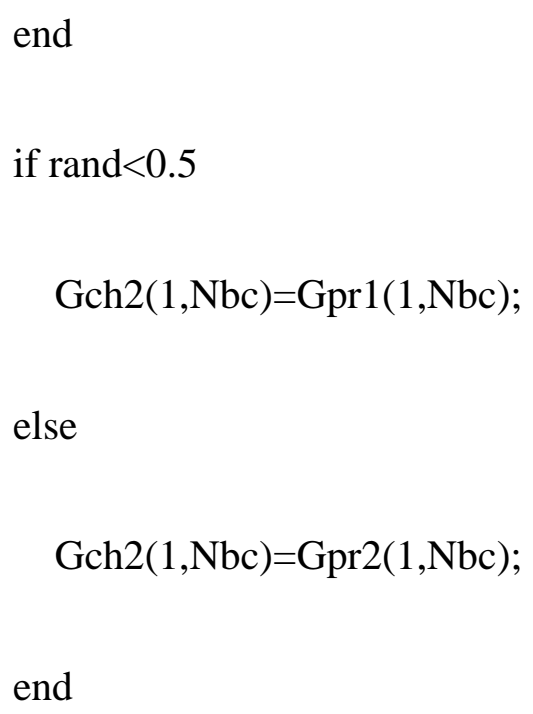


$\%$ position:

$\%$ child 1 :

$\%$ i3=ceil $(3 *$ rand $)$;

$\%$ i3=roulette_wheel_indexes(1,[0.2 0.4 0.4] $)$;

$\mathrm{i} 3=1+\operatorname{ceil}(2 *$ rand $)$;

switch i3

case $1 \%$ get mean position

$\operatorname{Gch} 1(3, \mathrm{Nbc})=(\operatorname{Gpr} 1(3, \mathrm{Nbc})+\mathrm{Gpr} 2(3, \mathrm{Nbc})) / 2 ;$

$\operatorname{Gch} 1(4, N b c)=(\operatorname{Gpr} 1(4, N b c)+\mathrm{Gpr} 2(4, \mathrm{Nbc})) / 2$;

case $2 \%$ get position of parent 1

$\operatorname{Gch} 1(3, \mathrm{Nbc})=\mathrm{Gpr} 1(3, \mathrm{Nbc})$

$\operatorname{Gch} 1(4, \mathrm{Nbc})=\mathrm{Gpr} 1(4, \mathrm{Nbc})$

case $3 \%$ get position of parent 2

$\operatorname{Gch} 1(3, \mathrm{Nbc})=\mathrm{Gpr} 2(3, \mathrm{Nbc})$

$\operatorname{Gch} 1(4, \mathrm{Nbc})=\mathrm{Gpr} 2(4, \mathrm{Nbc})$

end

$\%$ child 2 : 


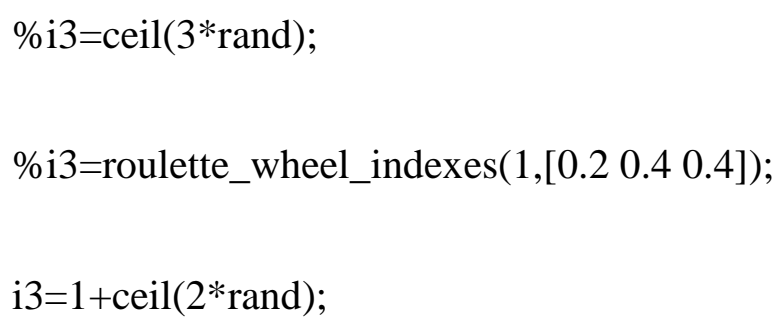




\section{$\operatorname{Gch}(n,:)=\operatorname{ch} 1$; \\ $\operatorname{Gch}(n+1,:)=\operatorname{ch} 2$;}

end

$\mathrm{G}=\mathrm{Gch} ; \%$ now children

$\%$ mutations:

$\%$ places exchange

for $\mathrm{Nc}=1: \mathrm{N} \%$ for each individual

if rand<pmpe

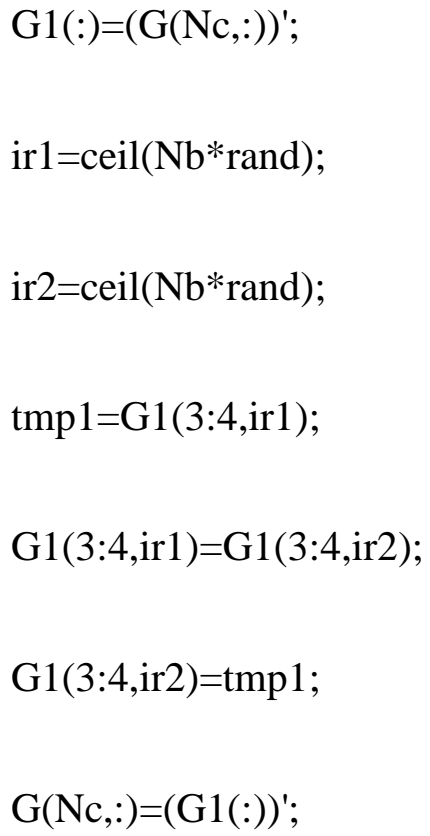

end 
end

$\%$ big gauss jump:

for $\mathrm{Nc}=1: \mathrm{N} \%$ for each individual

if rand $<\mathrm{pmbj}$

$$
\mathrm{G} 1(:)=(\mathrm{G}(\mathrm{Nc},:))^{\prime}
$$

$\operatorname{ir}=\operatorname{ceil}\left(\mathrm{Nb}^{*}\right.$ rand $)$;

$\mathrm{G} 1(3: 4, \mathrm{ir})=\mathrm{G} 1(3: 4, \mathrm{ir})+[0.05 * \mathrm{a} * \mathrm{randn}$;

$0.05 * \mathrm{~b} *$ randn];

$\mathrm{G}(\mathrm{Nc},:)=(\mathrm{G} 1(:))^{\prime}$;

end

end

$\%$ small gauss jump:

for $\mathrm{Nc}=1: \mathrm{N} \%$ for each individual

if rand $<$ pmsj

$\mathrm{G} 1(:)=(\mathrm{G}(\mathrm{Nc},:)){ }^{\prime}$

$\operatorname{ir}=\operatorname{ceil}\left(\mathrm{Nb}^{*}\right.$ rand $)$; 
$\mathrm{G} 1(3: 4, \mathrm{ir})=\mathrm{G} 1(3: 4, \mathrm{ir})+[0.005 * \mathrm{a} * \mathrm{randn}$;

$0.005 * b *$ randn];

$\mathrm{G}(\mathrm{Nc},:)=(\mathrm{G} 1(:))^{\prime}$

end

end

$\%$ random rotation:

for $\mathrm{Nc}=1: \mathrm{N} \%$ for each individual

if rand<pmrr

$\mathrm{G} 1(:)=(\mathrm{G}(\mathrm{Nc},:))^{\prime}$;

$\mathrm{ir}=\operatorname{ceil}(\mathrm{Nb} *$ rand $)$;

$\mathrm{G} 1(2$, ir $)=$ double $($ rand $<0.5)$;

$\mathrm{G}(\mathrm{Nc},:)=(\mathrm{G} 1(:))^{\prime}$

end

end

$\%$ random visible/invisible:

for $\mathrm{Nc}=1: \mathrm{N} \%$ for each individual

if rand<pmvi

$\mathrm{G} 1(:)=(\mathrm{G}(\mathrm{Nc},:))^{\prime}$; 


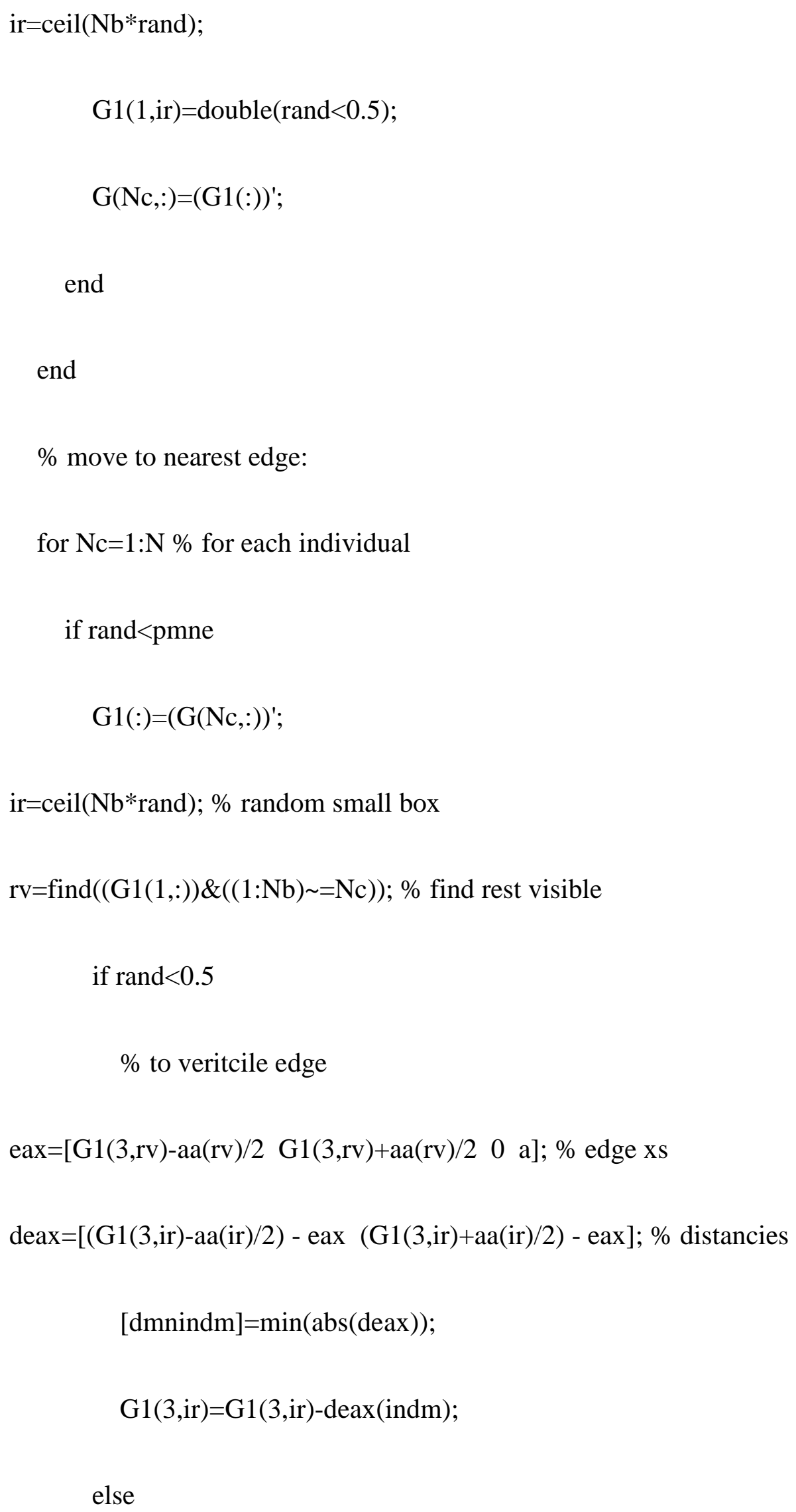


$\%$ to horizontal edge

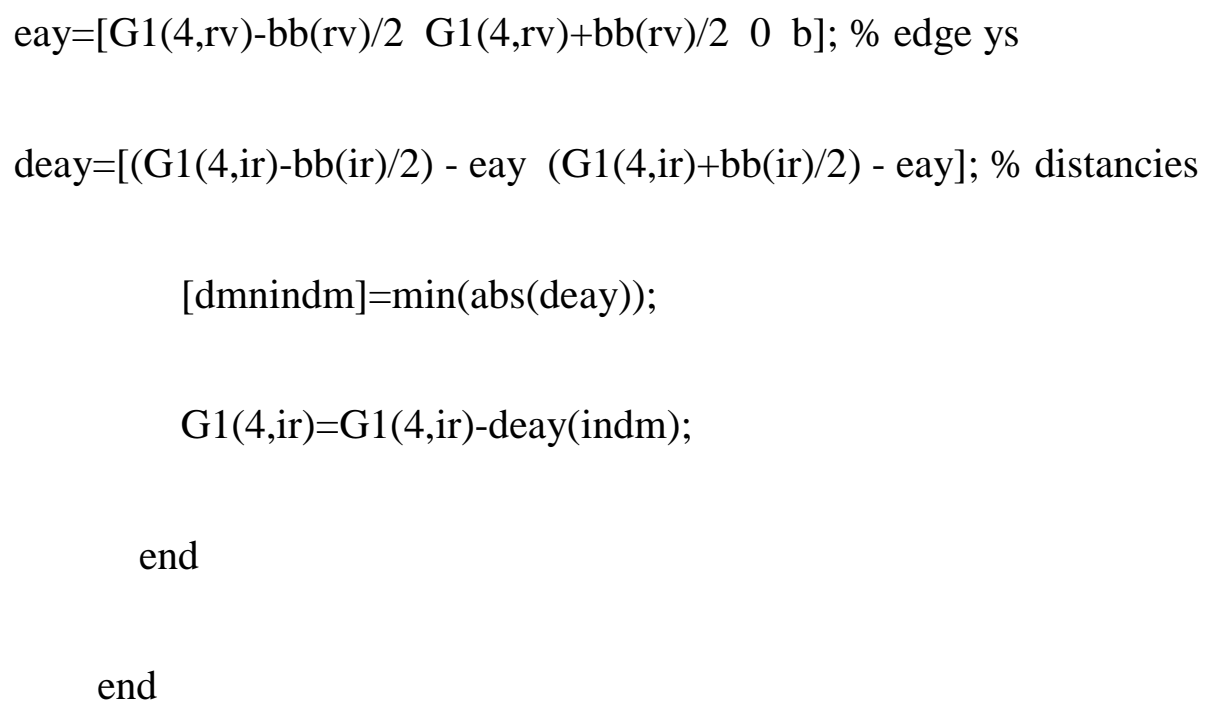




\section{APPENDIX C: LINGO model and solution}

\section{Lingo model to meet the limitation of the Build volume:}

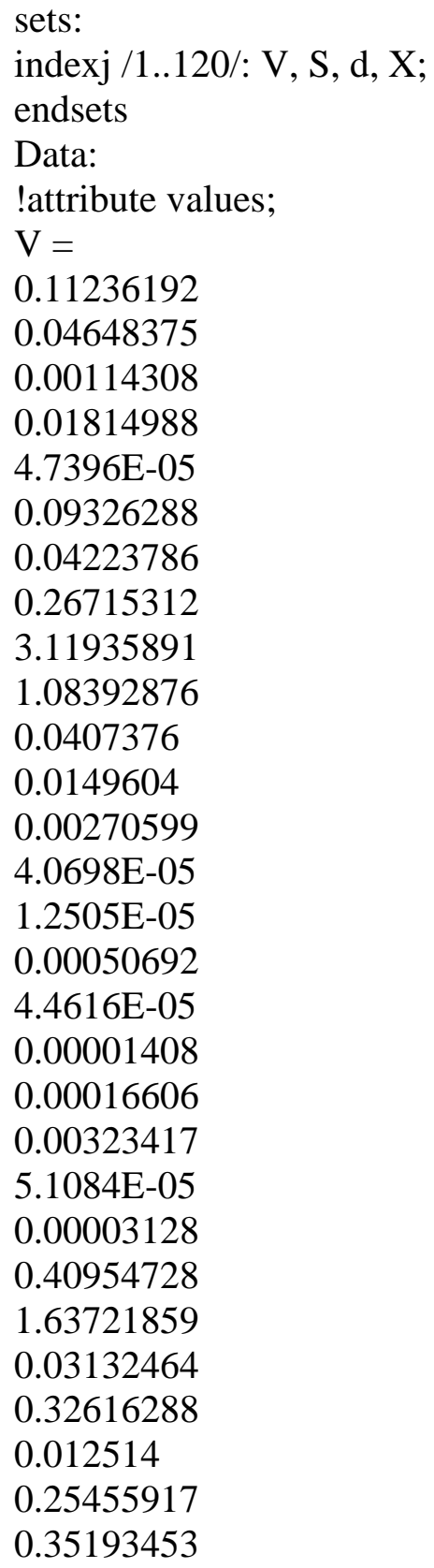


0.76125862

0.06685119

0.01967764

0.04581432

0.0689472

0.0686394

0.32616288

42.9375274

760.807465

352.309706

694.256744

114.004464

3.06608928

0.53345869

1.24864589

2.25995616

17.6826705

1975.13762

6.25255313

1528.24328

109.346805

0.09845078

3.6139938

0.8731778

4.9907936

72.6904328

35.9829999

4.36529331

21.003699

0.25606368

27.6163288

2.33790622

12.3799047

5.86273036

291.428026

496.56876

0.52299936

169.250445

0.28065345

228.857013

219.607098

159.012708

4.18196205

246.623247

99.4971947

0.21324398

40.5501431

331.845478 


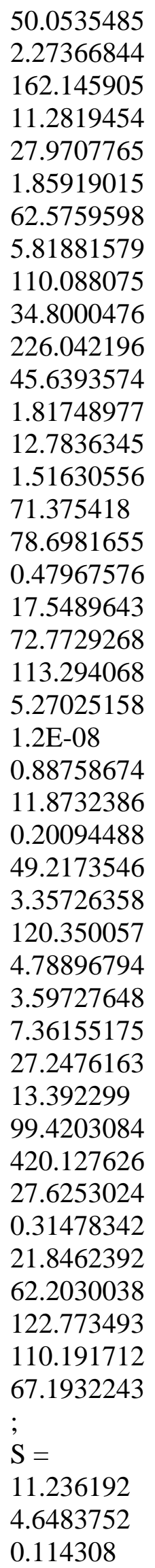




1.814988
0.0047396
9.3262884
4.2237864
26.715312
311.935891
108.392876
4.07376
1.49604
0.2705992
0.0040698
0.0012505
0.050692
0.0044616
0.001408
0.0166056
0.3234168
0.0051084
0.003128
40.954728
163.721859
3.132464
32.6162881
1.2513999
25.4559172
35.1934528
76.1258616
6.685119
1.9677636
4.581432
6.89472
6.86394
32.6162881
4293.75274
76080.7465
35230.9706
69425.6744
11400.4464
306.608928
53.3458688
124.864589
225.995616
1768.26705
197513.762
625.255313
152824.328
10934.6805
9.845078




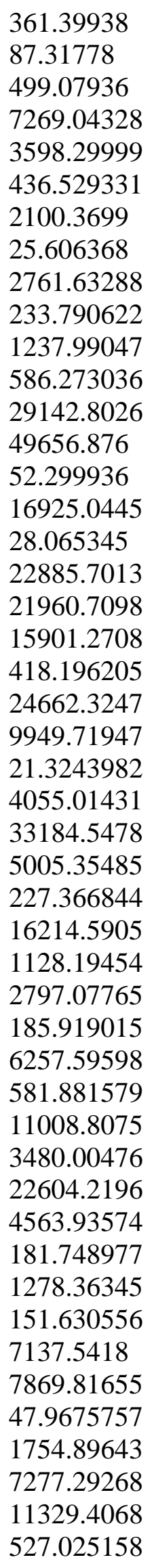

527.025158 


0.0000012
88.7586744
1187.32386
20.0944875
4921.73546
335.726358
12035.0057
478.896794
359.727648
736.155175
2724.76163
1339.2299
9942.03084
42012.7626
2762.53024
31.4783424
2184.62392
6220.30038
12277.3493
11019.1712
6719.32243
$;$
$d=$
8
9
11
4
10
7
11
4
4
5
5
3
7
7
9
6
5
7
12
6
3
10
5
5
6




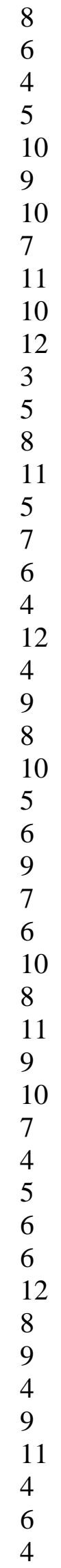




7
9
11
3
12
9
12
8
12
8
10
12
5
9
5
11
3
8
8
3
10
3
5
11
4
11
3
9
8
4
8
7
12
8
7
8
7
9
5
6
7
11
4
6
9
11
5
7


Enddata

$\operatorname{Max}=@ \operatorname{Sum}(\operatorname{indexj}(j): S(j) * X(j))$

@ SUM(indexj(j):V(j)*X(j))<=3510;

@FOR(indexj(j): @GIN(x(j)));

\section{Lingo Solution Report:}

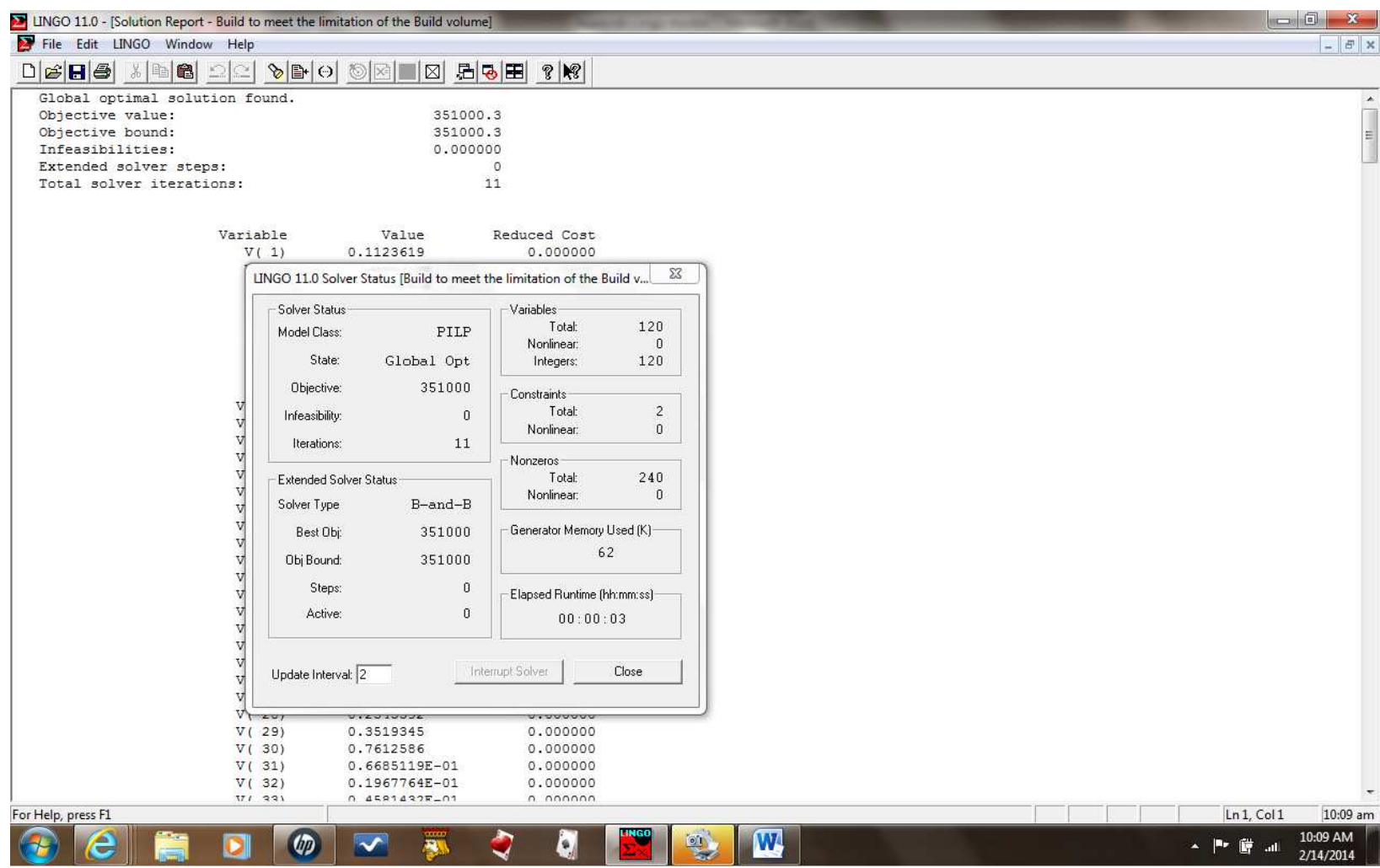

Global optimal solution found.

Objective value:

Objective bound:

Infeasibilities:

Extended solver steps:

Total solver iterations:

351000.3
351000.3
0.000000
0
11

11

\begin{tabular}{clc} 
Variable & \multicolumn{1}{c}{ Value } & Reduced Cost \\
V( 1) & 0.1123619 & 0.000000 \\
V( 2) & $0.4648375 E-01$ & 0.000000 \\
V( 3) & $0.1143080 \mathrm{E}-02$ & 0.000000 \\
V( 4) & $0.1814988 \mathrm{E}-01$ & 0.000000 \\
V( 5) & $0.4739600 \mathrm{E}-04$ & 0.000000
\end{tabular}




\begin{tabular}{|c|c|c|}
\hline$V(6)$ & $0.9326288 \mathrm{E}-01$ & 0.000000 \\
\hline $\mathrm{V}(7)$ & $0.4223786 \mathrm{E}-01$ & 0.000000 \\
\hline $\mathrm{V}(8)$ & 0.2671531 & 0.000000 \\
\hline $\mathrm{V}(9)$ & 3.119359 & 0.000000 \\
\hline $\mathrm{V}(10)$ & 1.083929 & 0.000000 \\
\hline $\mathrm{V}(11)$ & $0.4073760 \mathrm{E}-01$ & 0.000000 \\
\hline$V(12)$ & $0.1496040 \mathrm{E}-01$ & 0.000000 \\
\hline $\mathrm{V}(13)$ & $0.2705990 \mathrm{E}-02$ & 0.000000 \\
\hline $\mathrm{V}(14)$ & 0.4069800E-04 & 0.000000 \\
\hline$V(15)$ & $0.1250500 \mathrm{E}-04$ & 0.000000 \\
\hline$V(16)$ & $0.5069200 \mathrm{E}-03$ & 0.000000 \\
\hline $\mathrm{V}(17)$ & $0.4461600 \mathrm{E}-04$ & 0.000000 \\
\hline $\mathrm{V}(18)$ & $0.1408000 \mathrm{E}-04$ & 0.000000 \\
\hline$V(19)$ & $0.1660600 \mathrm{E}-03$ & 0.000000 \\
\hline$V(20)$ & $0.3234170 \mathrm{E}-02$ & 0.000000 \\
\hline $\mathrm{V}(21)$ & $0.5108400 \mathrm{E}-04$ & 0.000000 \\
\hline$V(22)$ & $0.3128000 \mathrm{E}-04$ & 0.000000 \\
\hline$V(23)$ & 0.4095473 & 0.000000 \\
\hline$V(24)$ & 1.637219 & 0.000000 \\
\hline$V(25)$ & $0.3132464 \mathrm{E}-01$ & 0.000000 \\
\hline$V(26)$ & 0.3261629 & 0.000000 \\
\hline$V(27)$ & $0.1251400 \mathrm{E}-01$ & 0.000000 \\
\hline $\mathrm{V}(28)$ & 0.2545592 & 0.000000 \\
\hline$V(29)$ & 0.3519345 & 0.000000 \\
\hline$V(30)$ & 0.7612586 & 0.000000 \\
\hline $\mathrm{V}(31)$ & $0.6685119 \mathrm{E}-01$ & 0.000000 \\
\hline$V(32)$ & 0.1967764E-01 & 0.000000 \\
\hline$V(33)$ & $0.4581432 \mathrm{E}-01$ & 0.000000 \\
\hline$V(34)$ & $0.6894720 \mathrm{E}-01$ & 0.000000 \\
\hline$V(35)$ & $0.6863940 \mathrm{E}-01$ & 0.000000 \\
\hline$V(36)$ & 0.3261629 & 0.000000 \\
\hline$V(37)$ & 42.93753 & 0.000000 \\
\hline$V(38)$ & 760.8075 & 0.000000 \\
\hline$V(39)$ & 352.3097 & 0.000000 \\
\hline$V(40)$ & & \\
\hline$V(41)$ & 114.0045 & 0.000000 \\
\hline$V(42)$ & 3.066089 & 0.000000 \\
\hline$V(43)$ & 0.5334587 & 0.000000 \\
\hline$V(44)$ & 1.248646 & 0.000000 \\
\hline$V(45)$ & 2.259956 & 0.000000 \\
\hline$V(46)$ & 17.68267 & 0.000000 \\
\hline$V(47)$ & 1975.138 & 0.000000 \\
\hline$V(48)$ & 6.252553 & 0.000000 \\
\hline$V(49)$ & 1528.243 & 0.000000 \\
\hline$V(50)$ & 109.3468 & 0.000000 \\
\hline $\mathrm{V}(51)$ & $0.9845078 \mathrm{E}-01$ & 0.000000 \\
\hline$V(52)$ & 3.613994 & 0.000000 \\
\hline$V(53)$ & 0.8731778 & 0.000000 \\
\hline
\end{tabular}




\begin{tabular}{|c|c|c|}
\hline V( 54) & 4.990794 & 0.000000 \\
\hline$V(55)$ & 72.69043 & 0.000000 \\
\hline V( 56) & 35.98300 & 0.000000 \\
\hline$V(57)$ & 4.365293 & 0.000000 \\
\hline V( 58) & 21.00370 & 0.000000 \\
\hline V( 59) & 0.2560637 & 0.000000 \\
\hline$V(60)$ & 27.61633 & 0.000000 \\
\hline $\mathrm{V}(61)$ & 2.337906 & 0.000000 \\
\hline$V(62)$ & 12.37990 & 0.000000 \\
\hline$V(63)$ & 5.862730 & 0.000000 \\
\hline V( 64) & 291.4280 & 0.000000 \\
\hline$V(65)$ & 496.5688 & 0.000000 \\
\hline V( 66) & 0.5229994 & 0.000000 \\
\hline V( 67) & 169.2504 & 0.000000 \\
\hline V( 68) & 0.2806535 & 0.000000 \\
\hline V( 69) & 228.8570 & 0.000000 \\
\hline $\mathrm{V}(70)$ & 219.6071 & 0.000000 \\
\hline $\mathrm{V}(71)$ & 159.0127 & 0.000000 \\
\hline$V(72)$ & 4.181962 & 0.000000 \\
\hline$V(73)$ & 246.6232 & 0.000000 \\
\hline V( 74) & 99.49719 & 0.000000 \\
\hline$V(75)$ & 0.2132440 & 0.000000 \\
\hline$V(76)$ & 40.55014 & 0.000000 \\
\hline$V(77)$ & 331.8455 & 0.000000 \\
\hline $\mathrm{V}(78)$ & 50.05355 & 0.000000 \\
\hline V( 79) & 2.273668 & 0.000000 \\
\hline $\mathrm{V}(80)$ & 162.1459 & 0.000000 \\
\hline $\mathrm{V}(81)$ & 11.28195 & 0.000000 \\
\hline $\mathrm{V}(82)$ & 27.97078 & 0.000000 \\
\hline $\mathrm{V}(83)$ & 1.859190 & 0.000000 \\
\hline V( 84) & 62.57596 & 0.000000 \\
\hline $\mathrm{V}(85)$ & 5.818816 & 0.000000 \\
\hline V( 86) & 110.0881 & 0.000000 \\
\hline V( 87) & 34.80005 & 0.000000 \\
\hline $\mathrm{V}(88)$ & 226.0422 & 0.000000 \\
\hline V( 89) & 45.63936 & 0.000000 \\
\hline V( 90) & 1.817490 & 0.000000 \\
\hline $\mathrm{V}(91)$ & 12.78363 & 0.000000 \\
\hline V( 92) & 1.516306 & 0.000000 \\
\hline V( 93) & 71.37542 & 0.000000 \\
\hline V( 94) & 78.69817 & 0.000000 \\
\hline V( 95) & 0.4796758 & 0.000000 \\
\hline V( 96) & 17.54896 & 0.000000 \\
\hline V( 97) & 72.77293 & 0.000000 \\
\hline V( 98) & 113.2941 & 0.000000 \\
\hline V( 99) & 5.270252 & 0.000000 \\
\hline$V(100)$ & $0.1200000 \mathrm{E}-07$ & 0.000000 \\
\hline$V(101)$ & 0.8875867 & 0.000000 \\
\hline
\end{tabular}




\begin{tabular}{|c|c|c|}
\hline $\mathrm{V}(102)$ & 11.87324 & 0.000000 \\
\hline $\mathrm{V}(103)$ & 0.2009449 & 0.000000 \\
\hline$V(104)$ & 49.21735 & 0.000000 \\
\hline $\mathrm{V}(105)$ & 3.357264 & 0.000000 \\
\hline$V(106)$ & 120.3501 & 0.000000 \\
\hline V( 107) & 4.788968 & 0.000000 \\
\hline $\mathrm{V}(108)$ & 3.597276 & 0.000000 \\
\hline $\mathrm{V}(109)$ & 7.361552 & 0.000000 \\
\hline $\mathrm{V}(110)$ & 27.24762 & 0.000000 \\
\hline $\mathrm{V}(111)$ & 13.39230 & 0.000000 \\
\hline $\mathrm{V}(112)$ & 99.42031 & 0.000000 \\
\hline $\mathrm{V}(113)$ & 420.1276 & 0.000000 \\
\hline $\mathrm{V}(114)$ & 27.62530 & 0.000000 \\
\hline$V(115)$ & 0.3147834 & 0.000000 \\
\hline$V(116)$ & 21.84624 & 0.000000 \\
\hline$V(117)$ & 62.20300 & 0.000000 \\
\hline $\mathrm{V}(118)$ & 122.7735 & 0.000000 \\
\hline$V(119)$ & 110.1917 & 0.000000 \\
\hline $\mathrm{V}(120)$ & 67.19322 & 0.000000 \\
\hline $\mathrm{S}(1)$ & 11.23619 & 0.000000 \\
\hline $\mathrm{S}(2)$ & 4.648375 & 0.000000 \\
\hline $\mathrm{S}(3)$ & 0.1143080 & 0.000000 \\
\hline$S(4)$ & 1.814988 & 0.000000 \\
\hline$S(5)$ & $0.4739600 \mathrm{E}-02$ & 0.000000 \\
\hline$S(6)$ & 9.326288 & 0.000000 \\
\hline$S(7)$ & 4.223786 & 0.000000 \\
\hline $\mathrm{S}(\mathrm{8})$ & 26.71531 & 0.000000 \\
\hline$S(9)$ & 311.9359 & 0.000000 \\
\hline$S(10)$ & 108.3929 & 0.000000 \\
\hline$S(11)$ & 4.073760 & 0.000000 \\
\hline$S(12)$ & 1.496040 & 0.000000 \\
\hline$S(13)$ & 0.2705992 & 0.000000 \\
\hline$S(14)$ & $0.4069800 \mathrm{E}-02$ & 0.000000 \\
\hline$S(15)$ & $0.1250500 \mathrm{E}-02$ & 0.000000 \\
\hline$S(16)$ & $0.5069200 \mathrm{E}-01$ & 0.000000 \\
\hline$S(17)$ & $0.4461600 \mathrm{E}-02$ & 0.000000 \\
\hline$S(18)$ & 0.1408000E-02 & 0.000000 \\
\hline$S(19)$ & $0.1660560 \mathrm{E}-01$ & 0.000000 \\
\hline$S(20)$ & 0.3234168 & 0.000000 \\
\hline$S(21)$ & $0.5108400 \mathrm{E}-02$ & 0.000000 \\
\hline$S(22)$ & $0.3128000 \mathrm{E}-02$ & 0.000000 \\
\hline$S(23)$ & 40.95473 & 0.000000 \\
\hline$S(24)$ & 163.7219 & 0.000000 \\
\hline$S(25)$ & 3.132464 & 0.000000 \\
\hline$S(26)$ & 32.61629 & 0.000000 \\
\hline$S(27)$ & 1.251400 & 0.000000 \\
\hline $\mathrm{S}(28)$ & 25.45592 & 0.000000 \\
\hline$S(29)$ & 35.19345 & 0.000000 \\
\hline
\end{tabular}




$\begin{array}{lll}\text { S }(30) & 76.12586 & 0.000000 \\ \mathrm{~S}(31) & 6.685119 & 0.000000 \\ \mathrm{~S}(32) & 1.967764 & 0.000000 \\ \mathrm{~S}(33) & 4.581432 & 0.000000 \\ \mathrm{~S}(34) & 6.894720 & 0.000000 \\ \mathrm{~S}(35) & 6.863940 & 0.000000 \\ \mathrm{~S}(36) & 32.61629 & 0.000000 \\ \mathrm{~S}(37) & 4293.753 & 0.000000 \\ \mathrm{~S}(38) & 76080.75 & 0.000000 \\ \mathrm{~S}(39) & 35230.97 & 0.000000 \\ \mathrm{~S}(40) & 69425.67 & 0.000000 \\ \mathrm{~S}(41) & 11400.45 & 0.000000 \\ \mathrm{~S}(42) & 306.6089 & 0.000000 \\ \mathrm{~S}(43) & 53.34587 & 0.000000 \\ \mathrm{~S}(44) & 124.8646 & 0.000000 \\ \mathrm{~S}(45) & 225.9956 & 0.000000 \\ \mathrm{~S}(46) & 1768.267 & 0.000000 \\ \mathrm{~S}(47) & 197513.8 & 0.000000 \\ \mathrm{~S}(48) & 625.2553 & 0.000000 \\ \mathrm{~S}(49) & 152824.3 & 0.000000 \\ \mathrm{~S}(50) & 10934.68 & 0.000000 \\ \mathrm{~S}(51) & 9.845078 & 0.000000 \\ \mathrm{~S}(52) & 361.3994 & 0.000000 \\ \mathrm{~S}(53) & 87.31778 & 0.000000 \\ \mathrm{~S}(54) & 499.0794 & 0.000000 \\ \mathrm{~S}(55) & 7269.043 & 0.000000 \\ \mathrm{~S}(56) & 3598.300 & 0.000000 \\ \mathrm{~S}(57) & 436.5293 & 0.000000 \\ \mathrm{~S}(58) & 2100.370 & 0.000000 \\ \mathrm{~S}(59) & 25.60637 & 0.000000 \\ \mathrm{~S}(60) & 2761.633 & 0.000000 \\ \mathrm{~S}(61) & 233.7906 & 0.000000 \\ \mathrm{~S}(62) & 1237.990 & 0.000000 \\ \mathrm{~S}(63) & 586.2730 & 0.000000 \\ \mathrm{~S}(64) & 29142.80 & 0.000000 \\ \mathrm{~S}(65) & 49656.88 & 0.000000 \\ \mathrm{~S}(66) & 52.29994 & 0.000000 \\ \mathrm{~S}(67) & 16925.04 & 0.000000 \\ \mathrm{~S}(68) & 28.06535 & 0.000000 \\ \mathrm{~S}(69) & 22885.70 & 0.000000 \\ \mathrm{~S}(70) & 21960.71 & 0.000000 \\ \mathrm{~S}(71) & 15901.27 & 0.000000 \\ \mathrm{~S}(72) & 418.1962 & 0.000000 \\ \mathrm{~S}(73) & 24662.32 & 0.000000 \\ \mathrm{~S}(74) & 9949.719 & 0.000000 \\ \mathrm{~S}(75) & 21.32440 & 0.000000 \\ \mathrm{~S}(76) & 4055.014 & 0.000000 \\ \mathrm{~S}(77) & 33184.55 & 0.000000\end{array}$




\begin{tabular}{|c|c|c|}
\hline$S(78)$ & 5005.355 & 0.000000 \\
\hline$S(79)$ & 227.3668 & 0.000000 \\
\hline$S(80)$ & 16214.59 & 0.000000 \\
\hline$S(81)$ & 1128.195 & 0.000000 \\
\hline$S(82)$ & 2797.078 & 0.000000 \\
\hline$S(83)$ & 185.9190 & 0.000000 \\
\hline$S(84)$ & 6257.596 & 0.000000 \\
\hline$S(85)$ & 581.8816 & 0.000000 \\
\hline$S(86)$ & 11008.81 & 0.000000 \\
\hline$S(87)$ & 3480.005 & 0.000000 \\
\hline$S(88)$ & 22604.22 & 0.000000 \\
\hline S( 89) & 4563.936 & 0.000000 \\
\hline$S(90)$ & 181.7490 & 0.000000 \\
\hline$S(91)$ & 1278.363 & 0.000000 \\
\hline$S(92)$ & 151.6306 & 0.000000 \\
\hline$S(93)$ & 7137.542 & 0.000000 \\
\hline S( 94) & 7869.817 & 0.000000 \\
\hline$S(95)$ & 47.96758 & 0.000000 \\
\hline$S(96)$ & 1754.896 & 0.000000 \\
\hline$S(97)$ & 7277.293 & 0.000000 \\
\hline $\mathrm{S}(98)$ & 11329.41 & 0.000000 \\
\hline$S(99)$ & 527.0252 & 0.000000 \\
\hline$S(100)$ & $0.1200000 \mathrm{E}-05$ & 0.000000 \\
\hline$S(101)$ & 88.75867 & 0.000000 \\
\hline$S(102)$ & 1187.324 & 0.000000 \\
\hline$S(103)$ & 20.09449 & 0.000000 \\
\hline$S(104)$ & 4921.735 & 0.000000 \\
\hline$S(105)$ & 335.7264 & 0.000000 \\
\hline$S(106)$ & 12035.01 & 0.000000 \\
\hline$S(107)$ & 478.8968 & 0.000000 \\
\hline$S(108)$ & 359.7276 & 0.000000 \\
\hline$S(109)$ & 736.1552 & 0.000000 \\
\hline$S(110)$ & 2724.762 & 0.000000 \\
\hline $\mathrm{S}(111)$ & 1339.230 & 0.000000 \\
\hline$S(112)$ & 9942.031 & 0.000000 \\
\hline$S(113)$ & 42012.76 & 0.000000 \\
\hline$S(114)$ & 2762.530 & 0.000000 \\
\hline$S(115)$ & 31.47834 & 0.000000 \\
\hline$S(116)$ & 2184.624 & 0.000000 \\
\hline$S(117)$ & 6220.300 & 0.000000 \\
\hline$S(118)$ & 12277.35 & 0.000000 \\
\hline$S(119)$ & 11019.17 & 0.000000 \\
\hline$S(120)$ & 6719.322 & 0.000000 \\
\hline $\mathrm{D}(1)$ & 8.000000 & 0.000000 \\
\hline $\mathrm{D}(2)$ & 9.000000 & 0.000000 \\
\hline $\mathrm{D}(3)$ & 11.00000 & 0.000000 \\
\hline $\mathrm{D}(4)$ & 4.000000 & 0.000000 \\
\hline \multirow[t]{2}{*}{$\mathrm{D}(5)$} & 10.00000 & 0.000000 \\
\hline & & 189 \\
\hline
\end{tabular}




$\begin{array}{lcc} & & \\ \mathrm{D}(6) & 7.000000 & 0.000000 \\ \mathrm{D}(7) & 11.00000 & 0.000000 \\ \mathrm{D}(8) & 4.000000 & 0.000000 \\ \mathrm{D}(9) & 4.000000 & 0.000000 \\ \mathrm{D}(10) & 5.000000 & 0.000000 \\ \mathrm{D}(11) & 5.000000 & 0.000000 \\ \mathrm{D}(12) & 3.000000 & 0.000000 \\ \mathrm{D}(13) & 7.000000 & 0.000000 \\ \mathrm{D}(14) & 7.000000 & 0.000000 \\ \mathrm{D}(15) & 9.000000 & 0.000000 \\ \mathrm{D}(16) & 6.000000 & 0.000000 \\ \mathrm{D}(17) & 5.000000 & 0.000000 \\ \mathrm{D}(18) & 7.000000 & 0.000000 \\ \mathrm{D}(19) & 12.00000 & 0.000000 \\ \mathrm{D}(20) & 6.000000 & 0.000000 \\ \mathrm{D}(21) & 3.000000 & 0.000000 \\ \mathrm{D}(22) & 10.00000 & 0.000000 \\ \mathrm{D}(23) & 5.000000 & 0.000000 \\ \mathrm{D}(24) & 5.000000 & 0.000000 \\ \mathrm{D}(25) & 6.000000 & 0.000000 \\ \mathrm{D}(26) & 8.000000 & 0.000000 \\ \mathrm{D}(27) & 6.000000 & 0.000000 \\ \mathrm{D}(28) & 4.000000 & 0.000000 \\ \mathrm{D}(29) & 5.000000 & 0.000000 \\ \mathrm{D}(30) & 10.00000 & 0.000000 \\ \mathrm{D}(31) & 9.000000 & 0.000000 \\ \mathrm{D}(32) & 10.00000 & 0.000000 \\ \mathrm{D}(33) & 7.000000 & 0.000000 \\ \mathrm{D}(34) & 11.00000 & 0.000000 \\ \mathrm{D}(35) & 10.00000 & 0.000000 \\ \mathrm{D}(36) & 12.00000 & 0.000000 \\ \mathrm{D}(37) & 3.000000 & 0.000000 \\ \mathrm{D}(38) & 5.000000 & 0.000000 \\ \mathrm{D}(39) & 8.000000 & 0.000000 \\ \mathrm{D}(40) & 11.00000 & 0.000000 \\ \mathrm{D}(41) & 5.000000 & 0.000000 \\ \mathrm{D}(42) & 7.000000 & 0.000000 \\ \mathrm{D}(43) & 6.000000 & 0.000000 \\ \mathrm{D}(44) & 4.000000 & 0.000000 \\ \mathrm{D}(45) & 12.00000 & 0.000000 \\ \mathrm{D}(46) & 4.000000 & 0.000000 \\ \mathrm{D}(47) & 9.000000 & 0.000000 \\ \mathrm{D}(48) & 8.000000 & 0.000000 \\ \mathrm{D}(49) & 10.00000 & 0.000000 \\ \mathrm{D}(50) & 5.000000 & 0.000000 \\ \mathrm{D}(51) & 6.000000 & 0.000000 \\ \mathrm{D}(52) & 9.000000 & 0.000000 \\ \mathrm{D}(53) & 7.000000 & 0.000000 \\ & & 190 \\ & & \\ & & \end{array}$




\begin{tabular}{|c|c|c|}
\hline $\mathrm{D}(54)$ & 6.000000 & 0.000000 \\
\hline $\mathrm{D}(55)$ & 10.00000 & 0.000000 \\
\hline D( 56) & 8.000000 & 0.000000 \\
\hline $\mathrm{D}(57)$ & 11.00000 & 0.000000 \\
\hline $\mathrm{D}(58)$ & 9.000000 & 0.000000 \\
\hline D( 59) & 10.00000 & 0.000000 \\
\hline $\mathrm{D}(60)$ & 7.000000 & 0.000000 \\
\hline $\mathrm{D}(61)$ & 4.000000 & 0.000000 \\
\hline $\mathrm{D}(62)$ & 5.000000 & 0.000000 \\
\hline $\mathrm{D}(63)$ & 6.000000 & 0.000000 \\
\hline D( 64) & 6.000000 & 0.000000 \\
\hline $\mathrm{D}(65)$ & 12.00000 & 0.000000 \\
\hline D( 66) & 8.000000 & 0.000000 \\
\hline D( 67) & 9.000000 & 0.000000 \\
\hline $\mathrm{D}(68)$ & 4.000000 & 0.000000 \\
\hline D( 69) & 9.000000 & 0.000000 \\
\hline $\mathrm{D}(70)$ & 11.00000 & 0.000000 \\
\hline $\mathrm{D}(71)$ & 4.000000 & 0.000000 \\
\hline $\mathrm{D}(72)$ & 6.000000 & 0.000000 \\
\hline $\mathrm{D}(73)$ & 4.000000 & 0.000000 \\
\hline $\mathrm{D}(74)$ & 7.000000 & 0.000000 \\
\hline $\mathrm{D}(75)$ & 9.000000 & 0.000000 \\
\hline $\mathrm{D}(76)$ & 11.00000 & 0.000000 \\
\hline D( 77) & 3.000000 & 0.000000 \\
\hline $\mathrm{D}(78)$ & 12.00000 & 0.000000 \\
\hline D( 79) & 9.000000 & 0.000000 \\
\hline $\mathrm{D}(80)$ & 12.00000 & 0.000000 \\
\hline $\mathrm{D}(81)$ & 8.000000 & 0.000000 \\
\hline $\mathrm{D}(82)$ & 12.00000 & 0.000000 \\
\hline $\mathrm{D}(\mathrm{83})$ & 8.000000 & 0.000000 \\
\hline D( 84) & 10.00000 & 0.000000 \\
\hline $\mathrm{D}(85)$ & 12.00000 & 0.000000 \\
\hline $\mathrm{D}(\mathrm{86})$ & 5.000000 & 0.000000 \\
\hline $\mathrm{D}(87)$ & 9.000000 & 0.000000 \\
\hline $\mathrm{D}(88)$ & 5.000000 & 0.000000 \\
\hline D( 89) & 11.00000 & 0.000000 \\
\hline $\mathrm{D}(90)$ & 3.000000 & 0.000000 \\
\hline D( 91) & 8.000000 & 0.000000 \\
\hline $\mathrm{D}(92)$ & 8.000000 & 0.000000 \\
\hline D( 93) & 3.000000 & 0.000000 \\
\hline D( 94) & 10.00000 & 0.000000 \\
\hline D( 95) & 3.000000 & 0.000000 \\
\hline D( 96) & 5.000000 & 0.000000 \\
\hline D( 97) & 11.00000 & 0.000000 \\
\hline D( 98) & 4.000000 & 0.000000 \\
\hline D( 99) & 11.00000 & 0.000000 \\
\hline $\mathrm{D}(100)$ & 3.000000 & 0.000000 \\
\hline $\mathrm{D}(101)$ & 9.000000 & 0.000000 \\
\hline
\end{tabular}




\begin{tabular}{|c|c|c|}
\hline $\mathrm{D}(102)$ & 8.000000 & 0.000000 \\
\hline $\mathrm{D}(103)$ & 4.000000 & 0.000000 \\
\hline $\mathrm{D}(104)$ & 8.000000 & 0.000000 \\
\hline $\mathrm{D}(105)$ & 7.000000 & 0.000000 \\
\hline $\mathrm{D}(106)$ & 12.00000 & 0.000000 \\
\hline $\mathrm{D}(107)$ & 8.000000 & 0.000000 \\
\hline $\mathrm{D}(108)$ & 7.000000 & 0.000000 \\
\hline $\mathrm{D}(109)$ & 8.000000 & 0.000000 \\
\hline $\mathrm{D}(110)$ & 7.000000 & 0.000000 \\
\hline $\mathrm{D}(111)$ & 9.000000 & 0.000000 \\
\hline $\mathrm{D}(112)$ & 5.000000 & 0.000000 \\
\hline $\mathrm{D}(113)$ & 6.000000 & 0.000000 \\
\hline $\mathrm{D}(114)$ & 7.000000 & 0.000000 \\
\hline $\mathrm{D}(115)$ & 11.00000 & 0.000000 \\
\hline $\mathrm{D}(116)$ & 4.000000 & 0.000000 \\
\hline $\mathrm{D}(117)$ & 6.000000 & 0.000000 \\
\hline $\mathrm{D}(118)$ & 9.000000 & 0.000000 \\
\hline $\mathrm{D}(119)$ & 11.00000 & 0.000000 \\
\hline $\mathrm{D}(120)$ & 5.000000 & 0.000000 \\
\hline $\mathrm{X}(1)$ & 0.000000 & -11.23619 \\
\hline$X(2)$ & 0.000000 & -4.648375 \\
\hline$X(3)$ & 0.000000 & -0.1143080 \\
\hline$X(4)$ & 0.000000 & -1.814988 \\
\hline$X(5)$ & 0.000000 & $-0.4739600 \mathrm{E}-02$ \\
\hline$X(6)$ & 0.000000 & -9.326288 \\
\hline$X(7)$ & 0.000000 & -4.223786 \\
\hline$X(8)$ & 0.000000 & -26.71531 \\
\hline$X(9)$ & 0.000000 & -311.9359 \\
\hline$X(10)$ & 0.000000 & -108.3929 \\
\hline$X(11)$ & 0.000000 & -4.073760 \\
\hline$X(12)$ & 0.000000 & -1.496040 \\
\hline$X(13)$ & 1297122. & -0.2705992 \\
\hline$X(14)$ & 0.000000 & $-0.4069800 \mathrm{E}-02$ \\
\hline$X(15)$ & 0.000000 & $-0.1250500 \mathrm{E}-02$ \\
\hline$X(16)$ & 1.000000 & $-0.5069200 \mathrm{E}-01$ \\
\hline$X(17)$ & 0.000000 & $-0.4461600 \mathrm{E}-02$ \\
\hline$X(18)$ & 0.000000 & $-0.1408000 \mathrm{E}-02$ \\
\hline$X(19)$ & 2.000000 & $-0.1660560 \mathrm{E}-01$ \\
\hline$X(20)$ & 0.000000 & -0.3234168 \\
\hline$X(21)$ & 0.000000 & $-0.5108400 \mathrm{E}-02$ \\
\hline$X(22)$ & 0.000000 & $-0.3128000 \mathrm{E}-02$ \\
\hline$X(23)$ & 0.000000 & -40.95473 \\
\hline$X(24)$ & 0.000000 & -163.7219 \\
\hline$X(25)$ & 0.000000 & -3.132464 \\
\hline$X(26)$ & 0.000000 & -32.61629 \\
\hline$X(27)$ & 0.000000 & -1.251400 \\
\hline$X(28)$ & 0.000000 & -25.45592 \\
\hline \multirow[t]{2}{*}{$X(29)$} & 0.000000 & -35.19345 \\
\hline & & 192 \\
\hline
\end{tabular}




\begin{tabular}{|c|c|c|}
\hline$X(30)$ & 0.000000 & -76.12586 \\
\hline$X(31)$ & 0.000000 & -6.685119 \\
\hline$X(32)$ & 0.000000 & -1.967764 \\
\hline$X(33)$ & 0.000000 & -4.581432 \\
\hline$X(34)$ & 0.000000 & -6.894720 \\
\hline$X(35)$ & 0.000000 & -6.863940 \\
\hline$X(36)$ & 0.000000 & -32.61629 \\
\hline$X(37)$ & 0.000000 & -4293.753 \\
\hline$X(38)$ & 0.000000 & -76080.75 \\
\hline X( 39) & 0.000000 & -35230.97 \\
\hline$X(40)$ & 0.000000 & -69425.67 \\
\hline$X(41)$ & 0.000000 & -11400.45 \\
\hline$X(42)$ & 0.000000 & -306.6089 \\
\hline$X(43)$ & 0.000000 & -53.34587 \\
\hline$X(44)$ & 0.000000 & -124.8646 \\
\hline$X(45)$ & 0.000000 & -225.9956 \\
\hline$X(46)$ & 0.000000 & -1768.267 \\
\hline$X(47)$ & 0.000000 & -197513.8 \\
\hline$X(48)$ & 0.000000 & -625.2553 \\
\hline$X(49)$ & 0.000000 & -152824.3 \\
\hline$X(50)$ & 0.000000 & -10934.68 \\
\hline$X(51)$ & 0.000000 & -9.845078 \\
\hline$X(52)$ & 0.000000 & -361.3994 \\
\hline$X(53)$ & 0.000000 & -87.31778 \\
\hline$X(54)$ & 0.000000 & -499.0794 \\
\hline$X(55)$ & 0.000000 & -7269.043 \\
\hline$X(56)$ & 0.000000 & -3598.300 \\
\hline$X(57)$ & 0.000000 & -436.5293 \\
\hline$X(58)$ & 0.000000 & -2100.370 \\
\hline X( 59) & 0.000000 & -25.60637 \\
\hline$X(60)$ & 0.000000 & -2761.633 \\
\hline$X(61)$ & 0.000000 & -233.7906 \\
\hline$X(62)$ & 0.000000 & -1237.990 \\
\hline$X(63)$ & 0.000000 & -586.2730 \\
\hline$X(64)$ & 0.000000 & -29142.80 \\
\hline$X(65)$ & 0.000000 & -49656.88 \\
\hline$X(66)$ & 0.000000 & -52.29994 \\
\hline$X(67)$ & 0.000000 & -16925.04 \\
\hline$X(68)$ & 0.000000 & -28.06535 \\
\hline X( 69) & 0.000000 & -22885.70 \\
\hline$X(70)$ & 0.000000 & -21960.71 \\
\hline$X(71)$ & 0.000000 & -15901.27 \\
\hline$X(72)$ & 0.000000 & -418.1962 \\
\hline$X(73)$ & 0.000000 & -24662.32 \\
\hline$X(74)$ & 0.000000 & -9949.719 \\
\hline$X(75)$ & 0.000000 & -21.32440 \\
\hline$X(76)$ & 0.000000 & -4055.014 \\
\hline \multirow[t]{2}{*}{$X(77)$} & 0.000000 & -33184.55 \\
\hline & & 193 \\
\hline
\end{tabular}




\begin{tabular}{|c|c|c|}
\hline$X(78)$ & 0.000000 & -5005.355 \\
\hline$X(79)$ & 0.000000 & -227.3668 \\
\hline$X(80)$ & 0.000000 & -16214.59 \\
\hline$X(81)$ & 0.000000 & -1128.195 \\
\hline$X(82)$ & 0.000000 & -2797.078 \\
\hline$X(83)$ & 0.000000 & -185.9190 \\
\hline$X(84)$ & 0.000000 & -6257.596 \\
\hline$X(85)$ & 0.000000 & -581.8816 \\
\hline$X(86)$ & 0.000000 & -11008.81 \\
\hline$X(87)$ & 0.000000 & -3480.005 \\
\hline $\mathrm{X}(\mathrm{88})$ & 0.000000 & -22604.22 \\
\hline X( 89) & 0.000000 & -4563.936 \\
\hline$X(90)$ & 0.000000 & -181.7490 \\
\hline $\mathrm{X}(91)$ & 0.000000 & -1278.363 \\
\hline$X(92)$ & 0.000000 & -151.6306 \\
\hline$X(93)$ & 0.000000 & -7137.542 \\
\hline$X(94)$ & 0.000000 & -7869.817 \\
\hline$X(95)$ & 0.000000 & -47.96758 \\
\hline$X(96)$ & 0.000000 & -1754.896 \\
\hline$X(97)$ & 0.000000 & -7277.293 \\
\hline$X(98)$ & 0.000000 & -11329.41 \\
\hline X( 99) & 0.000000 & -527.0252 \\
\hline$X(100)$ & 14.00000 & $-0.1200000 \mathrm{E}-05$ \\
\hline $\mathrm{X}(101)$ & 0.000000 & -88.75867 \\
\hline$X(102)$ & 0.000000 & -1187.324 \\
\hline$X(103)$ & 0.000000 & -20.09449 \\
\hline$X(104)$ & 0.000000 & -4921.735 \\
\hline$X(105)$ & 0.000000 & -335.7264 \\
\hline$X(106)$ & 0.000000 & -12035.01 \\
\hline$X(107)$ & 0.000000 & -478.8968 \\
\hline$X(108)$ & 0.000000 & -359.7276 \\
\hline $\mathrm{X}(109)$ & 0.000000 & -736.1552 \\
\hline$X(110)$ & 0.000000 & -2724.762 \\
\hline$X(111)$ & 0.000000 & -1339.230 \\
\hline$X(112)$ & 0.000000 & -9942.031 \\
\hline$X(113)$ & 0.000000 & -42012.76 \\
\hline$X(114)$ & 0.000000 & -2762.530 \\
\hline$X(115)$ & 0.000000 & -31.47834 \\
\hline$X(116)$ & 0.000000 & -2184.624 \\
\hline$X(117)$ & 0.000000 & -6220.300 \\
\hline$X(118)$ & 0.000000 & -12277.35 \\
\hline$X(119)$ & 0.000000 & -11019.17 \\
\hline$X(120)$ & 0.000000 & -6719.322 \\
\hline Row & Slack or Surplus & Dual Price \\
\hline 1 & 351000.3 & 1.000000 \\
\hline 2 & 0.1199976Е-07 & 0.000000 \\
\hline
\end{tabular}


Lingo model with penalty for not meeting number required for today:

sets:

parttypes /1..125/: V, S, n , p, X;

endsets

Data:

!attribute values;

$\mathrm{V}=$

1.8175

0.3262

0.0422

246.6232

3.1194

2.2600

33.3289

12.3799

27.6163

496.5688

420.1276

0.0000

0.0181

113.2941

0.7613

0.0000

11.8732

0.3262

99.4203

109.3468

27.9708

0.0313

0.4797

1.6372

3.3573

0.8732

3.5973

49.2174

0.0000

226.0422

0.2561

694.2567

5.8188

2.3379

331.8455

228.8570

0.2807

352.3097

4.3653

162.1459 


13.3923
0.0686
0.0465
99.4972
62.2030
67.1932
0.0985
7.3616
0.0032
0.0027
7.1344
21.0037
17.5490
4.7890
50.0535
6.2526
122.7735
0.8876
4.1820
45.6394
71.3754
1528.2433
5.2703
0.0001
0.0002
12.7836
11.2819
0.2546
0.0458
110.0881
72.6904
1.2486
17.6827
0.0689
0.0011
0.3148
3.6140
0.0000
0.3519
34.8000
120.3501
1.5163
0.0005
114.0045
110.1917
72.7729
1.5377
19.8701




0.0197
219.6071
1.0839
1975.1376
0.0000
0.2132
0.4095
0.2672
35.9830
0.5335
159.0127
2.2737
21.8462
191.8055
27.6253
0.0407
0.1124
3.0661
0.0000
62.5760
27.2476
1.8592
0.0150
4.9908
0.0933
42.9375
40.5501
5.8627
291.4280
0.2009
0.0669
78.6982
169.2504
0.5230
0.0000
760.8075
0.0125
$;$
S
25.89
4.65
0.60
3513.15
44.44
32.19
474.77
176.35
393.39


7073.63

5984.72

0.00

0.26

1613.88

10.84

0.00

169.13

4.65

1416.24

1557.65

398.44

0.45

6.83

23.32

47.82

12.44

51.24

701.10

0.00

3219.97

3.65

9889.70

82.89

33.30

4727.14

3260.07

4.00

5018.66

62.18

2309.77

190.77

0.98

0.66

1417.34

886.08

957.17

1.40

104.87

0.05

0.04

101.63

299.20

249.99

68.22

713.01

89.07

1748.91 


12.64
59.57
650.13
1016.74
21769.85
75.07
0.00
0.00
182.10
160.71
3.63
0.65
1568.21
1035.48
17.79
251.89
0.98
0.02
4.48
51.48
0.00
5.01
495.73
1714.39
21.60
0.01
1624.00
1569.68
1036.65
21.91
283.05
0.28
3128.31
15.44
28135.86
0.00
3.04
5.83
3.81
512.58
7.60
2265.14
32.39
311.20
2732.27
393.52
0.58
1.60




43.68
0.00
891.40
388.14
26.48
0.21
71.09
1.33
611.65
577.64
83.51
4151.40
2.86
0.95
1121.06
2410.98
7.45
0.00
10837.71
0.18
$;$
$\mathrm{n}=$
1
1
2
4
1
4
1
0
1
4
3
3
1
1
4
3
1
1
0
3
0
2
2
0
4
1




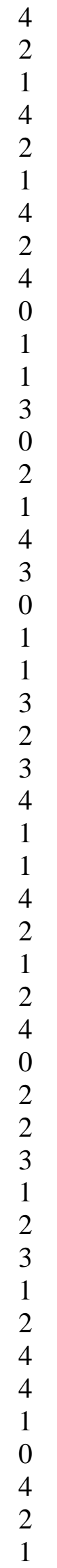




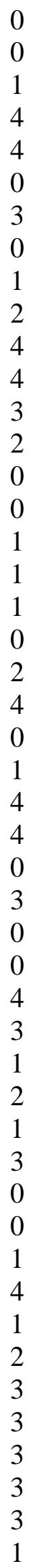




3
2
0
$;$
p $=$
12.95
2.32
0.30
1756.58
22.22
16.10
237.39
88.18
196.70
3536.81
2992.36
0.00
0.13
806.94
5.42
0.00
84.57
2.32
708.12
778.82
199.22
0.22
3.42
11.66
23.91
6.22
25.62
350.55
0.00
1609.99
1.82
4944.85
41.44
16.65
2363.57
1630.04
2.00
2509.33
31.09
1154.89
95.39
0.49
0.33




708.67
443.04
478.58
0.70
52.43
0.02
0.02
50.81
149.60
124.99
34.11
356.51
44.53
874.46
6.32
29.79
325.07
508.37
10884.9
2
37.54
0.00
0.00
91.05
80.36
1.81
0.33
784.10
517.74
8.89
125.94
0.49
0.01
2.24
25.74
0.00
2.51
247.86
857.19
10.80
0.00
812.00
784.84
518.33
10.95
141.53
0.14
1564.15


7.72

14067.9

3

0.00

1.52

2.92

1.90

256.29

3.80

1132.57

16.19

155.60

1366.14

196.76

0.29

0.80

21.84

0.00

445.70

194.07

13.24

0.11

35.55

0.66

305.82

288.82

41.76

2075.70

1.43

0.48

560.53

1205.49

3.73

0.00

5418.86

0.09

;

Enddata

!objective function;

$\operatorname{Max}=@ \operatorname{Sum}(\operatorname{parttypes}(\mathrm{i}):(\mathrm{S}(\mathrm{i}) * \mathrm{X}(\mathrm{i}))-\mathrm{p}(\mathrm{i}) *(\mathrm{n}(\mathrm{i})-\mathrm{X}(\mathrm{i})))$;

!constraints;

@ SUM(parttypes(i):V(i)*X(i)) <=3510;

@ FOR(parttypes(i):X(i) <= n(i)); 
@FOR(parttypes:@GIN(X));

End

Lingo Solution Report:

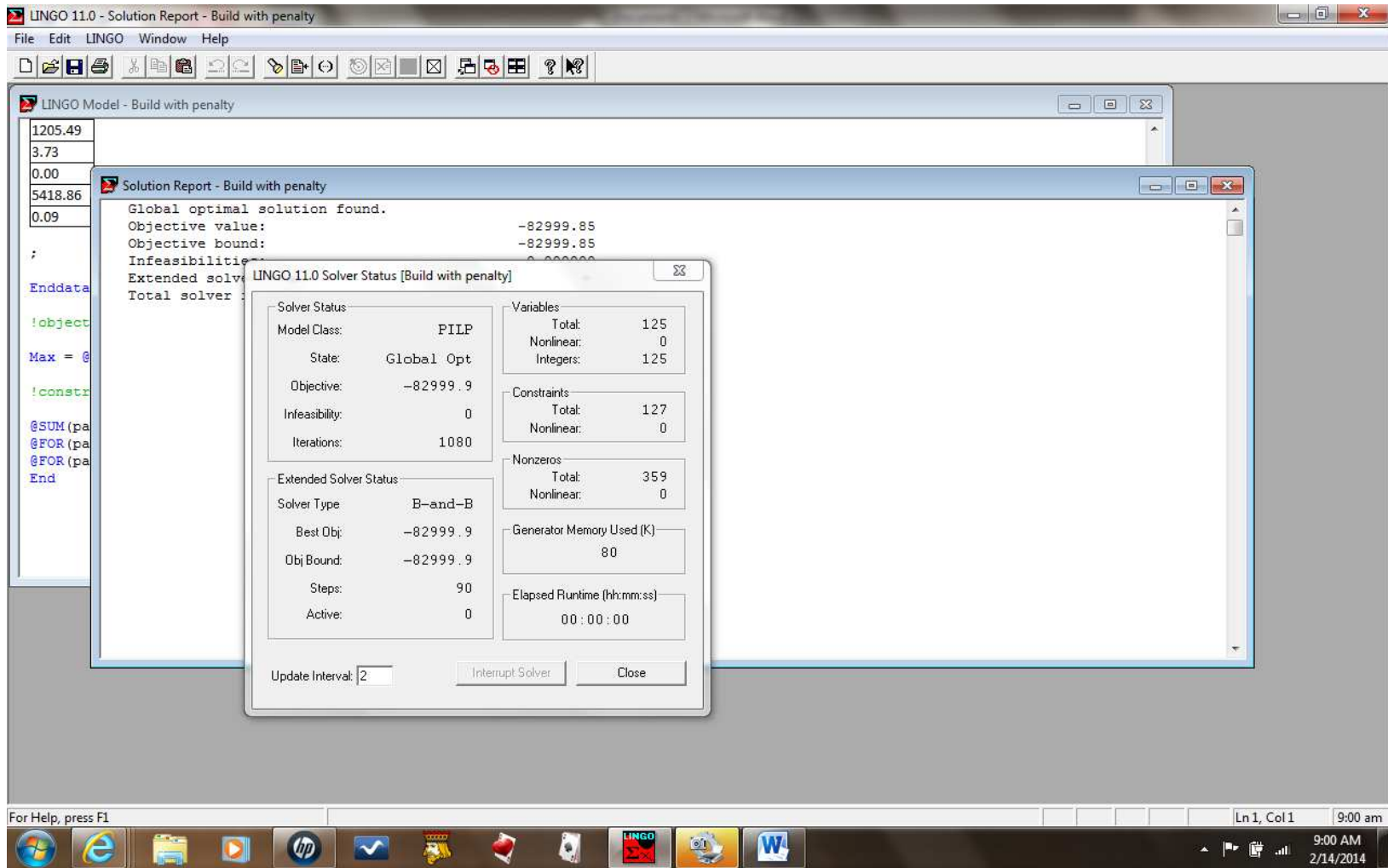

Global optimal solution found.

Objective value:

Objective bound:

Infeasibilities:

Extended solver steps:

Total solver iterations:

$$
\begin{gathered}
-82999.85 \\
-82999.85 \\
0.000000 \\
90 \\
1080
\end{gathered}
$$

\begin{tabular}{ccc} 
Variable & \multicolumn{1}{c}{ Value } & Reduced Cost \\
V( 1) & 1.817500 & 0.000000 \\
V( 2) & 0.3262000 & 0.000000 \\
V( 3) & $0.4220000 \mathrm{E}-01$ & 0.000000 \\
V( 4) & 246.6232 & 0.000000 \\
V( 5) & 3.119400 & 0.000000 \\
V( 6) & 2.260000 & 0.000000
\end{tabular}




$\begin{array}{ccc}\mathrm{V}(7) & 33.32890 & 0.000000 \\ \mathrm{~V}(8) & 12.37990 & 0.000000 \\ \mathrm{~V}(9) & 27.61630 & 0.000000 \\ \mathrm{~V}(10) & 496.5688 & 0.000000 \\ \mathrm{~V}(11) & 420.1276 & 0.000000 \\ \mathrm{~V}(12) & 0.000000 & 0.000000 \\ \mathrm{~V}(13) & 0.1810000 \mathrm{E}-01 & 0.000000 \\ \mathrm{~V}(14) & 113.2941 & 0.000000 \\ \mathrm{~V}(15) & 0.7613000 & 0.000000 \\ \mathrm{~V}(16) & 0.000000 & 0.000000 \\ \mathrm{~V}(17) & 11.87320 & 0.000000 \\ \mathrm{~V}(18) & 0.3262000 & 0.000000 \\ \mathrm{~V}(19) & 99.42030 & 0.000000 \\ \mathrm{~V}(20) & 109.3468 & 0.000000 \\ \mathrm{~V}(21) & 27.97080 & 0.000000 \\ \mathrm{~V}(22) & 0.3130000 \mathrm{E}-01 & 0.000000 \\ \mathrm{~V}(23) & 0.4797000 & 0.000000 \\ \mathrm{~V}(24) & 1.637200 & 0.000000 \\ \mathrm{~V}(25) & 3.357300 & 0.000000 \\ \mathrm{~V}(26) & 0.8732000 & 0.000000 \\ \mathrm{~V}(27) & 3.597300 & 0.000000 \\ \mathrm{~V}(28) & 49.21740 & 0.000000 \\ \mathrm{~V}(29) & 0.000000 & 0.000000 \\ \mathrm{~V}(30) & 226.0422 & 0.000000 \\ \mathrm{~V}(31) & 0.2561000 & 0.000000 \\ \mathrm{~V}(32) & 694.2567 & 0.000000 \\ \mathrm{~V}(33) & 5.818800 & 0.000000 \\ \mathrm{~V}(34) & 2.337900 & 0.000000 \\ \mathrm{~V}(35) & 331.8455 & 0.000000 \\ \mathrm{~V}(36) & 228.8570 & 0.000000 \\ \mathrm{~V}(37) & 0.2807000 & 0.000000 \\ \mathrm{~V}(38) & 352.3097 & 0.000000 \\ \mathrm{~V}(39) & 4.365300 & 0.000000 \\ \mathrm{~V}(40) & 162.1459 & 0.000000 \\ \mathrm{~V}(41) & 13.39230 & 0.000000 \\ \mathrm{~V}(42) & 0.6860000 \mathrm{E}-01 & 0.000000 \\ \mathrm{~V}(43) & 0.4650000 \mathrm{E}-01 & 0.000000 \\ \mathrm{~V}(44) & 99.49720 & 0.000000 \\ \mathrm{~V}(45) & 62.20300 & 0.000000 \\ \mathrm{~V}(46) & 67.19320 & 0.000000 \\ \mathrm{~V}(47) & 0.9850000 \mathrm{E}-01 & 0.000000 \\ \mathrm{~V}(48) & 7.361600 & 0.000000 \\ \mathrm{~V}(49) & 0.3200000 \mathrm{E}-02 & 0.000000 \\ \mathrm{~V}(50) & 0.2700000 \mathrm{E}-02 & 0.000000 \\ \mathrm{~V}(51) & 7.134400 & 0.000000 \\ \mathrm{~V}(52) & 21.00370 & 0.000000 \\ \mathrm{~V}(53) & 17.54900 & 0.000000 \\ \mathrm{~V}(54) & 4.789000 & 0.000000 \\ & & 207 \\ & & \end{array}$




$\begin{array}{lcc}\mathrm{V}(55) & 50.05350 & 0.000000 \\ \mathrm{~V}(56) & 6.252600 & 0.000000 \\ \mathrm{~V}(57) & 122.7735 & 0.000000 \\ \mathrm{~V}(58) & 0.8876000 & 0.000000 \\ \mathrm{~V}(59) & 4.182000 & 0.000000 \\ \mathrm{~V}(60) & 45.63940 & 0.000000 \\ \mathrm{~V}(61) & 71.37540 & 0.000000 \\ \mathrm{~V}(62) & 1528.243 & 0.000000 \\ \mathrm{~V}(63) & 5.270300 & 0.000000 \\ \mathrm{~V}(64) & 0.1000000 \mathrm{E}-03 & 0.000000 \\ \mathrm{~V}(65) & 0.2000000 \mathrm{E}-03 & 0.000000 \\ \mathrm{~V}(66) & 12.78360 & 0.000000 \\ \mathrm{~V}(67) & 11.28190 & 0.000000 \\ \mathrm{~V}(68) & 0.2546000 & 0.000000 \\ \mathrm{~V}(69) & 0.4580000 \mathrm{E}-01 & 0.000000 \\ \mathrm{~V}(70) & 110.0881 & 0.000000 \\ \mathrm{~V}(71) & 72.69040 & 0.000000 \\ \mathrm{~V}(72) & 1.248600 & 0.000000 \\ \mathrm{~V}(73) & 17.68270 & 0.000000 \\ \mathrm{~V}(74) & 0.6890000 \mathrm{E}-01 & 0.000000 \\ \mathrm{~V}(75) & 0.1100000 \mathrm{E}-02 & 0.000000 \\ \mathrm{~V}(76) & 0.3148000 & 0.000000 \\ \mathrm{~V}(77) & 3.614000 & 0.000000 \\ \mathrm{~V}(78) & 0.000000 & 0.000000 \\ \mathrm{~V}(79) & 0.3519000 & 0.000000 \\ \mathrm{~V}(80) & 34.80000 & 0.000000 \\ \mathrm{~V}(81) & 120.3501 & 0.000000 \\ \mathrm{~V}(82) & 1.516300 & 0.000000 \\ \mathrm{~V}(83) & 0.5000000 \mathrm{E}-03 & 0.000000 \\ \mathrm{~V}(84) & 114.0045 & 0.000000 \\ \mathrm{~V}(85) & 110.1917 & 0.000000 \\ \mathrm{~V}(86) & 72.77290 & 0.000000 \\ \mathrm{~V}(87) & 1.537700 & 0.000000 \\ \mathrm{~V}(88) & 19.87010 & 0.000000 \\ \mathrm{~V}(89) & 0.1970000 \mathrm{E}-01 & 0.000000 \\ \mathrm{~V}(90) & 219.6071 & 0.000000 \\ \mathrm{~V}(91) & 1.083900 & 0.000000 \\ \mathrm{~V}(92) & 1975.138 & 0.000000 \\ \mathrm{~V}(93) & 0.000000 & 0.000000 \\ \mathrm{~V}(94) & 0.2132000 & 0.000000 \\ \mathrm{~V}(95) & 0.4095000 & 0.000000 \\ \mathrm{~V}(96) & 0.2672000 & 0.000000 \\ \mathrm{~V}(97) & 35.98300 & 0.000000 \\ \mathrm{~V}(98) & 0.5335000 & 0.000000 \\ \mathrm{~V}(99) & 159.0127 & 0.000000 \\ \mathrm{~V}(100) & 2.273700 & 0.000000 \\ \mathrm{~V}(101) & 21.84620 & 0.000000 \\ \mathrm{~V}(102) & 191.8055 & 0.000000 \\ & & 208 \\ & & \end{array}$




$\begin{array}{lcc}\text { V( 103) } & 27.62530 & 0.000000 \\ \text { V( 104) } & 0.4070000 \mathrm{E}-01 & 0.000000 \\ \mathrm{~V}(105) & 0.1124000 & 0.000000 \\ \mathrm{~V}(106) & 3.066100 & 0.000000 \\ \mathrm{~V}(107) & 0.000000 & 0.000000 \\ \mathrm{~V}(108) & 62.57600 & 0.000000 \\ \mathrm{~V}(109) & 27.24760 & 0.000000 \\ \mathrm{~V}(110) & 1.859200 & 0.000000 \\ \mathrm{~V}(111) & 0.1500000 \mathrm{E}-01 & 0.000000 \\ \mathrm{~V}(112) & 4.990800 & 0.000000 \\ \mathrm{~V}(113) & 0.9330000 \mathrm{E}-01 & 0.000000 \\ \mathrm{~V}(114) & 42.93750 & 0.000000 \\ \mathrm{~V}(115) & 40.55010 & 0.000000 \\ \mathrm{~V}(116) & 5.862700 & 0.000000 \\ \mathrm{~V}(117) & 291.4280 & 0.000000 \\ \mathrm{~V}(118) & 0.2009000 & 0.000000 \\ \mathrm{~V}(119) & 0.6690000 \mathrm{E}-01 & 0.000000 \\ \mathrm{~V}(120) & 78.69820 & 0.000000 \\ \mathrm{~V}(121) & 169.2504 & 0.000000 \\ \mathrm{~V}(122) & 0.5230000 & 0.000000 \\ \mathrm{~V}(123) & 0.000000 & 0.000000 \\ \mathrm{~V}(124) & 760.8075 & 0.000000 \\ \mathrm{~V}(125) & 0.1250000 \mathrm{E}-01 & 0.000000 \\ \mathrm{~S}(1) & 25.89000 & 0.000000 \\ \mathrm{~S}(2) & 4.650000 & 0.000000 \\ \mathrm{~S}(3) & 0.6000000 & 0.000000 \\ \mathrm{~S}(4) & 3513.150 & 0.000000 \\ \mathrm{~S}(5) & 44.44000 & 0.000000 \\ \mathrm{~S}(6) & 32.19000 & 0.000000 \\ \mathrm{~S}(7) & 474.7700 & 0.000000 \\ \mathrm{~S}(8) & 176.3500 & 0.000000 \\ \mathrm{~S}(9) & 393.3900 & 0.000000 \\ \mathrm{~S}(10) & 7073.630 & 0.000000 \\ \mathrm{~S}(11) & 5984.720 & 0.000000 \\ \mathrm{~S}(12) & 0.000000 & 0.000000 \\ \mathrm{~S}(13) & 0.2600000 & 0.000000 \\ \mathrm{~S}(14) & 1613.880 & 0.000000 \\ \mathrm{~S}(15) & 10.84000 & 0.000000 \\ \mathrm{~S}(16) & 0.000000 & 0.000000 \\ \mathrm{~S}(17) & 169.1300 & 0.000000 \\ \mathrm{~S}(18) & 4.650000 & 0.000000 \\ \mathrm{~S}(19) & 1416.240 & 0.000000 \\ \mathrm{~S}(20) & 1557.650 & 0.000000 \\ \mathrm{~S}(21) & 398.4400 & 0.000000 \\ \mathrm{~S}(22) & 0.4500000 & 0.000000 \\ \mathrm{~S}(23) & 6.830000 & 0.000000 \\ \mathrm{~S}(24) & 23.32000 & 0.000000 \\ \mathrm{~S}(25) & 47.82000 & 0.000000 \\ & & 209 \\ & & \end{array}$




\begin{tabular}{|c|c|c|}
\hline$S(26)$ & 12.44000 & 0.000000 \\
\hline$S(27)$ & 51.24000 & 0.000000 \\
\hline $\mathrm{S}(28)$ & 701.1000 & 0.000000 \\
\hline $\mathrm{S}(29)$ & 0.000000 & 0.000000 \\
\hline$S(30)$ & 3219.970 & 0.000000 \\
\hline$S(31)$ & 3.650000 & 0.000000 \\
\hline$S(32)$ & 9889.700 & 0.000000 \\
\hline$S(33)$ & 82.89000 & 0.000000 \\
\hline$S(34)$ & 33.30000 & 0.000000 \\
\hline$S(35)$ & 4727.140 & 0.000000 \\
\hline$S(36)$ & 3260.070 & 0.000000 \\
\hline$S(37)$ & 4.000000 & 0.000000 \\
\hline $\mathrm{S}(38)$ & 5018.660 & 0.000000 \\
\hline$S(39)$ & 62.18000 & 0.000000 \\
\hline$S(40)$ & 2309.770 & 0.000000 \\
\hline$S(41)$ & 190.7700 & 0.000000 \\
\hline$S(42)$ & 0.9800000 & 0.000000 \\
\hline$S(43)$ & 0.6600000 & 0.000000 \\
\hline$S(44)$ & 1417.340 & 0.000000 \\
\hline$S(45)$ & 886.0800 & 0.000000 \\
\hline$S(46)$ & 957.1700 & 0.000000 \\
\hline$S(47)$ & 1.400000 & 0.000000 \\
\hline$S(48)$ & 104.8700 & 0.000000 \\
\hline$S(49)$ & $0.5000000 \mathrm{E}-01$ & 0.000000 \\
\hline$S(50)$ & $0.4000000 \mathrm{E}-01$ & 0.000000 \\
\hline$S(51)$ & 101.6300 & 0.000000 \\
\hline$S(52)$ & 299.2000 & 0.000000 \\
\hline$S(53)$ & 249.9900 & 0.000000 \\
\hline$S(54)$ & 68.22000 & 0.000000 \\
\hline$S(55)$ & 713.0100 & 0.000000 \\
\hline$S(56)$ & 89.07000 & 0.000000 \\
\hline$S(57)$ & 1748.910 & 0.000000 \\
\hline$S(58)$ & 12.64000 & 0.000000 \\
\hline$S(59)$ & 59.57000 & 0.000000 \\
\hline$S(60)$ & 650.1300 & 0.000000 \\
\hline$S(61)$ & 1016.740 & 0.000000 \\
\hline$S(62)$ & 21769.85 & 0.000000 \\
\hline$S(63)$ & 75.07000 & 0.000000 \\
\hline$S(64)$ & 0.000000 & 0.000000 \\
\hline$S(65)$ & 0.000000 & 0.000000 \\
\hline$S(66)$ & 182.1000 & 0.000000 \\
\hline$S(67)$ & 160.7100 & 0.000000 \\
\hline$S(68)$ & 3.630000 & 0.000000 \\
\hline$S(69)$ & 0.6500000 & 0.000000 \\
\hline$S(70)$ & 1568.210 & 0.000000 \\
\hline$S(71)$ & 1035.480 & 0.000000 \\
\hline$S(72)$ & 17.79000 & 0.000000 \\
\hline \multirow[t]{2}{*}{$S(73)$} & 251.8900 & 0.000000 \\
\hline & & 210 \\
\hline
\end{tabular}




\begin{tabular}{|c|c|c|}
\hline$S(74)$ & 0.9800000 & 0.000000 \\
\hline$S(75)$ & $0.2000000 \mathrm{E}-01$ & 0.000000 \\
\hline$S(76)$ & 4.480000 & 0.000000 \\
\hline$S(77)$ & 51.48000 & 0.000000 \\
\hline$S(78)$ & 0.000000 & 0.000000 \\
\hline$S(79)$ & 5.010000 & 0.000000 \\
\hline$S(80)$ & 495.7300 & 0.000000 \\
\hline$S(81)$ & 1714.390 & 0.000000 \\
\hline$S(82)$ & 21.60000 & 0.000000 \\
\hline$S(83)$ & $0.1000000 \mathrm{E}-01$ & 0.000000 \\
\hline$S(84)$ & 1624.000 & 0.000000 \\
\hline$S(85)$ & 1569.680 & 0.000000 \\
\hline$S(86)$ & 1036.650 & 0.000000 \\
\hline$S(87)$ & 21.91000 & 0.000000 \\
\hline$S(88)$ & 283.0500 & 0.000000 \\
\hline S( 89) & 0.2800000 & 0.000000 \\
\hline $\mathrm{S}(90)$ & 3128.310 & 0.000000 \\
\hline $\mathrm{S}(91)$ & 15.44000 & 0.000000 \\
\hline$S(92)$ & 28135.86 & 0.000000 \\
\hline S( 93) & 0.000000 & 0.000000 \\
\hline S( 94) & 3.040000 & 0.000000 \\
\hline$S(95)$ & 5.830000 & 0.000000 \\
\hline$S(96)$ & 3.810000 & 0.000000 \\
\hline$S(97)$ & 512.5800 & 0.000000 \\
\hline $\mathrm{S}(98)$ & 7.600000 & 0.000000 \\
\hline S( 99) & 2265.140 & 0.000000 \\
\hline$S(100)$ & 32.39000 & 0.000000 \\
\hline$S(101)$ & 311.2000 & 0.000000 \\
\hline$S(102)$ & 2732.270 & 0.000000 \\
\hline$S(103)$ & 393.5200 & 0.000000 \\
\hline$S(104)$ & 0.5800000 & 0.000000 \\
\hline$S(105)$ & 1.600000 & 0.000000 \\
\hline S( 106) & 43.68000 & 0.000000 \\
\hline$S(107)$ & 0.000000 & 0.000000 \\
\hline $\mathrm{S}(108)$ & 891.4000 & 0.000000 \\
\hline S( 109) & 388.1400 & 0.000000 \\
\hline$S(110)$ & 26.48000 & 0.000000 \\
\hline $\mathrm{S}(111)$ & 0.2100000 & 0.000000 \\
\hline$S(112)$ & 71.09000 & 0.000000 \\
\hline$S(113)$ & 1.330000 & 0.000000 \\
\hline$S(114)$ & 611.6500 & 0.000000 \\
\hline$S(115)$ & 577.6400 & 0.000000 \\
\hline$S(116)$ & 83.51000 & 0.000000 \\
\hline$S(117)$ & 4151.400 & 0.000000 \\
\hline$S(118)$ & 2.860000 & 0.000000 \\
\hline $\mathrm{S}(119)$ & 0.9500000 & 0.000000 \\
\hline$S(120)$ & 1121.060 & 0.000000 \\
\hline$S(121)$ & 2410.980 & 0.000000 \\
\hline
\end{tabular}




\begin{tabular}{|c|c|c|}
\hline$S(122)$ & 7.450000 & 0.000000 \\
\hline$S(123)$ & 0.000000 & 0.000000 \\
\hline$S(124)$ & 10837.71 & 0.000000 \\
\hline$S(125)$ & 0.1800000 & 0.000000 \\
\hline $\mathrm{N}(1)$ & 1.000000 & 0.000000 \\
\hline $\mathrm{N}(2)$ & 1.000000 & 0.000000 \\
\hline $\mathrm{N}(3)$ & 2.000000 & 0.000000 \\
\hline $\mathrm{N}(4)$ & 4.000000 & 0.000000 \\
\hline $\mathrm{N}(5)$ & 1.000000 & 0.000000 \\
\hline $\mathrm{N}(6)$ & 4.000000 & 0.000000 \\
\hline $\mathrm{N}(7)$ & 1.000000 & 0.000000 \\
\hline $\mathrm{N}(8)$ & 0.000000 & 0.000000 \\
\hline N( 9) & 1.000000 & 0.000000 \\
\hline $\mathrm{N}(10)$ & 4.000000 & 0.000000 \\
\hline $\mathrm{N}(11)$ & 3.000000 & 0.000000 \\
\hline $\mathrm{N}(12)$ & 3.000000 & 0.000000 \\
\hline $\mathrm{N}(13)$ & 1.000000 & 0.000000 \\
\hline $\mathrm{N}(14)$ & 1.000000 & 0.000000 \\
\hline $\mathrm{N}(15)$ & 4.000000 & 0.000000 \\
\hline $\mathrm{N}(16)$ & 3.000000 & 0.000000 \\
\hline $\mathrm{N}(17)$ & 1.000000 & 0.000000 \\
\hline $\mathrm{N}(18)$ & 1.000000 & 0.000000 \\
\hline $\mathrm{N}(19)$ & 0.000000 & 0.000000 \\
\hline $\mathrm{N}(20)$ & 3.000000 & 0.000000 \\
\hline $\mathrm{N}(21)$ & 0.000000 & 0.000000 \\
\hline $\mathrm{N}(22)$ & 2.000000 & 0.000000 \\
\hline $\mathrm{N}(23)$ & 2.000000 & 0.000000 \\
\hline $\mathrm{N}(24)$ & 0.000000 & 0.000000 \\
\hline $\mathrm{N}(25)$ & 4.000000 & 0.000000 \\
\hline$N(26)$ & 1.000000 & 0.000000 \\
\hline$N(27)$ & 4.000000 & 0.000000 \\
\hline $\mathrm{N}(28)$ & 2.000000 & 0.000000 \\
\hline $\mathrm{N}(29)$ & 1.000000 & 0.000000 \\
\hline $\mathrm{N}(30)$ & 4.000000 & 0.000000 \\
\hline $\mathrm{N}(31)$ & 2.000000 & 0.000000 \\
\hline $\mathrm{N}(32)$ & 1.000000 & 0.000000 \\
\hline $\mathrm{N}(33)$ & 4.000000 & 0.000000 \\
\hline N( 34) & 2.000000 & 0.000000 \\
\hline$N(35)$ & 4.000000 & 0.000000 \\
\hline$N(36)$ & 0.000000 & 0.000000 \\
\hline $\mathrm{N}(37)$ & 1.000000 & 0.000000 \\
\hline $\mathrm{N}(38)$ & 1.000000 & 0.000000 \\
\hline $\mathrm{N}(39)$ & 3.000000 & 0.000000 \\
\hline $\mathrm{N}(40)$ & 0.000000 & 0.000000 \\
\hline $\mathrm{N}(41)$ & 2.000000 & 0.000000 \\
\hline $\mathrm{N}(42)$ & 1.000000 & 0.000000 \\
\hline $\mathrm{N}(43)$ & 4.000000 & 0.000000 \\
\hline \multirow[t]{2}{*}{$\mathrm{N}(44)$} & 3.000000 & 0.000000 \\
\hline & & 212 \\
\hline
\end{tabular}




\begin{tabular}{lll}
$\mathrm{N}(45)$ & 0.000000 & 0.000000 \\
$\mathrm{~N}(46)$ & 1.000000 & 0.000000 \\
$\mathrm{~N}(47)$ & 1.000000 & 0.000000 \\
$\mathrm{~N}(48)$ & 3.000000 & 0.000000 \\
$\mathrm{~N}(49)$ & 2.000000 & 0.000000 \\
$\mathrm{~N}(50)$ & 3.000000 & 0.000000 \\
$\mathrm{~N}(51)$ & 4.000000 & 0.000000 \\
$\mathrm{~N}(52)$ & 1.000000 & 0.000000 \\
$\mathrm{~N}(53)$ & 1.000000 & 0.000000 \\
$\mathrm{~N}(54)$ & 4.000000 & 0.000000 \\
$\mathrm{~N}(55)$ & 2.000000 & 0.000000 \\
$\mathrm{~N}(56)$ & 1.000000 & 0.000000 \\
$\mathrm{~N}(57)$ & 2.000000 & 0.000000 \\
$\mathrm{~N}(58)$ & 4.000000 & 0.000000 \\
$\mathrm{~N}(59)$ & 0.000000 & 0.000000 \\
$\mathrm{~N}(60)$ & 2.000000 & 0.000000 \\
$\mathrm{~N}(61)$ & 2.000000 & 0.000000 \\
$\mathrm{~N}(62)$ & 3.000000 & 0.000000 \\
$\mathrm{~N}(63)$ & 1.000000 & 0.000000 \\
$\mathrm{~N}(64)$ & 2.000000 & 0.000000 \\
$\mathrm{~N}(65)$ & 3.000000 & 0.000000 \\
$\mathrm{~N}(66)$ & 1.000000 & 0.000000 \\
$\mathrm{~N}(67)$ & 2.000000 & 0.000000 \\
$\mathrm{~N}(68)$ & 4.000000 & 0.000000 \\
$\mathrm{~N}(69)$ & 4.000000 & 0.000000 \\
$\mathrm{~N}(70)$ & 1.000000 & 0.000000 \\
$\mathrm{~N}(71)$ & 0.000000 & 0.000000 \\
$\mathrm{~N}(72)$ & 4.000000 & 0.000000 \\
$\mathrm{~N}(73)$ & 2.000000 & 0.000000 \\
$\mathrm{~N}(74)$ & 1.000000 & 0.000000 \\
$\mathrm{~N}(75)$ & 0.000000 & 0.000000 \\
$\mathrm{~N}(76)$ & 0.000000 & 0.000000 \\
$\mathrm{~N}(77)$ & 1.000000 & 0.000000 \\
$\mathrm{~N}(78)$ & 4.000000 & 0.000000 \\
$\mathrm{~N}(79)$ & 4.000000 & 0.000000 \\
$\mathrm{~N}(80)$ & 0.000000 & 0.000000 \\
$\mathrm{~N}(81)$ & 3.000000 & 0.000000 \\
$\mathrm{~N}(82)$ & 0.000000 & 0.000000 \\
$\mathrm{~N}(83)$ & 1.000000 & 0.000000 \\
$\mathrm{~N}(84)$ & 2.000000 & 0.000000 \\
$\mathrm{~N}(85)$ & 4.000000 & 0.000000 \\
$\mathrm{~N}(86)$ & 4.000000 & 0.000000 \\
$\mathrm{~N}(87)$ & 3.000000 & 0.000000 \\
$\mathrm{~N}(88)$ & 2.000000 & 0.000000 \\
$\mathrm{~N}(89)$ & 0.000000 & 0.000000 \\
$\mathrm{~N}(92)$ & 0.000000 & 0.000000 \\
& 1.000000 & 0.000000 \\
\hline
\end{tabular}




\begin{tabular}{|c|c|c|}
\hline $\mathrm{N}(93)$ & 1.000000 & 0.000000 \\
\hline $\mathrm{N}(94)$ & 0.000000 & 0.000000 \\
\hline $\mathrm{N}(95)$ & 2.000000 & 0.000000 \\
\hline $\mathrm{N}(96)$ & 4.000000 & 0.000000 \\
\hline $\mathrm{N}(97)$ & 0.000000 & 0.000000 \\
\hline $\mathrm{N}(98)$ & 1.000000 & 0.000000 \\
\hline $\mathrm{N}(99)$ & 4.000000 & 0.000000 \\
\hline $\mathrm{N}(100)$ & 4.000000 & 0.000000 \\
\hline $\mathrm{N}(101)$ & 0.000000 & 0.000000 \\
\hline$N(102)$ & 3.000000 & 0.000000 \\
\hline$N(103)$ & 0.000000 & 0.000000 \\
\hline $\mathrm{N}(104)$ & 0.000000 & 0.000000 \\
\hline $\mathrm{N}(105)$ & 4.000000 & 0.000000 \\
\hline$N(106)$ & 3.000000 & 0.000000 \\
\hline$N(107)$ & 1.000000 & 0.000000 \\
\hline $\mathrm{N}(108)$ & 2.000000 & 0.000000 \\
\hline $\mathrm{N}(109)$ & 1.000000 & 0.000000 \\
\hline$N(110)$ & 3.000000 & 0.000000 \\
\hline$N(111)$ & 0.000000 & 0.000000 \\
\hline$N(112)$ & 0.000000 & 0.000000 \\
\hline$N(113)$ & 1.000000 & 0.000000 \\
\hline$N(114)$ & 4.000000 & 0.000000 \\
\hline$N(115)$ & 1.000000 & 0.000000 \\
\hline$N(116)$ & 2.000000 & 0.000000 \\
\hline $\mathrm{N}(117)$ & 3.000000 & 0.000000 \\
\hline $\mathrm{N}(118)$ & 3.000000 & 0.000000 \\
\hline $\mathrm{N}(119)$ & 3.000000 & 0.000000 \\
\hline$N(120)$ & 3.000000 & 0.000000 \\
\hline $\mathrm{N}(121)$ & 3.000000 & 0.000000 \\
\hline $\mathrm{N}(122)$ & 1.000000 & 0.000000 \\
\hline $\mathrm{N}(123)$ & 3.000000 & 0.000000 \\
\hline $\mathrm{N}(124)$ & 2.000000 & 0.000000 \\
\hline $\mathrm{N}(125)$ & 0.000000 & 0.000000 \\
\hline $\mathrm{P}(1)$ & 12.95000 & 0.000000 \\
\hline$P(2)$ & 2.320000 & 0.000000 \\
\hline $\mathrm{P}(3)$ & 0.3000000 & 0.000000 \\
\hline$P(4)$ & 1756.580 & 0.000000 \\
\hline$P(5)$ & 22.22000 & 0.000000 \\
\hline$P(6)$ & 16.10000 & 0.000000 \\
\hline$P(7)$ & 237.3900 & 0.000000 \\
\hline $\mathrm{P}(8)$ & 88.18000 & 0.000000 \\
\hline $\mathrm{P}(9)$ & 196.7000 & 0.000000 \\
\hline$P(10)$ & 3536.810 & 0.000000 \\
\hline $\mathrm{P}(11)$ & 2992.360 & 0.000000 \\
\hline $\mathrm{P}(12)$ & 0.000000 & 0.000000 \\
\hline $\mathrm{P}(13)$ & 0.1300000 & 0.000000 \\
\hline$P(14)$ & 806.9400 & 0.000000 \\
\hline$P(15)$ & 5.420000 & 0.000000 \\
\hline
\end{tabular}




\begin{tabular}{|c|c|c|}
\hline$P(16)$ & 0.000000 & 0.000000 \\
\hline $\mathrm{P}(17)$ & 84.57000 & 0.000000 \\
\hline $\mathrm{P}(18)$ & 2.320000 & 0.000000 \\
\hline $\mathrm{P}(19)$ & 708.1200 & 0.000000 \\
\hline $\mathrm{P}(20)$ & 778.8200 & 0.000000 \\
\hline $\mathrm{P}(21)$ & 199.2200 & 0.000000 \\
\hline $\mathrm{P}(22)$ & 0.2200000 & 0.000000 \\
\hline$P(23)$ & 3.420000 & 0.000000 \\
\hline $\mathrm{P}(24)$ & 11.66000 & 0.000000 \\
\hline$P(25)$ & 23.91000 & 0.000000 \\
\hline$P(26)$ & 6.220000 & 0.000000 \\
\hline$P(27)$ & 25.62000 & 0.000000 \\
\hline $\mathrm{P}(28)$ & 350.5500 & 0.000000 \\
\hline $\mathrm{P}(29)$ & 0.000000 & 0.000000 \\
\hline $\mathrm{P}(30)$ & 1609.990 & 0.000000 \\
\hline $\mathrm{P}(31)$ & 1.820000 & 0.000000 \\
\hline $\mathrm{P}(32)$ & 4944.850 & 0.000000 \\
\hline $\mathrm{P}(33)$ & 41.44000 & 0.000000 \\
\hline $\mathrm{P}(34)$ & 16.65000 & 0.000000 \\
\hline $\mathrm{P}(35)$ & 2363.570 & 0.000000 \\
\hline$P(36)$ & 1630.040 & 0.000000 \\
\hline$P(37)$ & 2.000000 & 0.000000 \\
\hline $\mathrm{P}(38)$ & 2509.330 & 0.000000 \\
\hline $\mathrm{P}(39)$ & 31.09000 & 0.000000 \\
\hline $\mathrm{P}(40)$ & 1154.890 & 0.000000 \\
\hline$P(41)$ & 95.39000 & 0.000000 \\
\hline$P(42)$ & 0.4900000 & 0.000000 \\
\hline$P(43)$ & 0.3300000 & 0.000000 \\
\hline $\mathrm{P}(44)$ & 708.6700 & 0.000000 \\
\hline$P(45)$ & 443.0400 & 0.000000 \\
\hline$P(46)$ & 478.5800 & 0.000000 \\
\hline $\mathrm{P}(47)$ & 0.7000000 & 0.000000 \\
\hline $\mathrm{P}(48)$ & 52.43000 & 0.000000 \\
\hline$P(49)$ & $0.2000000 \mathrm{E}-01$ & 0.000000 \\
\hline$P(50)$ & $0.2000000 \mathrm{E}-01$ & 0.000000 \\
\hline$P(51)$ & 50.81000 & 0.000000 \\
\hline$P(52)$ & 149.6000 & 0.000000 \\
\hline $\mathrm{P}(53)$ & 124.9900 & 0.000000 \\
\hline$P(54)$ & 34.11000 & 0.000000 \\
\hline$P(55)$ & 356.5100 & 0.000000 \\
\hline$P(56)$ & 44.53000 & 0.000000 \\
\hline$P(57)$ & 874.4600 & 0.000000 \\
\hline $\mathrm{P}(58)$ & 6.320000 & 0.000000 \\
\hline$P(59)$ & 29.79000 & 0.000000 \\
\hline$P(60)$ & 325.0700 & 0.000000 \\
\hline$P(61)$ & 508.3700 & 0.000000 \\
\hline$P(62)$ & 10884.92 & 0.000000 \\
\hline \multirow[t]{2}{*}{$P(63)$} & 37.54000 & 0.000000 \\
\hline & & 215 \\
\hline
\end{tabular}




\begin{tabular}{|c|c|c|}
\hline$P(64)$ & 0.000000 & 0.000000 \\
\hline$P(65)$ & 0.000000 & 0.000000 \\
\hline$P(66)$ & 91.05000 & 0.000000 \\
\hline$P(67)$ & 80.36000 & 0.000000 \\
\hline$P(68)$ & 1.810000 & 0.000000 \\
\hline$P(69)$ & 0.3300000 & 0.000000 \\
\hline $\mathrm{P}(70)$ & 784.1000 & 0.000000 \\
\hline $\mathrm{P}(71)$ & 517.7400 & 0.000000 \\
\hline $\mathrm{P}(72)$ & 8.890000 & 0.000000 \\
\hline$P(73)$ & 125.9400 & 0.000000 \\
\hline$P(74)$ & 0.4900000 & 0.000000 \\
\hline$P(75)$ & $0.1000000 \mathrm{E}-01$ & 0.000000 \\
\hline$P(76)$ & 2.240000 & 0.000000 \\
\hline $\mathrm{P}(77)$ & 25.74000 & 0.000000 \\
\hline $\mathrm{P}(78)$ & 0.000000 & 0.000000 \\
\hline $\mathrm{P}(79)$ & 2.510000 & 0.000000 \\
\hline $\mathrm{P}(80)$ & 247.8600 & 0.000000 \\
\hline $\mathrm{P}(81)$ & 857.1900 & 0.000000 \\
\hline $\mathrm{P}(82)$ & 10.80000 & 0.000000 \\
\hline $\mathrm{P}(83)$ & 0.000000 & 0.000000 \\
\hline $\mathrm{P}(84)$ & 812.0000 & 0.000000 \\
\hline $\mathrm{P}(85)$ & 784.8400 & 0.000000 \\
\hline $\mathrm{P}(86)$ & 518.3300 & 0.000000 \\
\hline $\mathrm{P}(87)$ & 10.95000 & 0.000000 \\
\hline $\mathrm{P}(88)$ & 141.5300 & 0.000000 \\
\hline $\mathrm{P}(89)$ & 0.1400000 & 0.000000 \\
\hline $\mathrm{P}(90)$ & 1564.150 & 0.000000 \\
\hline $\mathrm{P}(91)$ & 7.720000 & 0.000000 \\
\hline $\mathrm{P}(92)$ & 14067.93 & 0.000000 \\
\hline$P(93)$ & 0.000000 & 0.000000 \\
\hline $\mathrm{P}(94)$ & 1.520000 & 0.000000 \\
\hline $\mathrm{P}(95)$ & 2.920000 & 0.000000 \\
\hline $\mathrm{P}(96)$ & 1.900000 & 0.000000 \\
\hline $\mathrm{P}(97)$ & 256.2900 & 0.000000 \\
\hline $\mathrm{P}(98)$ & 3.800000 & 0.000000 \\
\hline P( 99) & 1132.570 & 0.000000 \\
\hline$P(100)$ & 16.19000 & 0.000000 \\
\hline$P(101)$ & 155.6000 & 0.000000 \\
\hline$P(102)$ & 1366.140 & 0.000000 \\
\hline$P(103)$ & 196.7600 & 0.000000 \\
\hline$P(104)$ & 0.2900000 & 0.000000 \\
\hline$P(105)$ & 0.8000000 & 0.000000 \\
\hline$P(106)$ & 21.84000 & 0.000000 \\
\hline$P(107)$ & 0.000000 & 0.000000 \\
\hline$P(108)$ & 445.7000 & 0.000000 \\
\hline $\mathrm{P}(109)$ & 194.0700 & 0.000000 \\
\hline$P(110)$ & 13.24000 & 0.000000 \\
\hline $\mathrm{P}(111)$ & 0.1100000 & 0.000000 \\
\hline
\end{tabular}




\begin{tabular}{|c|c|c|}
\hline$P(112)$ & 35.55000 & 0.000000 \\
\hline$P(113)$ & 0.6600000 & 0.000000 \\
\hline $\mathrm{P}(114)$ & 305.8200 & 0.000000 \\
\hline$P(115)$ & 288.8200 & 0.000000 \\
\hline$P(116)$ & 41.76000 & 0.000000 \\
\hline$P(117)$ & 2075.700 & 0.000000 \\
\hline $\mathrm{P}(118)$ & 1.430000 & 0.000000 \\
\hline$P(119)$ & 0.4800000 & 0.000000 \\
\hline$P(120)$ & 560.5300 & 0.000000 \\
\hline $\mathrm{P}(121)$ & 1205.490 & 0.000000 \\
\hline $\mathrm{P}(122)$ & 3.730000 & 0.000000 \\
\hline$P(123)$ & 0.000000 & 0.000000 \\
\hline$P(124)$ & 5418.860 & 0.000000 \\
\hline$P(125)$ & $0.9000000 \mathrm{E}-01$ & 0.00000 \\
\hline$X(1)$ & 1.000000 & -38.84000 \\
\hline$X(2)$ & 0.000000 & -6.970000 \\
\hline$X(3)$ & 2.000000 & -0.9000000 \\
\hline$X(4)$ & 0.000000 & -5269.730 \\
\hline$X(5)$ & 1.000000 & -66.66000 \\
\hline$X(6)$ & 0.000000 & -48.29000 \\
\hline$X(7)$ & 1.000000 & -712.1600 \\
\hline$X(8)$ & 0.000000 & -264.5300 \\
\hline$X(9)$ & 0.000000 & -590.0900 \\
\hline$X(10)$ & 0.000000 & -10610.44 \\
\hline$X(11)$ & 0.000000 & -8977.080 \\
\hline$X(12)$ & 3.000000 & 0.000000 \\
\hline$X(13)$ & 1.000000 & -0.3900000 \\
\hline$X(14)$ & 1.000000 & -2420.820 \\
\hline$X(15)$ & 0.000000 & -16.26000 \\
\hline$X(16)$ & 3.000000 & 0.000000 \\
\hline$X(17)$ & 0.000000 & -253.7000 \\
\hline$X(18)$ & 0.000000 & -6.970000 \\
\hline$X(19)$ & 0.000000 & -2124.360 \\
\hline$X(20)$ & 0.000000 & -2336.470 \\
\hline$X(21)$ & 0.000000 & -597.6600 \\
\hline$X(22)$ & 0.000000 & -0.6700000 \\
\hline$X(23)$ & 2.000000 & -10.25000 \\
\hline$X(24)$ & 0.000000 & -34.98000 \\
\hline$X(25)$ & 0.000000 & -71.73000 \\
\hline$X(26)$ & 1.000000 & -18.66000 \\
\hline$X(27)$ & 0.000000 & -76.86000 \\
\hline$X(28)$ & 0.000000 & -1051.650 \\
\hline$X(29)$ & 1.000000 & 0.000000 \\
\hline$X(30)$ & 0.000000 & -4829.960 \\
\hline$X(31)$ & 0.000000 & -5.470000 \\
\hline$X(32)$ & 0.000000 & -14834.55 \\
\hline$X(33)$ & 0.000000 & -124.3300 \\
\hline \multirow[t]{2}{*}{$X(34)$} & 0.000000 & -49.95000 \\
\hline & & 217 \\
\hline
\end{tabular}




\begin{tabular}{|c|c|c|}
\hline$X(35)$ & 0.000000 & -7090.710 \\
\hline$X(36)$ & 0.000000 & -4890.110 \\
\hline$X(37)$ & 1.000000 & -6.000000 \\
\hline$X(38)$ & 0.000000 & -7527.990 \\
\hline$X(39)$ & 0.000000 & -93.27000 \\
\hline$X(40)$ & 0.000000 & -3464.660 \\
\hline$X(41)$ & 0.000000 & -286.1600 \\
\hline$X(42)$ & 1.000000 & -1.470000 \\
\hline$X(43)$ & 0.000000 & -0.9900000 \\
\hline$X(44)$ & 0.000000 & -2126.010 \\
\hline$X(45)$ & 0.000000 & -1329.120 \\
\hline$X(46)$ & 0.000000 & -1435.750 \\
\hline$X(47)$ & 0.000000 & -2.100000 \\
\hline$X(48)$ & 2.000000 & -157.3000 \\
\hline$X(49)$ & 2.000000 & $-0.7000000 \mathrm{E}-01$ \\
\hline$X(50)$ & 3.000000 & $-0.6000000 \mathrm{E}-01$ \\
\hline$X(51)$ & 0.000000 & -152.4400 \\
\hline$X(52)$ & 1.000000 & -448.8000 \\
\hline$X(53)$ & 1.000000 & -374.9800 \\
\hline$X(54)$ & 4.000000 & -102.3300 \\
\hline$X(55)$ & 0.000000 & -1069.520 \\
\hline$X(56)$ & 0.000000 & -133.6000 \\
\hline$X(57)$ & 2.000000 & -2623.370 \\
\hline$X(58)$ & 0.000000 & -18.96000 \\
\hline$X(59)$ & 0.000000 & -89.36000 \\
\hline$X(60)$ & 0.000000 & -975.2000 \\
\hline$X(61)$ & 0.000000 & -1525.110 \\
\hline$X(62)$ & 0.000000 & -32654.77 \\
\hline$X(63)$ & 0.000000 & -112.6100 \\
\hline$X(64)$ & 0.000000 & 0.000000 \\
\hline$X(65)$ & 0.000000 & 0.000000 \\
\hline$X(66)$ & 0.000000 & -273.1500 \\
\hline$X(67)$ & 2.000000 & -241.0700 \\
\hline$X(68)$ & 0.000000 & -5.440000 \\
\hline$X(69)$ & 4.000000 & -0.9800000 \\
\hline$X(70)$ & 0.000000 & -2352.310 \\
\hline$X(71)$ & 0.000000 & -1553.220 \\
\hline$X(72)$ & 4.000000 & -26.68000 \\
\hline$X(73)$ & 0.000000 & -377.8300 \\
\hline$X(74)$ & 0.000000 & -1.470000 \\
\hline$X(75)$ & 0.000000 & $-0.3000000 \mathrm{E}-01$ \\
\hline$X(76)$ & 0.000000 & -6.720000 \\
\hline$X(77)$ & 0.000000 & -77.22000 \\
\hline$X(78)$ & 4.000000 & 0.000000 \\
\hline$X(79)$ & 4.000000 & -7.520000 \\
\hline$X(80)$ & 0.000000 & -743.5900 \\
\hline$X(81)$ & 0.000000 & -2571.580 \\
\hline$X(82)$ & 0.000000 & -32.40000 \\
\hline & & 218 \\
\hline
\end{tabular}




\begin{tabular}{|c|c|c|}
\hline$X(83)$ & 0.000000 & $-0.1000000 \mathrm{E}-01$ \\
\hline$X(84)$ & 2.000000 & -2436.000 \\
\hline$X(85)$ & 0.000000 & -2354.520 \\
\hline$X(86)$ & 4.000000 & -1554.980 \\
\hline$X(87)$ & 3.000000 & -32.86000 \\
\hline$X(88)$ & 2.000000 & -424.5800 \\
\hline$X(89)$ & 0.000000 & -0.4200000 \\
\hline$X(90)$ & 0.000000 & -4692.460 \\
\hline$X(91)$ & 1.000000 & -23.16000 \\
\hline$X(92)$ & 0.000000 & -42203.79 \\
\hline$X(93)$ & 1.000000 & 0.000000 \\
\hline$X(94)$ & 0.000000 & -4.560000 \\
\hline$X(95)$ & 2.000000 & -8.750000 \\
\hline$X(96)$ & 4.000000 & -5.710000 \\
\hline$X(97)$ & 0.000000 & -768.8700 \\
\hline $\mathrm{X}(98)$ & 0.000000 & -11.40000 \\
\hline X( 99) & 3.000000 & -3397.710 \\
\hline$X(100)$ & 0.000000 & -48.58000 \\
\hline $\mathrm{X}(101)$ & 0.000000 & -466.8000 \\
\hline$X(102)$ & 0.000000 & -4098.410 \\
\hline$X(103)$ & 0.000000 & -590.2800 \\
\hline$X(104)$ & 0.000000 & -0.8700000 \\
\hline$X(105)$ & 1.000000 & -2.400000 \\
\hline X( 106) & 3.000000 & -65.52000 \\
\hline X( 107) & 1.000000 & 0.000000 \\
\hline X( 108) & 2.000000 & -1337.100 \\
\hline X( 109) & 0.000000 & -582.2100 \\
\hline$X(110)$ & 0.000000 & -39.72000 \\
\hline $\mathrm{X}(111)$ & 0.000000 & -0.3200000 \\
\hline$X(112)$ & 0.000000 & -106.6400 \\
\hline$X(113)$ & 0.000000 & -1.990000 \\
\hline$X(114)$ & 4.000000 & -917.4700 \\
\hline$X(115)$ & 1.000000 & -866.4600 \\
\hline X( 116) & 0.000000 & -125.2700 \\
\hline$X(117)$ & 3.000000 & -6227.100 \\
\hline $\mathrm{X}(118)$ & 0.000000 & -4.290000 \\
\hline$X(119)$ & 2.000000 & -1.430000 \\
\hline$X(120)$ & 3.000000 & -1681.590 \\
\hline$X(121)$ & 3.000000 & -3616.470 \\
\hline$X(122)$ & 1.000000 & -11.18000 \\
\hline$X(123)$ & 3.000000 & 0.000000 \\
\hline $\mathrm{X}(124)$ & 0.000000 & -16256.57 \\
\hline$X(125)$ & 0.000000 & -0.2700000 \\
\hline Row & Slack or Surplus & Dual Price \\
\hline 1 & -82999.85 & 1.000000 \\
\hline 2 & $0.2000000 \mathrm{E}-03$ & 0.000000 \\
\hline \multirow[t]{2}{*}{3} & 0.000000 & 0.000000 \\
\hline & & 219 \\
\hline
\end{tabular}




$\begin{array}{ccc}4 & 1.000000 & 0.000000 \\ 5 & 0.000000 & 0.000000 \\ 6 & 4.000000 & 0.000000 \\ 7 & 0.000000 & 0.000000 \\ 8 & 4.000000 & 0.000000 \\ 9 & 0.000000 & 0.000000 \\ 10 & 0.000000 & 0.000000 \\ 11 & 1.000000 & 0.000000 \\ 12 & 4.000000 & 0.000000 \\ 13 & 3.000000 & 0.000000 \\ 14 & 0.000000 & 0.000000 \\ 15 & 0.000000 & 0.000000 \\ 16 & 0.000000 & 0.000000 \\ 17 & 4.000000 & 0.000000 \\ 18 & 0.000000 & 0.000000 \\ 19 & 1.000000 & 0.000000 \\ 20 & 1.000000 & 0.000000 \\ 21 & 0.000000 & 0.000000 \\ 22 & 3.000000 & 0.000000 \\ 23 & 0.000000 & 0.000000 \\ 24 & 2.000000 & 0.000000 \\ 25 & 0.000000 & 0.000000 \\ 26 & 0.000000 & 0.000000 \\ 27 & 4.000000 & 0.000000 \\ 28 & 0.000000 & 0.000000 \\ 29 & 4.000000 & 0.000000 \\ 30 & 2.000000 & 0.000000 \\ 31 & 0.000000 & 0.000000 \\ 32 & 4.000000 & 0.000000 \\ 33 & 2.000000 & 0.000000 \\ 34 & 1.000000 & 0.000000 \\ 35 & 4.000000 & 0.000000 \\ 36 & 2.000000 & 0.000000 \\ 37 & 4.000000 & 0.000000 \\ 38 & 0.000000 & 0.000000 \\ 39 & 0.000000 & 0.000000 \\ 40 & 1.000000 & 0.000000 \\ 41 & 3.000000 & 0.000000 \\ 42 & 0.000000 & 0.000000 \\ 43 & 2.000000 & 0.000000 \\ 44 & 0.000000 & 0.000000 \\ 45 & 4.000000 & 0.000000 \\ 46 & 3.000000 & 0.000000 \\ 47 & 0.000000 & 0.000000 \\ 48 & 1.000000 & 0.000000 \\ 59 & 1.000000 & 0.000000 \\ 51 & 1.000000 & 0.000000 \\ & 0.000000 & 0.000000\end{array}$




$\begin{array}{lll}52 & 0.000000 & 0.000000 \\ 53 & 4.000000 & 0.000000 \\ 54 & 0.000000 & 0.000000 \\ 55 & 0.000000 & 0.000000 \\ 56 & 0.000000 & 0.000000 \\ 57 & 2.000000 & 0.000000 \\ 58 & 1.000000 & 0.000000 \\ 59 & 0.000000 & 0.000000 \\ 60 & 4.000000 & 0.000000 \\ 61 & 0.000000 & 0.000000 \\ 62 & 2.000000 & 0.000000 \\ 63 & 2.000000 & 0.000000 \\ 64 & 3.000000 & 0.000000 \\ 65 & 1.000000 & 0.000000 \\ 66 & 2.000000 & 0.000000 \\ 67 & 3.000000 & 0.000000 \\ 68 & 1.000000 & 0.000000 \\ 69 & 0.000000 & 0.000000 \\ 70 & 4.000000 & 0.000000 \\ 71 & 0.000000 & 0.000000 \\ 72 & 1.000000 & 0.000000 \\ 73 & 0.000000 & 0.000000 \\ 74 & 0.000000 & 0.000000 \\ 75 & 2.000000 & 0.000000 \\ 76 & 1.000000 & 0.000000 \\ 77 & 0.000000 & 0.000000 \\ 78 & 0.000000 & 0.000000 \\ 79 & 1.000000 & 0.000000 \\ 80 & 0.000000 & 0.000000 \\ 81 & 0.000000 & 0.000000 \\ 82 & 0.000000 & 0.000000 \\ 83 & 3.000000 & 0.000000 \\ 84 & 0.000000 & 0.000000 \\ 85 & 1.000000 & 0.000000 \\ 86 & 0.000000 & 0.000000 \\ 87 & 4.000000 & 0.000000 \\ 88 & 0.000000 & 0.000000 \\ 89 & 0.000000 & 0.000000 \\ 90 & 0.000000 & 0.000000 \\ 91 & 0.000000 & 0.000000 \\ 92 & 0.000000 & 0.000000 \\ 93 & 0.000000 & 0.000000 \\ 94 & 1.000000 & 0.000000 \\ 95 & 0.000000 & 0.000000 \\ 96 & 0.000000 & 0.000000 \\ 98 & 0.000000 & 0.000000 \\ 99 & 0.000000 & 0.000000 \\ & 0.000000 & 0.000000\end{array}$




$\begin{array}{lll}100 & 1.000000 & 0.000000 \\ 101 & 1.000000 & 0.000000 \\ 102 & 4.000000 & 0.000000 \\ 103 & 0.000000 & 0.000000 \\ 104 & 3.000000 & 0.000000 \\ 105 & 0.000000 & 0.000000 \\ 106 & 0.000000 & 0.000000 \\ 107 & 3.000000 & 0.000000 \\ 108 & 0.000000 & 0.000000 \\ 109 & 0.000000 & 0.000000 \\ 110 & 0.000000 & 0.000000 \\ 111 & 1.000000 & 0.000000 \\ 112 & 3.000000 & 0.000000 \\ 113 & 0.000000 & 0.000000 \\ 114 & 0.000000 & 0.000000 \\ 115 & 1.000000 & 0.000000 \\ 116 & 0.000000 & 0.000000 \\ 117 & 0.000000 & 0.000000 \\ 118 & 2.000000 & 0.000000 \\ 119 & 0.000000 & 0.000000 \\ 120 & 3.000000 & 0.000000 \\ 121 & 1.000000 & 0.000000 \\ 122 & 0.000000 & 0.000000 \\ 123 & 0.000000 & 0.000000 \\ 124 & 0.000000 & 0.000000 \\ 125 & 0.000000 & 0.000000 \\ 126 & 2.000000 & 0.000000 \\ 127 & 0.000000 & 0.000000\end{array}$




\section{APPENDIX E: List of Abbreviations}

$\begin{array}{ll}\text { AABB } & \text { Axis-Aligned Bounding Boxes } \\ \text { ABS } & \text { Acrylonitrile butadiene styrene } \\ \text { ACO } & \text { Ant Colony Optimization } \\ \text { AM } & \text { Additive Manufacturing } \\ \text { ARCAM } & \text { A\&R Cambridge Ltd } \\ \text { ASTM } & \text { American Society for Testing and Materials } \\ \text { BL } & \text { Bottom-Left } \\ \text { BLF } & \text { Bottom-Left-Fill } \\ \text { CAD } & \text { Computer Aided Design } \\ \text { DIN } & \text { Coutsches Institut für Normung e.V. } \\ \text { CAM } & \text { Computer Aided Manufacturing } \\ \text { CBVH } & \text { Coons bounding volume hierarchy } \\ \text { CCG } & \text { Controlling The Maximum Number Of Crossed Genes } \\ & \end{array}$




\begin{tabular}{|c|c|}
\hline DMD & Direct Metal Deposition \\
\hline DMLS & Direct Metal Laser Sintering \\
\hline DP & Difference Process Algorithm \\
\hline DSPC & Direct Shell Production Casting \\
\hline EA & Evolutionary Algorithm \\
\hline EOS & Electro Optical Systems \\
\hline EP & Evolutionary Programming \\
\hline FDH & Fixed Directions Hulls \\
\hline FDM & Fused Deposition Modeling \\
\hline FEA & Finite Element Analysis \\
\hline FEM & Finite Element Method \\
\hline FF & First-Fit-Algorithm \\
\hline FFD & First-Fit-Decreasing-Algorithm \\
\hline GA & Genetic Algorithm \\
\hline GARP & Genetic Algorithm For Part Packing In A Rapid Prototyping Machine \\
\hline GEA & Genetic and Evolutionary Algorithm \\
\hline GEC & Genetic and Evolutionary Computation \\
\hline GR & Gap Reduction \\
\hline HGGA & Hybrid Grouping Genetic Algorithm \\
\hline IBEA & Indicator-Based Evolutionary Algorithm \\
\hline IGES & Initial Graphics Exchange Specification \\
\hline
\end{tabular}




$\begin{array}{ll}\text { IM } & \text { Injection Molding } \\ \text { IMSLS } & \text { Indirect Metal Selective Laser Sintering } \\ \text { ISO } & \text { International Organization for Standardization } \\ \text { JSSP } & \text { Job-Shop Scheduling Problem } \\ \text { LGFi } & \text { Lowest Gap Fill } \\ \text { LMT } & \text { Layer Manufacturing Techniques } \\ \text { LS } & \text { Laser Sintering } \\ \text { LOM } & \text { Laminated Object Manufacturing } \\ \text { MATLAB } & \text { Matrix Laboratory } \\ \text { MHz } & \text { Megahertz } \\ \text { MIT } & \text { Massachusetts Institute of Technology } \\ \text { MOO } & \text { Multi-Objective Optimization } \\ \text { MOPSO } & \text { Multiple-Objective Particle Swarm Optimizer } \\ \text { NSPOS } & \text { Maximum Spread Pareto Optimal Solutions } \\ \text { NTP } & \text { Martello-Tooth Procedure } \\ \text { ND } & \text { Nth-Dimensional } \\ \text { NF } & \text { Naive Evolution } \\ \text { Non-Dominated Sorting Genetic Algorithm } \\ \text { Next-Fit-Algorithm }\end{array}$




$\begin{array}{ll}\text { OR } & \text { Operations Research } \\ \text { PC } & \text { Personal Computer } \\ \text { PMX } & \text { Partially Matched Crossover } \\ \text { PPSF } & \text { Polyphenylsulfone } \\ \text { PR } & \text { Packing Ratio } \\ \text { PR } & \text { Partial Reordering } \\ \text { PVM } & \text { Parallel Virtual Machine } \\ \text { Ra } & \text { Surface Roughness } \\ \text { RM } & \text { Rapid Manufacturing } \\ \text { RP } & \text { Rapid Prototyping } \\ \text { RS } & \text { Restricted Swapping } \\ \text { SA } & \text { Simulated Annealing } \\ \text { SFM } & \text { Solid Freeform Manufacturing } \\ \text { SJX } & \text { Stefan Jakobs Crossover } \\ \text { SL } & \text { Stereolithography } \\ \text { SLA } & \text { Stereolithography Apparatus } \\ \text { SLS } & \text { Selective Laser Melting } \\ \text { SP } & \text { Selective Laser Sintering } \\ \text { Stratistical process control } \\ \text { Sareto Evolutionary Algorithm }\end{array}$




$\begin{array}{ll}\text { STL } & \text { Surface Triangulation Language } \\ \text { T } & \text { Build Time } \\ \text { UML } & \text { Unified Modeling Language } \\ \text { UV } & \text { Ultraviolet } \\ \text { VDA } & \text { Verband der Automobilindustrie } \\ \text { VIV } & \text { Virtual Virus } \\ \text { VR } & \text { Virtual Reality } \\ \text { VRML } & \text { Virtual Reality Modeling Language } \\ \text { 1D } & \text { One-Dimensional } \\ \text { 2D } & \text { Two-Dimensional } \\ \text { 3D } & \text { Three-Dimensional } \\ \text { 3DP } & \text { 3D Printing }\end{array}$




\section{CURRICULUM VITAE}

NAME

\section{EDUCATION}

\& TRAINING
Sonja Dieder

Diploma in Business Administration

specialized in Information Management,

AKAD, Private-Academy

University of Applied Sciences Pinneberg

2000-2004

M.Sc. Master of Science in Industrial Engineering,

University of Louisville

2008-2010

Ph.D. Industrial Engineering

University of Louisville

2011-2014 